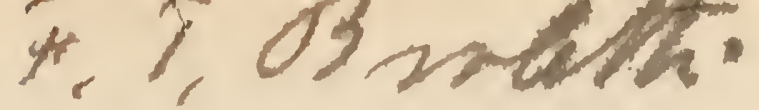

UNIVERSITY OF CALIFORNIA PUBLICATIONS

COLLEGE OF AGRICULTURE

AGRICULTURAL EXPERIMENT STATION

BERKELEY, CALIFORNIA

\title{
California Plant Diseases
}

By RALPH E. SMITH AND ELIZABETH H. SMITH

BULLETIN No. 218

(Berkeley, Cal., June, 1911)

S A CR A M E N T O

W. W. SIIANNON

- - Superintendent of state printing 1911 
Benj. Ide Wheeler, Ph.D., LL.D., President of the University.

\section{EXPERIMENT STATION STAFF.}

E. J. WICKSoN, M.A., Director and Horticulturist.

E. W. Hilgard, Ph.D., LL.D., Chemist (Emeritus).

W. A. Setchell, Ph.D., Botanist.

LEROY ANDERSON, Ph.D., Dairy Industry and Superintendent University Farm Schools.

M. E. JAFFA, M.S., Nutrition Expert, in charge of the Poultry Station.

R. H. Loughridge, Ph.D., Soil Chemist and Physicist (Emeritus).

C. W. WOODWORTH, M.S., Entomologist.

Ralph E. Smith, B.S., Plant Pathologist and Superintendent of Southern California Pathological Laboratory and Experiment Station.

G. W. SHAw, M.A., Ph.D., Experimental Agronomist and Agricultural Technologist, in charge of Cereal Stations.

E. W. MAJor, B.Agr., Animal Industry, Farm Manager, University Farm, Davis.

F. T. BioletTI, M.S., Viticulturist.

B. A. EtcheverRy, B.S., Irrigation Expert.

George E. Colby, M.S., Chemist (Fruits, Waters and Insecticides), in charge of Chemical Laboratory.

H. J. QuAYle, A.B., Assistant Entomologist, Plant Disease Laboratory, Whittier.

W. T. Clarke, B.S., Assistant Horticulturist and Superintendent of University Extension in Agriculture.

H. M. HALl, Ph.D., Assistant Botanist.

C. M. HARING, D.V.M., Assistant Veterinarian and Bacteriologist.

JoHN S. Burd, B.S., Chemist, in charge of Fertilizer Control.

E. B. BABCoCK, B.S., Assistant Agricultural Education.

W. B. HerMs, M.A., Assistant Entomologist.

J. H. Norton, M.S., Assistant Chemist, in charge of Citrus Experiment Station, Riverside.

W. T. Horne, B.S., Assistant Plant Pathologist.

J. E. CoIT, PH.D., Assistant Pomologist, Plant Disease Laboratory, Whittier.

C. B. LIPMAN, PH.D., Soil Chemist and Bacterioligist.

R. E. MANSELL, Assistant in Horticulture, in charge of Central Station grounds.

A. J. Gaumnitz, M.S., Assistant in Cereal Investigations, University Farm, Davis.

E. H. HagemanN, Assistant in Dairying, Davis.

B. S. Brown, B.S.A., Assistant in Horticulture, University Farm, Davis.

F. D. HAw K, B.S.A., Assistant in Animal Industry.

J. I. Thompson, B.S., Assistant in Animal Industry, Davis.

R. M. RoBerts, B.S.A., University Farm Manager, University Farm, Davis.

J. C. BRIDWELL, B.S., Assistant Entomologist.

C. H. MCCharles, B.S., Assistant in Agricultural Chemical Laboratory.

N. D. InghaM, B.S., Assistant in Sylviculture, Santa Monica.

E. H. Smith, M.S., Assistant Plant Pathologist.

T. F. Hunt, B.S., Assistant Plant Pathologist.

C. O. Smith, M.S., Assistant Plant Pathologist, Plant Disease Laboratory, Whittier.

F. L. YEAw, B.S., Assistant Plant Pathologist, Vacaville.

F. E. Johnson, B.L., M.S., Assistant in Soil Laboratory.

Charles Fuchs, Curator Entomological Museum.

P. L. HibBard, B.S., Assistant Fertilizer Control Laboratory.

L. M. Davis, B.S., Assistant in Dairy Husbandry, University Farm, Davis.

L. BONNETT, I.S., Assistant in Viticulture.

S. S. Rogers, B.S., Assistant Plant Pathologist, Plant Disease Laboratory, Whittier.

B. A. MADson, B.S.A., Assistant in Cereal Laboratory.

WALter E. PACKARD, M.S., Field Assistant, Imperial Valley Investigations, El Centro.

M. E. Stover, B.S., Assistant in Agricultural Chemical Laboratory.

P. L. MCCreary, B.S., Laboratory Assistant in Fertilizer Control.

F. C. H. Flossfeder, Field Assistant in Viticulture, Davis.

E. E. Thomas, B.S., Assistant Chemist, Plant Disease Laboratory, Whittier.

ANNA Hamilton, Assistant in Entomology.

MrS. D. L. BunNell, Secretary to Director.

W. H. VolcK, Field Assistant in Entomology, Watsonville.

E. L. Morris, B.S., Field Assistant in Entomology, San Jose.

J. S. Hunter, Field Assistant in Entomology, San Mateo.

J. C. Roper, Patron University Forestry Station, Chico.

JoHN T. BEARss, Foreman Kearney Park Station, Fresno.

E. C. Miller, Foreman University Forestry Station, Chico. 


\section{CALIFORNIA PLANT DISEASES.}

By Ralph E. Smith and Elizabeth H. Smith.

An important part of the work of every agricultural experiment station consists in the dissemination of useful information, as well as the carrying on of investigations seeking for new knowledge. It is the former phase of station work which is represented in the present bulletin. This publication is intended as a handbook of plant diseases occurring in California, giving a brief description of the nature of the principal troubles, together with directions for their control. Many iniscellaneous and less important troubles are also described, the plan being to record all plant diseases of any possible interest which have been observed in California by members of the department.

The illustrations are all original in this department, save those illustrating vine diseases reproduced from Bulletin 197 of this experiment station. The photographs have been taken by various members of the staff, while the drawings are by Miss E. H. Smith.

The meaning of the word "disease," as it applies in the present sense tc plant production, is decidedly less specific than the conception of the same word as applied to the human race or domestic animals. In the latter case disease may be defined as the opposite of health, and health means a condition of normal functional activity of the body. In the growing of cultivated plants or "crops," however, there are always two distinct objects or considerations involved for successful, satisfactory results. These are as follows:

(1) The plant must make a vigorous development and maintain to as great an extent as possible that condition which we denote as "thrift." In almost all cases of crop production it is desirable to maintain thrifty and vigorous growth. This corresponds quite closely to what we call "health" in the animal body.

(2) Along with this thrifty condition it is likewise necessary to attain certain arbitrary qualities or characteristics of the root, stem, leaf, flower, fruit or seed, such characteristics being those which make the product of the plant most desirable from a commercial standpoint. Most of these qualities are not at all necessary to a condition of ordinary health or thrift, and some of them are even opposed to it.

We may, therefore, say in the present sense that we are considering inder the term "disease" any condition of a plant in which there is 
a decided failure of thrifty development, or failure of the plant to produce a commereial produet of satisfactory quality or quantity.

This bulletin will impress many, at first sight, as being of a much more general nature and wider in scope than the usual plant disease manual. It may seen to some to leave the provinee of the plant pathologist and invade that of the soil chemist and physicist, the agronomist and the horticulturist. Such a conception of the scope of plant pathology results from the common impression that all plant diseases are cansed by insects, fungi, bacteria or other living organisms of the nature known as parasites. 'This is far from being the ease, particularrly in a region like California, where the conditions attending the culture of plants are extremely artificial, the soils largely in a semiarid or desert condition before being brought under cultivation, and where the commercial crops are produced by plants which have been introduced from all sorts of climates and conditions. Under such circumstances it is not surprising that soil and climatic conditions should have powerful influences upon plant growth, and produce many abnormal effects and disturbances. Such is the case, and in diagnosing plant troubles in California it is quite as necessary and usually more difficult to judge such influences accurately than to determine the work of parasitic organisms. Many of these effects can not be distinctly segregated or described as specific diseases of certain plants, but they will be briefly summarized and described in a later chapter.

The development of plants and the nature of the products which they bear are influenced by two principal factors: first, the inherent quality of the plant itself, transmitted through the seed or bud; second, the nature of the environment in which the plant develops. One factor is as important as the other, and the plant pathologist must work through both in order to attain the desired results. In the former case he enters the field or calls upon the services of the plant breeder, in order to obtain varieties of plants having the desired qualities, while in the latter case he investigates the effects of the various influences and agencies which act upon the plant during its growth and seeks means to counteract or stimulate such influences, as the case may be. Here again the aid of various sciences must be invoked in order to obtain the desired results. In a recent text-book the matter is well expressed in the following language: "Every plant has definite requirements for its best development. The character of the mature plant is the result of two sets of forces. The first of these is the inherent eapacity of the seed to develop and produce a normal individual of its kind. The second set of forces constitutes the environment in which the plant grows, and of which the soil is one part, the other component being 
climate. Every plant is an expression of the combination and interaction of these three groups of forces-the seed, the climate, and the soil. ${ }^{\prime}{ }^{*}$

Ideal conditions for the production of any crop may be summarized as follows :

In the Plant:

Proper Inherent Qualities of Growth and Production.

In the Air:

Proper Temperature;

Proper Moisture;

Proper Light;

Proper Chemical Composition;

Freedom from Injurious Influences.

In the Soil :

Proper moisture:

Proper Aeration;

Proper Chemical Composition;

Proper Physical Composition;

Freedom from Injurious Influences.

In other words, the plant needs in its environment, for successful development, a proper degree of heat, moisture, air, light, and food, and freedom from injurious influences. Any serious departure from these ideal conditions results, in the present sense, in disease.

\section{PLANT PHYSIOLOGY.}

A clear understanding of the fundamental principles of normal plant physiology is necessary to enable one to judge abnormal or diseased conditions with any degree of accuracy. A brief exposition of this subject may, therefore, be of use at this point.

Every plant consists of certain parts or organs, each with its particular duty to perform to maintain the life and activities of the whole. These parts are commonly as follows: The root, stem, branch, leaf, flower, fruit and seed. Any or all of these parts is liable to disease, either in the strict sense of the word, meaning that they may be so g.ffected as to cause an unhealthy condition, or they may be affected in the broader sense of having undesirable commercial characteristics, since all of these parts, in various plants, represent the commercially desirable portion. Some plants, for instance, like the turnip or carrot, are cultivated for the root, some for the stem or branches, like the asparagus or celery, some for the leaf, like the lettuce, and a great many different kinds for the flowers, fruit, or seed. If the root or stem be diseased, in a sense of being in an injured or unhealthy condition, the flow of water from the ground will be cut off or interfered with and the remainder of the plant suffer accordingly. If the leaves are injured or destroyed their functions will be interfered with and the rest of the

\footnotetext{
* Soils. Lyon and Fippin.
} 
plant suffer from starvation. Likewise, the value of the crop will be injured or destroyed if the particular part of which the plant is cultivated has imperfections or undesirable characteristics, whether the health or thrift of the plant is injured or not.

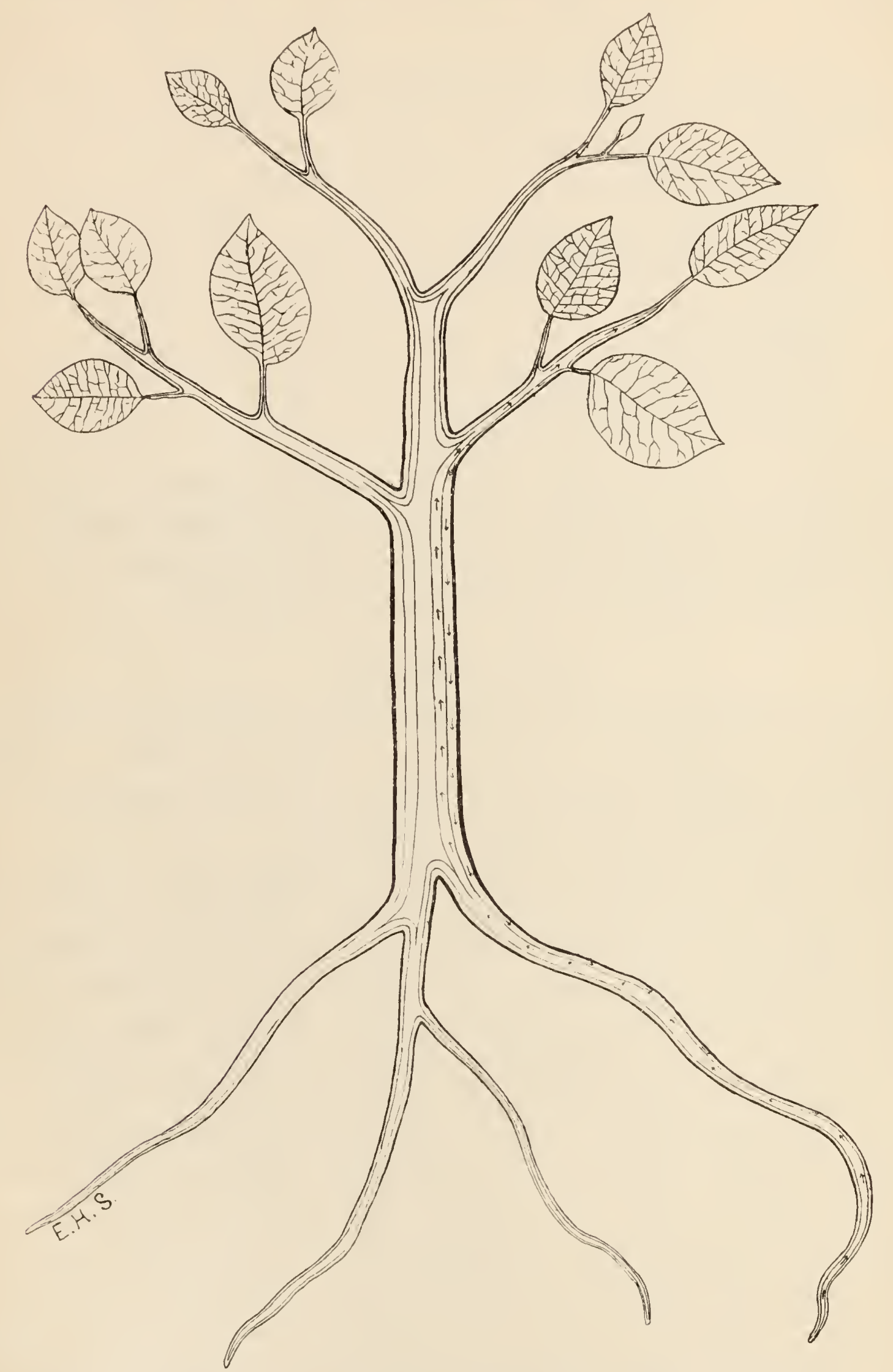

FIG. 1.-Diagram of tree showing movements of fluids as shown by arrows.

Of the organs mentioned, the root commonly grows in the soil and the remainder of the plant in the air. 
SOIL RELATION.

The soil has two general purposes in relation to plant growth. In the first place it furnishes a medium through which the root is able to accomplish its mechanical function of holding the plant upright in the air and exposing its parts to the air and sunlight. Second and more important, the soil is a storehouse of food and moisture, both of which are indispensable to plant growth. The soil is composed of an aggregation of various sized particles of mineral matter, resulting from the disintegration of rocks, into which is mixed various amounts of crganic matter, resulting from the decomposition of plant and animal remains. Being composed of individual particles of irregular shape there is more or less space between these particles, which is filled either with water or with air and other gases. The size of the spaces and, therefore, the amount of water or air which the soil may contain depends upon the size of the particles and the degree to which they are comracted together.

Far from being an inert mass of dead mineral and organic matter, the soil is likewise the home of uncounted myriads of living organisms, not only soil bacteria, of which much has been heard of late, but also many other forms of low plant life, hosts of simple animal organisms, and likewise more highly developed creatures, such as earth worms and many other forms. All of these exert a profound influence upon the soil and its relation to plant production.

The features of the soil which particularly interest us in this connection have three phases: chemical, physical and biological. Chemically, the soil furnishes most of the elements of food which the plant requires, said elements being derived from the original rocks from which the soil was formed and the decaying plant and animal remains which it contains, all being gradually brought into solution in the water which permeates the soil. The soil may likewise contain substances of a nature injurious to plants. It is, therefore, most evident that the student of plant pathology must carefully consider the chemical nature of the soil in studying the condition and health of the plant.

Physically, the texture of the soil has a very great influence upon the development of the root, upon the supply of moisture which the soil may furnish to the plant, upon the availability and accessibility of the food supply stored up in the soil, upon the performance of cultural operations necessary to the proper development of the plant and is in every way fully as important as the chemical consideration.

Biologically, both the chemical and physical condition of the soil are largely influenced by the activities of the living organisms which it contains, and this relation is of great importance in many ways to the growth of the plant. We need not consider these matters in further 
detail in this place more than to call attention to their fundamental importance.

The root of the plant spreads through the soil by growth and subdivision, forming a network of fine branches, the extremities of which are the delicate, minute root hairs through which food and water are absorbed (Fig. 2). Air is also required by the root as well as by other parts of the plant. The activities of the root are therefore entirely

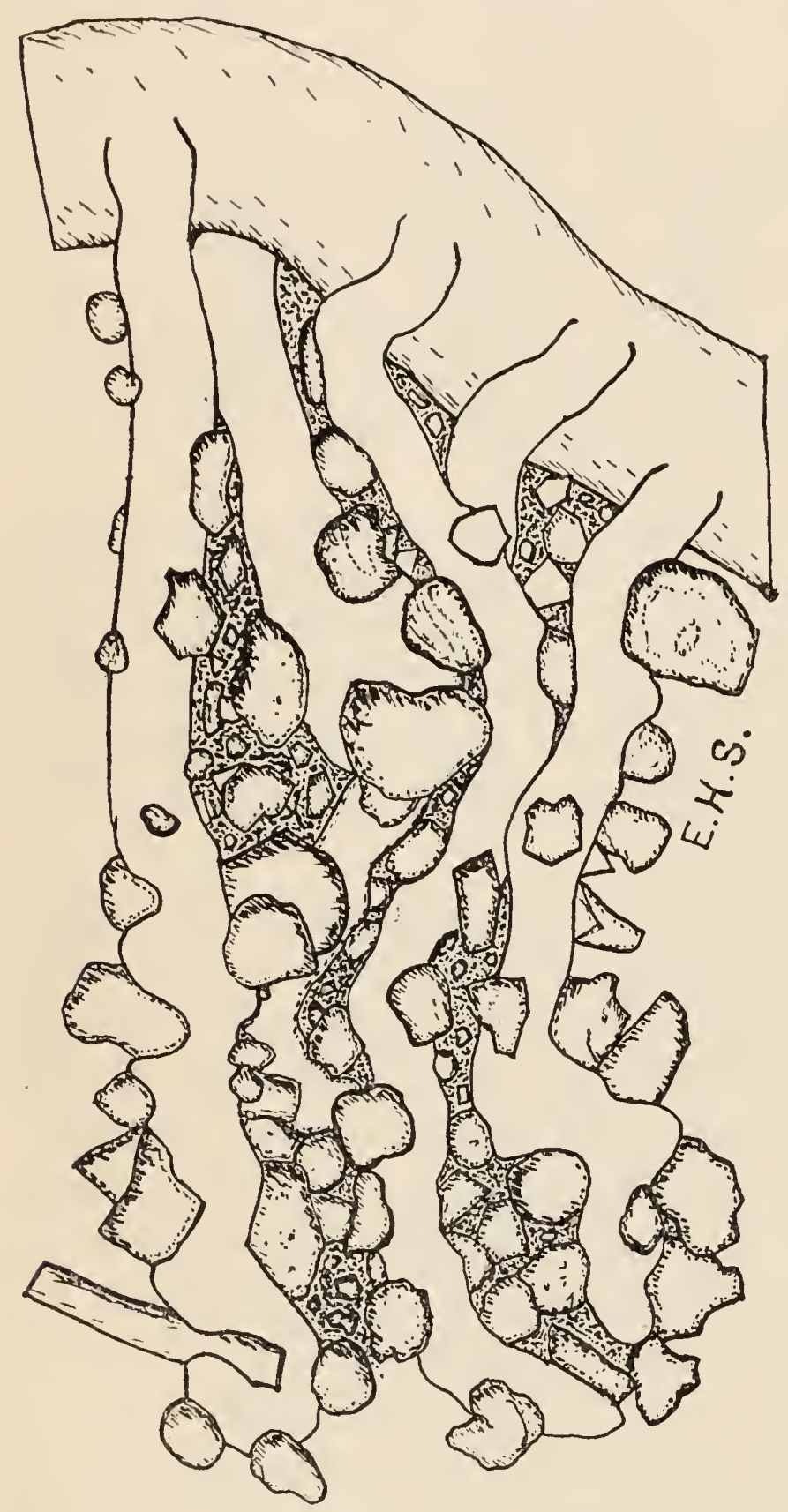

FIG. 2.-Root hairs in soil. dependent upon the physical texture, moisture supply, temperature and chemical composition of the soil. If these conditions are favorable, the plant flourishes so far as the functions of the root are concerned. If decidedly unfarorable in any important respect, bad results or disease follow.

The specific food substances taken from the soil by the root are as follows: Nitrogen, hydrogen, sulphur, phosphorus, calcium, potassium, iron, magnesium and oxygen. Some of these elements may be replaced to some extent by others, as, for instance, sodium and calcium may partly take the place of potassium and magnesium. Other non-essential substances may also be taken up, and indeed it may be said that almost any element in the soil may be absorbed in considerable quantities. All these elements are absorbed by the plant through the root in the form of a solution in water. In other words, the water of the soil is a weak solution of these and any other soluble substances which the soil may contain. Each of these substances, with the exceptions stated, is indispensable to the growth of ordinary plants. In other words, the plant is unable to develop if any one of these be lacking. Some of them are needed only in very small amount, and we can scarcely imagine a soil which would be entirely deficient in any one of these elements. Soils differ, how- 
ever, in the relative amounts of these substances which they contain and there is likewise a great difference in the amounts of them which are demanded by plants. The three elements most likely to be lacking in quantities sufficient for the maximum development of plants are nitrogen, phosphorus and potassium. Less commonly calcium (lime) is lacking, and in some instances an addition of iron to the soil shows a beneficial effect upon the growth of plants.

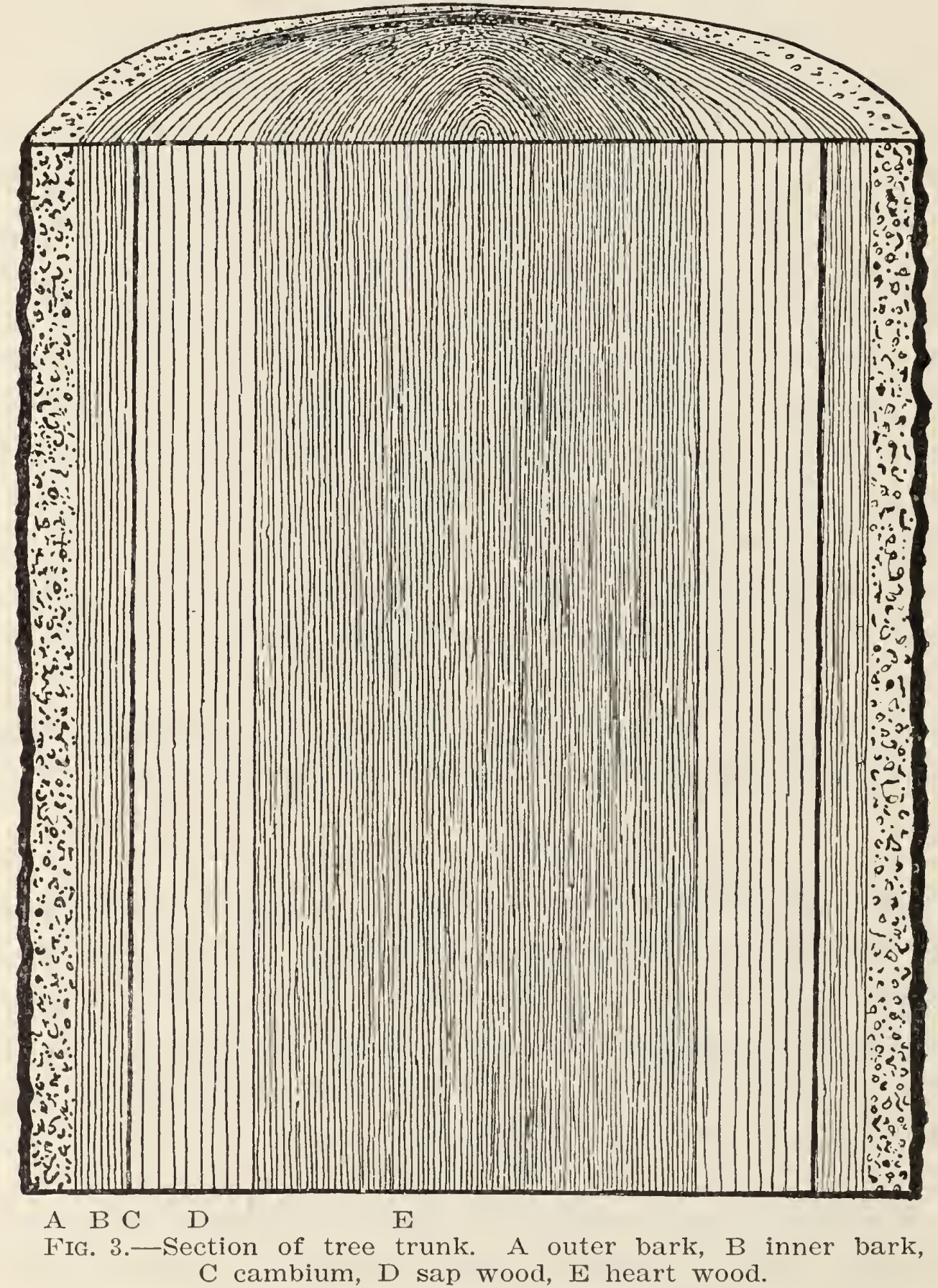

The chemical nature of the soil and its modification by the addition of various substances in the practice of fertilization or soil modification, form a very complicated subject in regard to its effect upon the growth of plants. Such effects, while sometimes comparatively simple and consisting merely in a direct addition to the supply of food material taken up by the plant, are often extremely indirect, and the ultimate effect upon the plant may come about through the chemical action of the 
material upon other chemical substances in the soil, its effect upon living organisms, or in various other ways. We may cite here, for example, the recent discussions which have come up in southern California in regard to the ratio of lime and magnesia contained in soils, the injurious effects upon plant life of certain combinations of this sort, and the possibilities of correcting such troubles by the addition of lime or magnesia to the soil.

From the standpoint of the plant pathologist, the chemical nature of the soil, through which most of the physical and biological effects are ultimately expressed, has three main considerations : first, the limiting of growth by a deficiency in one or more necessary constituents, including water; second, a possibility of injurious effects resulting from the presence in the soil of certain substances in excessive amounts; third, specific effects of the chemical elements of the soil upon the character of the commercial product of the plant, such, for instance, as the color, flavor or texture of the fruit. In other words, the question arises in numerous instances as to whether poor growth, lack of fruit production, deficiency in size, or some other partial failure may be due to a lack or an excess of some substance in the soil, and also to what extent arbitrary characteristics in the commercial product such as color, flavor, or texture may be influenced by chemical treatment or the chemical nature of the soil. This, in California, is one of the most important phases of our subject.

Another feature of the soil, which relates to plant physiology, is its temperature, a factor which may be of some importance.

\section{MOVEMENTS OF FLUIDS.}

After being absorbed by the root the soil solution, or as we may now call it the sap, passes upward into the plant from the smaller into the main, larger roots, on up into the trunk. The particular path of this upward stream is located in the xylem or woody portion of the conducting fibers; in woody trees of considerable size this upward flow of sap from the roots is most active in the newer, outer layers of wood or what we call the "sap wood." Very large amounts of water, with food materials in solution, pass up through the stems of plants in this way, as may readily be seen when we consider the amount of the soil elements which plants contain, and the fact that the solution in which they come into the plant from the soil is an extremely dilute one. A large supply of water is therefore necessary and indispensable to the growth of the plant, not only for its actual use as food, but also as a conveyor of other elements, and likewise to maintain the turgidity or rigidity of the whole plant body. We may say, indeed, that up to a certain point the growth of a plant is proportionate to the amount of water which it receives, since the more water the soil contains the more food material will be dissolved 
and given entry to the root. Beyond a certain point the soil may receive too much water, aeration be too much reduced, and the roots become sluggish, injured, or even killed. Under the semi-arid conditions of California, however, nothing is so striking in regard to plant life as the marvelous effect of an abundant water supply upon growth and fruit production. The crude sap solution passes along up through the wood or xylem of the stem out into the branches and finally reaches the leaves.

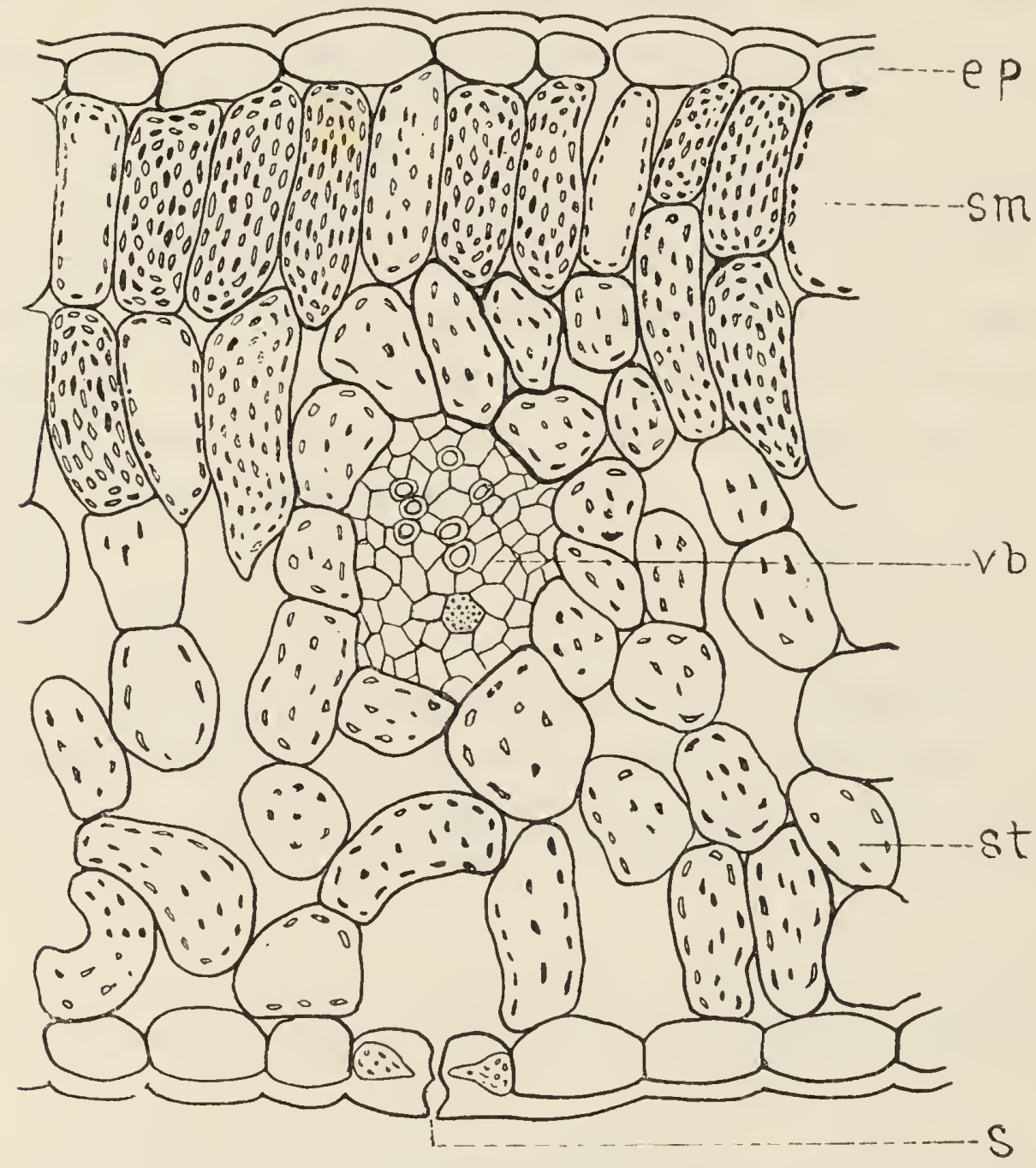

FIG. 4.-Cross section of leaf. ep upper epidermis, sm and st sugar and starch-making cells, vb fibrovascular bundle, s stoma.

\section{AIR RELATION.}

The relation of the plant to the atmosphere which surrounds it is of supreme importance, its relation being expressed most largely through the leaves, which act as organs both of absorption and excretion. The water supply coming from the roots, with its food elements in solution, comes into the leaves and there the larger portion of the water is evaporated off into the air by the process called transpiration. This excess of water passes off in the form of vapor, reaching the air through minute openings called stomata in the leaf surface. These are usually more abundant on the lower than on the upper surface of the leaf, and in the leaves of some plants are confined entirely to the lower portion. 
At the same time that this process is going on the leaves absorb large quantities of carbon from the air in the form of carbon dioxide gas. Carbon completes the list of food substances necessary to the plant, taken together with those mentioned as being derived from the soil. The leaves are able, by means of a process exerted through the influence of sunlight upon their green coloring material or chlorophyll, to decompose this carbon dioxide and bring the carbon into combination with hydrogen and oxygen derived from the soil. As a result of this process, which is called photosynthesis, a succession of chemical changes occurs which results in the formation of sugar in the leaf, followed by large quantities of starch. This process goes on during sunlight, and is indispensable to the life of the plant. During active sunlight in the daytime a large excess of these substances is formed, so that by evening the leaf contains an accumulation of starch and sugar. Neantime, both day and night, the starch is digested into sugar, and a solution of the latter substance is continually being distributed from the leaves to all parts of the plant where growth is taking place or where food material is being stored up. This current passes largely through vessels called the sieve tubes, which in woody plants are located in the inner bark.

Before the materials formed by photosynthesis can be assimilated by living substance, they are formed into new compounds containing nitrogen. A variety of complicated chemical processes goes on all over the plant in which use is made of the various materials taken from the soil, and the various substances formed build up the growth of new parts, the formation of fruit, or are otherwise made use of in the activities of the plant.

Respiration goes on in the leaves in a manner chemically similar to that in animals. Oxygen is taken in and carbon dioxide given off.

RELATION OF THE PLANT TO CLIMATIC CONDITIONS.

The atmosphere has many relations to the growth of plants other than that of supplying carbon dioxide and oxygen to the leaves. Its temperature, for instance, is one of the most important factors in controlling the distribution of plants or the choice of location where certain species can be grown. The humidity of the air, its degree of moisture or dryness, is also of considerable importance. The degree of light which the leaves receive is a very important matter, especially as it influences the process of photosynthesis, which is the first, fundamental operation in the nutrition of the plant. The air may also contain substances injurious to vegetation, although this rarely, if ever, occurs naturally. 
Non-I'arasitic Troubles.

Atmospheric:

Excessive Cold;

Excessive Heat;

Excessive Dryness;

Excessive Moisture;

Wind ;

Hail ; Soil :

Artificial Influences.

Deficiency of Necessary Substances;

Excess of Certain Substances (Alkali, Salt, Acid) ;

Excessive Dryness;

Excessive Moisture;

Faulty Physical Structure (Hard-pan, Heavy or Coarse subsoil);

Aitificial Influences.

Parasitic Troubles.

Higher Animals (Gophers, Moles, Squirrels);

Insects ;

Worms ;

Mollusks (Slugs, Snails) ;

Higher Plants (Dodder, Mistletoe);

Fungi ;

Bacteria ;

Slime Moulds.

The above table indicates most of the influences which affect plants injuriously in California, so far as they can be definitely tabulated. It should be further mentioned that, in many cases, various combinations of the above have disastrous results which could not be attributed to any influence acting alone.

DIRECTIONS FOR EXAMINATION OF DISEASED PLANTS.

Before proceeding to a description of the principal troubles of our various crops it may be useful to give the following general directions for the examination of unhealthy plants:

1. Note whether any particular portion of the orchard or field shows the trouble worse or less and, if so, seek to find wherein conditions are different there from those in the remainder of the planting.

2. Note whether any particular kind or variety of the crop is more or less affected than others, also whether any particular individuals show marked resistance, immunity or freedom from the trouble. Ascertain the commercial qualities and desirability of any seemingly resistant or immune variety or individuals.

3. Determine as accurately as possible the part of the plant which is actually affected. In many cases, for instance, the leaves or top may wilt and die when the real trouble is in the roots.

4. Look first for the simplest effects, such as those of animals, frost or other climatic influences, simple injuries or other obvious causes of trouble. 
5. Look for indications of alkali, salt, poor drainage, too light or too heavy soil or other injurious soil conditions, as shown by surface incrustations, the occurrence of native vegetation peculiar to certain conditions or any peculiarity in the appearance of the soil in the region of the affected plants.

6. Look for the presence of fungi, insects or other parasites, so far as one's ability extends in this direction. Endeavor to observe accurately and judge intelligently whether the organisms found are the cause of the trouble or simply secondary.

7. If nothing is found above ground to indicate the cause of the trouble, dig or bore a hole to the depth reached by the lowest roots. During the digging notice the condition of the roots, the consistency of the layers of soil, the amount of moisture which they contain, and their relation to the development of the roots. Look carefully for any peculiar or suspicious condition, either in the roots or soil, and continue the examination out to the smallest roots and down to an ample depth.

8. Ascertain as closely as possible all that can be found out about the previous history and treatment of the soil and plants, all information of possible value as to irrigation practice, fertilization, cultural methods and previous climatic conditions; also the nature of the trouble from its very first appearance.

9. If necessary, examine healthy groves, trees or plants of the same kind, making the same examinations and inquiries; and endeavor to ascertain wherein conditions differ from those where the trees or plants are diseased.

After this examination, if more information is desired, endeavor to select the most characteristic samples, either of parts of the plant or soil, and send them to the proper authority with complete information as to the nature and occurrence of the trouble. In sending parts of plants, pack them so that they will remain as fresh as possible. In obtaining soil samples take a fair sample from each foot down to a depth of four feet. 


\section{SOME OF THE MOST COMMON EFFECTS OF INJURIOUS ATMOSPHERIC AND SOIL CONDITIONS IN CALIFORNIA.}

\section{ATMOSPHERIC INFLUENCES.}

Frost and Cold.-The effects of low temperature, in most of the cultivated portions of California, are only such as are produced by infrequent frosts or injurious effects of temperatures very little below the freezing point and lasting usually but a few hours. Such effects are in most cases evident and unmistakable, needing no detailed description and resulting simply in the death of the parts or organs which are severely frozen. This is seen, for instance, in the not infrequent killing of fruit blossoms and young shoots by late spring frosts, the nipping back of young and tender growth of citrus trees during occasional cold nights in the winter, and other similar effects. In regard to such injuries, the grower was formerly at the mercy of the elements, depending for protection only upon choice of location in planting and avoiding places known to be dangerous for a certain crop on account of likelihood to frost. In comparatively recent times, however, appliances and methods of frost protection have received much attention, and a high degree of satisfaction has been obtained. By the development of such methods, the culture of some of our more tender plants has been extended into regions hitherto dangerous.

One of the most difficult frost injuries to detect is the slight freezing of oranges, which occurs now and then in some sections. When this happens the internal texture of the fruit is injured, its juice partially disappears, and a greater or less portion of the pulp of the orange becomes dry and insipid. Fruit which is badly affected in this way may be readily detected in handling by the experienced sorter, but occasionally there may be a considerable quantity of slightly affected fruit which is extremely difficult of detection until the oranges reach the consumer. $\dot{A}$ specific gravity method has been employed to some extent, eliminating all the oranges which float in a liquid of a certain density. This method works somewhat to the disadvantage of the producer, taking out all the lighter oranges, whether frozen or not.

Another somewhat obscure effect of freezing is seen occasionally in young citrus and other trees in a killing of the inner bark just above the surface of the ground. Not infrequently young trees, which appear to have gone through the winter without harm, as indicated by the appearance of the top, begin to fail and die later in the spring, and on examination it is found that the inner bark and wood in the vicinity of the cambium layer are entirely dead for some distance just above ground.

In the case of deciduous fruits (see Almond, Apricot, Cherry, Peach and Pear), severe frost just after the fruit has set sometimes kills the 
young germ of the seed without causing the fruit to drop or even checking its growth for some time. Such fruit sometimes reaches considerable size before falling and is then found to contain a black, shriveled seed germ, killed by frost.

In citrus districts most subject to low temperatures during the winter, with occasional severe freezes, there sometimes seems to occur a general lowering of the vitality of the trees, and an appearance of weak, unhealthy, mottled-leaf condition. In such regions where a considerable portion of the young growth of the trees is frequently killed back, a condition of degeneration lasting all through the season may occur, particularly if the trees do not receive the best cultural treatment.

The matter of frost injury in most parts of California, where the injurious degree of temperature is very slight, its duration short, and its occurrence comparatively rare, is very much affected by comparatively slight influences, particularly the condition of growth in the plant and the degree of moisture in the soil. By so handling the crop as to keep down as much as possible the production of tender new growth during the cold season, by keeping the soil in moist condition, and by the use of the comparatively simple protective means about to be described, much of the frost damage which is likely to happen in California may be prevented.

Frost prevention, both for citrus and other crops, has received much attention in recent years, and with a large measure of success. For preventing damage to tender growth, fruit or blossoms on cold nights, methods have been perfected which consist in burning smoky, sooty fuel, such as soft coal or low grade oils, in numerous small receptacles placed upon the ground at proper intervals whenever the temperature approaches the danger mark. A variety of patented devices for this purpose is upon the market, and literature upon the same may be obtained from the makers.

In the case of young trees, particularly citrus, special attention is required to carry them through the first three or four years in localities subject to occasional frosts. The damage described above, where the tree is killed just at the surface of the ground, and likewise the killing back of the top is successfully prevented by banking up the earth somewhat about the trunk in the fall, and by the use of a wrapping or protector of some sort about the trunk. A common practice with citrus trees consists in tying several cornstalks, palm leaves, tule or similar material about the trunk of sufficient length to enclose and protect most of the ton of the tree at the same time. In many places citrus groves have been successfully developed by thus protecting the trees during their first two or three years in the orchard, when without such protection it would have been almost out of the question to get a growth started. 
Heat.-Cultivated plants in some portions of California are subjected to very extreme degrees of heat during the summer time, and the choice of crops for certain localities is largely influenced by this factor. Beyond this, injury from unusual degrees of heat, particularly when combined with extreme atmospheric dryness, is of quite frequent occurrence. The effect of this is usually seen in a sudden burning and withering of the leaves, producing an effect sometimes called sun-scald. Much damage is sometimes caused in the same manner to fruit, particularly grapes, and occasionally some of the deciduous fruits. This injury shows itself as a burning or withering of the fruit on the exposed side, or a shriveling and drying of the fruit before it reaches full size. This trouble is frequently seen in prunes in the northern part of the State. Trouble of the same sort is also common with the English walnut. Quite frequently an unusually hot, dry period, particularly when the crop is approaching maturity, causes a withering and blackening of the exposed sides of the green hulls which enclose the nuts, and this burning extends as a discoloration into the meat of the nut itself, causing the hull to stick to the nut on that side, and the nut to blacken, both inside and out. This form of sunburn often causes large losses to the walnut grower, and also limits the growth of this crop to regions where the sun is not too severe:

The condition of weather, commonly known in this State as a "hot norther" or "Santa Ana," is frequently the cause of much damage to some crops, especially when occurring early in the season. The condition referred to consists in a hot, extremely dry, electrical wind, blowing from the interior or desert portions of the State toward the coast. When such winds occur the blossoms of fruit trees are sometimes killed and young sprouts dried up and destroyed, the latter particularly in the case of buds or grafts which have recently been put in. The English walnut is also particularly susceptible to this form of injury when in bloom. The damage in this case appears to be done mainly to the pollen, and if this sort of weather occurs just when the catkins are shedding their pollen, the setting of the crop may be very seriously affected.

Another condition commonly called sunburn is of frequent occurrence, affecting the stems or trunks of young trees. This is almost invariably seen on the southwest side 'of the tree, although local peculiarities may influence this feature somewhat. The trouble is due to a killing of the cambium layer by the heat of the sun and results in an area of dead bark extending up and down the trunk or on the sides of larger limbs, through which decay often sets in and the tree is badly injured or killed. This form of sunburn is seen particularly in young trees recently set out, where the trunks are exposed to hot sun before the trees have been able to draw a plentiful supply of moisture from the soil by the formation 
of new roots. Trees which for any reason make a poor start and fail to root properly are especially liable to sumburn in the trunk. When, for example, nursery trees are allowed to become too dry before planting this frequently occurs and the trees may be entirely killed, damaged on one side or, in some cases, may throw out new shoots from the lower portion of the trunk.

This occurrence of sunburn is by no means confined to the summer season, but takes place even more commonly during the winter in our climate. Particularly with such trees as the walnut, apple, peach and prune, which shed their leaves in the winter, the sap movement does not become entirely dormant during the winter but is kept in a state of irregvlar activity by the occurrence of frequent periods of warm weather. Especially in regions where the nights are fairly cold and the days hot during a considerable portion of the winter, trees of this sort become badly sunburned. The sap starts and stops again in the trunk and without the presence of leaves to regulate this flow in a normal manner abnormal conditions occur in the cambium and the hot afternoon sun causes a burning of one side of the trunk. Toadstool or other fungi causing decay may then effect an entrance through such a wound and the tree is destroyed. Sunburn is prevented by the presence of an abundant supply of moisture in the soil more than by any other influence. We may, of course, except from this statement the influence of shade, or climatic conditions not conducive to damage of this sort. Other things being equal, however, trees or plants having an abundant supply of moisture in the ground are much less likely to suffer from sunburn, either in the trunk or as affecting the fruit. It is therefore advisable to give plants and trees a particularly abundant supply of water' in hot, dry times when the fruit may be kept from injury by this means, and also during the fall and winter, if abundant rains do not occur, in order to prevent damage to the trunks and buds. In the case of nursery trees which have become too dry before planting, it is often advisable to cut them back nearly to the ground and allow a new shoot to come up and form the trunk. This should always be done when the tree is found to be badly sunburned and standing in a dormant condition without throwing out any new growth. By thus bringing up a fresh shoot from below, through which the sap is able to circulate freely, a good, thrifty tree is often produced, while if the tree is not cut back it stands all through the season throwing out a few stunted, sickly shoots from its sunburned trunk and very likely dies entirely.

In the case mentioned of deciduous trees which become sunburned in the trunk during the winter time on account of an irregular activity of the sap, this condition is usually aggravated if the surface of the soil is bare and free from vegetation. Frequently the same influences which cause sunburn prevent the development of vegetation on such soils, on 
account of the extreme variation in temperature in winter between the day and the night. Heavy frosts occur at night, freezing the surface of the ground, while the hot sun of the day heaves it up and destroys any seedlings which may have started. The only thing which can be done in such a case is to make every effort to get some sort of growth started during the fall before the coldest nights come on. This is frequently difficult on account of a lack of water for starting such a growth. If it is not feasible the next best thing is to mulch the surface of the ground about the trees, covering it with straw or any similar material which may be available. It is also advisable to cover the trunks and main limbs of any trees which are in danger of sunburn with a coating of thick whitewash. This should also be done to prevent sunburn when the tops of trees are heavily cut back for any purpose, as for instance, after top-working them to other varieties.

Before leaving the subject of the relation of temperature to vegetation in California, we may say that many peculiar and obscure effects frequently occur as a result of bringing plants native to the temperate zone and accustomed to a definite period of dormancy during the winter, to a region where the change of the seasons is so slightly marked. These plants are by nature accustomed to and prepared for a dormant period during a portion of the year. They not only drop their leaves and cease their growth at the approach of winter, but also undergo chemical and various other physiological changes in preparation for this dormant period. The stimulation or irritation caused by the frequent occurrence during the winter of weather conditions entirely similar to those normal to the spring time, must cause a frequent starting and stopping again of those processes which go on in the tree during the normal commencement of growth in the spring, and in this way pathological conditions are produced. To conditions of this sort appear to be partially due such troubles as little leaf of the peach, walnut yellows, sour sap of stone fruits and possibly other of the so-called physiological or chimatic diseases. The only relief to be expected from this trouble is through the planting of species or varieties of fruit which are known to be unaffected by such disturbances.

Excessive Dryness.-This subject has already been treated in connection with extremes of temperature. High temperature in California is almost invariably accompanied by extreme dryness and the two work together in producing burning of foliage, withering of fruit and similar effects.

Excessive Moisture.-Little trouble of this sort is experienced in California, since no rain falls during most of the growing season of the majority of our crops. Fruit setting is sometimes prevented by violent or long continued rains during the blossoming period, this result being 
produced largely by interference with or prevention of the process of pollination. Most of our deciduous fruits have the unfortunate habit of blooming just when our most abundant rains are likely to occur and the setting of fruit is sometimes considerably diminished by this means. In many cases also imperfect pollination results and the fruit either falls after growing for a short time or the seed does not properly fill.

Our most serious effect of excessive moisture in the air is probably that of favoring the development of various fungus diseases and causing thus an indirect injury. It is an almost universal rule that the development of parasitic fungi is favored by atmospheric moisture and very marked differences result in California in the occurrence of plant diseases in various seasons according to the amount of moisture which occurs. The same comparative effect is seen in different sections of the State, the same crop being badly affected by a fungus disease in one place and entirely free from it in another, as a result of a difference in atmospheric moisture conditions.

Wind.-This is an important consideration in connection with California agriculture, particularly in the case of the production of tree fruits. In choosing a location for an orchard, and particularly a citrus grove, this feature should be considered along with temperature, character of the soil and water supply. The bad effects of wind are mostly mechanical, consisting in a bruising of the fruit by contact with the branches and twigs. More than this, serious loss is often caused in windy localities by quantities of fruit being actually blown from the trees on to the ground before it is ready for picking. In very windy localities the growth and form of the trees are decidedly affected, the tendency usually being to cause the tree to lean over and make its principal growth in the direction of the prevailing wind. In a few cases, notably the apricot tree, it is a curious fact that the tree shows the opposite response, its branches curving over and pointing directly into the face of the wind. In very windy localities, particularly along the coast, the young shoots in the tops of the trees are continually killed back by the wind, which, together with the breaking off of large limbs, gives the trees a stunted and deformed appearance. Citrus fruit from windy localities loses much in quality on account of being covered with scars and blemishes, and also in quantity, as just stated, on account of being blown from the trees.

On the other hand, a locality otherwise desirable for orcharding should not be too hastily condemned on account of wind. Most parts of California are comparatively windy in their primitive state on account of the absence of trees to break the force of the wind. It is very noticeable that as a given locality or valley becomes settled, and the 
country is broken up with buildings and trees, the wind currents become less severe and less damage results from this cause than at first. In almost all orchard planting in new districts this fact is taken into account, and protection from the wind is attempted and attained to a more or less extent by the planting of rows of trees called wind-breaks. This is done by planting close rows of suitable trees at intervals across the path of the prevailing wind, on the windward side of orchards, or home sites, or in any position which will best break the wind in the locality where protection is desired.

For this purpose eucalyptus trees have been most commonly used in California, particularly the blue gum, Eucalyptus globulus, in all regions adapted to its growth. It is customary to plant these trees about eight feet apart, using two or three rows in an alternate manner. Another tree much used for wind-breaks is the Monterey cypress. This makes a much denser growth close to the ground than eucalyptus, and needs to be planted only in a single row. Its growth is slower than that of the blue gum but rapid compared with that of most trees other than eucalyptus. Often a combination is made of cypress and eucalyptus planted alternately in a single row. This makes a taller and more rapid growing break than cypress alone and a denser one than eucalyptus alone.

Wind-breaks have a serious objection on account of the large amount of moisture and plant food which these large, rapid-growing trees take up. With eucalyptus, particularly, it is impossible to grow thrifty fruit trees within a space of fifty or more feet of the wind-break after the trees become large. The shade of the trees also has a detrimental effect upon the neighboring fruit trees, and a still further objection is the formation of so-called frost pockets, the latter being due to a lack of air circulation on cold nights in the portions of the grove most sheltered by the wind-break. The grower must decide for himself in individual cases whether the benefit of such a planting will more than repay its disadvantages. There is a marked tendency at present in our older settled districts to cut down the original wind-breaks, since the general development of the country has broken up the sweep of the wind and the land occupied by these eucalyptus or other trees is now more valuable for fruit trees or other purposes.

Hail.-Violent hail storms are of occasional occurrence, even in the most frost-free portions of California. Damage is sometimes caused through the bruising of fruit and the breaking of foliage and twigs.

Artificial Substances in the Air.-We have already said that the atmosphere never contains normally anything injurious to plants. Frequently, however, in the vicinity of cities or industrial enterprises, various emanations are poured into the air and act disastrously upon 
vegetation. Such effects are frequently seen in the vicinity of smelters, chemical works, or in localities where soft coal containing large amounts of sulphur is burned. Particularly injurious are the fumes resulting from the burning of sulphur in any form, if they come into contact with vegetation without being very much diluted with air.

The subject of smelter fume injuries has received very extensive investigation both in this country and Europe for many years. This has also been the subject of a rast amount of expensive litigation between smelting and other companies on the one hand, and agricultural or timber interests on the other. There is no subject which needs the most competent expert attention and the most careful judicial consideration more than this. Grave and extensive injustice may be done by an improper finding for either the smelting or the agricultural interests. Both industries are of great importance, and their relative rights and standing must be carefully considered in cases where their interests seem to clash. From the standpoint of the smelting company, there should be clearly and positively established the amount of damage which is actually being caused by the fumes and the relative value of the agricultural interests affected in proportion to that of the smelting and mining interests. There is invariably a very natural tendency in the vicinity of smelting and similar plants to lay to the smoke all sorts of plant and animal troubles, real and imaginary, which are not caused by any other very obvious agency. In all agricultural pursuits there is a certain element of uncertainty, due to climate, soil conditions, and other uncontrollable and obscure factors. In normal districts a certain amount of animal and plant disease, crop failure and similar conditions is expected from such sources. Given, however, a specific, ever-present agency, known to be injurious under certain conditions, and it is a natural tendency to lay all sorts of troubles which can not be otherwise accounted for to this one cause. On the other hand, it is sometimes the tendency of the smelting company, partly perhaps in self-protection, to attempt to lay all troubles and injuries to effects other than smoke, and minimize as much as possible the damage which is actually caused.

There can be but one satisfactory basis of settlement of all such cases, namely, as we have already said, a careful, expert, and unprejudiced examination of actual conditions and a settlement of damages or determination of future policy on this basis. In many European districts permanent courts or arbitration boards have been established under state control to settle these questions and this method is far superior to a constant wrangling in the courts with final decisions based on the relative arguing ability of the opposing attorneys or the influence of more or less incompetent, so-called experts, subsidized by the opposing sides to present their cases in the best possible light. If this matter is properly 
managed, there is no reason why agriculture and mining should not both be carried on to mutual advantage and without antagonism.

The specific effects of smelter fumes upon vegetation can not be stated or described in such a manner as to make their identification absolutely certain. In a general way it may be said that such effects consist in a spotting or burning of the leaves, and we may also say that there can be no injury without such spotting or burning. In other words, there is no such thing as an invisible damage to plants by smelter fumes. Leaf spot, however, is caused by so many other agencies and conditions that

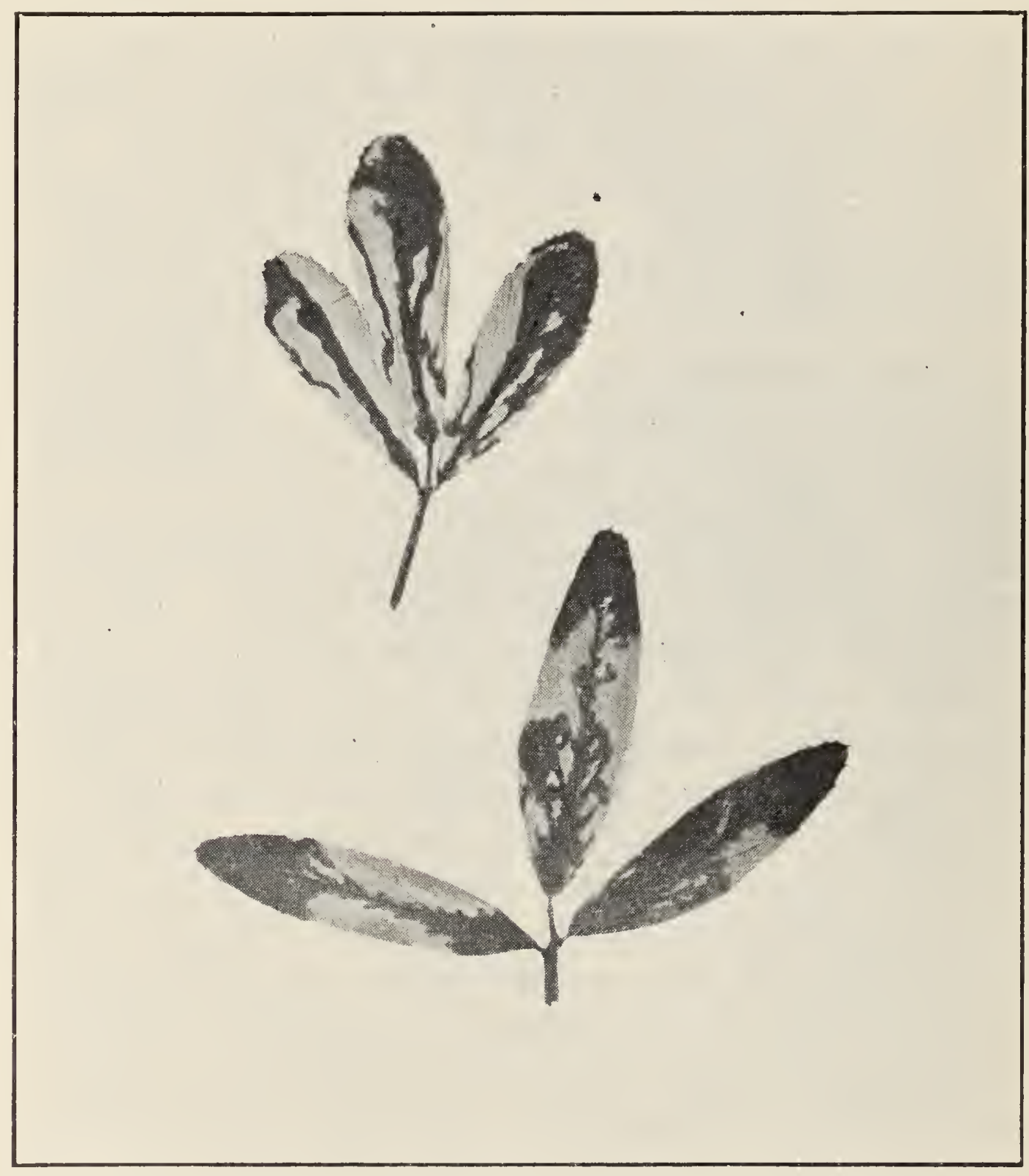

FIG. 5.-Effect of smelter fumes on leaves of alfalfa.

only the most careful local examination, and broad, general knowledge of other effects which act injuriously upon vegetation, can enable one to positively distinguish smoke injury. Microscopic study of injured tissues is of much assistance to the experienced investigator, but here again no definite symptoms can be laid down which distinguish this injury from all others. Chemical analysis, also, has its place, but does not suffice to distinguish arbitrarily and specifically all smelter smoke 
injury from every other possible source of trouble. One having a general knowledge of plant pathology and entomology can usually soon eliminate in a smoke district many fungus, bacterial and insect effects which have been ascribed more or less to the smoke, but beyond this he inay encounter effects of frost, unfavorable soil or climatic conditions, lack of proper cultivation, effects of fire and many other influences which must be thoroughly understood and considered. On the other hand, he must not exaggerate such effects as these and attribute to them injuries which are really due to the smoke.

Different species of plants vary widely in their susceptibility to smoke injury, and the amount of injury is also decidedly influenced by weather conditions. Other things being equal, more damage to vegetation is caused during wet than in dry weather. This may be due to the fact that the injurious substances are absorbed by moisture, and thus brought into contact with vegetation in a more concentrated form when it is wet. More injury is caused in localities where the wind tends to blow steadily in one direction much of the time than in places where the currents of air are constantly shifting. In the latter case, a fairly concentrated smoke may cause no appreciable damage, while, in the former, quite dilute fumes may mark out a very evident path of destruction on the vegetation in the direction of the prevailing wind.

Damage is also sometimes caused by manufacturing plants which discharge large amounts of dust into the atmosphere. This is the case in the manufacture of cement, where great quantities of dust go out into the air and settle upon the leaves of surrounding vegetation, the dust often setting like cement to a considerable extent. This is very destructive to the appearance and selling quality of fruit or vegetables upon which it occurs, and in the case of trees, particularly evergreens like the orange and lemon, there appears to be in some cases considerable damage to the vitality of the tree. This may come about through an interference with photosynthesis, caused by the light being cut off through the layer of dust upon the leaves and resulting in injury to the nutrition of the tree, although this fact has not been clearly established. There is nothing in the dust itself which would be chemically injurious to the tree or soil. Question has also been raised as to the effect of such dust deposition upon pollination and the setting of fruit. With citrus fruit it is well to bear in mind that damage of this sort is very doubtful in many cases, since in our most popular variety of orange, the Washington Navel, and to some extent in other citrus fruits, pollination is not necessary, and does not ordinarily occur, the fruit developing by vegetative growth. The same condition exists to a greater or less extent in other citrus fruits which have a tendency toward seedlessness. 
SOIL INFLUENCES.

Deficiencies.-We have shown before that the plant requires from the soil certain specific chemical elements in proper amounts and proportions, together with a large amount of water. The plant differs from the animal body in that it may continue growing in size throughout its whole life rather than ceasing to increase at a certain stage of maturity. The amount or rapidity of this increase, if temperature conditions are favorable and no injurious influences present, depends almost entirely upon the amount of the necessary elements and the supply of water which is available in the soil. Particularly noteworthy in this connection is the fact that the lack of one element may keep back the whole developinent of the plant, even though all the others are present and abundant. On this account the whole matter of successful soil fertilization depends almost entirely upon the determination of the limiting element or elements and applying these in sufficient quantities for maximum results, without at the same time using quantities or elements. which are wasteful and without effect.

In this connection the function of water and the possibility of its being the limiting factor, rather than any chemical element, can not be too strongly emphasized. There is no question that in a large portion of the citrus acreage of California, for instance, where artificial fertilizers are applied more or less regularly and in fairly large amounts, the deficiency of water is greater than that of any chemical element and a large portion of the fertilizers applied remains inert in the soil or is washed away by rain without ever reaching the interior of the tree.* For this reason it is extremely important in the examination of unthrifty trees to inquire carefully into the irrigation treatment which the trees have received, and, much more important, to examine the soil to a depth of several feet and find out positively the moisture condition of the lower layers of soil. This is discussed more particularly in a later paragraph.

We would not infer by this that soils are never deficient in chemical elements, or that fertilization is never effective. Many soils are decidedly deficient in one or more of the essential elements, and practically all

* In order to give further weight to this point we append the following quotation:

"From a theoretical point of view it is not possible to say that any one of the main soil constituents is more important than any other, since all are necessary to a proper functioning. Practically, however, there can be no two opinions as to the supreme importance of the soil water. Nine times out of ten it is the supply of this constituent which limits crop production. Usually the other constituents are sufficiently if not maximally, favorable, and poor water supply and infertility go hand in hand. Controlled water usually means controlled fertility. The soil water must occupy, then, a very prominent place in the theories of the soil physicist, and the study of its nature and movements must ever be a most important and absorbing branch of his activity. Nor is the importance of the soil water intrinsic only. It. is the medium of the soil solution and only through it are the necessary food elements carried from soil to plant. From soil chemist, as from soil physicist, the soil water is receiving ever increased attention and especially so in the light of the most modern theories of the dynamics of plant food." - E. E. Price, "Studies in Soil Physics, II," The Plant World, Vol. 14, page 59. 
soils, after continuous cultivation for several years, become exhausted. Moreover, there are many cases of soils where thrifty plants and profitable crops can still be grown without fertilization, and yet, by such practice, an increased crop can be obtained which will prove a profitable investment on the cost of fertilization.

The effects of a deficiency of any of the elements most commonly lacking in soils, nitrogen, phosphoric acid or potash, are seen as a backwardness in the development of the plant. Nitrogen is most noticeable in its effect upon growth, and is most likely to be lacking in California soils, yet an actual deficiency of any of the other necessary elements is equally effective in cliecking development. The specific effects of the various elements upon plant life are frequently described, but we have little definite information of this sort as applied to California crops. With the orange, for instance, we are frequently told that nitrogen promotes especially the growth of the tree; that phosphorus is most concerned in the setting of the fruit, and that the application of potash produces more sugar in the fruit. Various statements are also frequently made as to the effect of these various elements upon the fruit in its time of maturity, its flavor, texture, color, and various other characteristics. We are also told that lack of iron has a marked influence in causing yellow, light-colored foliage, and that an application of this element will remedy such a condition. In regard to these ideas, however, we may say that certainly most of them have never been definitely proven in California. The most careful experiments have almost entirely failed to show any specific effects or differences of this sort. So many other influences come in, such as those of temperature and other climatic conditions, soil moisture, variation in trees and other complicated factors, that it is very easy to ascribe marked differences, noticeable in a single season, to some substance which has been applied to the soil, when really some other influence altogether was responsible for the effect observed. The best evidence goes to show that any fertilizing element or any other influence which promotes the growth of the citrus tree likewise promotes and increases the production of fruit. It also appears to be a fact that citrus trees which are best nourished and in the most thrifty condition bear the best fruit, and are in every way most profitable.

The specific subject of the methods and materials of soil fertilization is too extensive a one for complete consideration here. Persons desiring information along this line should consult some of the numerous publications upon the subject.

TVe may say, in brief, that the substances mentioned as being most likely to be needed, nitrogen, phosphorus, and potash, are commonly supplied either in the form of stable manure or in various substances, the preparation of which forms a large and important industry. Nitro- 
gen is supplied in the form of salts, such as nitrate of soda and sulphate of ammonia, or in various substances prepared from slaughterhouse refuse, such as bone, dried blood, and tankage. Phosphorus comes commonly either from finely ground mineral phosphates, which are usually treated with sulphuric acid to make them more soluble and are then called superphosphate, or in the form of bone or other animal refuse. Potash, as used in California, comes almost exclusively from the salt sulphate of potash, which is mined in Germany. The various fertilizer dealers supply these different materials and are also in the habit of mixing them together in supposedly proper proportions into so-called complete fertilizers, which are easier and, for the inexperienced, sometimes safer to use.

Deficiencies in nitrogen in the soil are also supplied in many cases very satisfactorily and economically by growing and plowing under so-called green manure or cover crops. For this purpose are used certain plants, such as clover, vetch, peas or other legumes, which have the power of absorbing nitrogen from the air. By adding large amounts of such material to the soil its stock of nitrogen is appreciably increased and its mechanical condition likewise improved.

Excesses.-Plant troubles due to an excess of certain substances in the soil are very frequently met with in California. This is particularly the case in so-called alkali soils. In such cases the soil is impregnated with excessive and harmful amounts of certain salts which in more humid climates are dissolved by the frequent rains and carried away in the drainage.

Alkali Soils.-The most common of the alkali salts are the so-called white alkali, sodium sulphate, and black alkali, sodium carbonate. Another substance frequently found in soils in injurious amounts is common salt, sodium chloride. The presence of these salts is not usually difficult of detection in a superficial examination, while by chemical analysis their presence and amount can be absolutely determined. Alkali lands are usually characterized by spots or areas of greater or less extent where a white incrustation can be seen upon the surface of the ground. Black alkali is so called from the fact that when wet it dissolves the humus of the soil, forming a black, greasy looking substance upon the surface of the soil, or giving a black color to surface water. The effect upon native vegetation is always quite characteristic of the presence and amount of alkali salts. Certain species of plants prefer alkali soil and flourish according to the amount of these substances which the soil contains. Most plants, however, are easily injured by them, with the result that spots containing any considerable amount of these injurious salts either have upon them the above mentioned characteristic plants or remain bare of vegetation with the alkali 
crust upon the surface, while the surrounding ground is covered with normal vegetation. In every case where there is any reason to suspect the effects of alkali or other injurious salts, the soil should be chemically analyzed down to a depth of several feet.

The present subject, although belonging more in the field of the soil chemist than that of the plant pathologist, is of so much importance in the study of plant diseases in California that we have thought it desirable in this chapter to make the following quotations from Professor E. W. Hilgard's authoritative treatment of the subject:*

Effects of Alkali Upon Culture Plants.-In land very strongly impregnated with alkali salts, most culture plants, if their seed germinates at all, will show a sickly srowth for a short time, "spindle up" and then die without fruiting. In soils less lieavily clarged the plants may simply become dwarfed, and fruit scantily. The effect on grown trees around which alkali has come up, is first, scanty leafage and short growth of shoots, themselves but sparsely clothed with leaves.

Nature of the Injury to Plants from Alkali. - When we examine plants that have been injured by alkali, we will mostly find that the visible damage has been done near the base of the trunk, or root crown; rarely at any considerable depth in the soil itself. In the case of green herbaceous stems, the bark is found to have been turned to a brownish tinge for half an inch or more, so as to be soft and easily peeled (rff. In the case of trees, the rough bark is found to be of a dark, almost black, tint, and the green layer underneath has, as in the case of herbaceous stems, been turned brown to a greater or less extent. In either case the plant has been practically "girdled," the effect being aggravated by the diseased sap poisoning more or" less the whole stem and roots. The plant may not die, but it will be quite certain to become unprofitable to the grower.

It is mainly in the case of land very heavily charged with common salt, as in the marshes bordering the sea, or salt lakes, that injury arises from the direct effects of the salty soil-water upon the feeding roots themselves. In a few cases the gradual rise of salt water from below, in consequence of defective drainage, has seriously injured, and even destroyed, old orange orchards. The natural occupancy of the ground by certain native plants may be held to indicate that the soil is too heavily charged with saline ingredients to permit healthy root growth or nutrition until the excess of salts is remored.

The fact that in cultivated land the injury is usually found to occur near the surface of the soil, concurrently with the well-known fact that the maximum accumulation of salts at the surface is always found near the end of the dry season, indicates clearly that this accumulation is due to evaporation at the surface. The latter is often found covered with a crust consisting of earth cemented by the crystallized salts and later in the season with a layer of whitish dust resulting from the drying-out of the crust first formed. It is this dust which becomes so annoying to the inhabitants and travelers in alkali regions, when high winds prevail, irritating the eyes and nostrils and parching the lips.

Effects of Irrigation.-One of the most annoying and discouraging features of the cultivation of lands in alkali regions is that, although in their natural condition they may show but little alkali on their surface, and that mostly in limited spots, these spots are found to enlarge rapidly as irrigation is practiced. Yet since alkali salts are the symptoms and result of insufficient rainfall, irrigation is a necessary condition of agriculture wherever they prevail. Under irrigation, neighboring spots vill oftentimes merge together into one large one, and at times the entire area, once highly productive and perhaps covered with valuable plantations of trees or vines, will become incapable of supporting useful growth. 'This annoying phenomenon is

*"Soils," pages 426-429. 
popularly known as "the rise of the alkali" in the western United States, but is equally well known in India and other irrigation regions.

The soil being impregnated with a solution of the alkali salts, and acting like a wick, the salts naturally remain behind on the surface as the water evaporates, the rrocess only stopping when the moisture in the soil is exhausted. We thus not infrequently find that after an unusually heavy rainfall there follows a heavier accumulation of alkali salts at the surface, while a right shower produces no perceptible permanent effect. We are thus tanght that, within certain limits, the more water evaporates during the season the heavier will be the rise of the alkali; provided that the water is not so abundant as to leach the salts through the soil and sub-soil into the subdrainage.

Leaky Irrigation Ditches.-Worst of all, however, is the effect of irrigation ditches laid in sandy lands (such as are naturally predominant in arid regions) without rroper provision against seepage. The ditch water then gradually fills up the entire substrata so far as they are permeable, and the water-table rises from below until it reaches nearly to the ditch level, shallowing the subsoil, drowning out the deep roots of all vegetation, and bringing close to the surface the entire mass of alkali salts previously diffused through many feet of substrata.

An effect similar to that described in the last paragraph is sometimes seen in the case of young seedlings, as in seed beds of eucalyptus or orange trees, grown in soil containing a considerable amount of alkali or salt, especially if they are watered with water of a similar nature. In such cases the young plants frequently begin dying in a manner very similar to that produced by damping-off fungi. The natural tendency for the grower is then to use less water and endeavor to keep the soil as dry as possible, which in the present case has the effect of increasing rather than preventing the injury, since the injurious salts tend to accumulate by evaporation about the stem of each seedling. As to the best method of procedure in such cases, assuming that the trouble is known to be due to injurious salts and not a case of true damping-off caused by the fungi, we may again quote from Hilgard (p. 249):

Mode of Using Saline Irrigation Waters.-The fact that abundant growth of native as well as cultivated plants may sometimes be seen on the margins of "alkali likes" where water of over a hundred grains of mineral salts per gallon continuously bathes the roots, while the same plants perish at some distance from the water's edge, points the way to the utilization, in emergencies, of fairly strong saline waters, riz., by the prevention of their concentration to the point of injury by evaporation. It is clear that when such waters are used sparingly, so as to penetrate but a few feet underground, whence the moisture re-ascends for evaporation at the surface, a few repetitions of its use will accumulate so much alkali near the surface as to bring about serious injury. If, on the other hand, the water is used so abundantly that the roots may be considered as being, like the marginal vegetation of alkali lakes, bathed only by water of moderate strength, no such injury need occur; and what does accumulate in consequence of the inevitable measure of evaporation occurring in the course of a season, may be washed out of the land by copious winter irrigation.

This, of course, presupposes that the land, as is mostly the case in the arid region, is readily drained downwards when a sufficiency of water is used. When this is not the case, e. g., in clay or adobe soils, or in those underlaid by hardpan, waters which in sandy land could have been used with impunity, may become inapplicable to irrigation use.

Apparent Paradox.-The prescription to use saline waters more abundantly than purer ones, in order to avoid injury from alkali, though paradoxical at first sight, is 
therefore plainly justified by common sense as well as by experience, in pervious (sandy) soils; while in difficultly permeable ones, their use may be either wholly impracticable, or subject to very close limitation.

Sometimes the alternate use of pure and salt-charged water serves to eke out a too scant supply of the former. But in all such cases, close attention to the measure (if water that will wet the soil to a certain depth, and "eternal vigilance" with respect to the accumulation of alkali near the surface, must be the price of immunity from injury. In all cases the farmer should know how much of alkali salt he introduces into the land with the irrigation water, and watch that it does not approach too closely, or exceed, the tolerance of his crops for alkali salts.

A proper discussion of the methods of utilization and improvement of alkali lands would be too extensive to include in a publication of this sort. The subject is very fully treated by Hilgard, pages 422 to 484 . We may say, in a general way, that the possibilities in this direction lie, first in the planting of crops most resistant to such conditions, since cultivated plants vary widely in this respect. The date palm, for instance, grows and flourishes in soil where almost no other cultivated plant can maintain its existence. The grapevine and olive are also highly resistant, while the peach, apricot, and prune are much more sensitive. The specific substance present in the soil, whether sodium carbonate (black alkali), sodium sulphate (white alkali), or sodium chloride (common salt), is of great importance in this connection, as the relative tolerance of various plants for these different salts varies widely. It is also to be remembered that in the case of fruit trees there is usually some choice in regard to the kind of root upon which the trees may be budded or grafted, as the various roots vary considerably in their tolerance of saline salts.

In addition to the possibilities of utilizing alkali lands by the choice of resistant plants, the possibilities of reclaiming or improving such lands lie mostly in the direction of dissolving out the injurious salts by flooding with water, and then removing the water with the salts in solution by drainage. Much good may be done in this manner where an abundant supply of fairly pure water is available and the topography of the land is such that drainage can be secured. Something can also be done in the way of neutralizing or changing the composition of these soils by application of chemical substances to the soil. It has been demonstrated, for instance, that in the case of black alkali (sodium carbonate), a change of this substance to white alkali (sodium sulphate), can be effected by an application of gypsum, the sulphate being much less injurious to vegetation than the carbonate. This whole subject is discussed at length by Hilgard.

Acid Soils.-Vegetation is sometimes injured or its growth prevented by an acid or sour condition of the soil. This is much less common in California, however, than in the Atlantic States. It is more apt to occur in wet, swampy land, or in recently cleared forest soils, where there is 
a large amount of vegetable matter in the ground. Such a condition can be definitely determined by chemical analysis.

Soil acidity is corrected by the application of lime. (See Hilgard, pages 122 and 123.)

\section{EFFECTS OF DRYNESS.}

(The following discussion presupposes to a large extent the availability of water for irrigation purposes, yet it is to be remembered that large areas of fruit tree and other crops are grown in California without irrigation. What is said in regard to the use of irrigation water will, of course, not apply in such cases. The grower of non-irrigated crops must look to choice of soil and location and cultural methods of moisture conservation. What is said in regard to physical soil defects as affecting the moisture supply applies even more forcibly in this case than in that where irrigation is practiced.)

Some of the greatest mistakes in California horticulture have been made in the attempt to grow crops, particularly tree fruits, without irrigation. Many acres of dying or dead, abandoned orchards still remain to testify to the disastrous results of such experiments. Furthermore, it may be said that even in the case of a large acreage of orchard fruits which is still being cultivated and producing fairly profitable returns, such returns would be very much greater if water for irrigation were available. Even in cases where irrigation might not be necessary every year, a possible source of water supply to be drawn upon during dry years would be the most valuable form of insurance which the grower could obtain. There are many orchards and large areas of land in California where good returns are obtained year after year without irrigation, yet even in the most favorable cases as the trees grow older, filling the soil with roots, drawing more completely upon its moisture content, and demanding more and more water as the tops grow larger and the crops greater, the desirability of irrigation is likely to become more or less pronounced. Nothing should be considered more seriously by the intending planter than the water question, and he should undertake planting without the possibility of irrigation only with the utmost conservatism.

No doubt more trouble and failure in cultivated plants is caused in California from lack of soil moisture than from any other influence. While it would seem that so simple a cause would be readily seen and remedied, yet it is a fact that under our semi-arid conditions, where irrigation during most of the growing season is usually an absolute necessity, a lack of a sufficient amount of water quite unsuspected by the grower is one of our most common troubles. It is due in some cases to an insufficient supply of available water, making it impossible to obtain the necessary amount, but more often to a failure of the grower 
to realize or examine the condition of the soil beneath the surface, and a failure to apply the necessary amount of moisture or to use methods which would insure its absorption by the deeper layers of soil. In our citrus groves, for instance, no experience is more common in examining trees supposed to be suffering from some mysterious disease, than to dig down three or four feet or less below the surface and find the soil entirely dry, much to the surprise of the owner. Sometimes, also, in the case of deciduous as well as citrus groves, in the winter when rainfall is commonly expected to provide sufficient moisture, the subsoil may be found extremely dry because the usual amount of rain has not occurred. Trees often suffer severely from this cause, even when in a dormant condition. Particularly in the fall, after the crop and leaves are off, deciduous orchards often go for many weeks without rain or irrigation, the grower failing to realize that the trees need a plentiful supply of water even though they are not growing or carrying a crop of fruit. Severe injury is frequently caused in this manner to walnut, apple, and other similar trees, which injury shows itself in a poor crop or die-back condition the following season.

In citrus groves the uncertainties of our rainy season lead often to equally bad results. The usual practice in citrus irrigation consists in an application of water about every thirty days, on the average, during the dry summer season, which application is supposed to be supplemented by copious rainfall during the winter months. Such rainfall is expected to soak the ground more completely and deeply than can ordinarily be accomplished by irrigation, and is counted upon particularly to create a subterranean store of moisture in the subsoil. The citrus grower expects, in an average season, sufficient rainfall to make irrigation unnecessary during a period extending from about November first to May first. Relying upon such an expectation his tendency is to withhold irrigation after October, waiting for the expected rain, and to put it off as late as possible in the spring for the same reason. The grower of deciduous fruits, whose crop comes off in the summer and whose trees are leafless and dormant during the winter, stops irrigating still earlier and is apt to pay little attention to his trees after the crop is gathered.

Most seasons this confidence in the elements is not misplaced, rain coming soon enough and late enough to prevent serious damage. From time to time, however, a season occurs when the rain does not come on schedule time in the fall, or the rainy season ceases unusually early in the spring. In such seasons the grower, with each day's waiting, is more and more certain that rain will come and continues to postpone irrigation. Serious injury is sometimes caused in this way and one which may lead to more obscure after-effects, such as die-back, gumming, 
mottled leaf, and other pathological symptoms. Particularly when a dry fall follows a dry spring, making nearly a year without rain, is this sort of trouble likely to occur. In such a season, even with more irrigation than usual, the soil does not get the deep soaking which only long, heavy rains can give it, and the subsoil is likely to dry out. This condition is most pronounced, naturally, on soils underlaid with a porous subsoil not having the greatest water-retaining capacity, or where there is hardpan or other hard material beneath the surface, preventing a aeep soaking-in of the water. The average irrigation comes far from rqualling a good rain in wetting the ground. When the winter rain is up to or above the average in amount and distributed over its normal season, groves which receive even tolerable irrigation, upon soil of even moderate water-retaining properties, may go through in fairly good condition. Following the dry seasons the groves where the subsoil dried out begin to show up and exhibit signs of distress. In the very arriest years this may extend to groves upon soil which ordinarily is considered to have good water-retaining qualities.

The effect of frost and cold weather is much more decided on trees in this dry condition than upon those which have their tissue filled with the proper amount of moisture, and numerous instances are to be seen of severe frost injury to citrus and deciduous trees in groves allowed to become extremely dry in the fall, while neighboring groves, which receive proper irrigation, are entirely unaffected.

A dry condition of the subsoil is frequently brought about, even where the amount of water available is sufficient, through faulty physical conditions such as hardpan, soils underlaid with rock close to the surface, sandy or gravelly subsoil, or other similar conditions which prevent the retention of a proper amount of moisture several feet below the surface of the ground. All sorts of conditions may occur which have this effect of limiting the moisture supply available to the roots, and, as we have just said, nothing is more common in California than to find plant troubles due to this cause. This is one of the most important reasons, therefore, for digging down into the soil to an ample depth in investigating cases of failure or poor development.

In some parts of the State, particularly in the northern portion, a very irregular soil moisture condition occurs, due to the combination of a heavy winter rainfall and a very dry, hot summer, with a porous, gravelly soil more or less underlaid by hardpan. In such regions the soil becomes extremely wet in winter and if hardpan exists near the surface the water does not drain away but the soil remains saturated clear to the surface. After the rains cease, however, the moisture dries out rapidly, so that during the summer the dryness of the soil reaches an equally extreme stage. Large areas of orchard have been planted 
under conditions similar to this without irrigation under the impression that no irrigation would be needed, on account of the large amount of rainfall and the extremely wet condition of the soil during the winter. Such plantings, however, have in every case resulted in absolute failure, except where subsequently a permanent water supply for irrigation was secured. The trees linger along for a few years, making a fair growth at first, but ultimately becoming stunted, affected by die-back, and finally dying completely, except in the case of the most drouth-resistant species.

The remedy for such troubles is usually obvious, consisting in choosing, so far as possible, deep soils with fairly heavy subsoil, and in obtaining a sufficient water supply, using methods for its distribution and application which will insure a proper moistening of the soil to a sufficient depth. When trouble of this sort is once realized it is in many cases not difficult to remedy it by proper cultural methods, if the soil is of proper quality and particularly if sufficient water for irrigation is available. Again we would say, however, that a failure to examine the subsoil by deep digging and a consequent lack of knowledge of its moisture condition is one of our most common causes of tree failure. Frequently, even at the very time of irrigation, when the surface soil was saturated and covered with water, it has been found that at a depth of two or three feet the ground was completely dry on account of a plowsole or hardpan which prevented the water from soaking down to a proper depth. It will be seen from what has been said that this sort of trouble may occur from one of two causes: either from a too porous subsoil with insufficient water-retaining quality, or from a hard layer beneath the surface which does not allow the proper penetration of water.

The methods of improving these conditions are considered in another chapter, see page 1074. It is obvious that the remedy lies on the one hand in adding humus or organic matter to the lighter soils to make them hold water better, and on the other hand in breaking up the hard layer of subsoil in order to allow the water to penetrate more rapidly and deeply. Beyond these methods of soil improvement there must also be considered the methods of irrigation best adapted to each condition. In order to keep more moisture in the soil there are three possibilities in addition to what may be accomplished by cultural means: either more water must be put on at the usual time of irrigation, or the water must be put on more frequently, or the irrigation season must begin earlier or be extended later to connect more closely with the rainy season. It may, for instance, be necessary with an orchard having a light, porous subsoil, especially in a dry season, to irrigate oftener than every thirty days, if the water can be obtained, or to irrigate earlier or later in the season than is customary. On heavier soils, or where it is impossible to get 
water other than at the regular time, it may be possible and effective to put on more water than has been the practice. It is easier and cheaper, of course, to put on larger amounts of water at longer intervals rather than smaller amounts at shorter intervals. The former method is also more likely to conform with the established regulations in most irrigation districts. Such considerations and the water-retaining capacity of the subsoil must govern the grower.

In addition to the moistening of the soil by irrigation, there must not be forgotten the possibilities of preventing surface evaporation by frequent cultivation. This leads us, however, too far from our subject, and we must leave the matter with this suggestion. Most important of all is for the grower to know definitely the moisture condition of the soil at all times down to a depth of at least four feet, disregarding entirely the appearance on the surface, and irrigate accordingly.

\section{EFFECTS OF EXCESSIVE MOISTURE.}

Although a lack of moisture is so common in our cultivated soils, yet cases are also quite common and sometimes entirely unsuspected where there is too much water in the subsoil, and vegetation suffers accordingly. This, again, can be easily determined by digging a hole down to the depths of the lower roots and examining the condition of the soil as to moisture. In some regions the natural water level is near the surface, and this fact must be kept in mind and the level of the water accurately determined before making extensive plantings. Again, through irrigation or otherwise, the water level may be raised, either in the hollows and lower spots of a region where the surface is uneven, or under the whole surface of large areas where the surface is level. The latter case has already been alluded to in our discussion of alkali soils and the rise of water in the same, page 1064. Many large areas of good land in California have been rendered almost worthless in this manner and often this condition has come about and orchards and other plantings been severely injured before the true condition was realized by the owner. Here, again, the simple process of digging a hole to a depth of several feet in the ground is sufficient to indicate the cause of the trouble. Trees affected in this manner usually begin dying in the top and at the ends of the branches, the leaves developing poorly, turning yellow and falling off as the die-back proceeds. The effect is very similar to that produced by dryness of the soil, and, in fact, the effect upon the parts above ground is practically the same in either case. If the soil is too dry, the top suffers because the roots can not send up the proper amount of moisture, while if the soil is too wet the roots are injured and killed and again the top fails to receive what it should from the roots.

One of the worst troubles of this sort is experienced in cases where the 
water level does not remain constant, either high or low, but rises and falls a considerable number of feet during the year. This is a condition of quite frequent occurrence in some sections, particularly in the vicinity of large, uncemented irrigation canals in sandy soil. In such places the water level of the surrounding country may come up nearly to the surface of the ground during the irrigation season when the canals are constantly full of water, while after the water is shut off its level in the soil goes down for many feet. Under such conditions, the roots have no opportunity to accustom themselves to development at a certain level, but are continually subjected to alternate flooding and drying. Such a condition can be determined by digging an open pit or well to a depth of 10 or 15 feet, and watching the fluctuation of the water level during the season.

The only remedy for all these conditions consists in drainage to prevent the water rising above a certain level, and, in the last instance described, in cementing the bottom and sides of the main ditches so that seepage can not occur. The latter is expensive but is the only means of stopping the widespread injury of this sort, which is at present occurring in some regions.

EFFECTS OF FAULTY PHYSICAL STRUCTURE.

Cultivated plants frequently suffer or die on account of unfavorable conditions of structure or formation of the subsoil. Nothing is more fatal to the success of the land-seeker in California than to judge the value of a piece of ground by the nature of the surface soil. By digging or boring down to a depth of a few inches or feet he may encounter something entirely different from that seen on top, and something which would doom his proposed planting to absolute failure from the very start. Again, plantings may be made and flourish for a time, but then begin to fail as the roots reach the unfavorable conditions below.

Faults of this sort are most commonly of two general classes, namely, the subsoil is either too hard and impenetrable, preventing the roots from developing properly and limiting the supply of moisture available for them; or it is too coarse and porous, being unable to retain moisture, and deficient in plant food. In the former instance, on digging down into the soil one may encounter at a slight depth solid rock, hard clay (hardpan), or he may come into gravel, coarse sand, or some other undesirable soil formation. Again, in the case of old, long cultivated orchards, particularly in heavy soils, an artificial hardpan or plow-sole is frequently formed on account of the gathering together of the finest soil particles at a depth just below that reached by the plow and cultivator. All of these conditions can be readily determined by digging or boring down into soil.

The chief difficulty in this respect is that of judging accurately just 

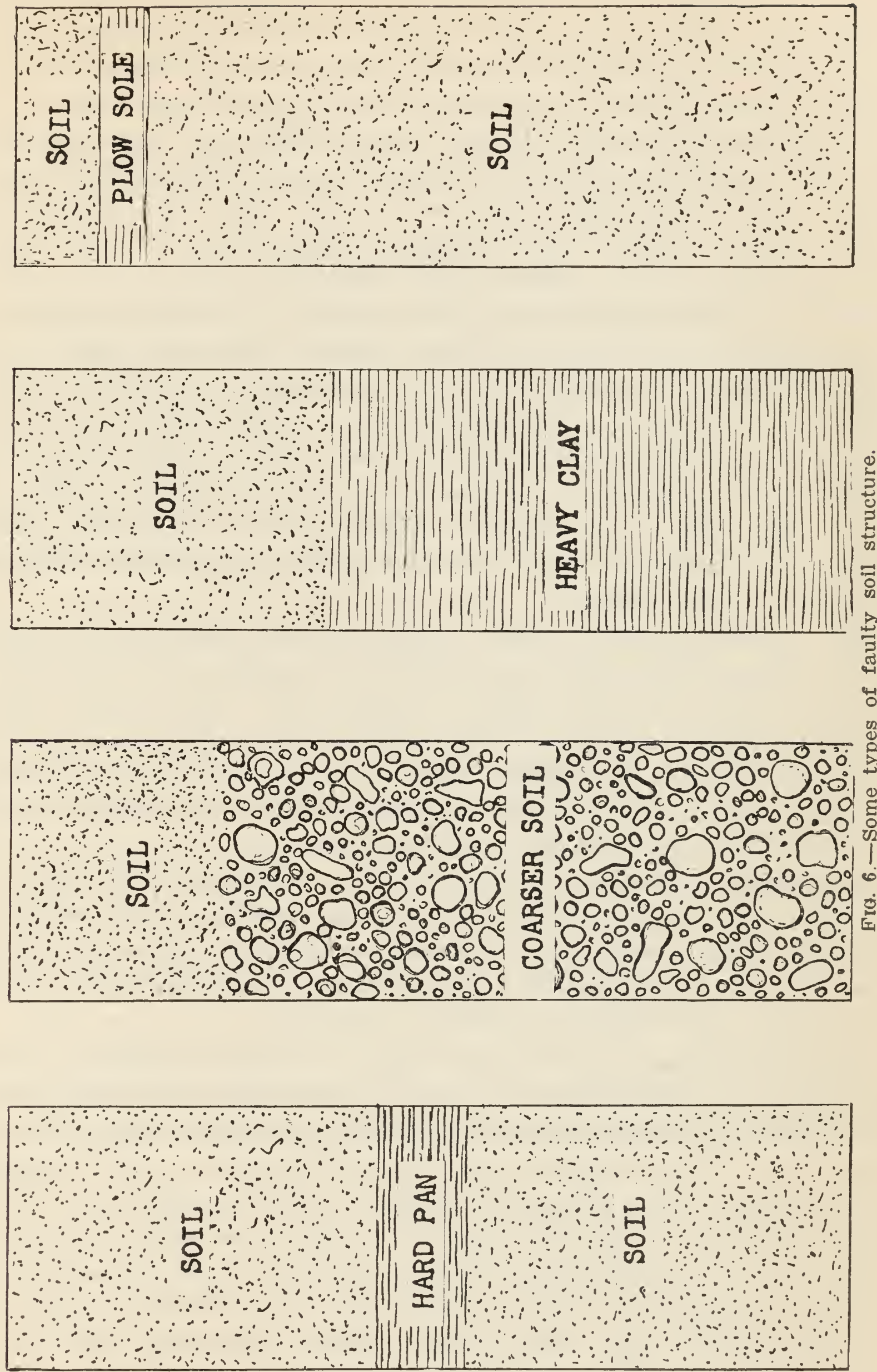
what degree of hardness or coarseness in the subsoil is undesirable or injurious, or what conditions in these respects are desirable and favorable to plant life. On the one hand, the heavier the soil the better it will retain moisture and plant food, so long as it is not so extremely hard or impervious as to prevent its being penetrated by roots and water. On the other hand, the heavier the soil the more difficult it is to cultivate, while if it is sandy and porous it is easier to handle, takes up water more readily, and is more easily penetrated by plant roots. On lighter soils plants usually respond more promptly to applications of water and plant food; such soils are easier to plow and cultivate and can be worked at any time of year, while heavy soils present an opposite condition in these respects. Furthermore, different kinds of trees and plants vary widely in their adaptability to heavy or light soils, or the depth of soil which they require for proper development. Soils which are entirely too light or too shallow for one kind of tree may be entirely fitted for another kind. Altogether, therefore, one may not judge too hastily or be too quick either to condemn or approve a soil for a certain plant without large experience, and expert knowledge of practical conditions and results in this respect.

The methods of improvement of soils of poor mechanical structure form a subject in themselves too extensive to be taken up in this place. Such improvement must be mainly brought about in one of two ways: First, through cultural operations, such as deep plowing and special cultivation; second, by adding materials to the soil, such as straw, manure, or green manure crops. Special treatises on this subject should be consulted for information along these lines.

In the case of hardpan of limited thickness underlaid by good soil, the radical practice is sometimes resorted to of blasting with powder or dynamite, blowing out a hole for each tree before it is planted. Even in established groves, blasting between the trees is sometimes done with good results. (See Hilgard's "Soils," page 181.)

Artificial Influences in the Soil.-Injury to plants sometimes occurs through the presence in the soil of injurious substances which have come there artificially through drainage, or by being placed in or upon the soil. These may be waste substances from manufacturing or result from any one of a great variety of causes, sometimes wholly unsuspected. As an instance of this, we may cite injury to citrus trees which sometimes occurs from the pouring upon the ground of the residue of sulphuric acid and potassium cyanide remaining after the process of fumigation for killing scale insects. Sometimes a single root or one side of the trunk will be affected by some injurious substance of this sort, and the injury reflect itself in only one limb, or on one side of the tree corre- 
sponding to the injured portion of the root or trunk. Some very mysterious cases of tree disease have been traced to this source.

A not infrequent source of injury to trees, particularly street trees, is the presence in the soil of illuminating gas escaping from leaky pipes. Great damage has resulted to the street trees of many cities from this source. In any case, where street trees commence to fail and die from no apparent reason, this sort of trouble should be looked for if there is a gas pipe in the street.

\section{INJURIES BY ANIMALS.}

Various animals are injurious to cultivated crops, but their effects and remedies are mostly obvious, and need no special consideration.

The most serious injury of this sort in California is that produced by the common gopher, which is one of our greatest pests. These animals feed upon the roots of all sorts of cultivated plants and trees, and under favorable conditions become very numerous. Their most evident effects are seen where plants suddenly wilt and die on account of the roots being eaten off. In the case of orchard trees of considerable size, the gopher often works on the bark of the main roots, causing the tree to gradually decline and its foliage to become yellow, finally bringing about the death of the tree. It may linger along for several years, however, before becoming entirely dead. In citrus groves, especially where gopher control has been neglected, trees are frequently seen with foliage of a bright yellow color and covered with an abnormally large number of small fruits. Such trees are an almost invariable indication of gopher attacks, and, if not taken in hand very promptly, will soon be killed. If, however, gophers are gotten rid of before the injury to the roots has gone too far, the tree may form new bark and finally recover. In such cases, it is well to cut the top back to an extent proportionate to the amount of injury and thus give the tree a better chance to recover.

Gophers can only be kept down by constant warfare through the use of traps, poison and shooting. Special traps and poisonous preparations are made for this purpose, some of which are very effective. See bulletin 172, "The Pocket Gopher," Kansas Experiment Station, Manhattan, Kansas.

Squirrels, moles, and other similar animals often cause much damage to vegetation and are to be controlled by means of the nature just alluded to, namely, poisoning, trapping, and shooting. See Circular 76, "The California Ground Squirrel," Bureau of Biological Survey, United States Department of Agriculture. See, also, Wickson's "California Fruits," page 410 , for methods of control of gophers, squirrels, rabbits, etc.

In regard to rabbits, we quote the following from the "California Cultivator" of March 23, 1911: "According to the experts of the North 
Dakota Agricultural College, damage to trees by rabbits gnawing the bark can be stopped in the following way: Make a thick whitewash; slaking the lime over night improves it. To each pailful of the whitewash add three tablespoonfuls of paris green, and paint the trees with it. Stir frequently when applying it."

Insects. - The control of insect pests will not be considered in this bulletin. This is a large subject in itself and publications are available covering most of our common pests.

Worms.-One organism of this group is of particular importance in connection with California plant diseases, namely, the Nematode Root Worm, Heterodera radicicola. This is a worm of microscopic size, which lives parasitically in the roots of many different plants, causing small nodules or galls upon them. Such nodules are quite frequently seen upon the roots of nursery stock, garden vegetables, and other plants, but for some reason this organism does not seem to become serious in this State. In the southeastern portion of the country it causes serious damage to orchard trees and other plantings, but this does not seem to be the case in California.

The organism in question is hatched from eggs which are deposited by adult female worms in the root galls. These eggs hatch and the young worms, which are so small as to be quite invisible to the eye, move about in the soil for a few days but soon burrow into the tips of young roots where they come to rest. By their presence in the roots they cause an irritation which produces a swelling and the formation of galls. The mature female worms can be seen with the naked eye by careful examination, being little, pearly-white, pear-shaped bodies, about the size of small pin head. They may be found embedded in the tissues just beneath the surface of the galls.

This form of injury is alluded to more specifically in connection with various plants in a later portion of this bulletin.

Slugs and Snails.-These creatures are frequently the cause of much damage to plants, especially in moist weather. They are best controlled by sprinkling dry lime dust upon the ground in circles about the plants, upon the leaves of the plants themselves, or in any way so that the slugs will be obliged to come into contact with the lime. This is very repulsive to them on account of its irritating effect upon their soft bodies. They may also be trapped to some extent by laying boards upon the ground in the vicinity of the plants upon which they feed, thus affording a shelter under which they may be found and killed. It is said that ducks are particularly fond of these creatures.

In regard to snails, we find the following in the Pacific Rural Press, of June 12, 1909, page 439: "These pests are quite common in England 
and in English gardeners' experience a mixture of salt and soot scattered upon the ground which they traverse seems to be most effective. Lime, which is something of a protection against the slug branch of the snail family, does not seem to be objectionable to the shell bearer."

Fungi, Bacteria, and Slime Molds.-Organisms of this sort are the cause of most of our specific plant diseases, and these are described in connection with their particular host plants in the following alphabetical list. A short description of the general nature of these organisms may be useful at this point.

Fungi.-The organisms called fungi are true plants but of a very low order. The largest and most highly developed members of the family are represented by the toadstools, mushrooms, and similar plants. Other common examples of fungi are the various molds and mildews often seen growing upon different organic materials, especially in moist air. Only certain fungi are injurious to vegetation. Those species which are not are called saprophytes. These grow upon dead material, like the toadstools which we see upon dead wood or manure and the molds which develop upon decaying fruit, moist leather, bread or jelly. Many kinds of fungi, however, are able to grow only upon the tissues of living plants. These are called parasites. Examples of this are seen in the rose mildew, a mold-like fungus which can not live except upon living leaves, and the various rusts which have the same habit. In the case of the rust most of the fungous plant develops in the interior tissue of the leaf, while in the rose mildew it grows mostly upon the surface.

It is characteristic of parasitic fungi that in most cases each particular species of fungus has a particular species of plant which it attacks, or its attacks are limited to a few closely related plants. Certain species of rust, for instance, attack only a few of the grains or grasses. Another species of rust attacks the asparagus, but the asparagus rust fungus can not develop upon grain nor the grain rust upon the asparagus plant. Some fungi are both parasitic and saprophytic, being able to grow either upon living plants or dead matter. Others are mainly saprophytic but may become parasites upon plants in a weakened or unhealthy condition.

The body of a fungous plant consists usually of a branching mass of very fine, thread-like filaments called the mycelium. In toadstools the mycelial filaments become very abundant and mass together into structures of considerable size and definite form. In the mold fungi the mycelium develops abundantly under favorable conditions and makes a cobweb-like or cottony mass. In most of the parasitic fungi the filaments of the mycelium grow through the interior tissues of the plant attacked (called the host plant) and at the same time withdraw 
nourishment for their own use. They also sometimes secrete poisonous substances, and thus are caused the leaf spots or dying of whole leaves which we see resulting from fungus attacks. Some fungi also cause active decay of fruit, fleshy roots, tubers, wood, and other vegetable material. The reproductive bodies of fungi, corresponding to the seeds of higher plants, are called spores. These are usually very small, dustlike particles, each of which is capable of sprouting and reproducing the fungus if it finds favorable conditions. In the case of the rusts we see the spores as a dusty powder which develops on affected plants. Most of the common molds also produce a dusty mass of spores on the surface of the mycelium.

The control of fungus diseases by spraying is almost always effected by covering the plants with the poisonous material before the fungus has made its attack, thus killing the spores before they can send out sprouts and reach the interior tissues. If the latter has been accomplished and the fungus is already inside the plant nothing can then be done to stop its effects save by preventing its spread to other leaves or plants not yet affected.

Bacteria.-The bacteria are organisms of even simpler nature than the fungi, having no mycelial body, but consisting of very minute, individual particles. Each of these individuals is able to multiply very extensively and rapidly by division, so that under favorable conditions bacteria can develop in sufficient abundance to form a mass visible to the eye. Such a mass of bacteria is usually of a slimy nature, as seen in fruit and vegetables which have become so thoroughly decayed as to be in a semi-liquid condition. Most of the bacteria are purely saprophytes, living only on dead matter and producing by their growth decay, fermentation, putrefaction and similar processes. A number of species, however, are parasitic on animals, causing many of the commonest and most serious human and animal diseases. The bacterial plant parasites are fewer in number, although the list of bacterial plant diseases is gradually growing. Some of the most conspicuous examples, like the pear blight and walnut blight, develop in the fresh, succulent tissues of the bark or in the fruit, causing the death of the parts affected.

It should be said in connection with fungus and bacterial diseases that the mere finding of an organism of this sort upon a diseased plant or any of its parts is by no means proof that the organism found is the cause of the trouble. If a leaf, for instance, is injured in any way so that its vitality is almost or quite destroyed, various kinds of saprophytic fungi or bacteria usually develop upon it very quickly. If a plant dies or becomes very much weakened from any cause its roots soon begin to decay and various saprophytic soil fungi and bacteria will be found in its tissues. It is practically impossible for dead or dying plant 
tissue, no matter how it was first affected, to remain in existence without falling prey to all sorts of fungi and bacteria which would have no power whatever of developing upon the same plant when in a healthy condition. The plant pathologist must, therefore, proceed with extreme caution to attribute plant troubles to organisms of this sort until he has absolutely proven that the initial injury was produced by the organism under suspicion, when the plant was still in a healthy condition. To make this absolutely certain, he must not only find the organism upon the plant, but must also produce all the characteristic symptoms of the disease by inoculating healthy plants of the same species with his fungus or bacterium. Long experience may make this unnecessary at times and obviate much tedious work, but the young investigator is more apt to err in the other direction, attributing plant troubles to fungi or bacteria which really had nothing to do with them.

Slime Molds (Myxomycetes).-A few plant diseases are caused by organisms of this class. They are grouped at the very bottom of the vegetable kingdom, and comprise some of the simplest forms of life.

\title{
A LIST OF THE MORE SPECIFIC PLANT DISEASES IN CALIFORNIA, WITH BRIEF DIRECTIONS FOR TREATMENT.
}

\author{
ALFALFA.
}

Crown Gall (Urophlyctis alfalf $x$ ). Figure 7 .

Gall-like swellings appear on the stems and main roots just at the surface of the ground and the plants die. The trouble is favored by excessive moisture in the soil. Caused by a fungus. This is a new disease in this State, and has not been reported elsewhere in the country at this writing.

Allow the ground in affected spots to dry thoroughly and do not use it again for some time.

LeAF Spot (Pseudopeniza medicaginis). Figure 8.

The leaves turn yellow and die, with small, dark spots upon the surface. The trouble is not a serious one in this State, and needs no special treatment. Caused by a fungus.

Cut and burn the crop if badly affected.

Rust (Uromyces striatus).

Reddish-brown, dusty pustules break out in small spots on the surface of the leaves. This trouble is caused by a true rust, and sometimes becomes quite destructive to alfalfa during the rainy season. It invariably disappears with the coming of dry weather, so need not be seriously feared.

Cut and burn badly affected crops. 


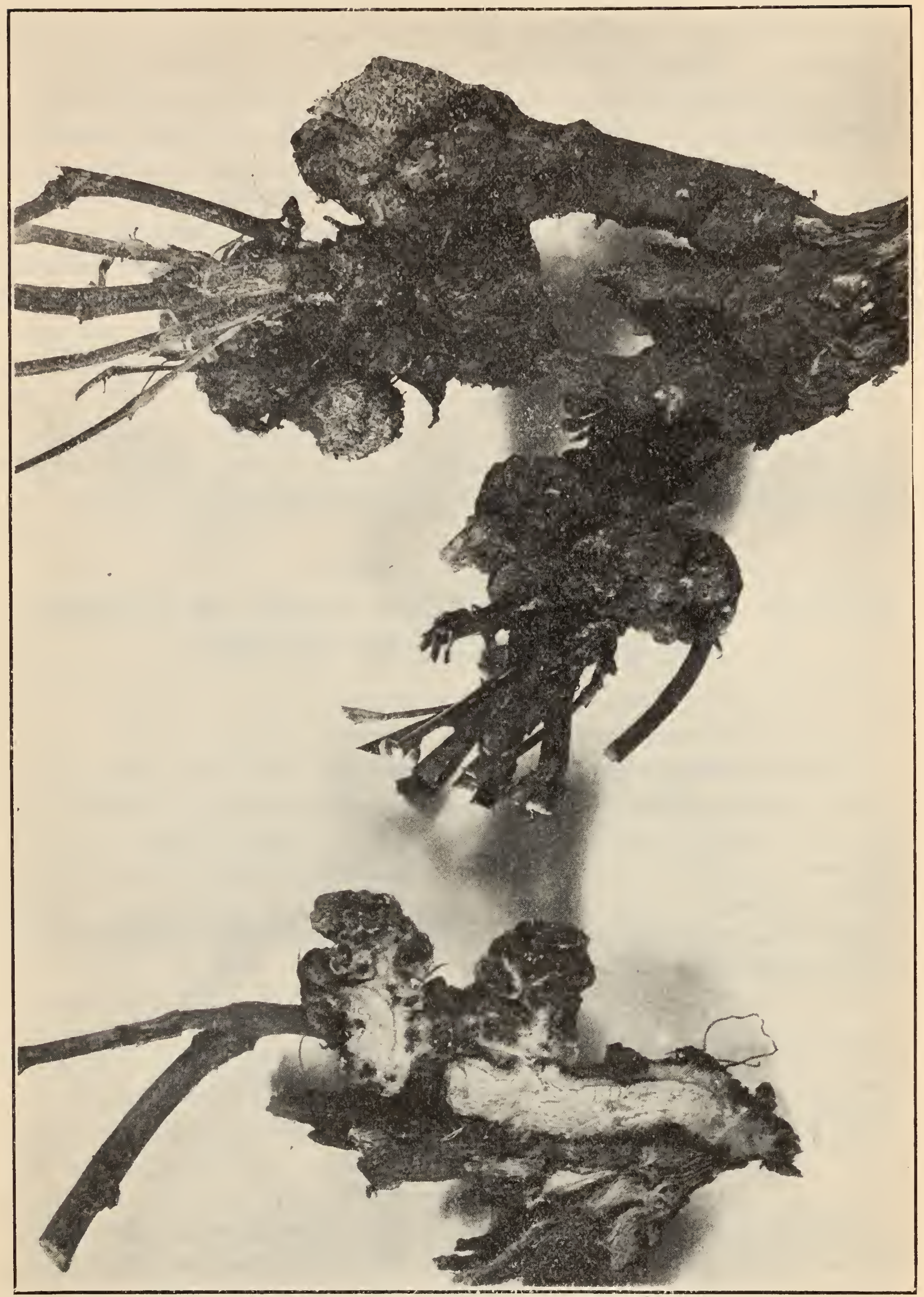

FIG. 7.-Crown gall of alfalfa (Urophlyctis alfalfae). 
Stem Rot (Sclerotinia libertiana).

The stems wilt and die after reaching nearly full size. Usually scattering stems here and there about the field are affected, and may be easily seen by their contrast with the thrifty, green appearance of the other stalks. This trouble usually occurs most abundantly where there is a thick stand of alfalfa, heavily shading the ground, particularly in the spring when the ground is very moist. On pulling an affected stem it is found to be decayed at the base, and usually shows a more or less abundant white mold upon the surface if there is an abundance of moisture. In this mold small, roundish, black bodies develop, which represent one stage of the fungus. This is apparently the same fungus which causes the cottony mold decay of lemons (page 1123) and also

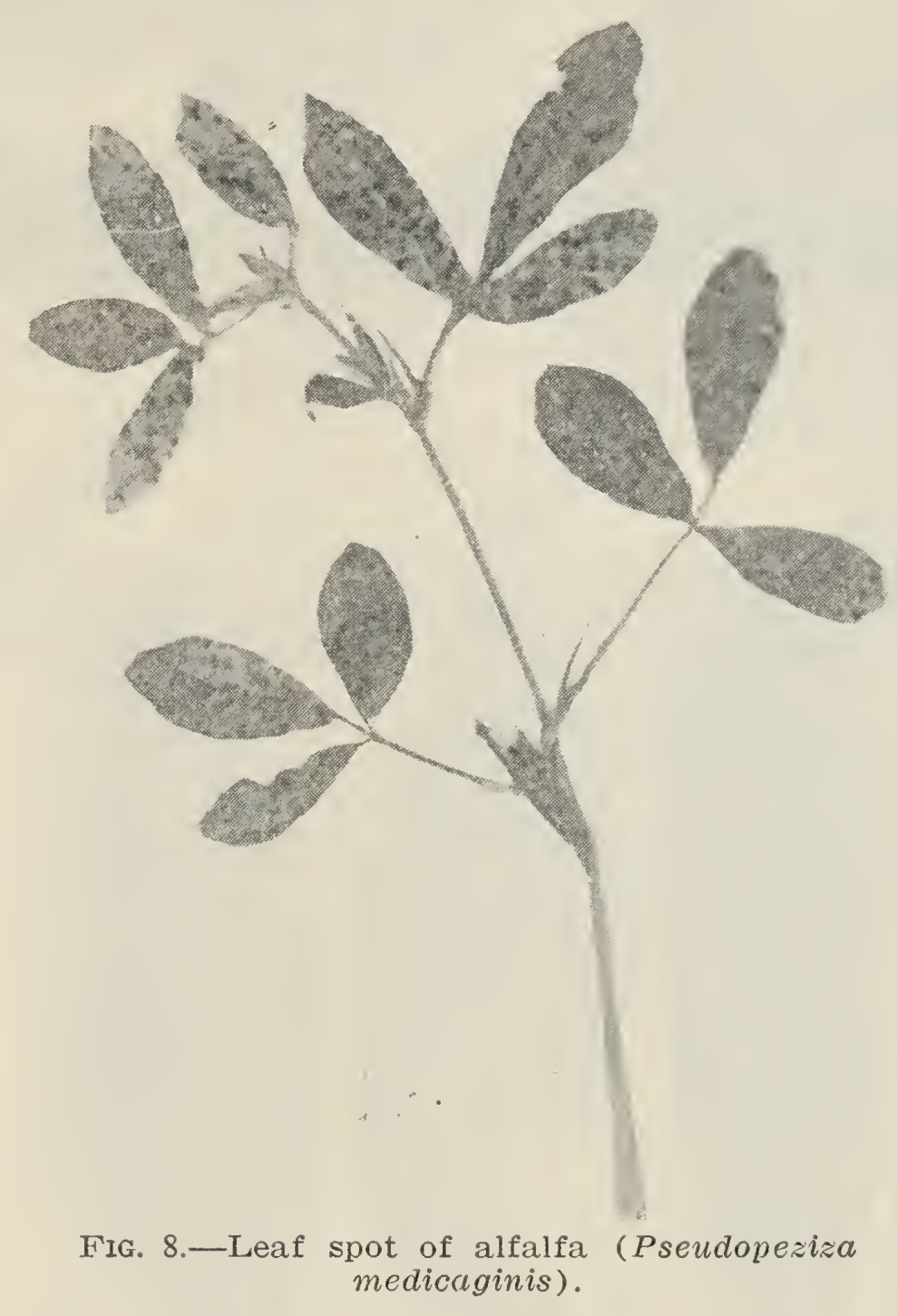

stem rot of various other plants. It causes considerable damage to alfalfa at times in this State, and it has been reported as a serious disease in other States. The fungus is common, affecting various plants all over the world.

No specific remedy can be suggested, but the disease usually disappears to a large extent during the summer and fall. Badly affected fields should be plowed up and used for some other crop for several years. 


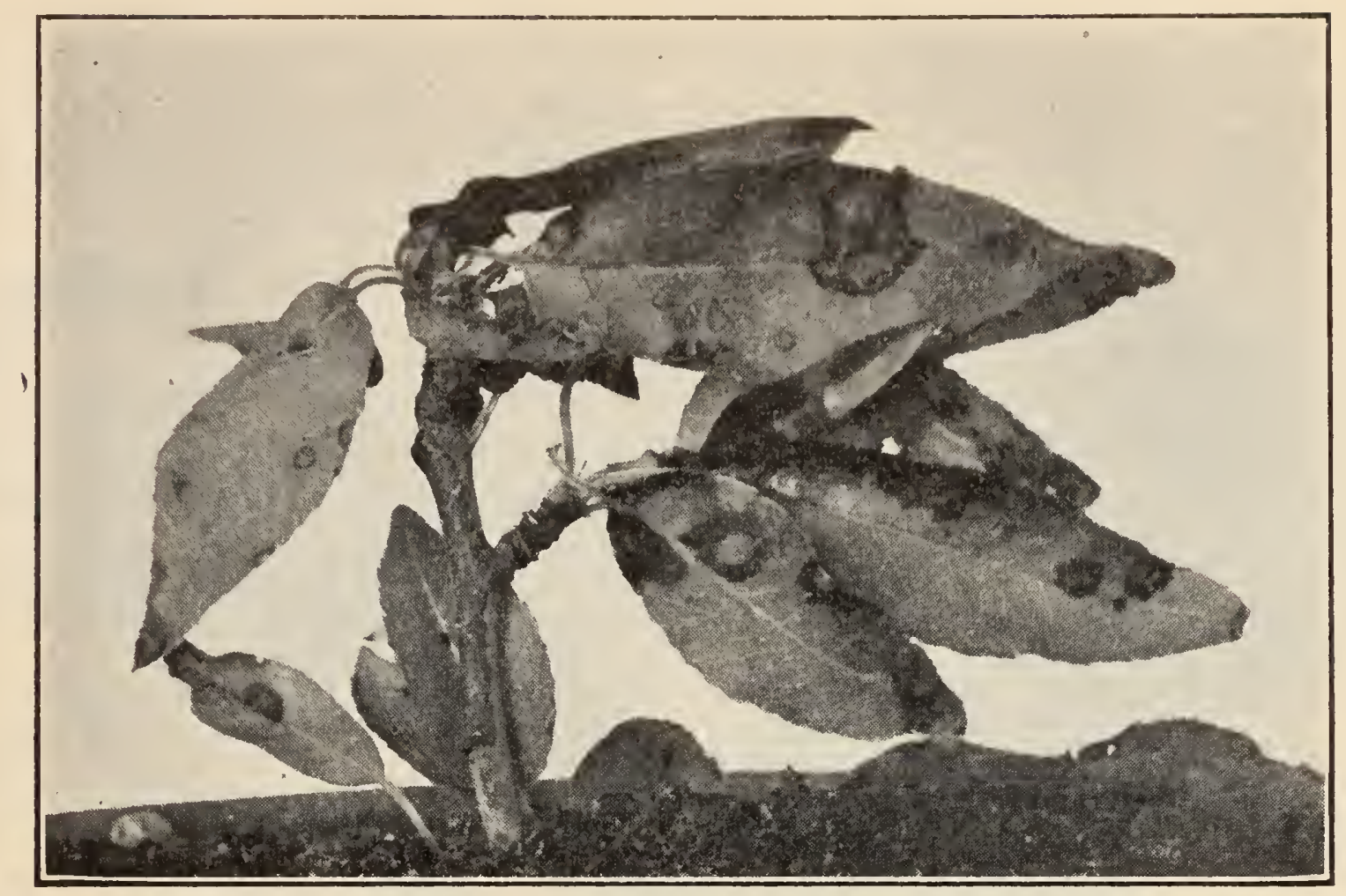

FIG. 9.-Shot-hole of almond (Cercospora circumscissa).

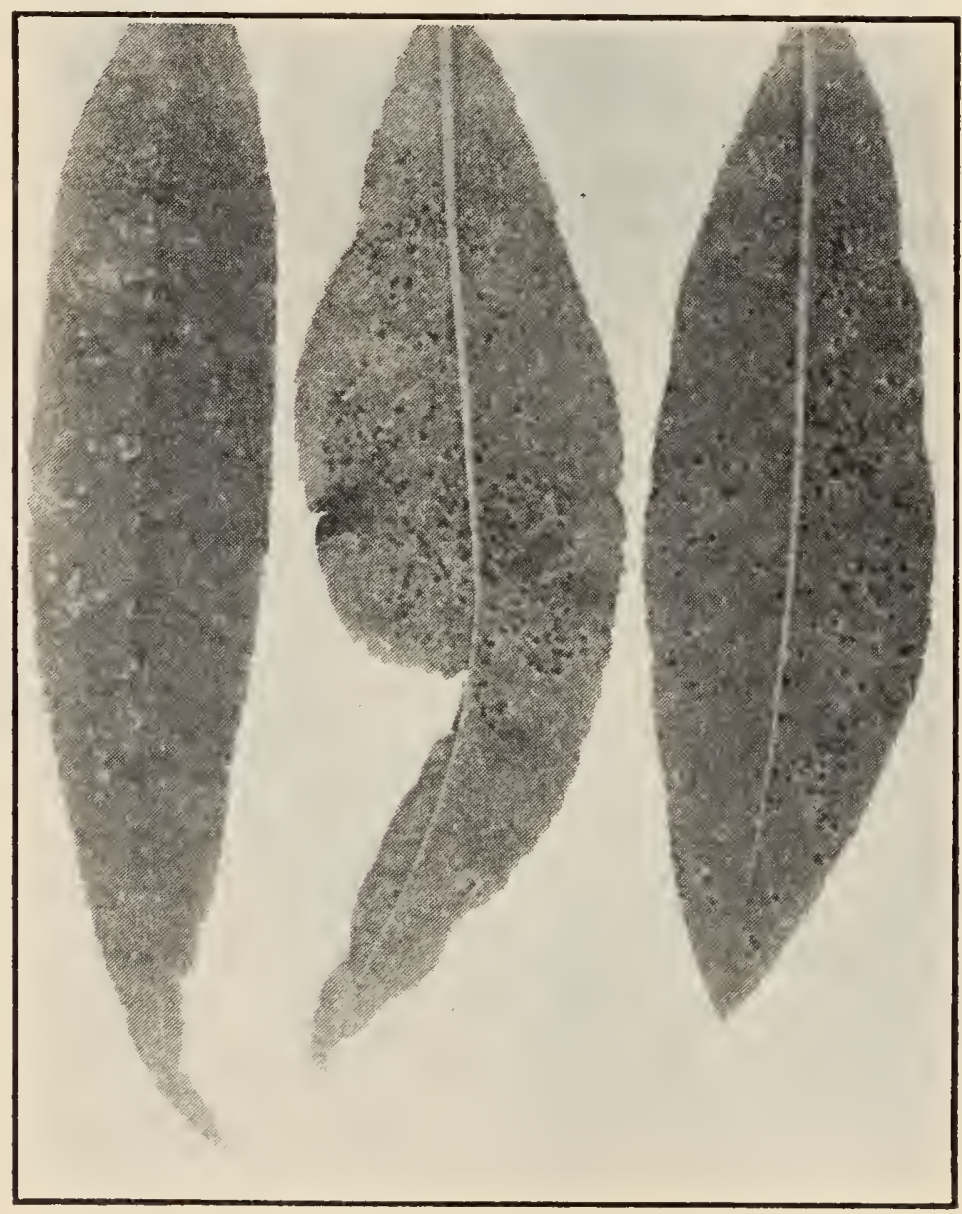

FIG. 10.-Almond rust (Puccinia pruni). 
Dodper (Cuscuta).

A thread-like, yellowish vine forms a thick mat in the alfalfa, and becomes parasitic upon it. It is a true flowering plant. In badly affected fields a large proportion of the crop is lost from this source. Allow the field to dry out for some time and the dodder will often

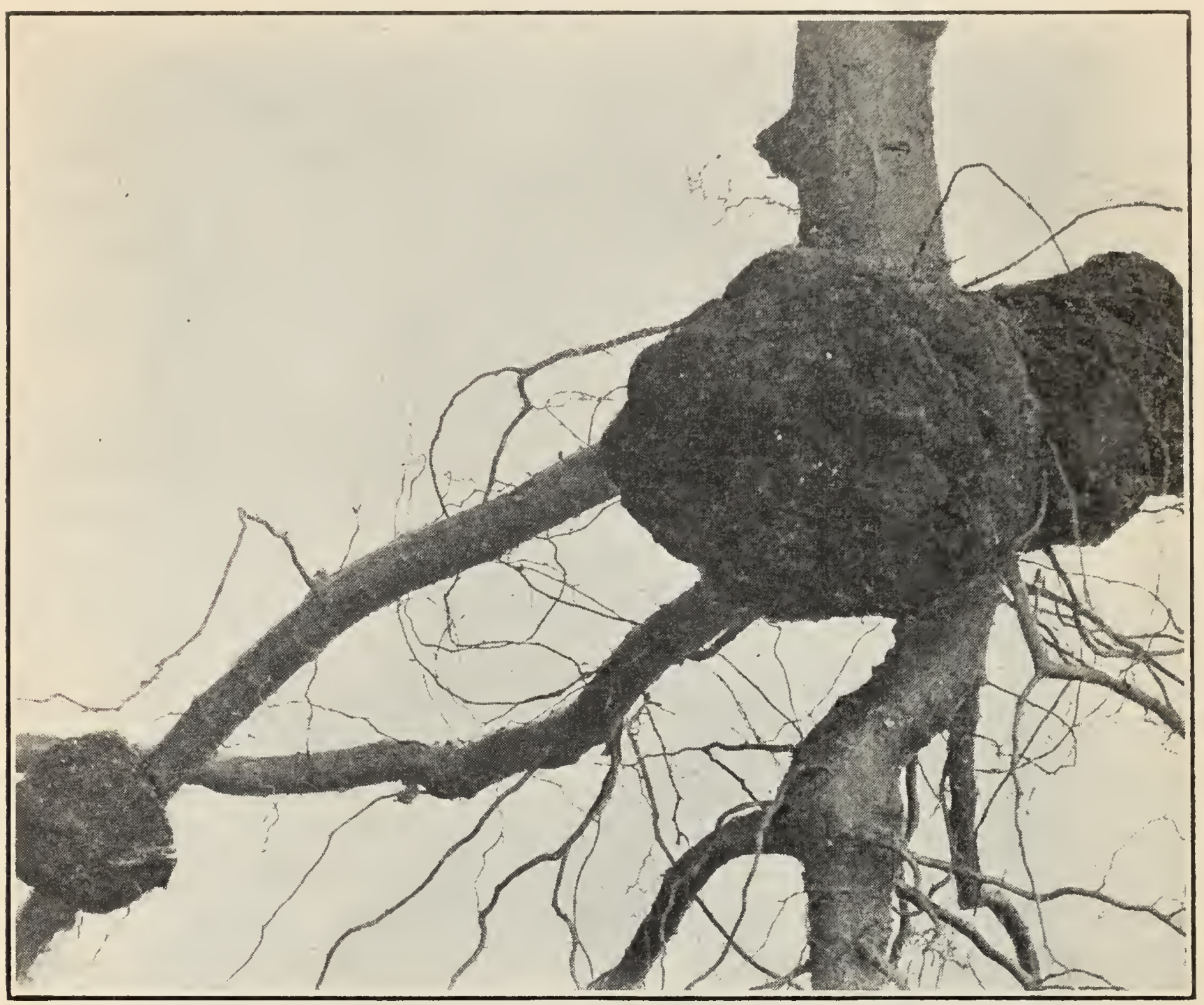

FIG. 11.-Crown gall of almond (Bacterium tumefaciens).

be entirely killed without destroying the alfalfa roots. If the field is badly affected plow and replant later.

Avoid planting infested seed. Dodder seed is often mixed with that of alfalfa.

\section{ALMOND.}

SHот-Hole (Cercospora circumscissa). Figure 9.

There appear on the leaves numerous, small, dead spots, which finally fall out, giving a shot-hole effect. The young twigs are also spotted. The trees are sometimes defoliated early in the season by this fungus and the crop badly injured.

Spray with Bordeaux mixture in the spring as the buds are opening. 
Rust (Puccinia pruni). Figure 10.

Red or brown, dusty pustules appear on the under side of the leaves, usually late in the season. The fungus may hasten the normal dropping of the leaves somewhat but is not serious on thrifty trees; worse where the trees suffer from drouth.

No treatment ordinarily needed.

Crown Gall (Bacterium tumefaciens). Figure 11.

Large swellings appear on the main root just below ground and to some extent on the smaller roots. This results in a gradual failure and dying of the trees. 'This is one of the commonest troubles of our stone fruit trees, being found both in the nursery and on mature orchard trees. This trouble is caused by a bacterial organism which infests the soil. The organism would seem to be abundant in California soils, since cases are not rare of infection on the roots of trees grown from pits in virgin soil.

Avoid planting nursery trees in affected ground and in orchard planting discard every tree which shows any evidence of this trouble. On old trees the galls may sometimes be chiseled off after digging down and exposing the main roots, but this treatment is not usually very satisfactory. Disinfect the cuts with strong bluestone or corrosive sublimate solution.

Root Rot-OAK Fungus. Figure 12.

Many orchards of almonds and other trees contain certain spots where the trees commence dying from a center, the trouble gradually proceeding outward in a circle, involving tree after tree. Clusters of toadstools frequently appear about the base of affected trees in the winter. These spots usually coincide with places where oak trees formerly stood and the destruction of the fruit trees is due to certain "toadstool" fungi which apparently live on the old oak roots and spread through the soil, infecting the roots of the orchard trees. Several different fungi seem to cause this disease, among which Armillaria mellea is probably the most important.

The progress of the trouble may be checked by digging a deep trench around the affected area, but this is impracticable in most cases.

The development of a resistant root presents the only practical remedy.

The pear root, fig and that of the California black walnut are some of the most resistant among fruit-bearing trees and these may usually be planted with safety. The cherry is the most resistant of the stone fruits.

\section{Frutt Drop.}

The fruit falls to the ground while still very small and undeveloped. Due partly to seasonal conditions which can not be controlled, and partly to a lack of cross pollination, which can be secured by mixing 
varieties in planting. Heavy rains at the time of blossoming may have this effect, and it may also be produced by frost, killing the young germ in the seed of the fruit. Many other fruits are affected in the same way, such as the apricot, cherry, peach, and pear. The fruit may remain on the tree and continue to grow in size for some time before dropping.

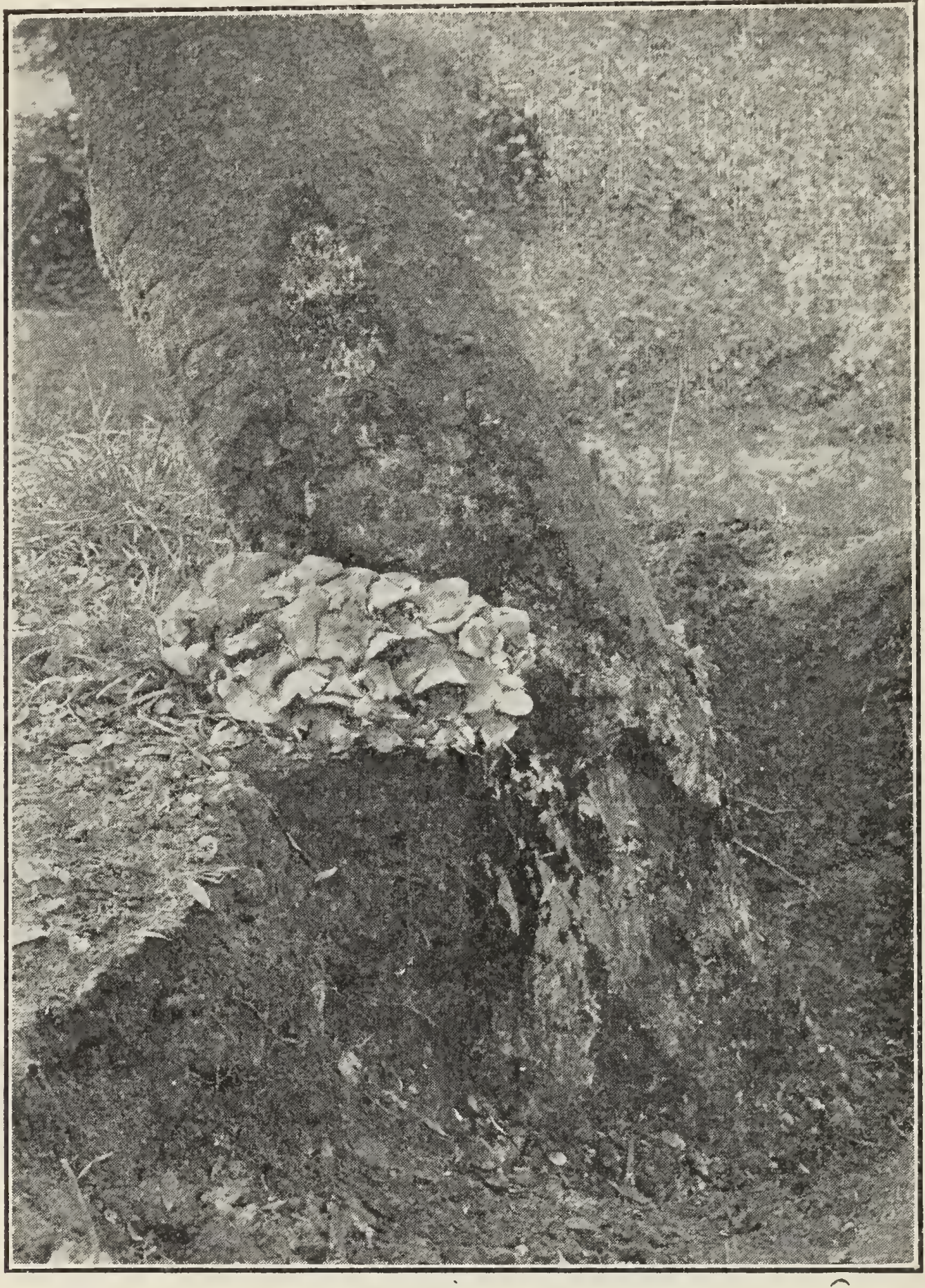

FIG. 12.-Root rot caused by the toad-stool fungus (Armillaria mellea) on live oak.

Sour SAP.

When affected with this trouble the tree may suddenly die just as it is coming out in the spring in full vigor, or the effect may be limited to one limb or one portion of the tree, which dies after the leaves have started, or even after the fruit is partly grown. All our stone fruits suffer frequently with the disease characterized by this name, while 
occasionally the pear and other trees are affected. The trouble appears to be due entirely to climatic conditions resulting from a combination of unseasonably warm, balmy weather in winter, followed by a marked change to colder weather. The sap of these trees frequently starts into active circulation with the first approach of spring, and when this occurs too early in the season, cold weather following suddenly, checks the flow of sap and other functional activities of the tree, causing a stagnation and finally fermentation.

Affected trees should be pruned back to healthy wood, where there is enough remaining to make a new top.

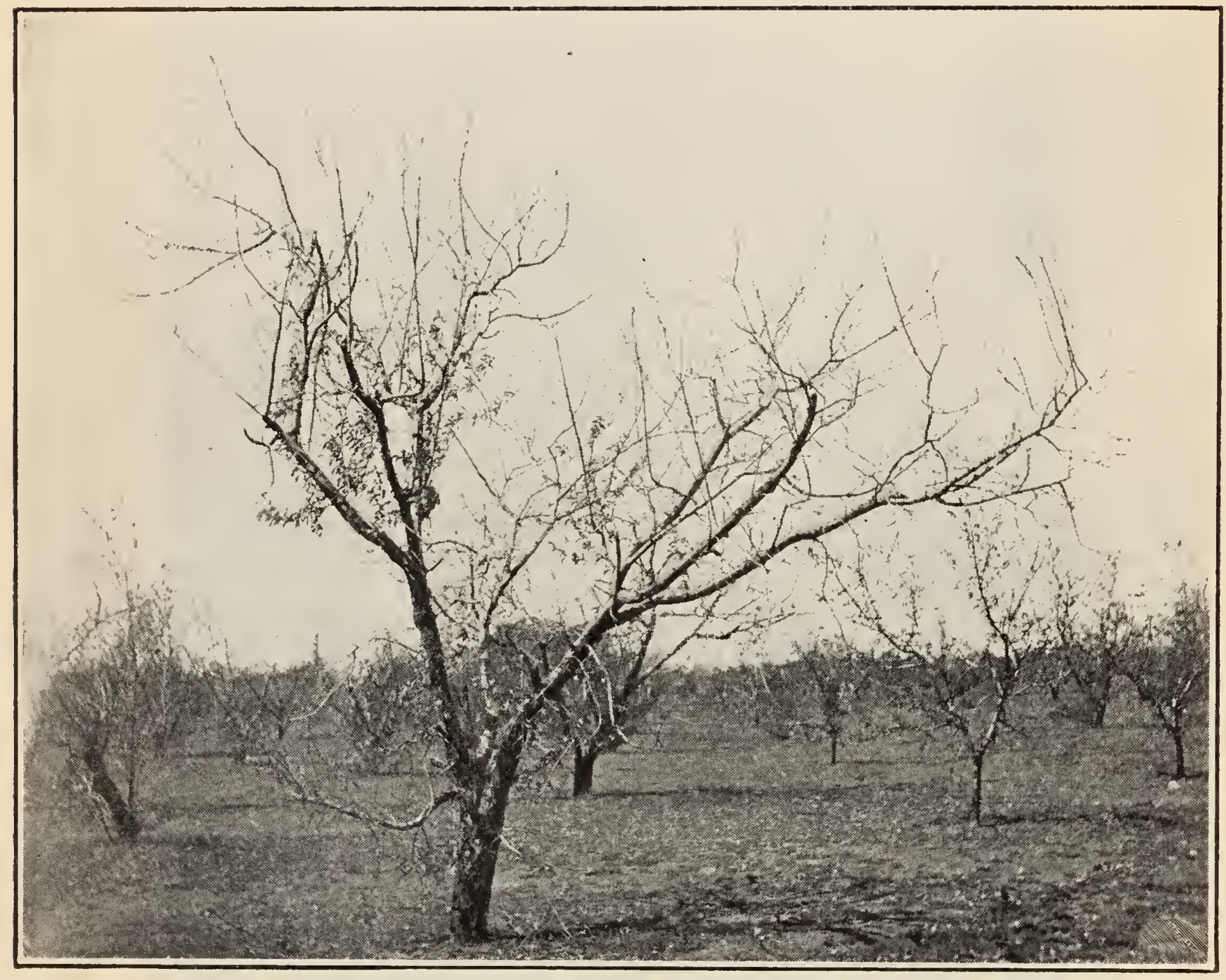

FIG. 13.-Die-back of orchard trees.

DIE-BACK.

Numerous more or less abandoned groves of almonds, as well as other deciduous fruit trees, are to be seen in California which present a distressing appearance on account of a dying back of the branches. In some cases the trees are entirely dead, while in others they show all stages of deterioration. The trouble in the majority of these cases is due primarily to a lack of water induced by a variety of causes, either an absolute lack of sufficient moisture during the year to keep the trees alive. or unfavorable soil conditions, such as hardpan, gravel, and similar 
troubles. Lack of soil fertility is frequently a contributory factor. Such cases of die-back are connected usually with some of the unfavorable soil conditions which we have described in connection with that

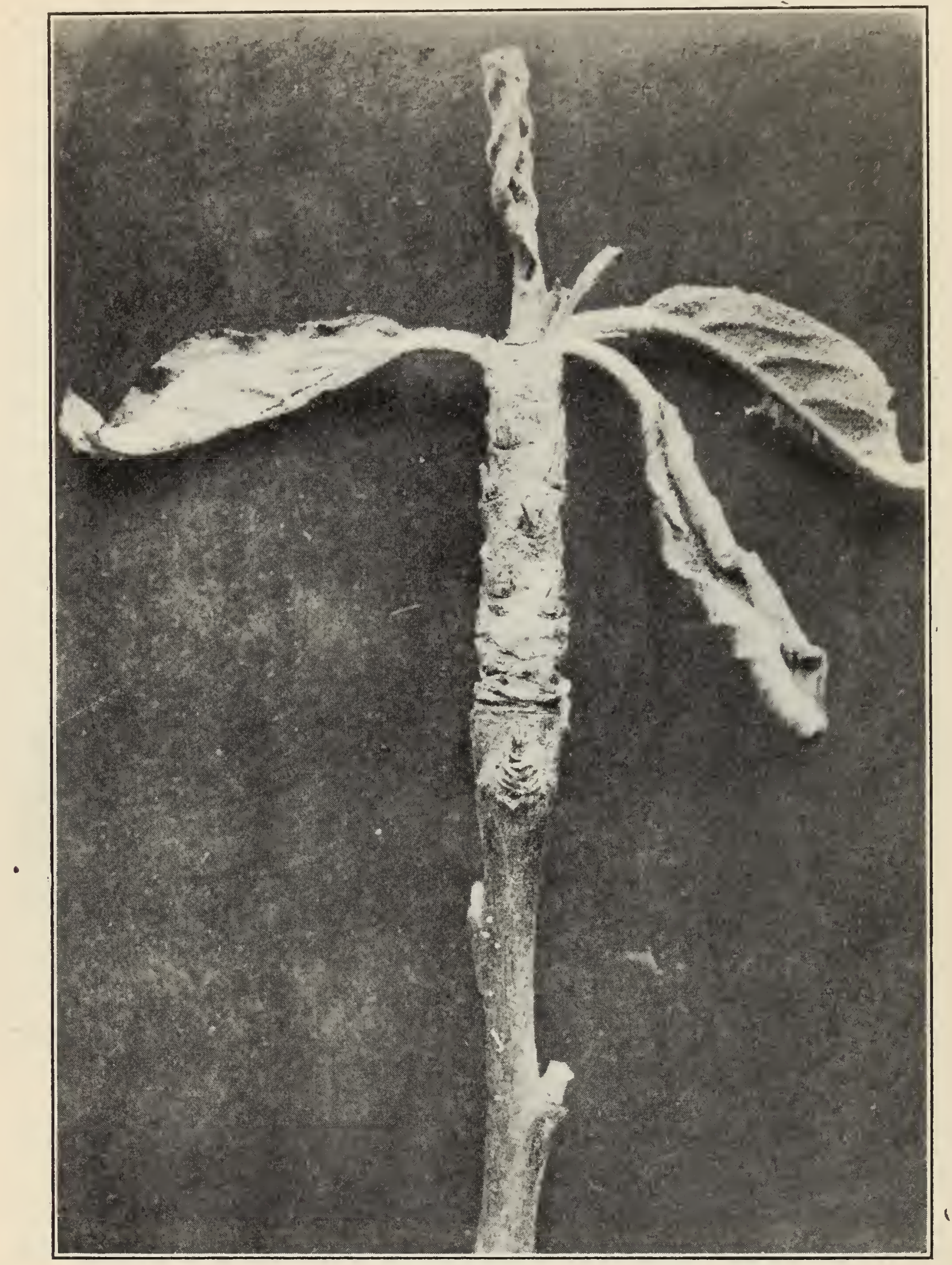

FIG. 14.-Apple twig affected by mildew (Podosphaera oxyacanthae).

subject. In the majority of cases these plantings were doomed to failure from the start and represent an ill-advised undertaking, or in some cases criminal deception. Various secondary causes may contribute to the 
dying of such trees as we have described, but such factors are usually of little importance, and in many cases are an actual blessing to the owner in hastening the time when his expenditures for the maintenance of such an orchard are brought to an end.

\section{APPLE.}

Mildew (Podosphacra oxyacantha). Figure 14.

Characterized by a dwarfing of the tips of the new shoots, which, together with the leaves which they bear, remain stunted and covered

FIG. 15.-Apple scab (Venturia inaequalis).

with the white mildew growth of the fungus. Much worse on some varieties than others.

Has not been controlled very successfully heretofore, but good results have been obtained in some instances by spraying quite frequently through the early part of the season, commencing just before the buds unfold, with sulphide sprays. (See page 1187.)

Some growers report success from spraying with the caustic sodasulphur spray, about 10 pounds of dry sulphur being added to each 50 gallons of spray. 
The iron sulphide spray mentioned on page 1187 is said to be particularly effective for mildew in the Pajaro Valley.

ScAB (Venturia inaequalis). Figure 15.

Easily identified by the scabby patches produced on the surface of the fruit, in which the brown, velvety growth of the fungus can be seen.

Spray with Bordeaux mixture just as the buds are opening, again after the petals fall, and once or twice at intervals later, where the variety or location is particularly susceptible. Arsenate of lead or paris green for codling moth may be combined with this spray.

\section{BLight (Bacillus amylovorus).}

See pear blight, which is caused by the same organism. Blight is not usually as destructive in apples as in pears, except occasionally with very susceptible varieties. Its worst effect in apples usually consists in killing the blossoms and thus destroying the crop, rather than causing the death of large limbs or whole trees. Sometimes the disease runs down into the large limbs and may remain alive there from year to year, forming a source of infection to neighboring pear and apple orchards. More often the infection proceeds only to the base of the fruit spurs, killing the twigs to that point.

Destroy old, worthless apple trees standing in the vicinity of valuable apple or pear orchards.

Root Rot.

The "toad-stool" disease, described for the almond, occasionally affects young apple trees recently set out, but it is not usually serious on established trees.

SteM Rot (Schizophyllum commune). Figure $\mathbf{1 6 .}$

This is another toad-stool disease, affecting the tree above ground. The fungus in question shows itself in clusters of small, bracket-like growths which appear on dead portions of the trunk or branches. This fungus infects the tree through wounds caused by pruning or any injury and in some cases develops rapidly in the heart wood of young trees, extending far up in the trunk and out into the branches, while the bark is still green and healthy and the whole tree appears to be in good condition. From the heart wood the fungus gradually works out into the outer sap wood and cambium, killing the tree. Affected trees often appear in good condition at the end of the growing season in the fall, but are found to be dead the following spring when they fail to leaf out. This sudden effect is produced by the development of the fungus into the sap wood and cambium during the winter while the tree is dormant and more susceptible.

Make all pruning cuts cleanly and close to the trunk, and paint over 


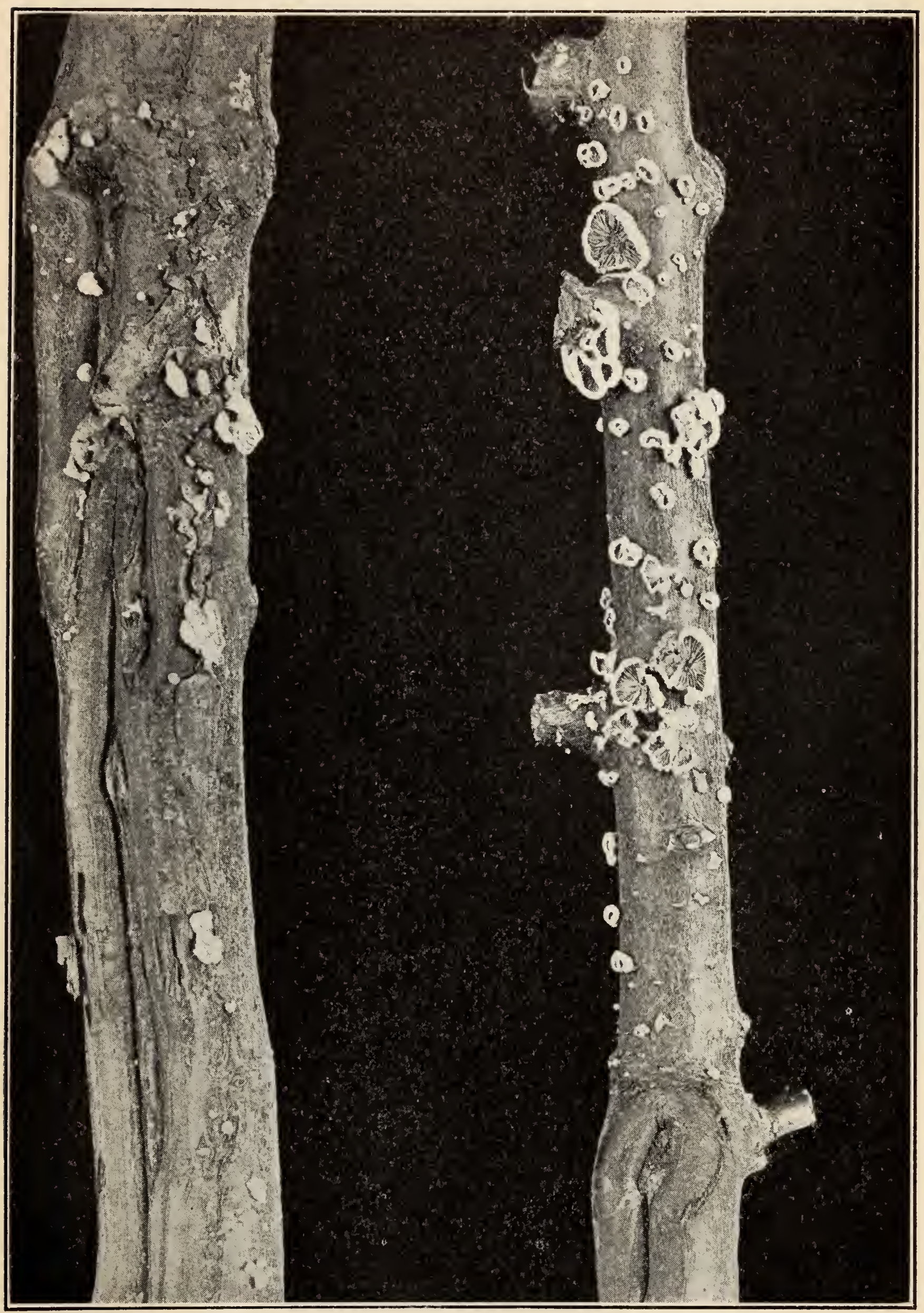

FIG. 16.-Canker of apple limbs caused by the fungus Schizophyllum. 
the scars with thick lead paint. In cases of trees unavoidably injured the wounds should be treated in the same manner as soon as possible.

SUN BURN. Figure 17.

The bark on one side of the trunk dies and the wounds thus produced frequently become infected with the little Schizophyllum fungus just described. The apple is quite susceptible to winter sun burn injury of the trunk and large branches. Especially in the higher foothill regions, where in late winter and spring the days are hot and the nights cold, trouble of this sort often occurs, as described on page 1054.

Paint the trunks with thick whitewash, and keep the ground about the trees covered in winter with vegetation or a mulch of some sort.

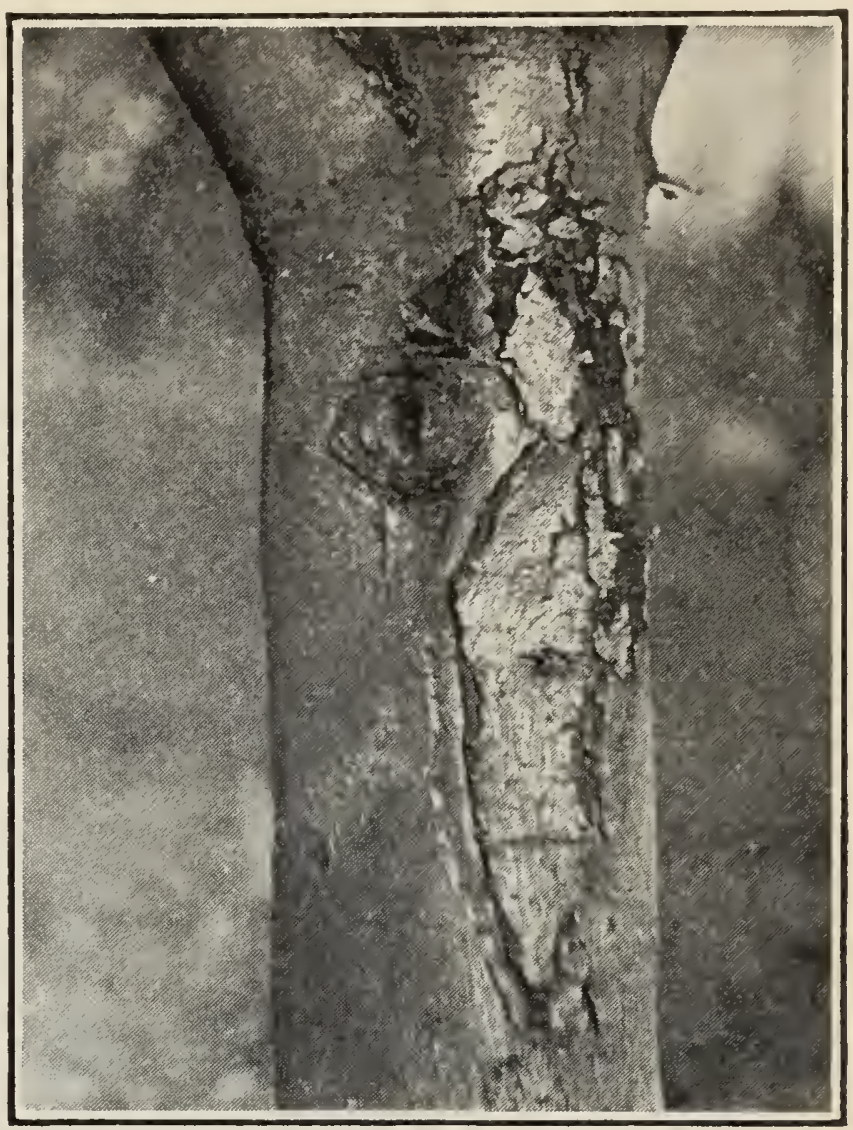

FIG. 17.-Effect of sun burn on trunk of apple tree.

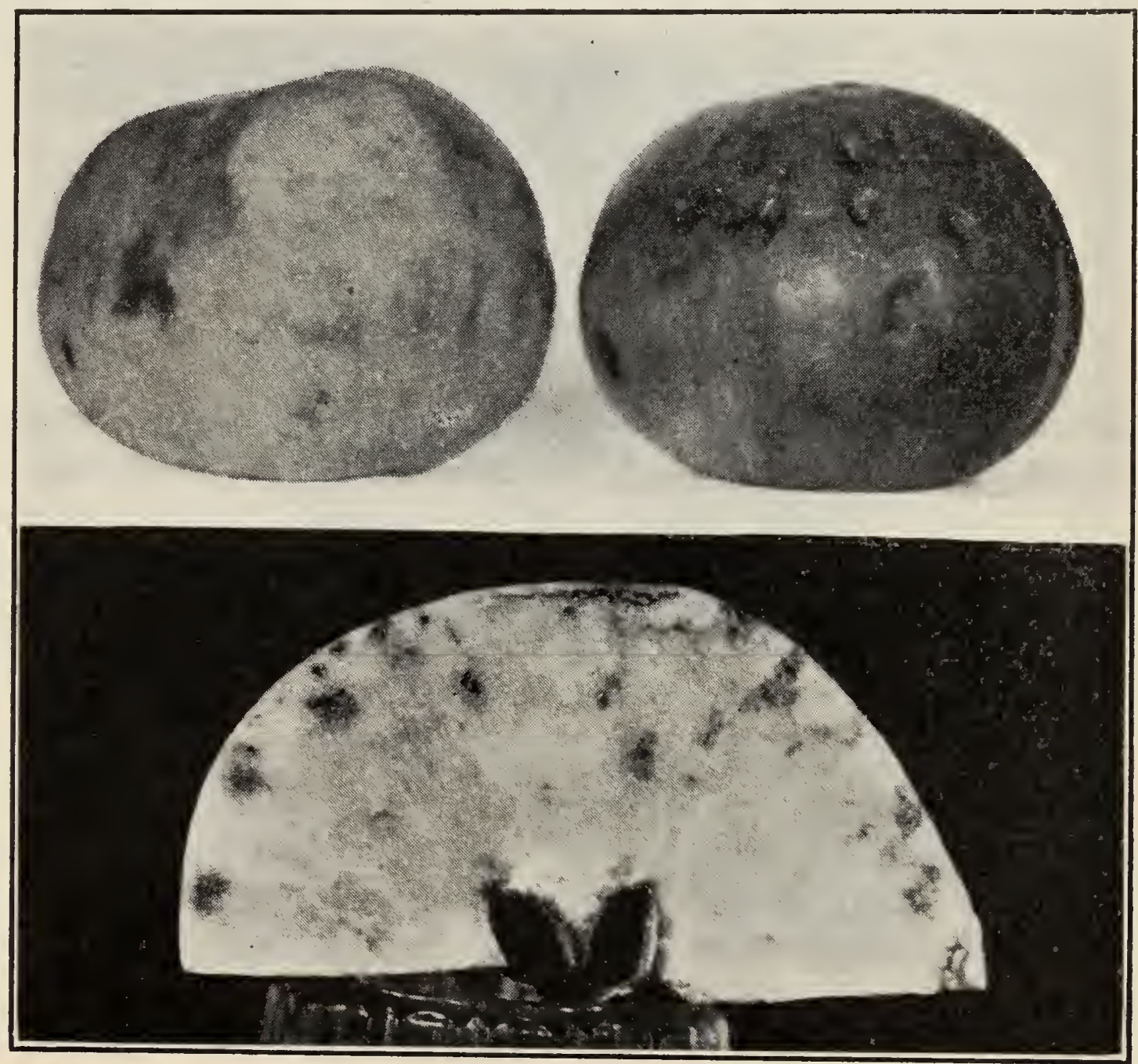

FIG. 18.-Fruit spot of apple. 
Die-BACK. See Almond.

Fruit Spot. Figure 18.

Characterized by the appearance of sunken, discolored spots on the surface of the apple, beneath which the tissue is found to be brown and dead. The dead tissue also extends to a considerable extent in streaks and lines through the flesh of the apple. This effect may show while the apple is still on the tree or sometimes develops only after the fruit has been picked for some time. The trouble has been ascribed to various causes. This disease is similar to that called "brown spot" or "Baldwin spot" in other portions of the country.

No cause or remedy satisfactorily demonstrated in California.

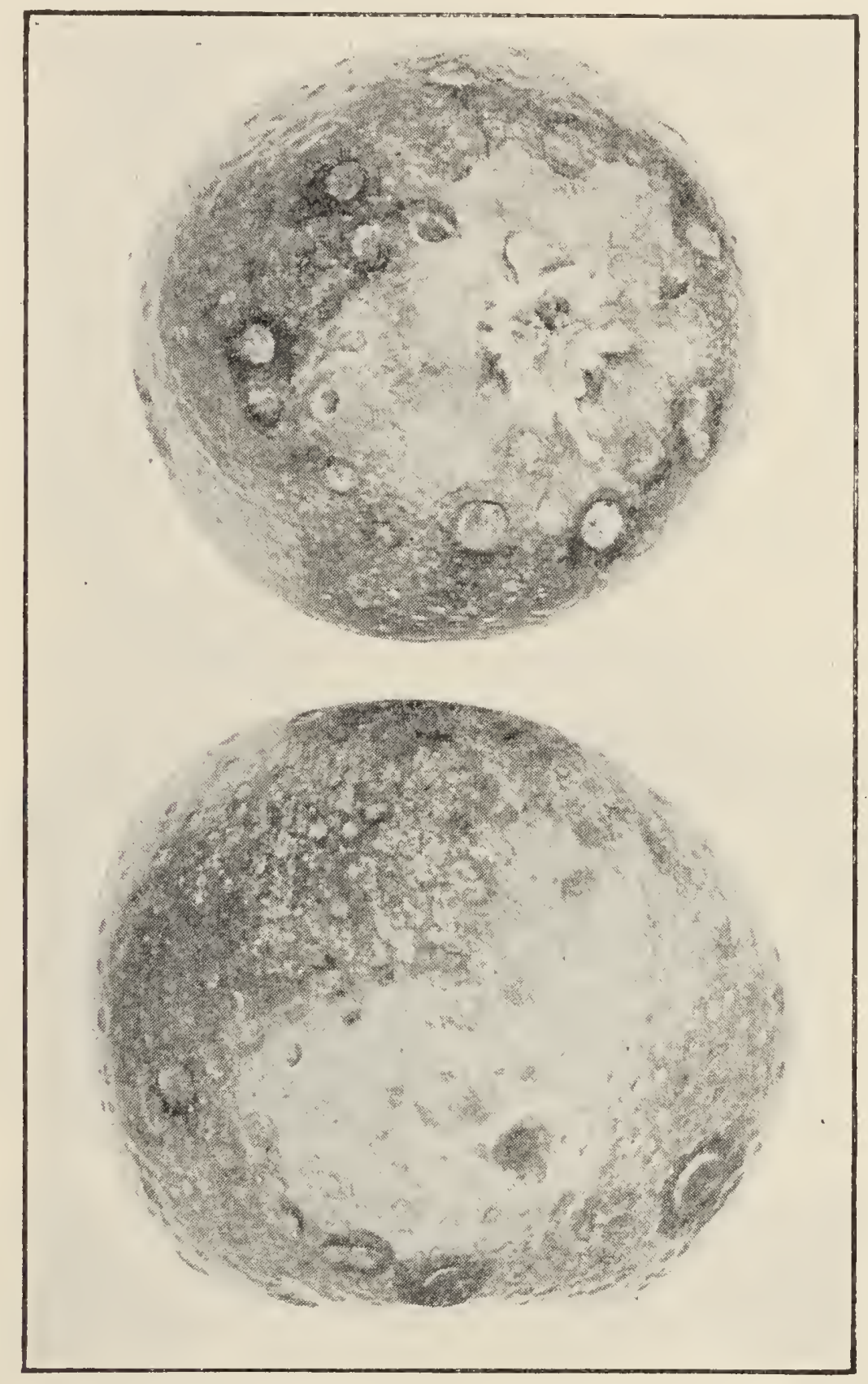

FIG. 19.-Storage spot of apple.

Storage Spot.

Numerous dark, dead spots appear on apples after being in storage for some time, usually on the upper side of each apple as it lies in the box. Especially common on the White Winter Pearmain, but also found on Jonathan and other varieties.

Cause not definitely known, but in storage not due to freezing. Has recently been attributed to after-effects of arsenical insecticides. 
Hollow APple. Figure 20.

A peculiar condition found in one or two instances. The affected fruit is sunken in on one side and has a misshapen appearance. On cutting through the apple large hollow cavities are found corresponding to the sunken areas on the surface. Due apparently to some injury while the fruit was small.

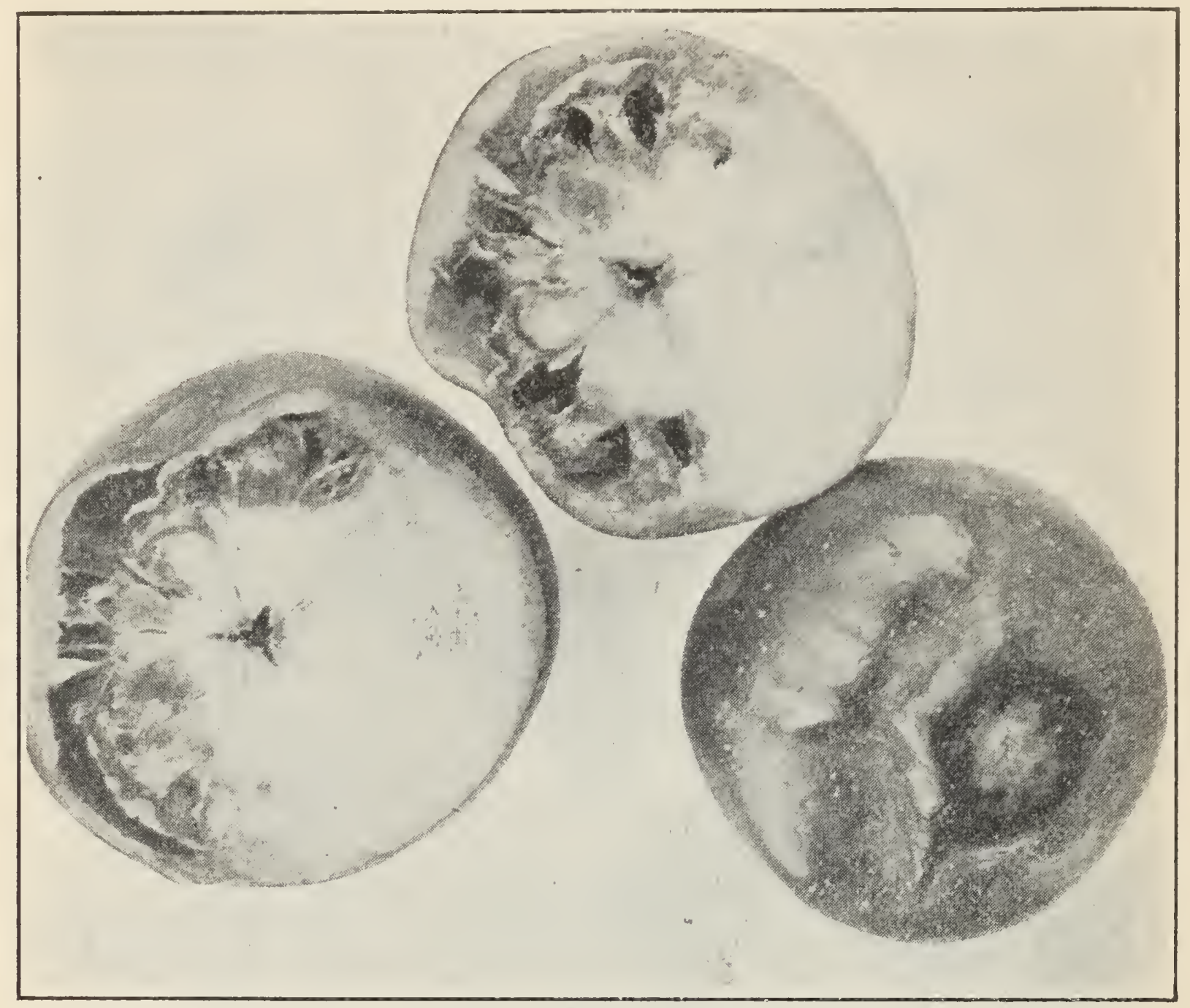

FIG. 20.-Hollow apple.

Club TIP.

Terminal buds die back or fail to grow and enlarged swellings develop at the ends of the living portion of the twigs. Lateral shoots may develop later from these. Affects some varieties more than others.

Due apparently to unfavorable soil or climatic conditions which check the growth of the terminal buds. Sometimes caused by apple mildew. No remedy, save in latter case, which see.

Seasonal Effects. Figure 21.

Apple trees in California, particularly in the valleys, are sometimes affected by the seasonal diseases described on page 1151 . These effects show themselves in die-back, blooming out of season, failure of the buds to open at the proper time, "Little Leaf," and a stunted, weak growth of the shoots. Such effects are produced most commonly, perhaps, by a long, dry season in the fall, causing the trees to become especially dor- 
mant, followed by warm, spring-like weather during the winter soon after the first rains. Again, they may be produced by long, continuous rainfall during the winter, followed by a very sudden end of the rainy season and a long period during the spring and early summer of hot, dry weather. These, and other irregular combinations may produce the effects described and other similar ones.

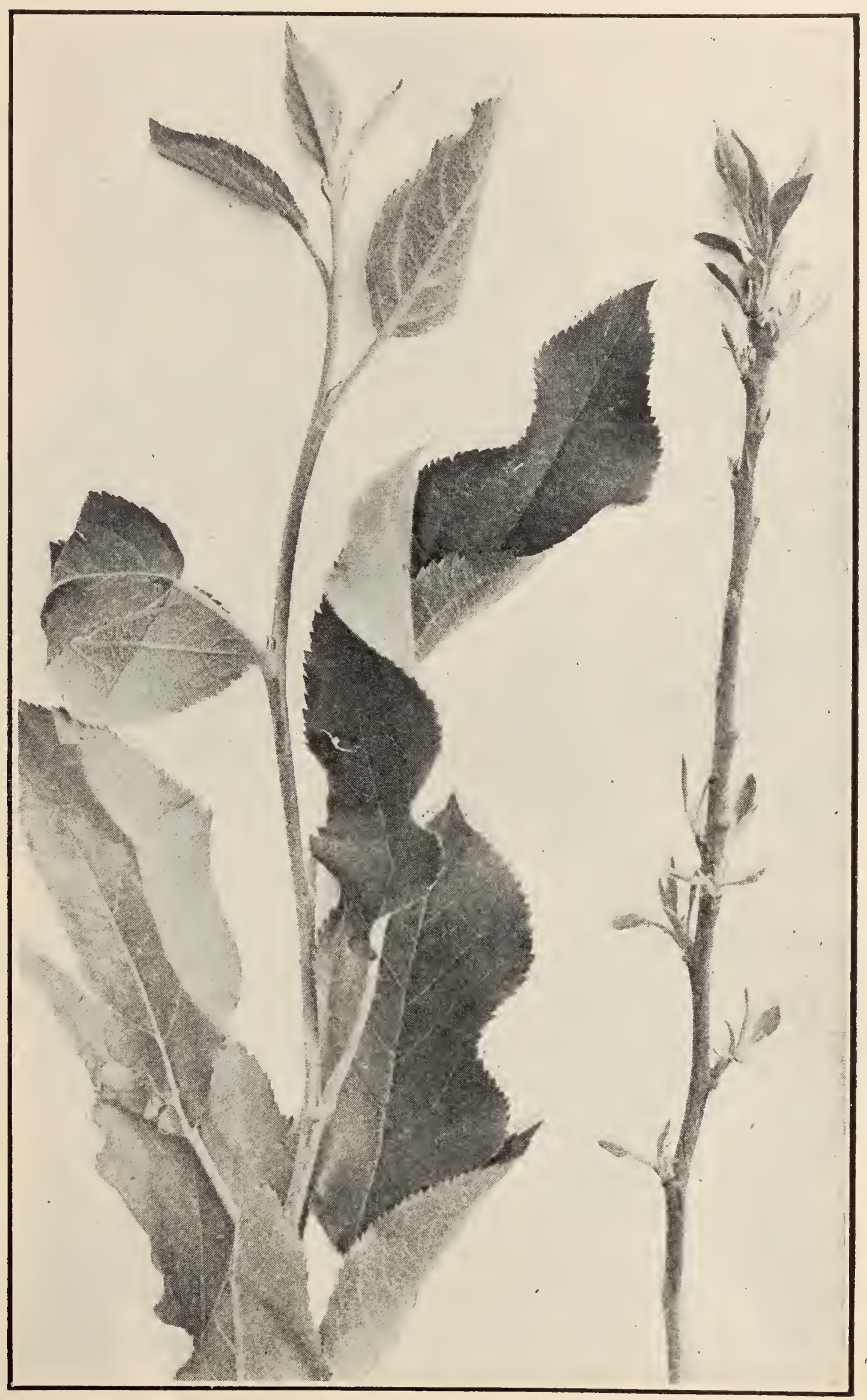

FIG. 21.-Little leaf of apple. 


\section{APRICO'T.}

Shot-Hole and Fruit Spot (Coryneum beyerinkii). Figure 22.

This fungus is the same as that causing the peach blight and produces in the apricot a spotting of the fruit, shot-hole effect in the leaves and killing of the buds.

Spray with Bordeaux mixture during November and again in spring just as the buds open.

See bulletin 203, page 33, California Experiment Station.

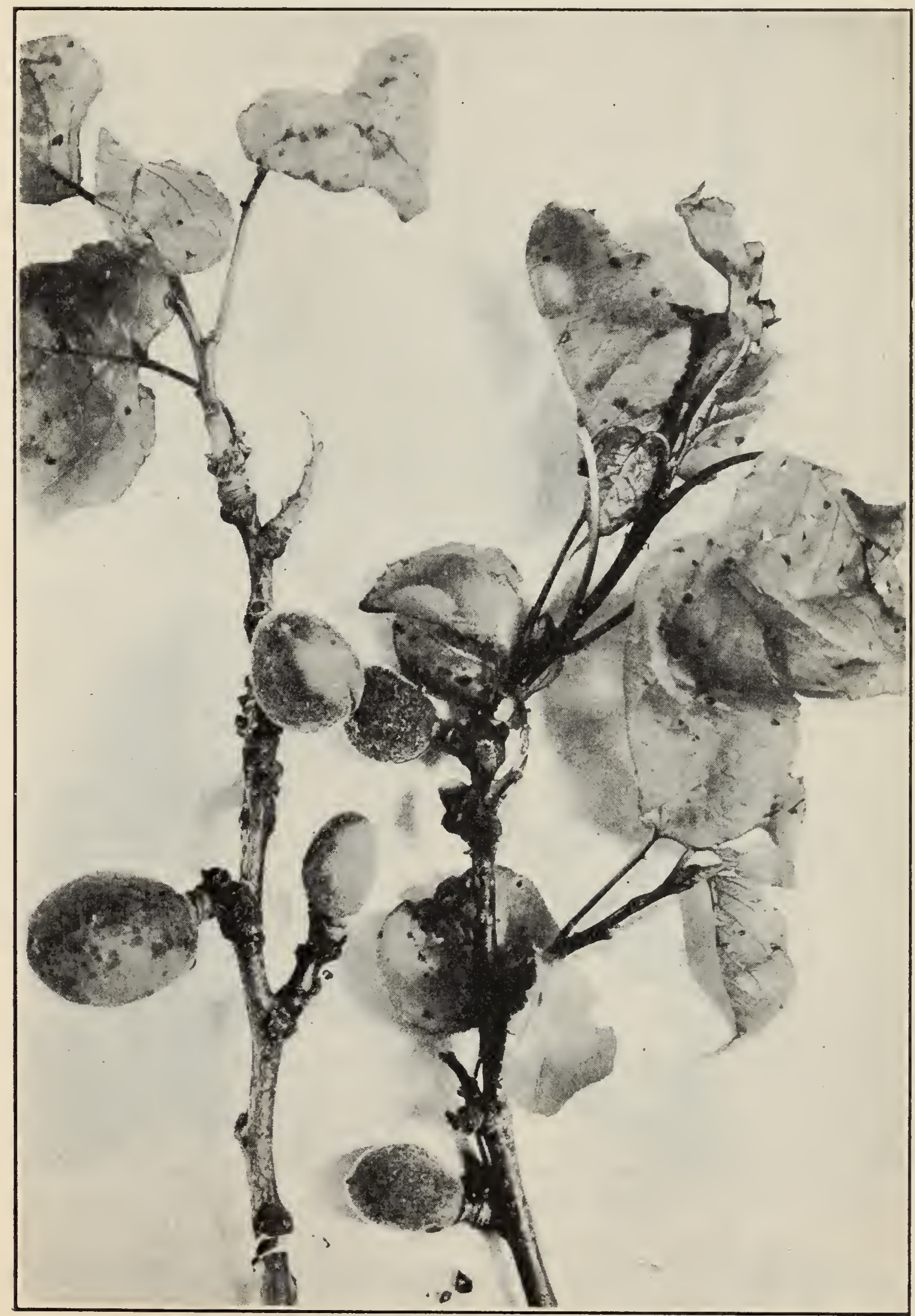

Fro. 22.-Apricot shot-hole and leaf spot (Coryneum beyerinkil). 


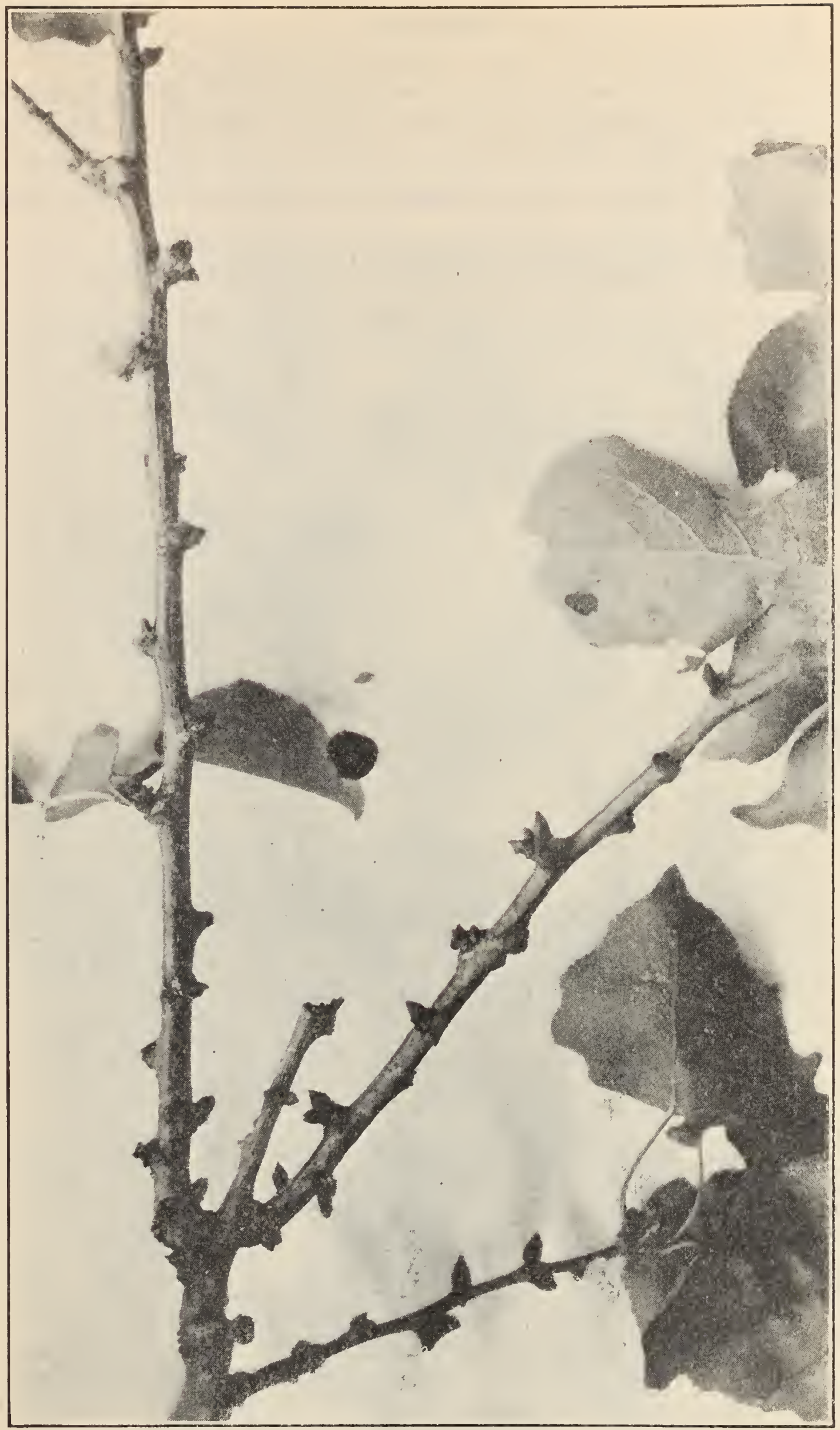

FIG. 23.-Apricot bud blight.

Bud Blight. Figure 23.

Characterized by a dying of the buds during the early winter and caused very largely by the fungus just mentioned.

Similar trouble is caused more or less by "Sour Sap" conditions. 
SCAB (Cladosporium carpophilum). Figure 24.

Causes a scabby spotting on the surface of the fruit.

Has never been sufficiently serious to warrant treatment in California.

Brown Rot (Sclerotinia fructigena). Figure 25.

A decay of the fruit while still on the tree, occurring some seasons in the vicinity of San Francisco Bay and other moist localities. The young growth as well as the fruit is also sometimes affected, the new shoots wilting and dying back from the attacks of this fungus. This is the most serious obstacle to stone fruit production in the eastern states, but does not find sufficient moisture for its development in California,

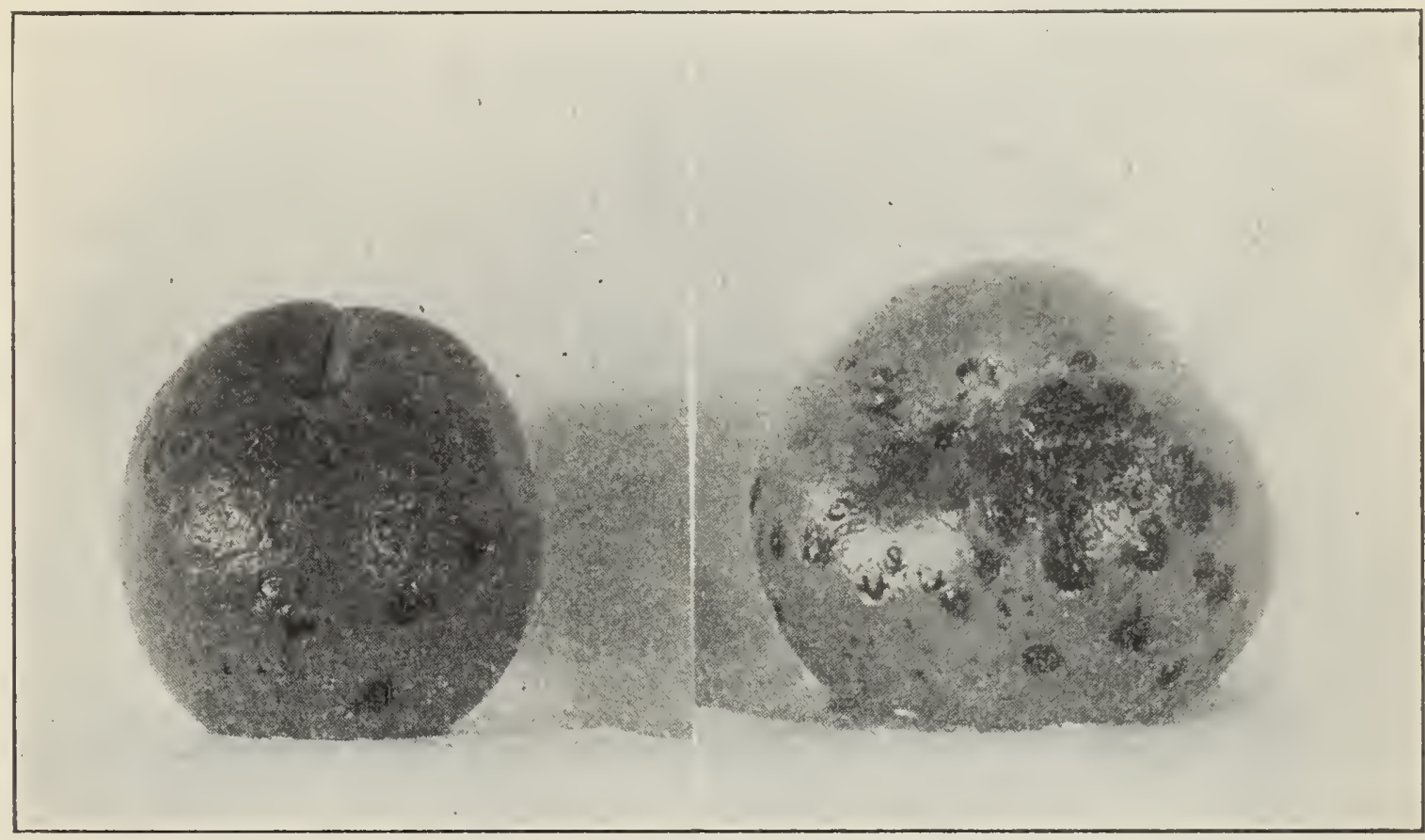

FIG. 24.-Apricot scab (Cladosporium carpophilum).

except on early varieties in occasional seasons of late rains in the localities mentioned above.

No definite remedy for this trouble has been demonstrated in California, but spraying with self-boiled lime sulphur just as the fruit is setting and again with the same following subsequent rains is recommended for trial.

See bulletin 203, page 39, California Experiment Station.

Brossom Rot. Figure 26.

The young fruit decays while still very small and enclosed by the calyx or outer cup of the blossom. The trouble occurs when wet rainy weather prevails during the time of fruit setting. It commences in a rotting of the calyx cup, which is dead and susceptible to decay by saprophytic fungi, which decay spreads to the young fruit. It is caused by various fungi, of which perhaps a species of Sclerotinia, apparently $S$. libertiana, is most common, causing a decay of the young fruit on the tree. When such fruit is picked and placed in moist chamber it develops an abundant cottony mold in which black sclerotia soon forms. This appears to be the same fringus causing the cottony mold or white rot of 
the lemon storage. Botrytis vulgaris is also common in this trouble. Same treatment as brown rot.

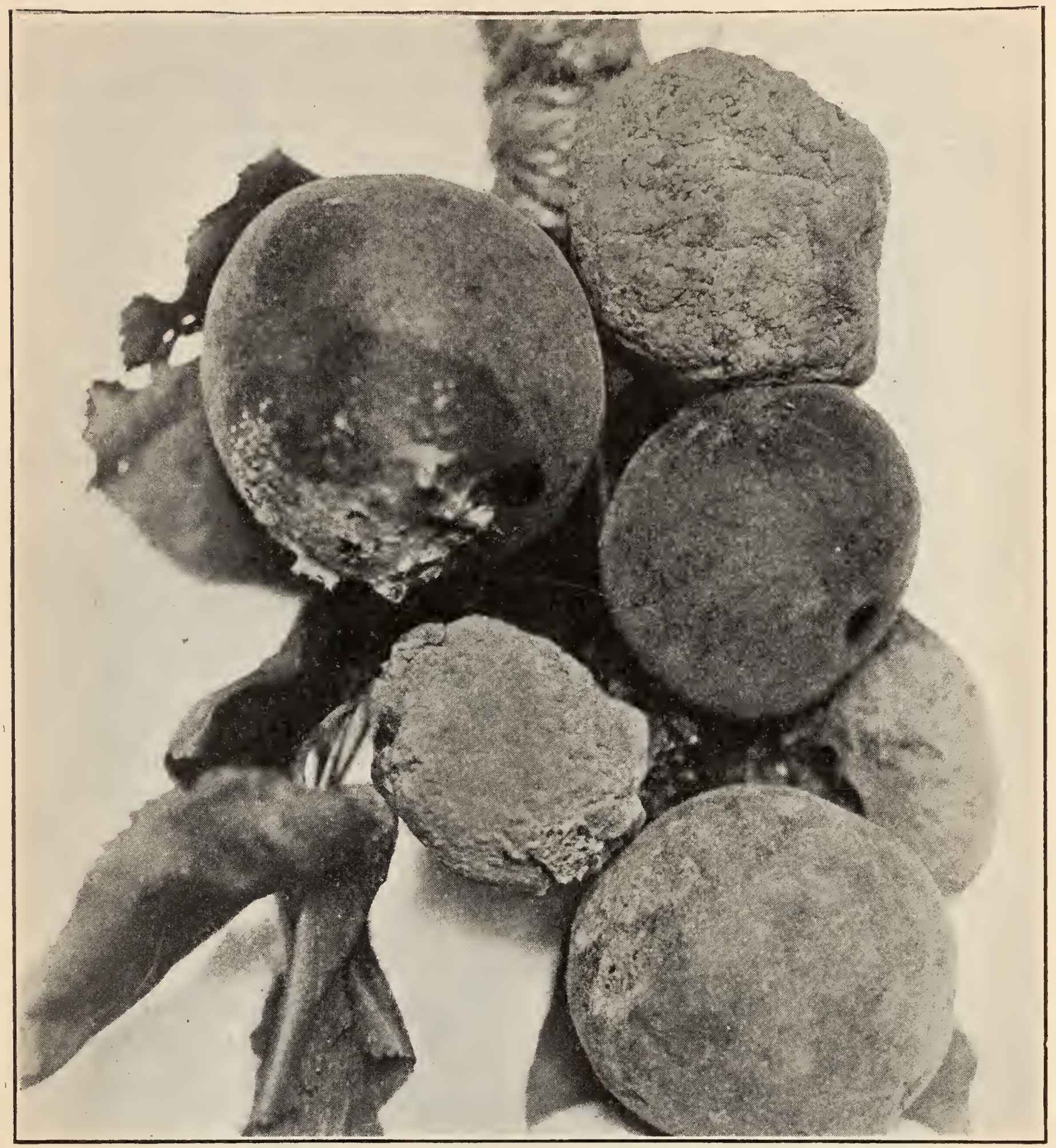

FIG. 25.-Brown rot of apricot (Sclerotinia fructigena).

Spraying for shot-hole fungus might also be of some benefit in this trouble.

Fruit Drop. See Almond.

Sour Sap and Seasonal Effects.

The apricot is particularly sensitive to sour sap (see Almond) and other seasonal effects. It is a tree having a free flow of sap, quick to respond to stimulating influences and one having the characteristic of all the stone fruits of forming an abundance of gum when injured in any manner. On this account, if any active sap movement from the 


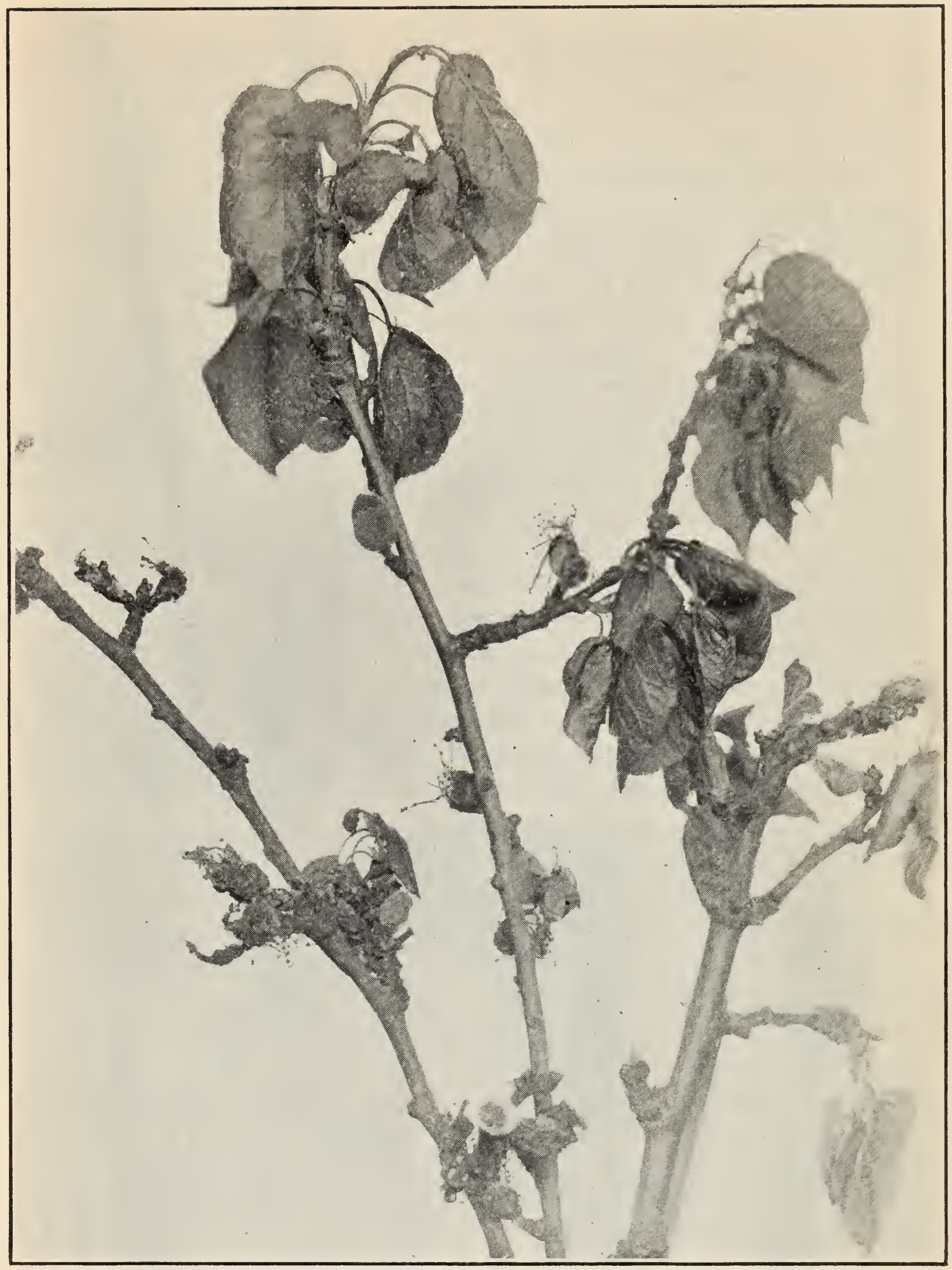

FIG. 26.-Apricot calyx rot (Sclerotinia libertiana).

roots is started early in the season by warm weather or an abundance of moisture and this activity be checked again by less stimulating weather conditions, trouble is very apt to follow. The sap becomes stagnant in the tissues, full of sugars and other easily fermentable substances, gum begins to form, sun burn may also occur and very often severe injury take place in the tissues of the sap wood and cambium layer. 
Crown Gall and Root Rot. See Almond.

Die-Back. See Almond.

Gummosis. See Cherry.

ASPARAGUS.

Rust (Puccinia asparagi). Figures 27 and 28.

Causes premature death of the bushy tops which grow up after the cutting season, thus injuring the vitality of the plants. The fungus causing the rust shows three different stages, the spring rust, appearing in the form of elliptical patches on the stems of plants which are allowed to grow up early in the season, the summer or red rust, which covers the tops with a reddish, dusty powder of spores during the summer, causing their death, and the black rust stage, which appears on the tops in the form of numerous black pustules following the red rust.

During the cutting season allow no wild asparagus to grow up.

Keep the fields well irrigated and cultivated during the summer and fall after cutting stops. Dust the tops thoroughly with flowers of sulphur about three weeks after

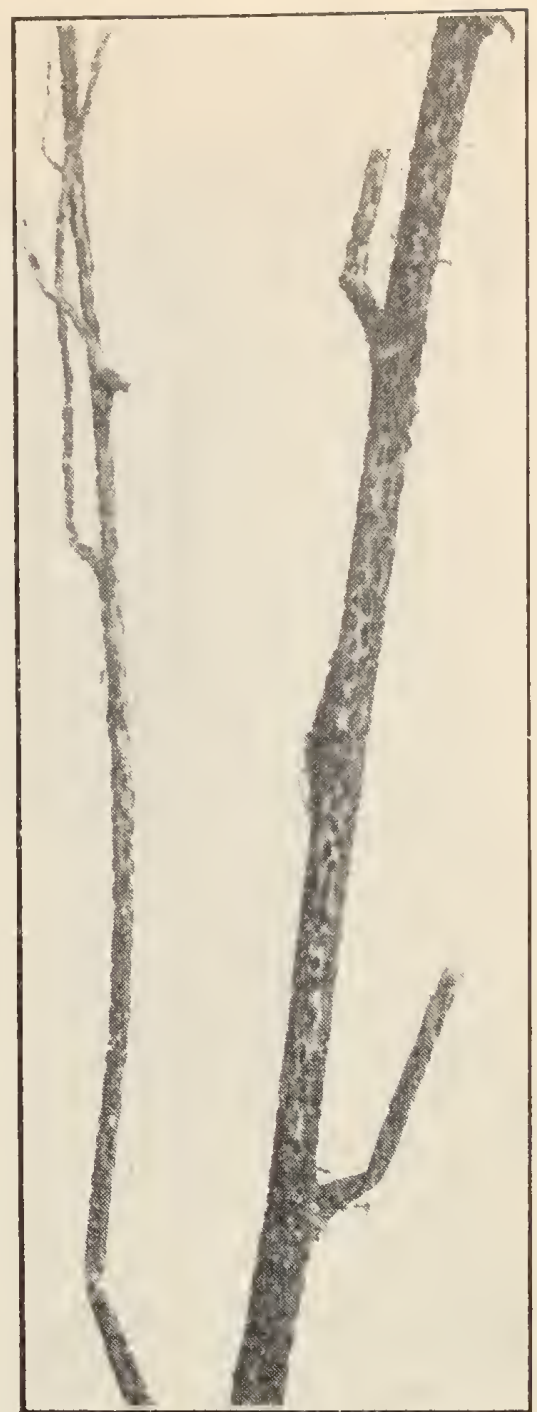

FIG. 27. - Asparagus rust, winter stage.

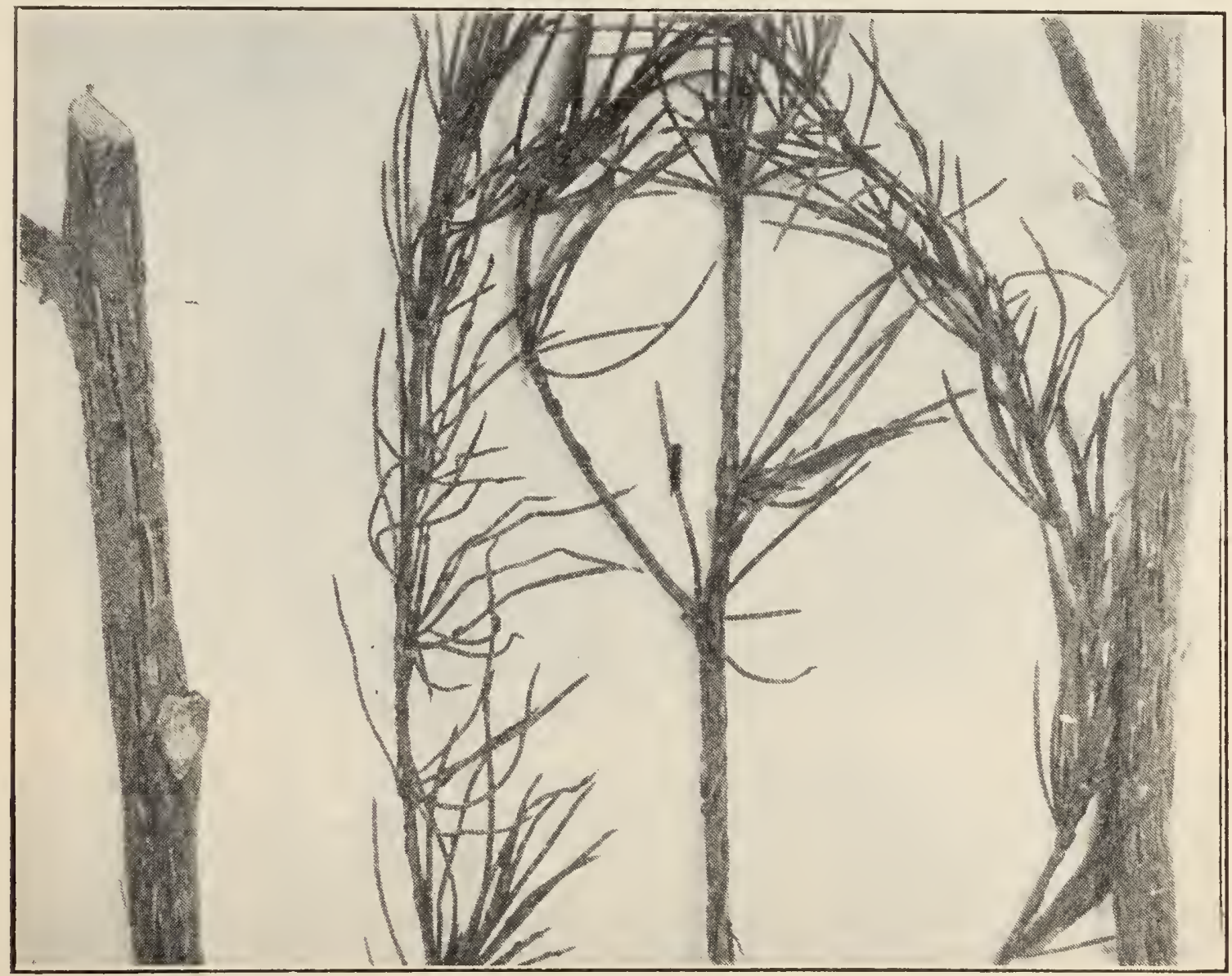

FIG. 28.-Asparagus rust, summer stage. 
the cutting season ends and repeat this two or three times during the remainder of the season.

Select seed for planting from the most rust-resistant plants. See Bulletins 165 and 172, California Experiment Station.

\section{ASTER.}

\section{YELLOWS.}

Characterized by the production of sickly, yellow shoots and abortion of the flowers. Apparently caused by climatic conditions. Not very serious in California. No remedy known.

\section{BARLEY.}

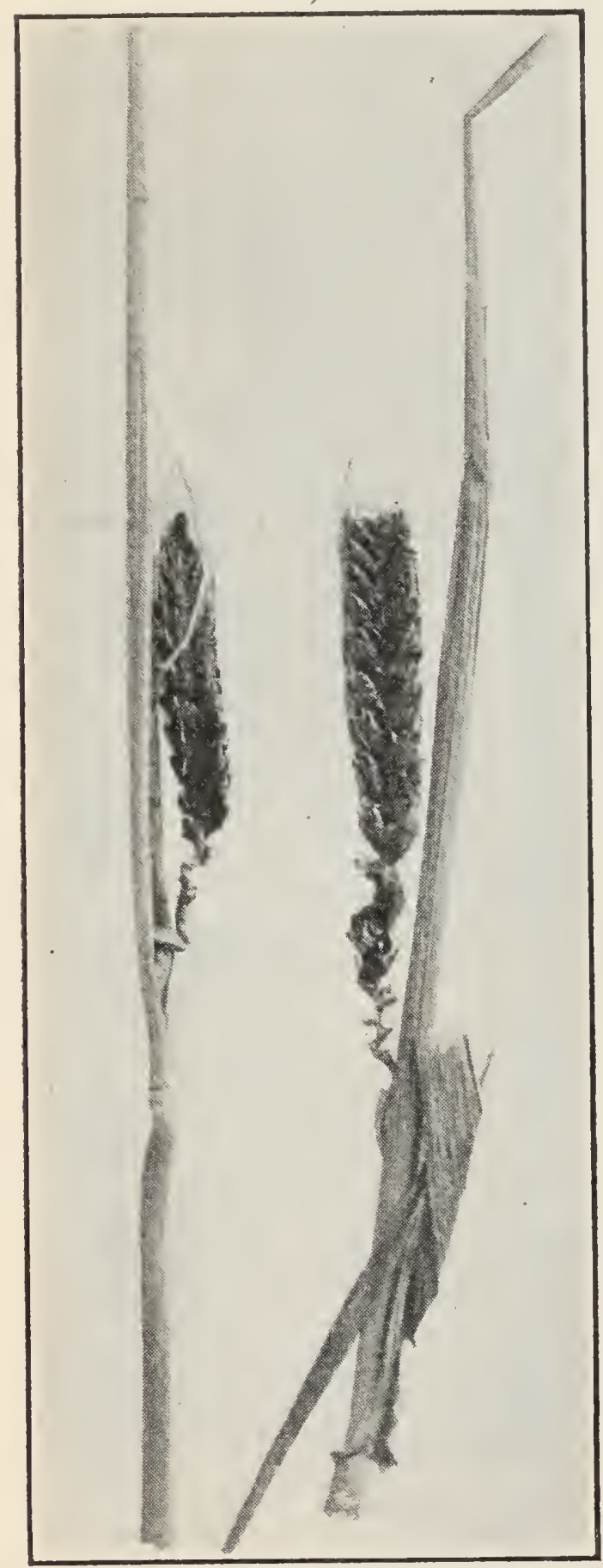

FIG. 29.-Loose smut of barley (Ustilago nuda).

\section{Closed SMut (Ustilago hordei).}

The grain is turned a dark color by the formation of the fungus spores in its substance. This remains firm rather than flying out in a dusty mass, as in the next form.

Loose Smut (Ustilago nuda). Figure 29.

Differs from the last in that the smutty substance of the grain scatters out in the form of black dust, leaving the heads empty.

Barley is not often affected with smut in California, so that we can not distinguish as to the occurrence of these two different species. It is advisable, however, to treat the seed as follows:

Soak for 10 minutes in one of the following solutions:

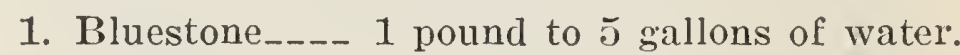

2. Formalin_._. 1 pint to 30 gallons of water.

The seed should be soaked long enough to get every grain thoroughly wet and then immediately taken out. If not planted at once the grain must be dried before storing. Plant a little more seed after this treatment than would be used with untreated grain.

Loose smut alone is more successfully controlled by the following seed treatment :

Soak in cold water for 5 hours. Then soak in water at a temperature of 125 degrees F. for 15 minutes. The proper temperature must be 
carefully maintained to make this treatment successful, but it is not usually necessary in California.

Blade Blight (Helminthosporium gramineum). Figure 30.

The leaves turn yellow and are covered with elongated black spots. This is frequently seen in unfavorable seasons when the plants are small and rather stunted. The plants usually overcome the diseased condition when weather conditions are favorable.

It is a question whether the primary trouble is not caused by weather conditions more than by the fungus. In periods of long continued, cold rain in winter, to which barley is often subjected, the plants grow very feebly, turn yellow and form their roots close to the surface of the water-soaked

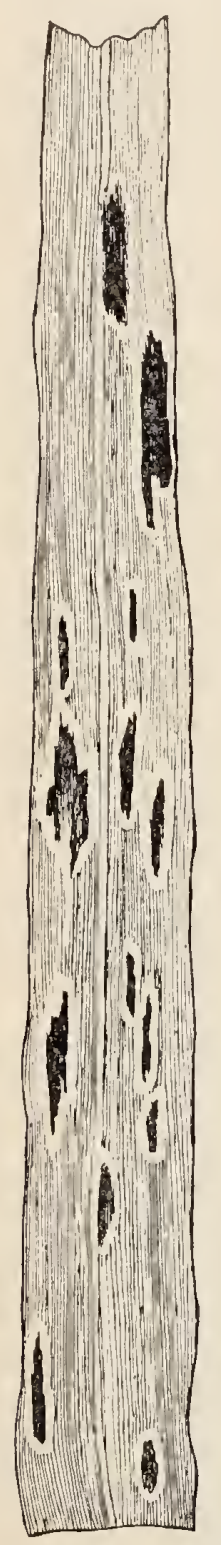

FIG. 30.-Blade blight of barley (Helminthospor $i u$ m gramineum). mixture. to fungi. weather.

ground. When, as sometimes happens, the seasonal rain suddenly ends and hot, dry windy weather follows, the surface soil dries out suddenly, the shallow-rooted barley is left without moisture and the already weakened plants fall an easy prey

No remedy feasible or commonly needed.

BEAN.

MILdew (Erysiphe polygoni).

Produces a white growth of the fungus covering the surface of the leaves in moist

Sprinkle with dry sulphur.

RUST (Uromyces appendiculatus).

Causes a yellowing and death of the leaves with the production of a dusty red rust on the under side. Not usually destructive except on plants growing poorly.

Sрот (Colletotrichum lindemuthianum). Figure 31.

Causes large, scabby, dead spots upon the pods. Not often serious in this State.

May be controlled by selecting clean seed and spraying the plants with Bordeaux

\section{BEET.}

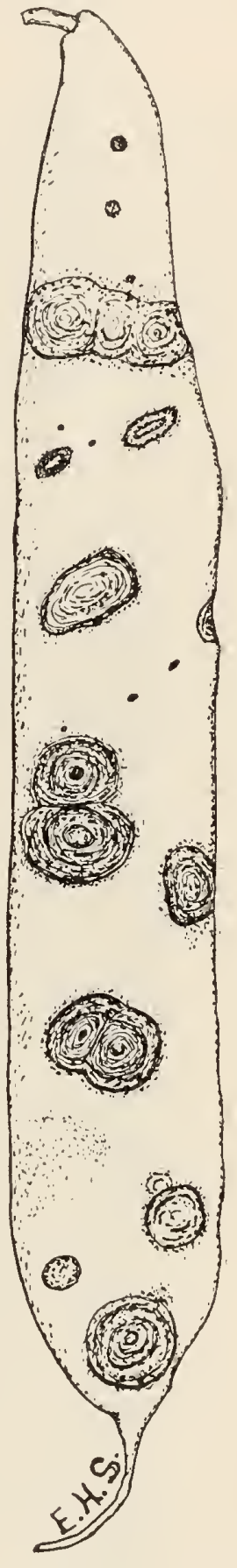

FIG. 31.-Anthracnose of bean (Colletotrichum lindemuthianum).

\section{Rust (Uromyces beta).}

A typical red rust on the leaves, common on sugar and garden beets if grown during the rainy season. Not serious. 


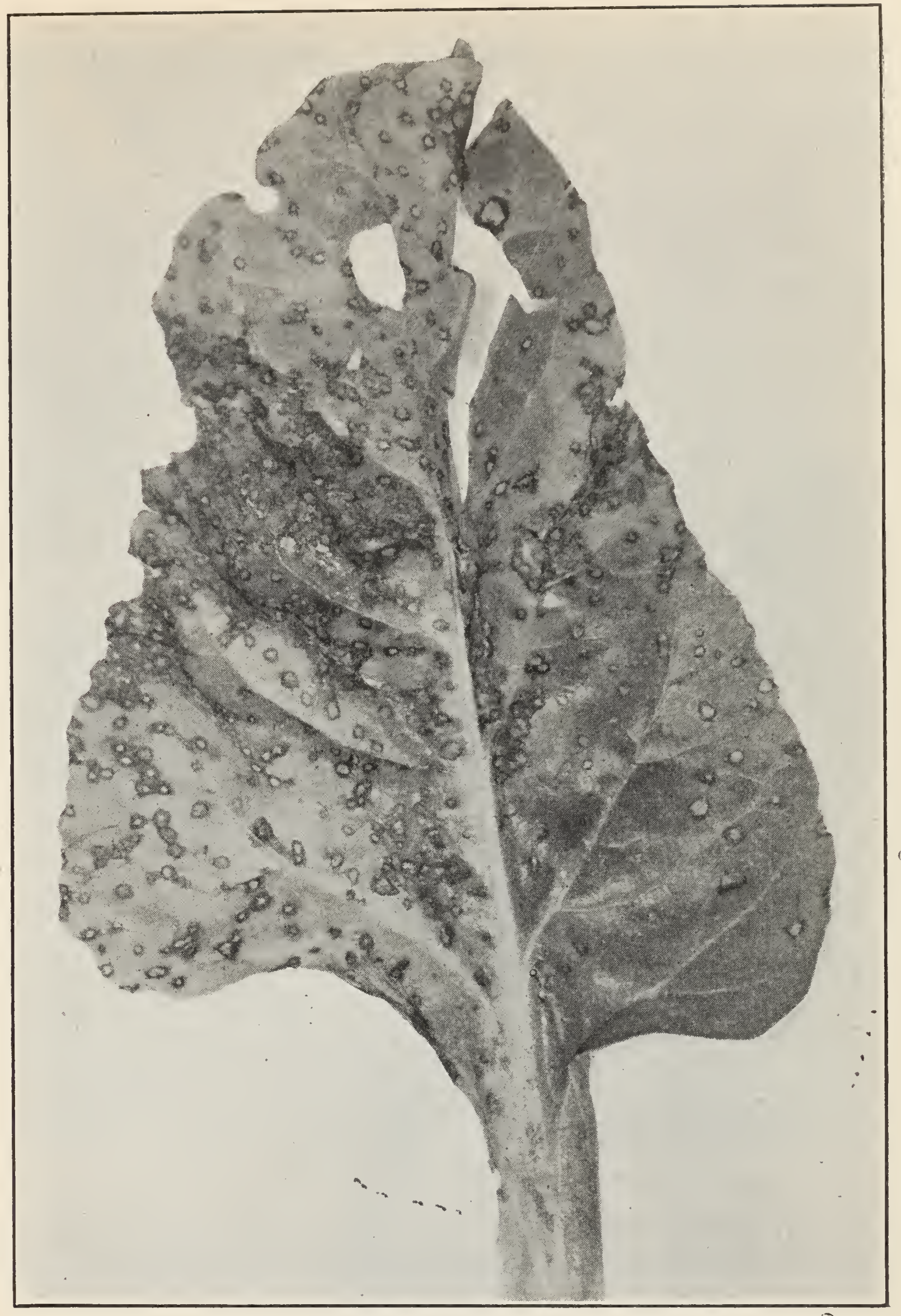

FIG. 32.-Leaf spot on beet (Cercospora beticola).

Leaf Spot (Cercospora bcticola). Figure 32.

Produces small dead spots all over the leaves. Quite common in California, but practically unknown on sugar beets.

Downy Mildew (Peronospora schachtii). Figure 33.

Causes a stunting of the inner leaves and a checking of the growth of the plant. The fungus is visible to the eye as a mildew on the under 
side of the affected leaves in the center of the plant. Found recently in California on sugar beets, this being the first report in this country. Not yet serious. Occurs only during the rainy season.

When found, the plants should be pulled and destroyed.

Root liot (Rhizoetonia).

Appears in young plants as a decay of the main root. Does not usually kill the plant but causes the root to fork and become misshapen. Not very serious.

\section{Curly Top-Blight. Figures 34 and 35.}

Characterized by thickened, curled leaves, stunted growth, an abundance of fibrous roots and a pronounced blackening of the concentric

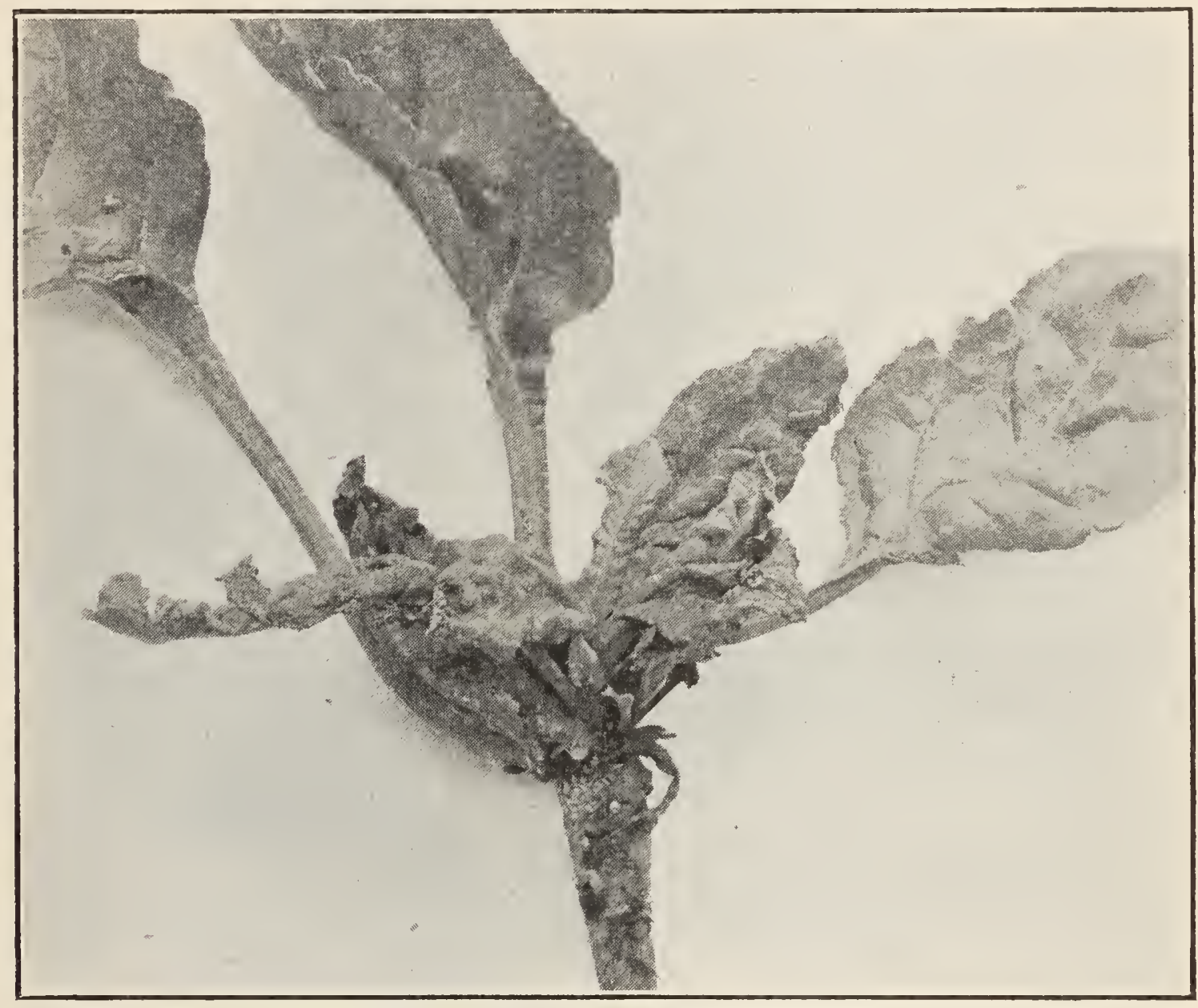

FIG. 33.-Downy mildew of beet (Peronospora schachtii).

rings in the interior of the beet. Our most serious sugar beet disease. The cause of this disease has recently been found to be an insect (Eutettix), but its development is very largely influenced by climatic conditions.

Avoided largely by determining the best time for planting in affected localities.

See bulletin 184, page 240, California Experiment Station.

Rоот KNот (Nematode).

Produces small, gall-like swellings on the roots. Has been found in California but does not seem to have become serious. See page 1076 . 


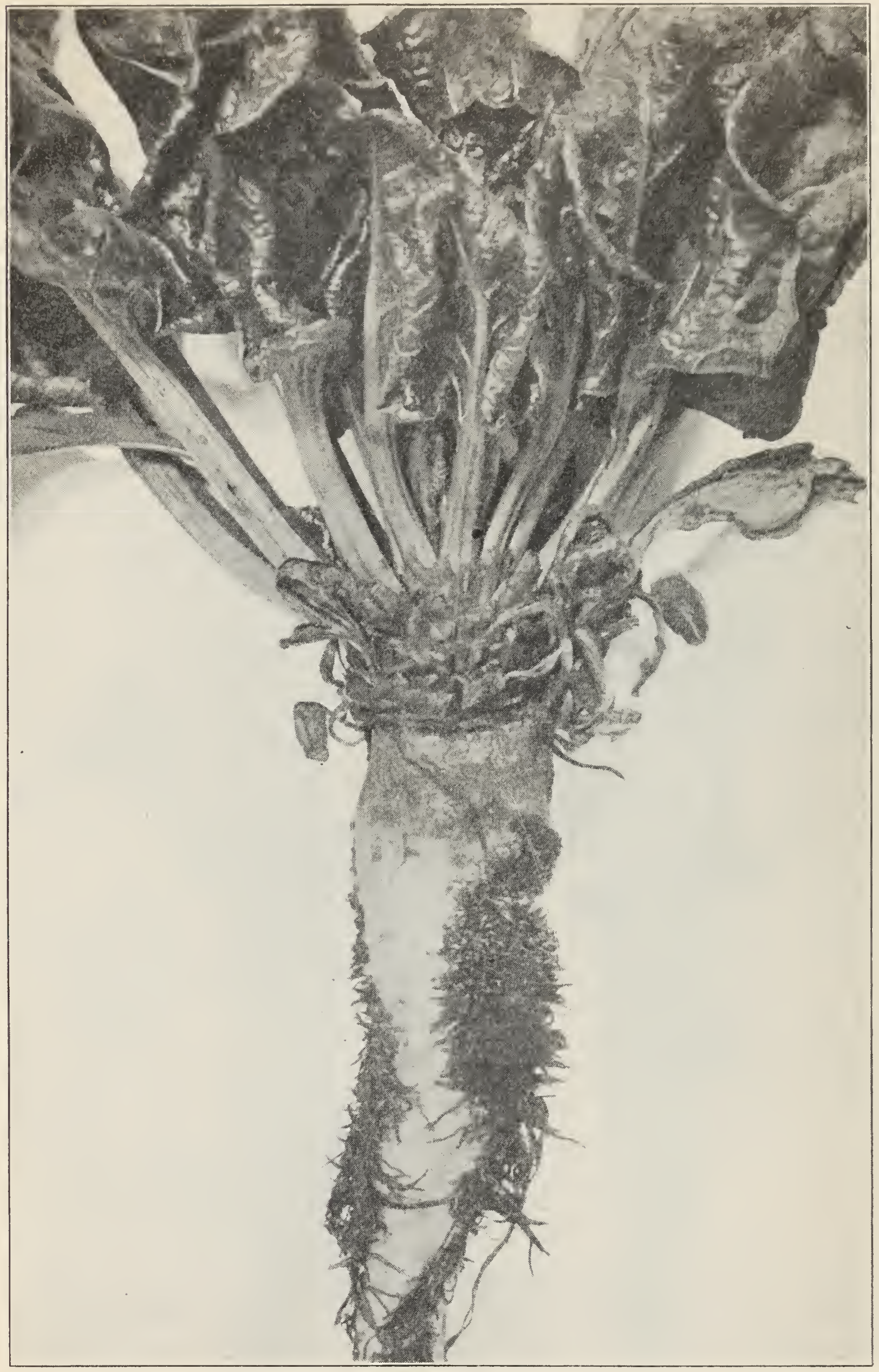

FIG. 34.-Curly top of beet. 


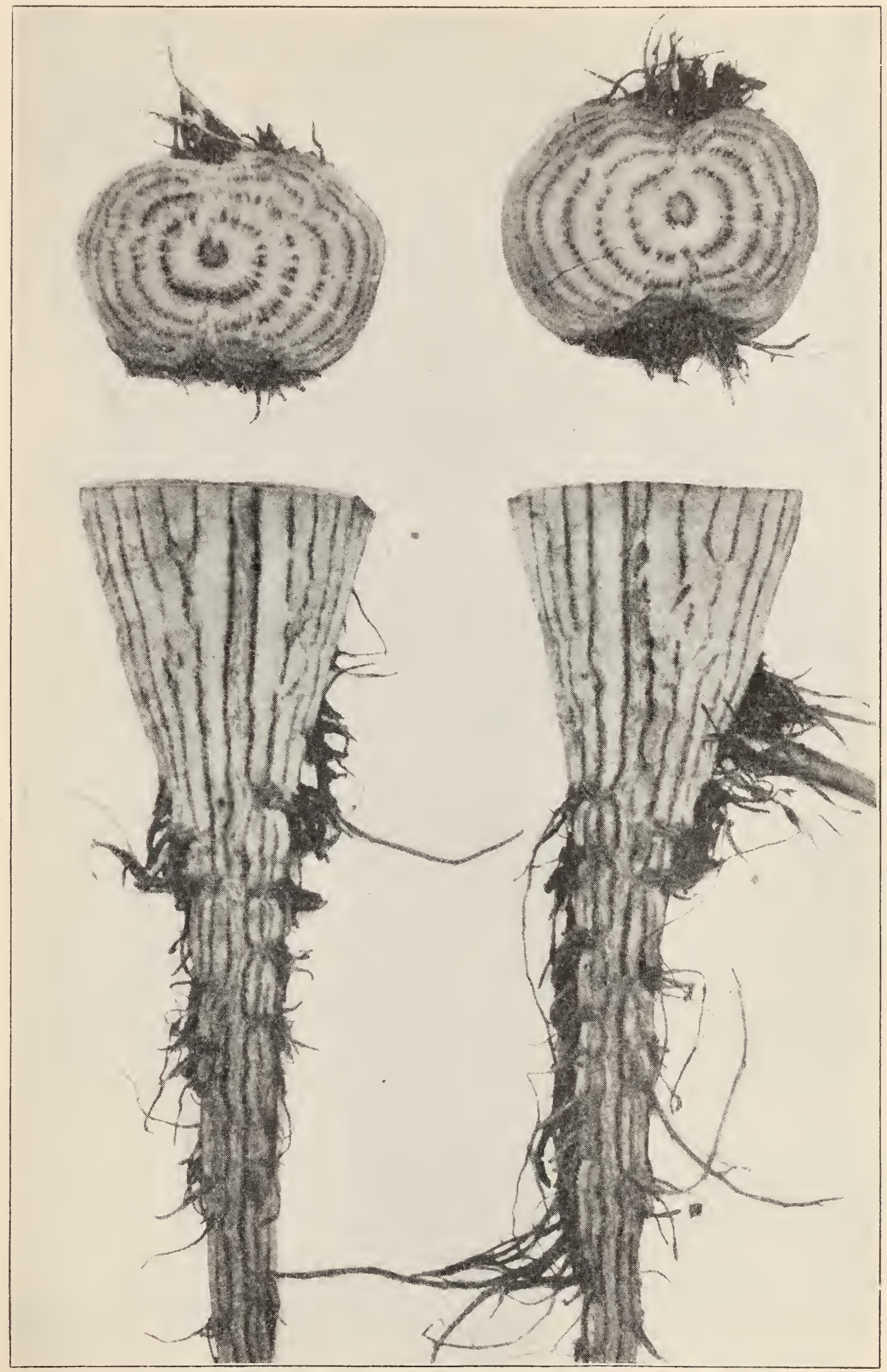

FIG. 35.-Curly top of beet. Sections showing blackened fibrovascular rings. 
BLACKBERRY.

Produces bright orange masses of spores all over the under side of the leaves. The fungus spreads all through the plant so that it is not easily controlled.

Cut aff e c ted plants to the ground and burn. Spray new growth with $\mathrm{B}$ ordea $\mathrm{ux}$ mixture.

\section{LEAF SPOT}

(Septoria rubi). Figure 36.

Produces small dead spots on the leaves. Not usually very serious.

Spray with Bor-

Rust (Gymnoconia interstitalis).

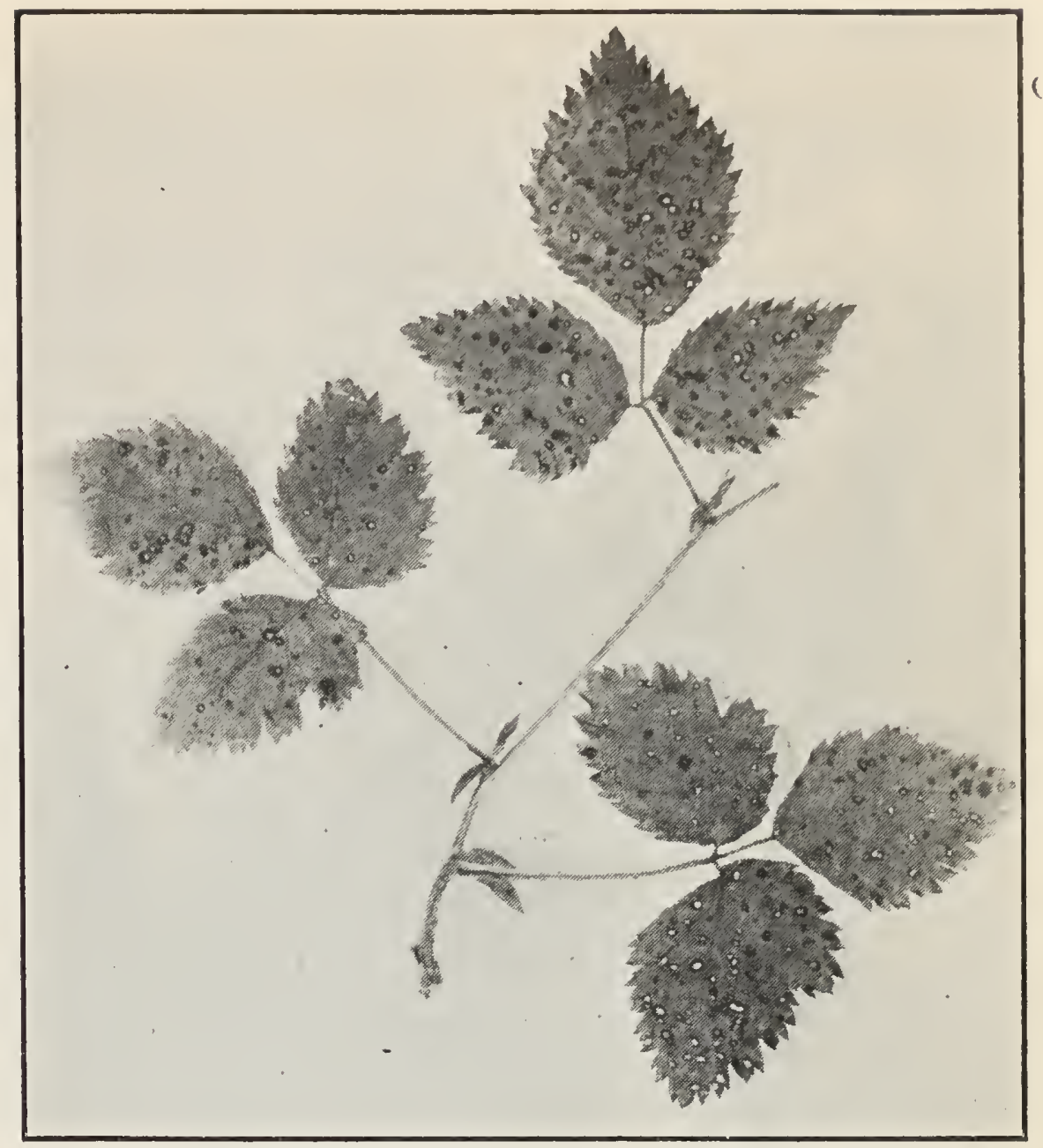

FIG. 36.-Leaf spot of blackberry (Septoria rubi).

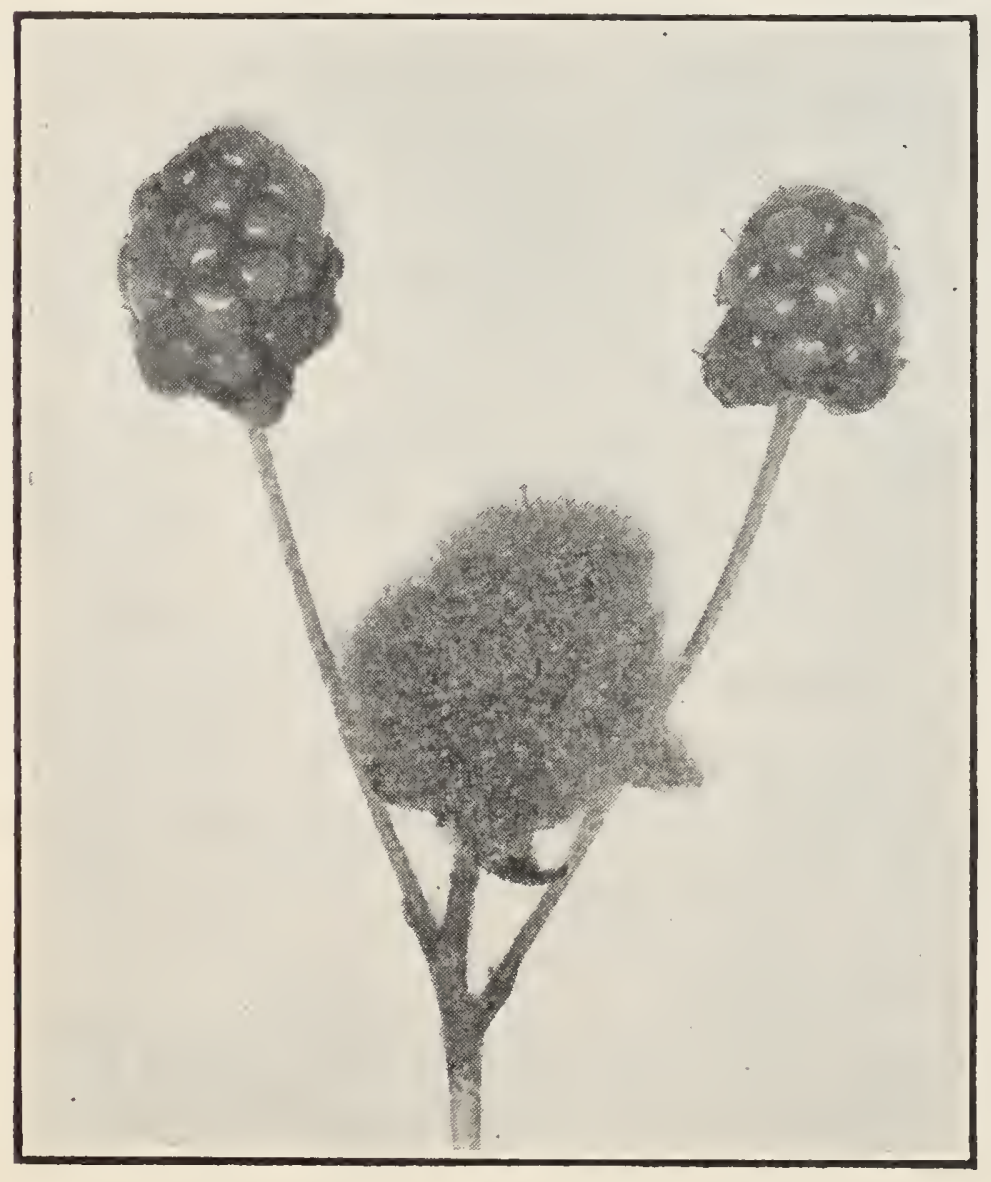

Fig. 37 - Fruit rot of blackberry (Botrytis vulgaris).

deaux mixture about four times at short intervals (of about ten days), the first application when the buds are beginning to unfold.

Crown GaLL

(Bacterium tumefaciens).

Produces large swellings or galls just below ground. Destroy affected plants and use care in planting clean stock.

Truit Rot (Botrytis). Figure 37 .

The ripe fruit decays on the bushes and is covered with a grey, dusty mold. Usually not abundant except in moist weather.

No treatment feasible. All affected fruit should be 
discarded and not mixed with that which is unaffected, as the rot will spread after picking.

\section{CABBAGE.}

Club Foot (Plasmodiophora brassica).

Produces large swellings on the roots and stunting or death of the plants. Not common in California.

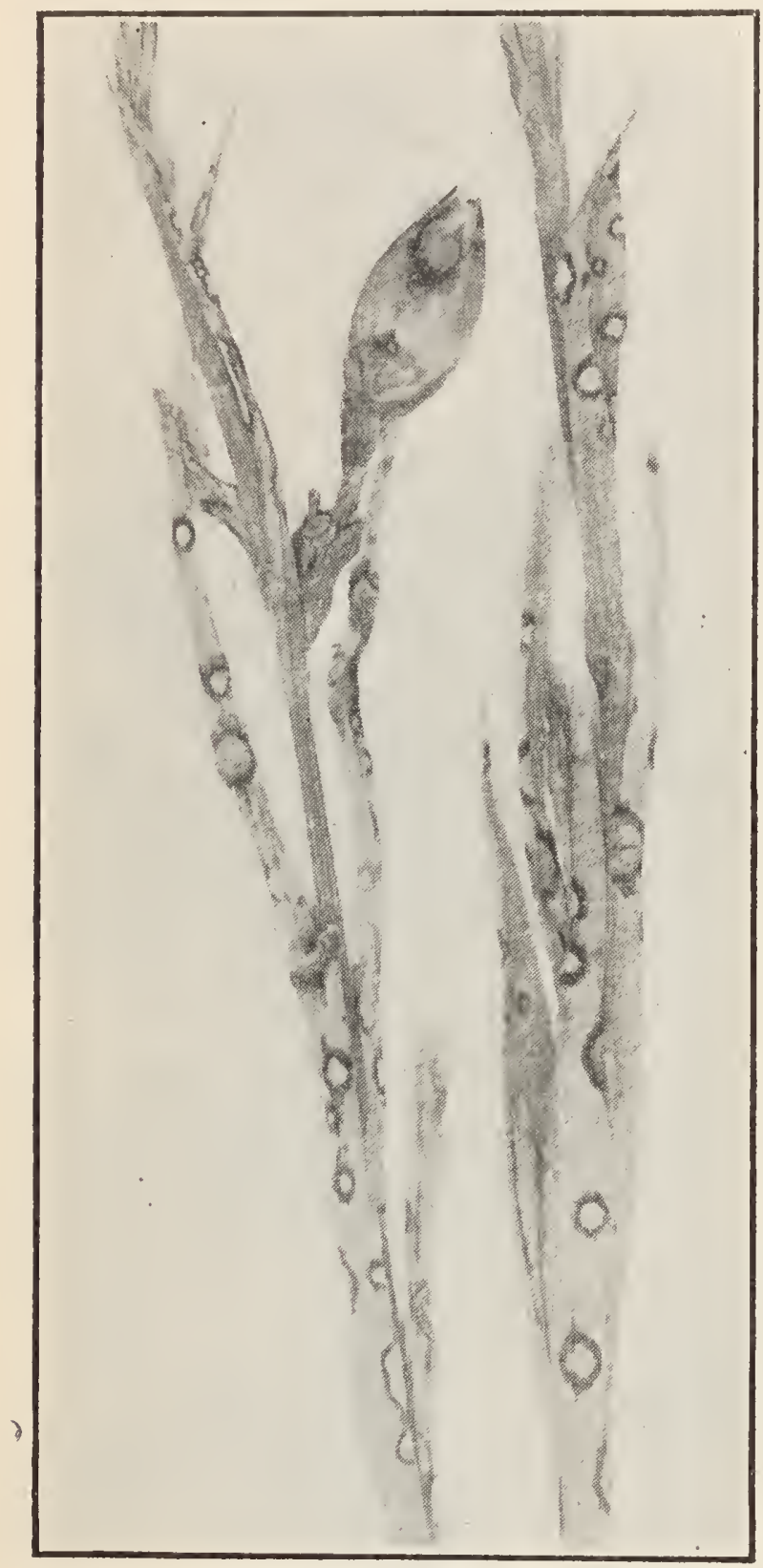

FIG. 38.-Leaf spot of carnation (Heterosporium echinulatum).

Brack Rot (Pseudomonas campestris).

This bacterial disease causes the ruin of the heads, the veins of the leaves turning black and decaying. The trouble is very uncommon in California if it occurs at all.

CARNATION.

Rust (Uromyces caryophyllinus).

Produces pustules containing the reddish, dusty spore masses of the fungus on the leaves. Not serious on healthy plants in this State.

Wilt-Stem Rot (Fusarium).

Causes a dry rot of the stem and root tissue of the plant. Not serious.

LEAF SPOT (Heterosporium echinulatum and Septoria dianthi). Figure 38.

Produces dead spots on the leaves. Not important in this State.

This disease, together with the rust, may be controlled to some extent by spraying with Bordeaux mixture if necessary. In both cases use care in selecting healthy cuttings for propagation and grow them in fresh soil.

CELERY.

Summer Blight (Cercospora apii).

Produces large, irregular dead spots on the leaves during the summer. Quite common in moist localities but not serious.

Winter Blight (Septoria petroselini, var. apii). Figure 39.

Produces smaller spots than the last, with numerous black pustules dotting them. Develops more during the rainy season, especially if the growth of the plants is checked by unfavorable conditions. The disease 
affects mostly the older outside leaves, causing a stunting of the plant and also decay in shipment.

Spray frequently with Bordeaux mixture at all times during the

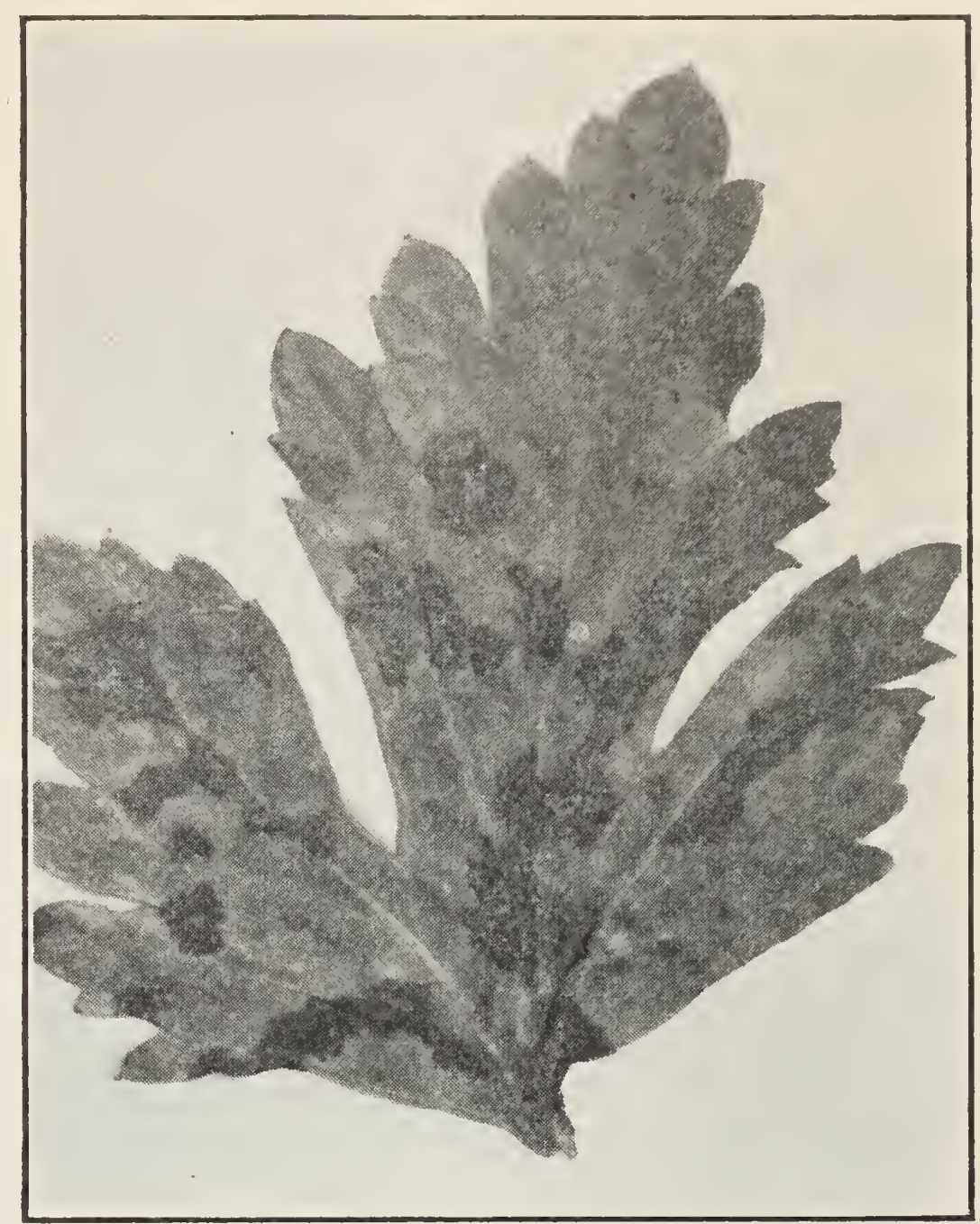

FIG. 39.-Winter blight of celery (Septoria petroselini).

growth of the plant, from the seed bed up to maturity, whenever there is much moisture in the air.

See Bulletin 208, California Experiment Station.

Stem Rot (Sclerotinia).

Causes a reddish, soft decay of the stalks.

Root Rot (Fusarium).

A decay of the roots. Both this and the last occur only when the land is wet and heavy and the plants growing poorly. Neither is common nor serious.

\section{CHERRY.}

Brown Rot (Sclerotinia fructigcna). See Apricot.

Root Rot. See Almond.

Gummosis.

The cherry, like other stone fruit trees, is very subject to gumming of the trunk and branches, as a result of any injury. In seasons of heavy rains during the spring cherry trees frequently show a trouble 
of this sort quite similar to that of citrus trees. Masses of gum break out on the trunk and the trees frequently die. Young trees are sometimes affected much like citrus trees, the gum breaking out just at the surface of the ground. This is a climatic or seasonal effect and can not be controlled. 'Trees on wet ground usually show the trouble worst. This is especially true with young trees which have been planted too deeply.

\section{DIE-BACK.}

Cherry trees, while not attacked by many fungus diseases in California, are very subject to injury from unfavorable conditions of soil, moisture, etc. As a result of such injuries the trees frequently die back from the top and suffer severely in this way.

This trouble can be controlled only by planting on soil which is particularly suited to the cherry and by determining the best root stock for any given type of soil or locality.

Trees in which die-back and gummosis are produced by unusual climatic conditions should be cut back in the top to sound wood, and have the trunks protected from sun burn by whitewash or wrapping.

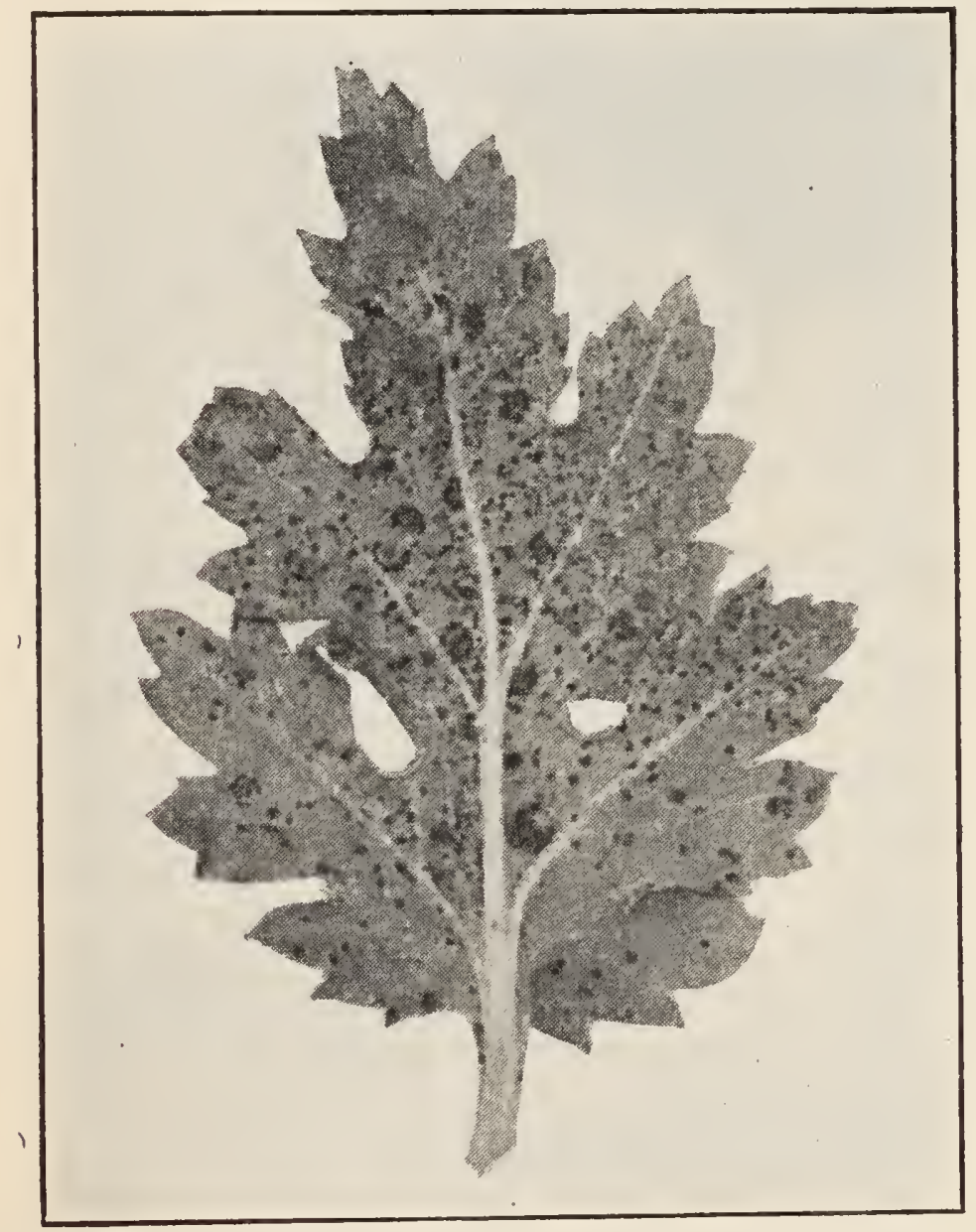

Fig. 40.-Chrysanthemum rust (Puccinia chrysanthemi).
Fruit Drop. See Almond.

CHRYSANTHEMUM.

Rust (Puccinia chrysanthemi). Figure 40.

A true red rust causing injury to the growth of the plants with the production of powdery spore masses on the leaves. Only serious with us when the plants do not receive sufficient water. Vigorously growing plants which are well irrigated do not suffer from this trouble.

\section{CORN.}

Syut (Ustilago maydis).

Produces large, tumorlike swellings on the ears, stalks or tassels. These finally break and discharge

their contents in the form of a black, powdery dust which is chiefly composed of the spores of the fungus. Not seriously abundant. 


\section{Rust (Puccinia sorghi).}

A powdery, red rust on the leaves. Not serious.

MoLn (Diplodia $\approx C(x)$.

The corn becomes moldy and covered with fungus growth in the ear. Quite common in this State on moist land. Affected ears should be destroyed.

\section{COTTONON.}

\section{Ror.t Rot.}

The seed and a part of the lint are affected with a soft decay while the bolls are still green.

Cause unknown. Possibly bacterial. Noticed for the first time in Imperial Valley in 1910.

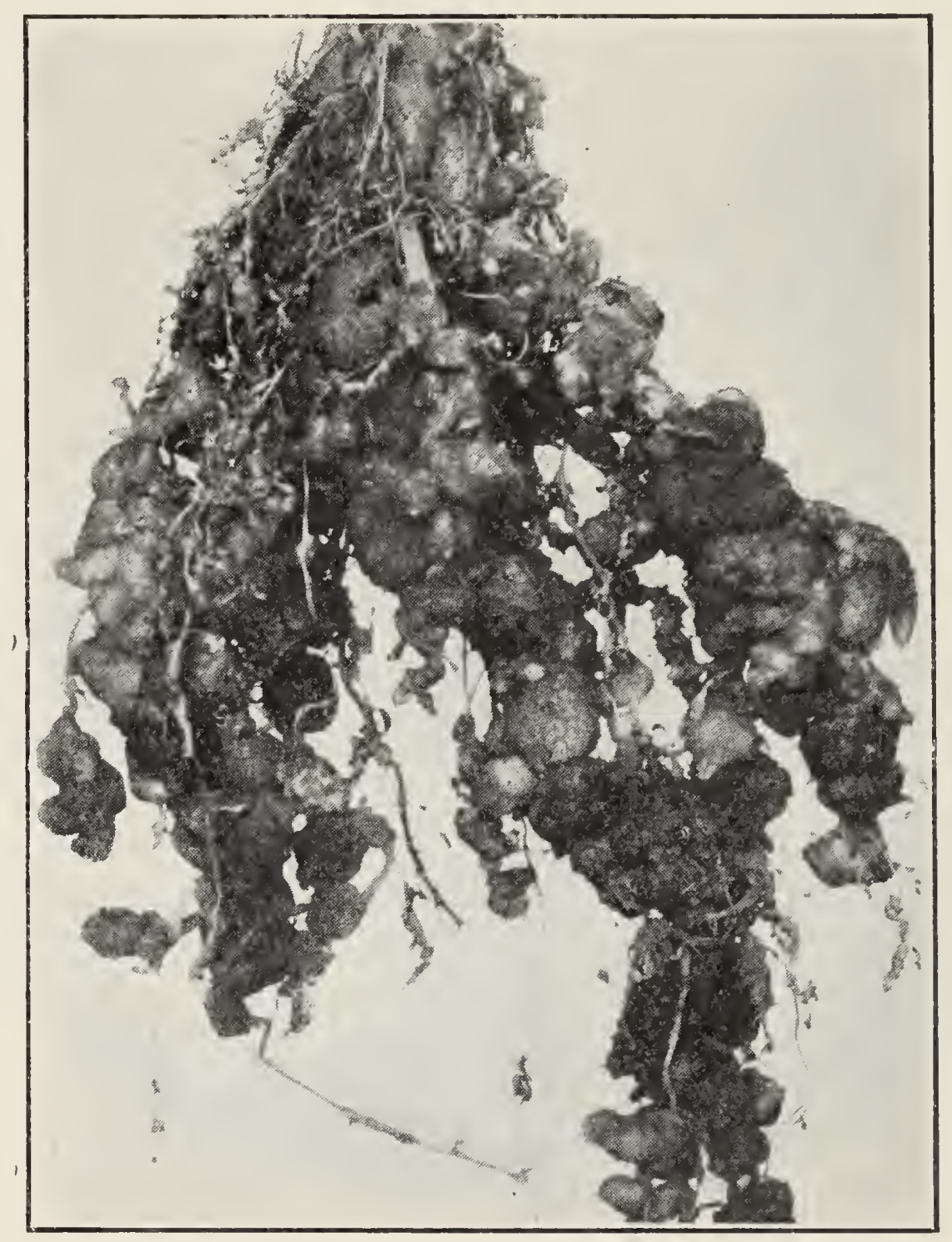

FIG. 41.-Nematode galls on cucumber root.

\section{CUCUMBER.}

MILDEw (Erysiphe cichoracearum).

A white fungus growth all over the surface of the leaves. Not serious.

STEM Rot (Sclerotinia libcrtiana).

This dry rot of the stem and root has been found on plants growing in greenhouses. Not serious except under such circumstances. Use fresh, unaffected soil. 
Root KNoт (Nematode). Figure 41.

Causes swellings all over the main and smaller roots. Found only in greenhouses. See page 1076.

Control as in Stem Rot.

\section{IeAF SPOT (Altemaria brassica, var, nigrescens).}

This fungus has been known to do considerable damage in a few cases, causing large dead spots, later covered with the black fruiting fungus.

Not important as yet.

Can be controlled with Bordeaux mixture.

CURRANT.

MILDEW (Sphacrotheca mors-uve).

A white, powdery mildew on the leaves and fruit.

Dust with dry sulphur while the leaves are wet with dew, if treatment seems necessary.

\section{DAHLIA.}

\section{MILDEW.}

A white, powdery mildew on the leaves. Not serious.

Treatment as for currant mildew.

DEWBERRY. See Blackberry.

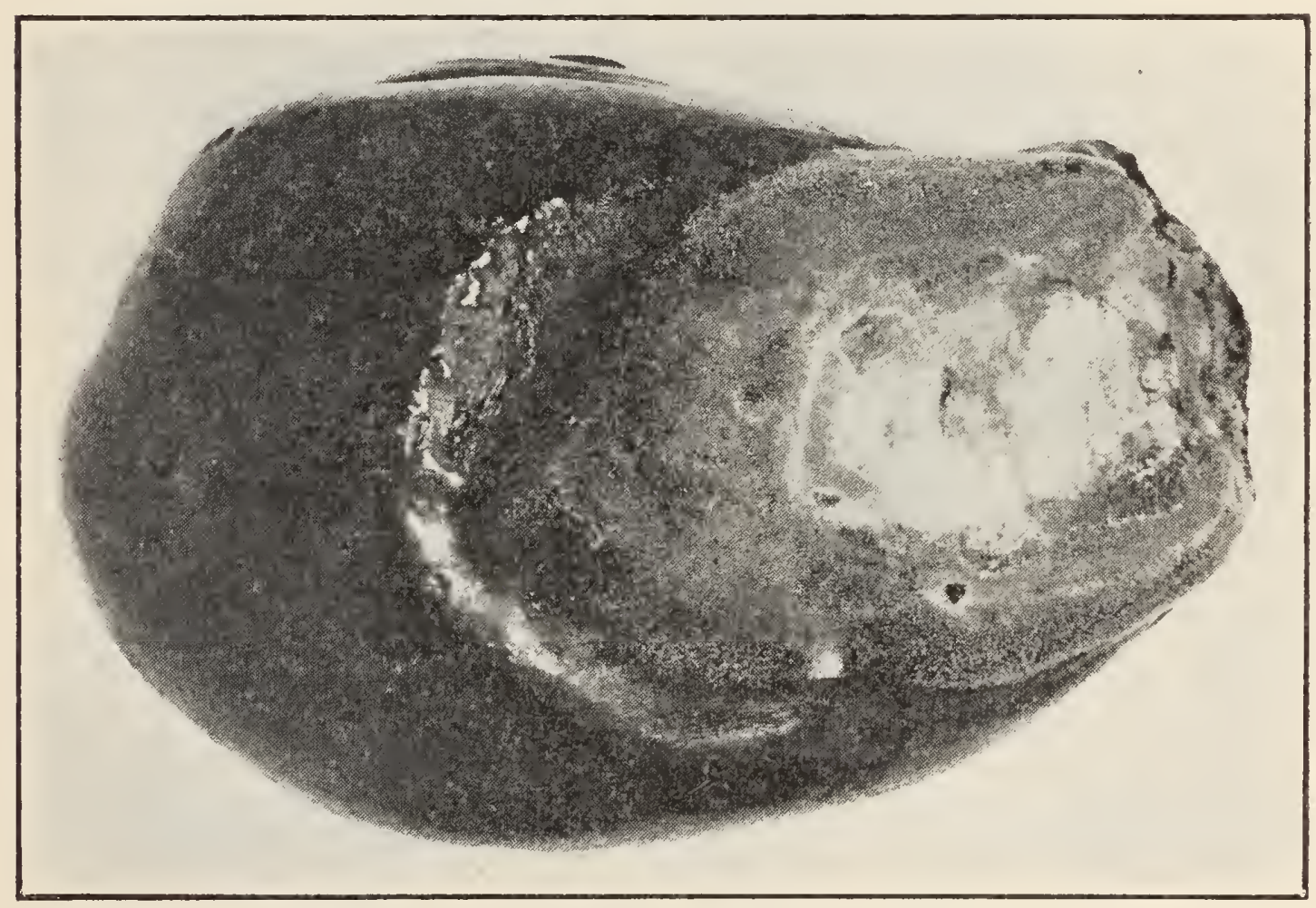

FIG. 42.-Fruit rot of egg plant (Botrytis vulgaris).

EGG PLANT.

Rot (Botrytis). Figure 42.

A moldy decay of the fruit. The fungus mentioned has a grey, dusty appearance. Not serious. 
Wilt-Stenr Rot (Nectria ipomoew).

This fungus causes a dry rot of the stem and root. Usually occurs only on old plants in which the stem has been injured.

Do not plant in affected soil if the trouble is serious.

\section{EUCALYPTUS.}

\section{DAMPING OFF.}

Causes great losses by a stem rot and dying of the young plants in the seed bed.

Sow the seed in clear sand, transplanting to better soil as soon as the seedlings are large enough to handle. Keep as dry as possible without checking the growth seriously.

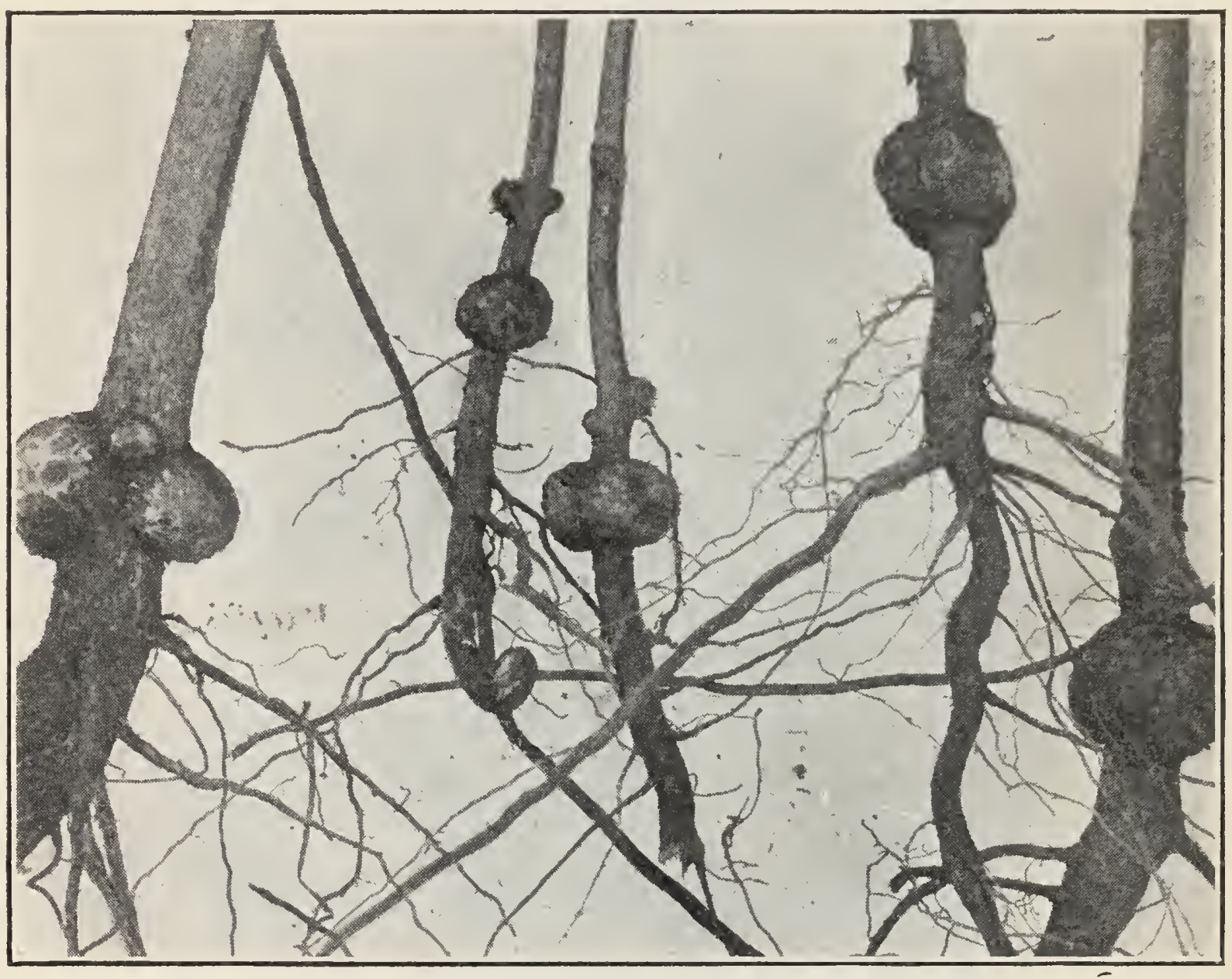

FIG. 43.-Crown gall of eucalyptus.

Water only in the morning and as little as possible on cloudy days. MILDEW.

A powdery mildew has been known to occur on seedlings, but is not of general occurrence.

Treat with dry sulphur as for other mildews, after destroying badly affected plants. Observe precautions as for damping off with regard to water.

\section{LEAF SPOT (Hondersonia sp.).}

Sometimes seen on the blue gum (Eu. globulus), causing dead spots on the leaves. Not serious. 
Crown Gall. Figure 43.

The seedlings of some species frequently develop gall-like swellings. on the stem near the surface of the ground. This condition does not seem to be particularly injurious. Cause unknown. Possibly a normal condition.

GRAPE.

Mundew (Uncinula spiralis). Figure 44.

A white powdery mildew on the leaves and fruit clusters.

Dust thoroughly with flowers of sulphur in moist weather before the fungus develops extensively. See Bulletin 186, California Experiment

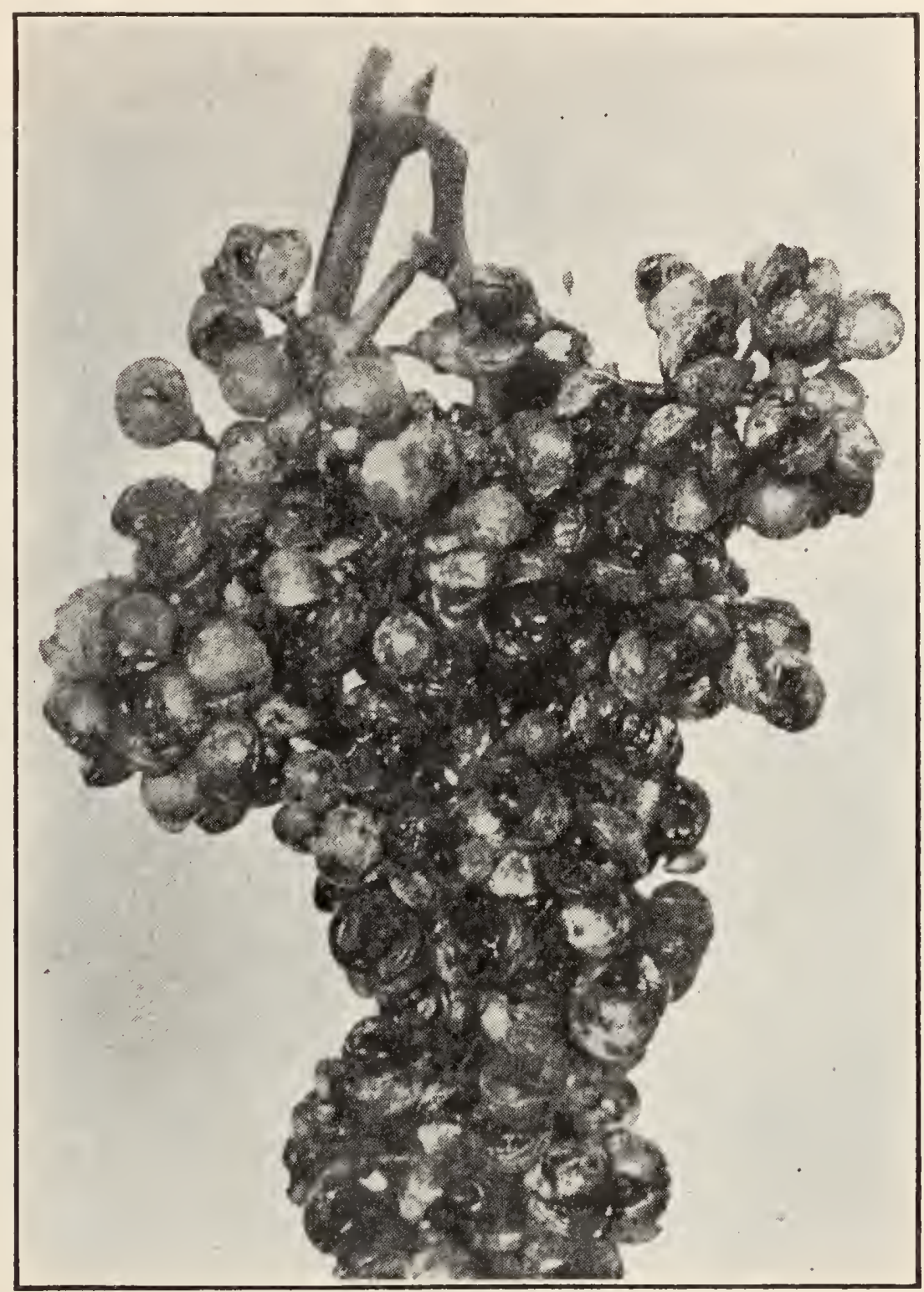

FIG. 44.-Powdery mildew of grape (Uncinula spiralis).

Station. On account of the importance of this disease, we quote as follows from California Experiment Station Bulletin 197:

"The most common mistake of those who have attempted to follow the directions of the bulletin (186) has been a failure to treat the vines. thoroughly or rapidly enough in the beginning of the season. It can not be too strongly urged that the most effective way to control the mildew is by a thorough and effective sulfuring in the beginning of the season. This alone will in most parts of the State keep the vines free, 
and the sulfuring during the blossoming is needed only for its effect on the setting of the fruit, and as an extra precaution. Sulfuring later, if needed, is a proof that the first two have not been well done. This is true for the whole of the two central valleys and for most of California, except the coast belt subject to summer ocean fog.

"Definition of a Thorough and Effective First Sulfuring. -The first sulfuring should be made when the shoots are between 6 and 15 inches long. It should be done in such a way that every part of every leaf of every vine in all parts of the vineyard receives some sulfur, and the whole vineyard should be gone over in as short a time as possible. This will be a thorough sulfuring. To be effective, it must be followed immediately by two or three days of warm weather. Unless this happens, the sulfuring should be repeated as many times as are necessary until the proper weather conditions are obtained."

Black Кіnot. Figure 45.

(California Experiment Station Bulletin 197): "This is one of the commonest and most widely distributed diseases of the vine in California.

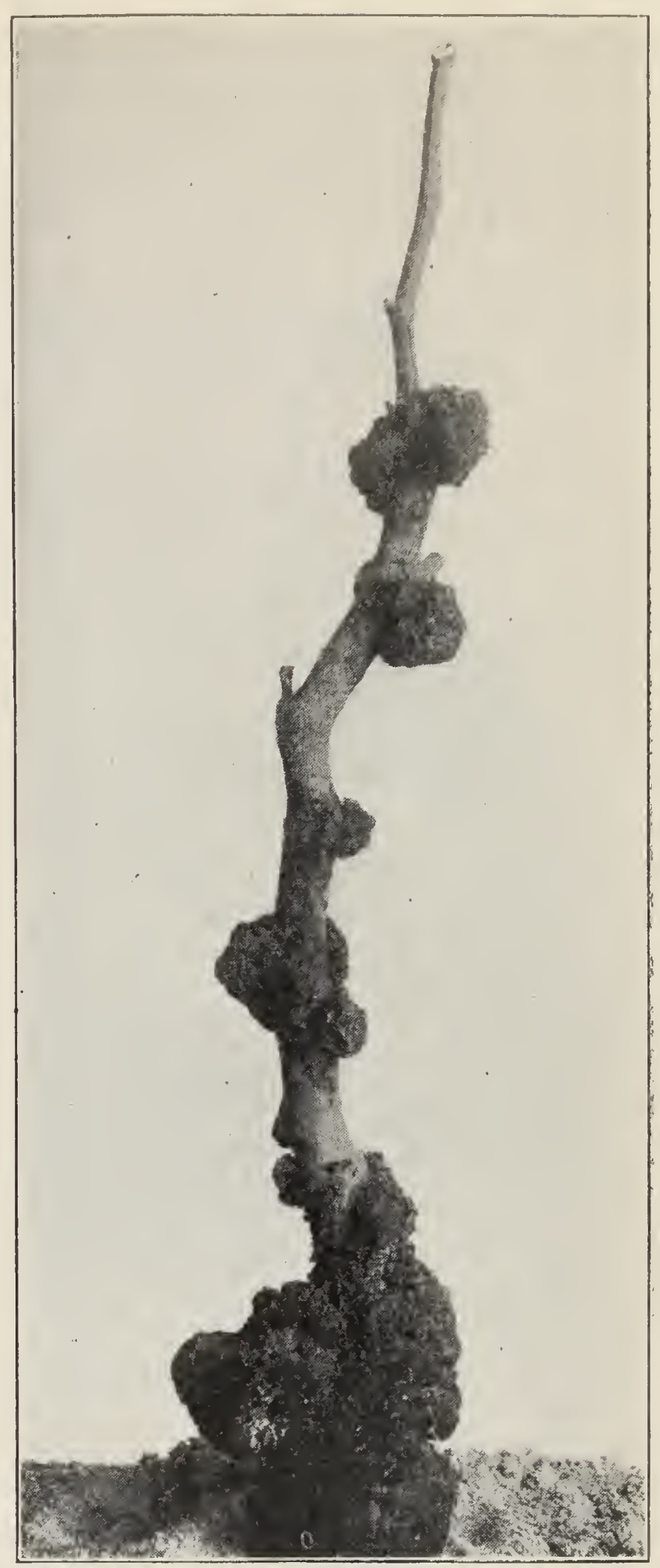

FIG. 45.-Black knot of grape (Bacterium tumefaciens).

Many specimens are received by the Experiment Station every year, from nearly all vine-growing sections. It consists of peculiar growths, or swellings, usually near the surface of the ground on the upper parts of the roots or the lower part of the trunk. It often occurs, also, on all parts of the trunk and branches, but only rarely on the canes.

"As a rule it does little damage unless it occurs on young vines, or attacks old vines very severely. Figure 45 is a photograph of a young 
vine very badly attacked, showing a large mass of knots at the surface of the ground, and four on the stem above the surface. Such a vine is almost girdled and could never develop into a healthy plant. In some cases where the knots oceur on a branch or arm they could be removed and the vine might recover perfectly.

"It is not uncommon to find vines with large masses of knots on all sides of the trunk and on all the arms, which yet make a vigorous growth and produce good crops. When the knots extend all around

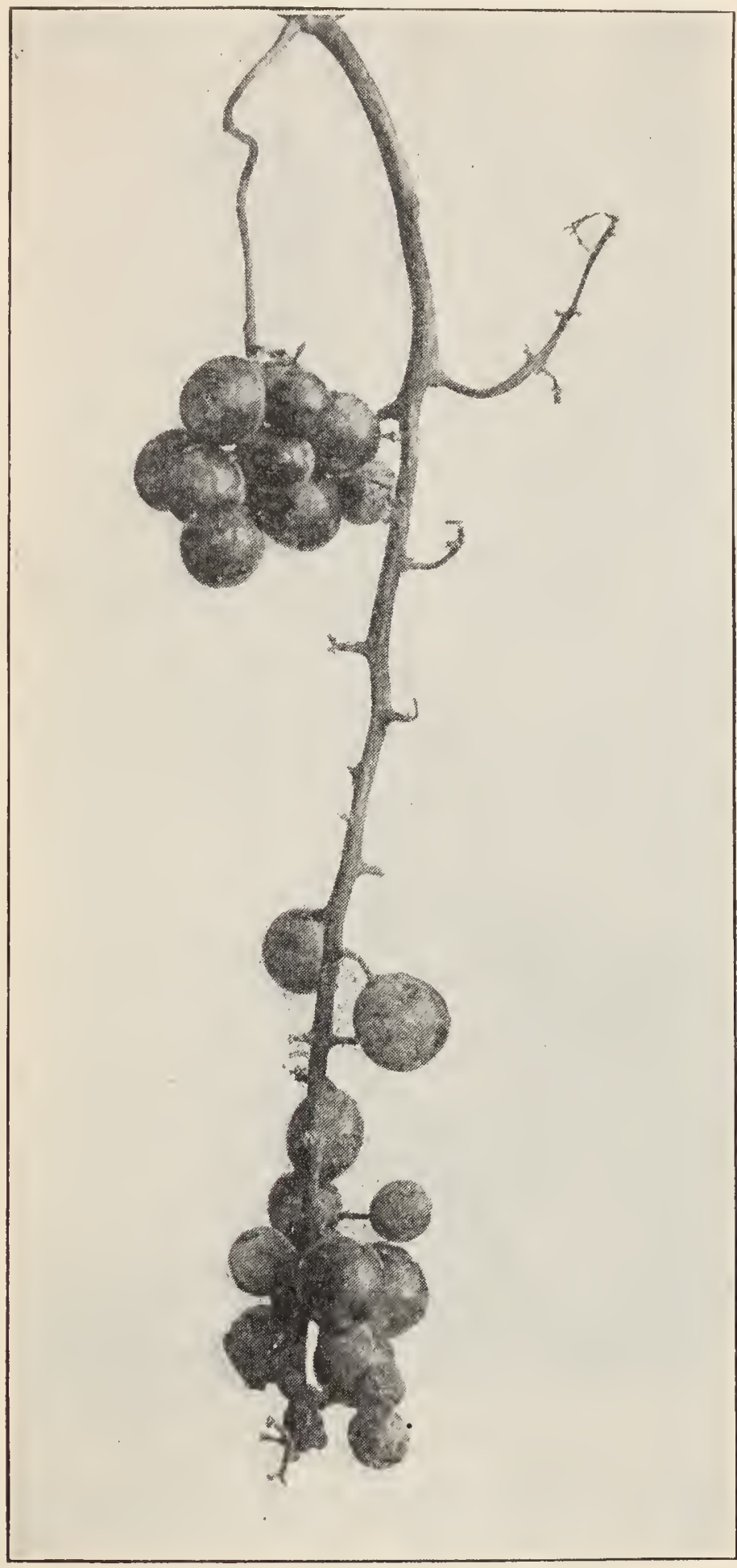

Fig. 46.-Coulure disease of the vine. the trunk of an old vine, however, it may be girdled, and, while it seldom dies, it may become weak and worthless.

"Various theories have been advanced as to the cause of this disease, but the most commonly accepted is that it is due to abrupt changes of temperature, and especially to autumn frost occurring before the vine has become thoroughly dormant. This cause alone, however, does not seem to be sufficient to cause the disease. The knots appear only on vines growing in moist places, and especially in sandy soil in the hotter regions.*

"Anything which causes a vine to grow vigorously late in the season and prevents the proper ripening of the wood, renders it susceptible to the disease.

"In accordance with these ideas, the remedies advocated aim at causing the vine to ripen its wood early and completely. These remedies are drainage of the soil, fertilization with phosphatic manures, longer pruning, raising the trunk of the vine, and removal of the knots. Swabbing with lime, sulfate of iron, and other antiseptics has proven useless."

* It is now known to be due to an infection by the crown gall organism, Bacterium tumefaciens. 
COULURE OF MUSCATS. Figure 46.

(California Experiment Station Bulletin 197): "The Muscat of Alexandria, from which the bulk of our raisins is made, has a tendency to drop its blossoms without setting. 'This trouble is usually known in California by the French term of 'coulure,' which may be translated 'dropping.' The first crop is particularly subject to this defect, which is often so serious that a large part and sometimes the whole of the first erop is lost."

This trouble is due to a failure of pollination of the blossom. The author recommends as a remedy planting occasional rows of other varieties with the Muscat. For this purpose the Palomino, Perruno, Beba and Berger are suggested.

\section{MISCELLANEOUS DISEASES.}

The grape is affected in California by several miscellaneous and peculiar diseases, most of which are not very clearly defined. Some of these have received the names Anaheim Disease, Red Leaf, Little Leaf and other local names.

The first named, also called the California Vine Disease, was of the greatest importance a number of years ago when almost all the vineyards in southern California died from a mysterious trouble which received this name. Although carefully investigated at the time by Professor Newton B. Pierce, at that time of the United States Department of Agriculture, no definite cause of this disease was ever discovered. At present vines are occasionally affected with something which might pass for the same disease, but it is difficult or impossible even for the experienced plant pathologist, save, perhaps, one who was familiar with the Anaheim disease at the time of its first and greatest period of prevalence, to say just what is really Anaheim disease and what is one of the various troubles which have received other names. So little is understood about these vine diseases at present that it is scarely worth while to attempt to discuss them in a publication of this sort. We quote as follows from California Experiment Station bulletin 197:

Mysterious Dying of Vines (Anaheim Disease).-The vine, like most plants. especially fruit trees, which are cultivated on a large scale, is subject to diseases of more or less intensity whose cause is not thoroughly understood. These diseases are (1) caused by parasitic organisms which have so far escaped detection, or (2) what is usually known as "physiological."

Physiological diseases are presumably due to some unfavorable conditions. For example, chlorosis, or the failure of the leaves to develop chlorophyll properly, is due to an excess of soluble lime carbonate in the soil, and is intensified by cold, dampness and the susceptibility of the variety.

The most serious of these two classes of diseases, which affects the vines, is the Anaheim, or, as it is sometimes called, the California Vine Disease. Notwithstanding that it has been the subject of continuous investigation for over fifteen years its cause is still quite obscure. Even the characterization and detection of the disease are so uncertain that vineyards, which after several years of observation by the most 6-BUL. 218 
experienced investigators have been pronounced infected, have later been declared free. This has led to such a diversity of opinion that while one expert claims that the disease exists in every vineyard in the State, another would have us believe that wo such disease exists at all, and that all cases of dying vines can be ascribed to one or other of the recognized vine diseases.

Neither of these extreme views seems to explain completely the observed facts. While many cases of supposed Anaheim have proved to be nothing but Phylloxera, root-rot, vine-hopper, drought, etc., there still remain a large number of unexplained cases.

In some cases the symptoms are practically identical with those of some of the "physiological" diseases which affect the vine in Europe. Typical cases of Rougeot have been noted in Contra Costa County, of Brunissure in San Joaquin, and of Folletage in Fresno, Kings, and other counties. In Sonoma County the disease of Red-leaf, which has some analogy with Anaheim, has been studied by Mr. O. Butler. An account of these diseases may be found in Bulletin 168, entitled "Observations on Some Vine Diseases in Sonoma County."

In a general way, as these troubles are due to soil and climatic conditions which weaken the vine, they are to be combated by cultural methods which tend to invigorate. Shorter pruning, thorough cultivation, irrigation or drainage, and fertilization will in most cases be effective in curing vines which are not too far gone.

Many cases have been brought to the attention of the station during the last two years, in which vines which were apparently healthy the previous year have failed to bud out in the spring, or budded out weakly and very late. The cause, in most cases, seemed to be some injury to the vines during the growing season of the previous year. This cause was in many cases the attacks of vine-hoppers. Black Prince vines growing in Tokay vineyards have very often been killed. This seems to be because the vine-hoppers, having a special fondness for this variety, congregate in large numbers on such isolated vines. Whenever the hoppers are sufficiently abundant to cause the dropping of the leaves in summer, the vine fails to ripen its wood properly. Without mature green leaves the buds and canes do not receive the stores of starch which they need for the new growth in spring, and will either grow poorly the following year or fail to start at all.

When a new growth of leaves in autumn follows summer defoliation by hoppers, mildew, or other causes, the effect is even worse. The new shoots which start exhaust what food reserves the vine possesses, and the leaves are killed by the early winter frosts before they have been able to return the supplies they have taken from the canes. Similar, but less severe, effects have been observed following a bad attack of mildew.

This starvation of the canes and buds may be brought about in another way, namely, by the production of too large a crop. It is often possible, by excessively long pruning, to cause a vine to produce an abnormally large crop of grapes. The larger the crop the more material it takes from the vine, and if too large, the vine is unable to support it and at the same time lay up reserve materials in its canes and buds. In consequence, an extra large crop is often followed by weak growth in the spring, and a consequent small crop the following autumn. Vines of heavy kearing varieties may even be killed in this way, by repeated long pruning.

This fact has been long recognized by practical grape-growers. Lately, Professor L. Ravaz,* of the National School of Agriculture at Montpellier, France, has advanced the opinion that the death of vines, as a consequence of overbearing, is much commoner than is usually supposed. This overbearing may occur as a consequence of various conditions other than long pruning. Some seasons are peculiarly favorable to heavy crops. Certain diseases and injuries induce temporary heavy bearing. Whatever the cause of abnormally heavy crops, Professor Ravaz believes that they may result in the death of vines. This is the explanation he gives of the death of large numbers of vines in southern France, Algeria, and other countries, and he ascribes our so-called Anaheim disease to the same cause.

This is substantially the explanation given of the dying of vines in Santa Clara,

* "Influence de la surproduction sur la Vegetation de la Vigne," by L. Ravaz, Coulet et fils, Montpellier, 1906. 
in Bulletin 134, which was published before the region was declared infested by Anaheim disease. Whether this explanation is sufficient is still doubtful, though it is rendered probable by the fact that healthy young vineyards are now growing in Santa Clara, on the same soil where vines have been killed by Anaheim disease.

\section{GRAPE FRUIT. See Orange.}

\section{GUAVA.}

RUSSETING.

In this trouble the surface of the fruit shows a scabby condition indicated by the above name. Thought to be caused by an insect.

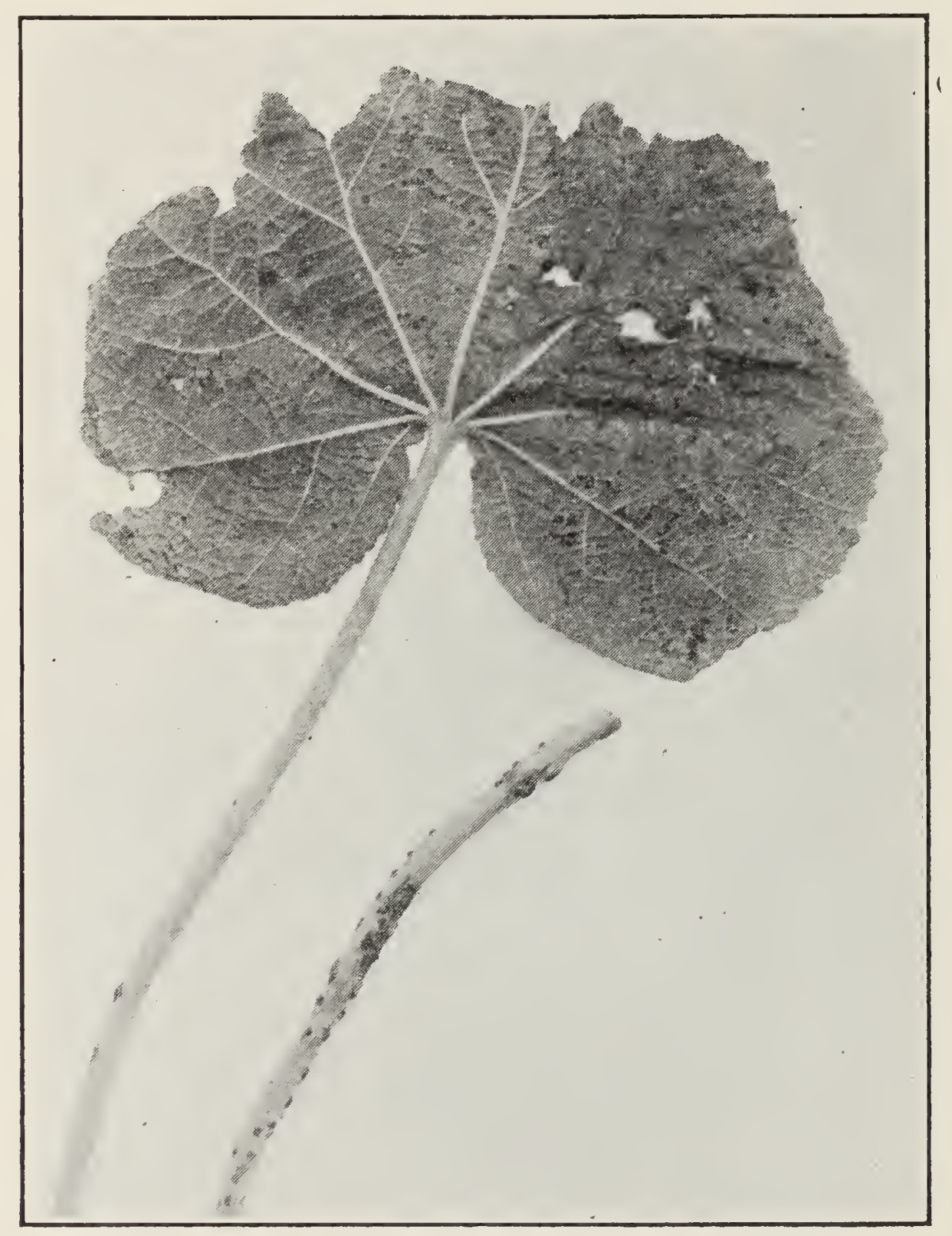

FIG 47.-Rust of hollyhock (Puccinia malvacearum).

\section{HOLLYHOCK.}

Rust (Puccinia malvacearum). Figure 47.

In this disease the fungus injures the leaves seriously, becoming visible in the form of numerous small pustules of spores on the under side. These pustules are dense and compact rather than dusty as in most rusts. The wild mallows are affected with the same fungus. Hollyhocks grown in rich soil with an abundance of water are much less affected than those which lack moisture. 
Irrigating and fertilizing abundantly will control this disease.

Spraying with Bordeaux mixture and other fungicides is sometimes resorted to, but this treatment is not very satisfactory.

IRIS.

Leak Spot (Heterosporillm gracile). Figure 48.

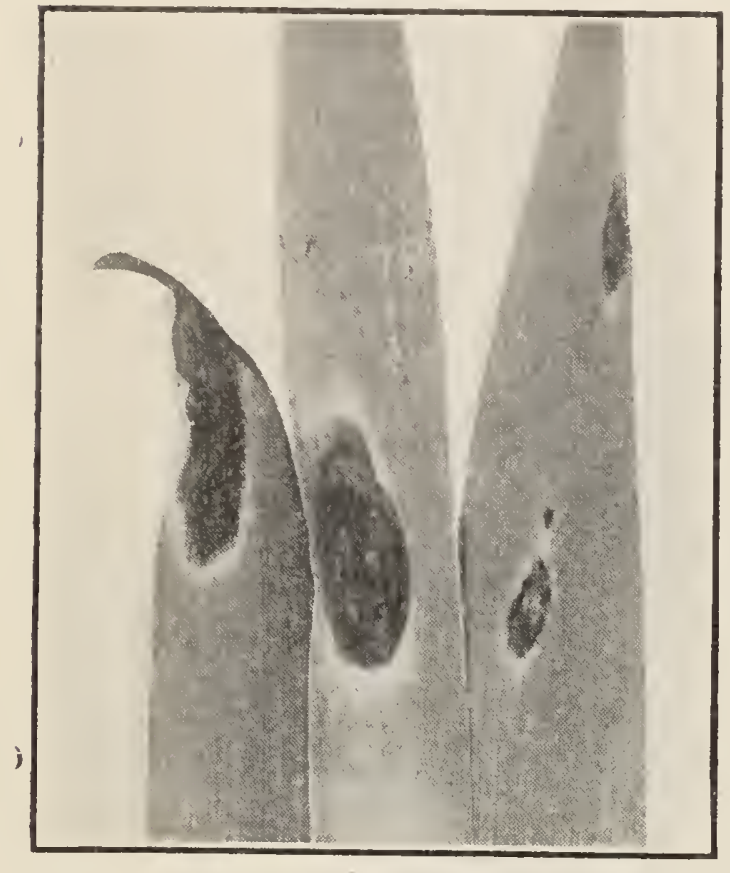

FIG. 48.-Leaf spot of iris (Heterosporium gracile).

Large, elliptical dead spots appear on the leaves, with a yellow margin between the dead and the green tissue.

Quite disfiguring, but no treatment ordinarily considered necessary.

LEMION.

Gunirosis. Figure 49.

Characterized by the exudation of gum from the trunk of the tree just above the point of budding. The tree appears yellow and dies when badly affected. Occurs on poorly drained, heavy soil, especially if the point of budding is deeply covered with earth and where the soil about the trunk is undisturbed by cultivation. This

trouble is more common on lemons than on oranges.

Gumming is a characteristic of the citrus tree when affected by any injurious condition. Frequently, for instance, when trees have been extremely dry and suffering from a lack of moisture gum will break out at the crotches or twig axils when an abundant supply of water is furnished. If the twigs in this or any other manner are caused to die back for a short distance gum is very likely to exude after irrigation at the point where the dead portions of the twig join the live tissue. Any injury or irritation may have the same effect. When citrus trees are budded, either in the nursery or in the case of orchard trees, gumming often occurs at the point of budding, particularly if a large supply of moisture is furnished soon after the budding is done. Many buds are often killed in this way as a result of rain or irrigation. Such effects as these are not usually very serious, except that in the case of budding the process may have to be repeated.

Orange or lemon nursery trees one or two years of age sometimes gum badly just above the point of budding from no very apparent cause. As a result of such gumming the cambium layer is killed and if the injury is extensive the tree may die. In the majority of cases, however, if the trees are affected on only one side and planted and cared for properly, they make a complete recovery and after a year or two the injury disap- 
pears. These cases probably start in the majority of instances from an excessive flooding of the soil with water, put on either while the trees are growing to force them along or just before they are dug in order to assist the operation of "balling." Trees affected in this way when received for planting should not be looked upon as having any serious contagious disease, but the buyer should simply discard those in which

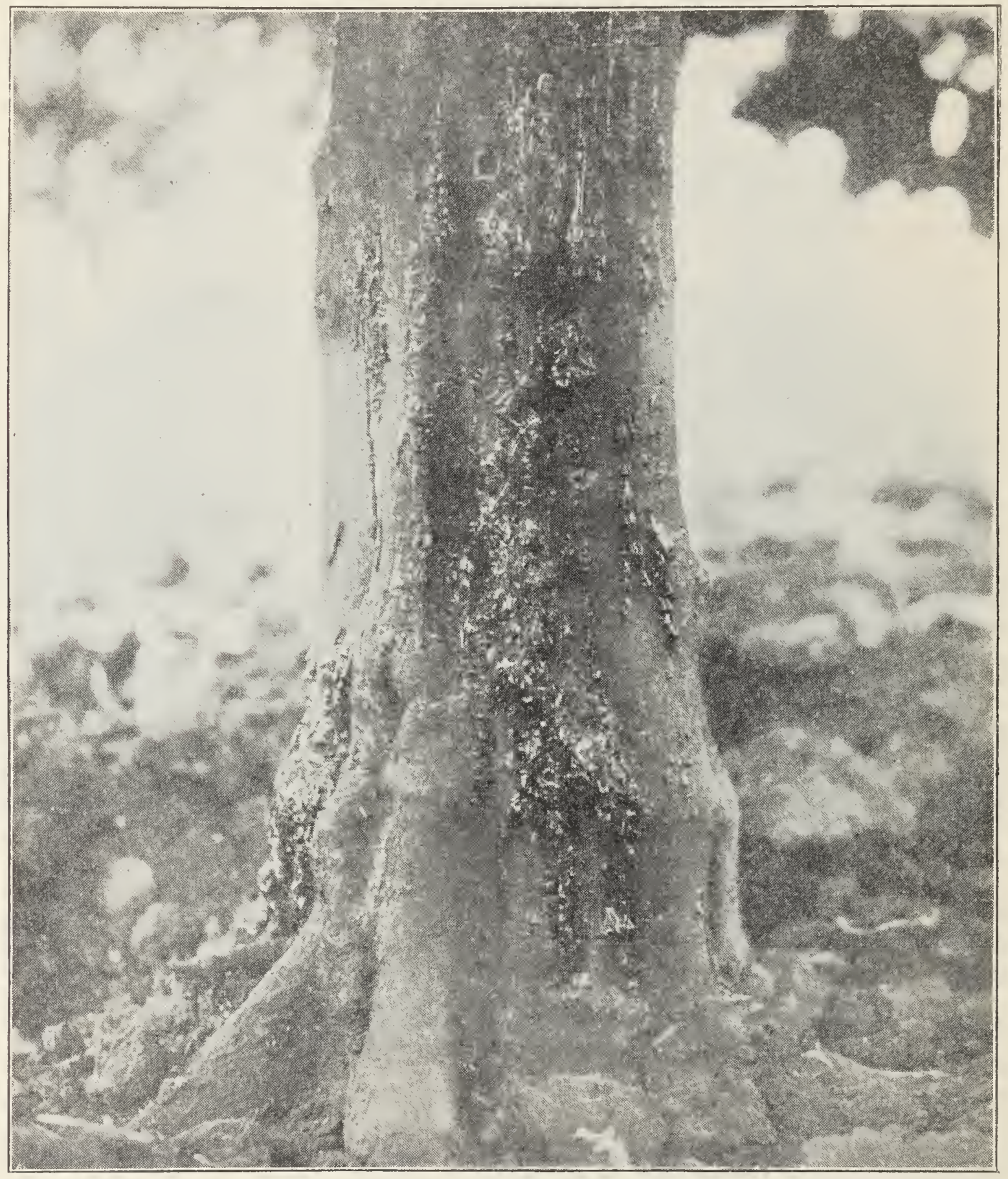

FIG. 49.-Gum disease of lemon.

the inner bark is badly affected and notify the nurseryman of the number of trees found in this condition. If the trees have once been planted and then die or fail to grow it is impossible to decide whether the gumming took place before or after the trees were planted.

In order to successfully control gum disease in orchard trees, soil conditions must first of all be improved by securing drainage, removing 
soil from about the bud and thoroughly cultivating or digging about the tree. Water must not be allowed to stand about the trunk or the soil remain continually saturated. After thus improving conditions, the tree itself may be treated by taking out narrow slits of bark on several sides of the trunk, extending from the ground up to the fork. These slits shoukd pass through the gummy portion and also the unaffected bark. This will usually suffice to effect a cure if taken in time and if soil conditions are sufficiently improved.

For further treatment see Bulletin 200, California Experiment Station.

Brow Rot (P'ythiacystis citrophthora). Figure 50 .

A very virulent form of decay spreading rapidly through the boxes from fruit to fruit. Affected specimens show a brown, rather dry decay

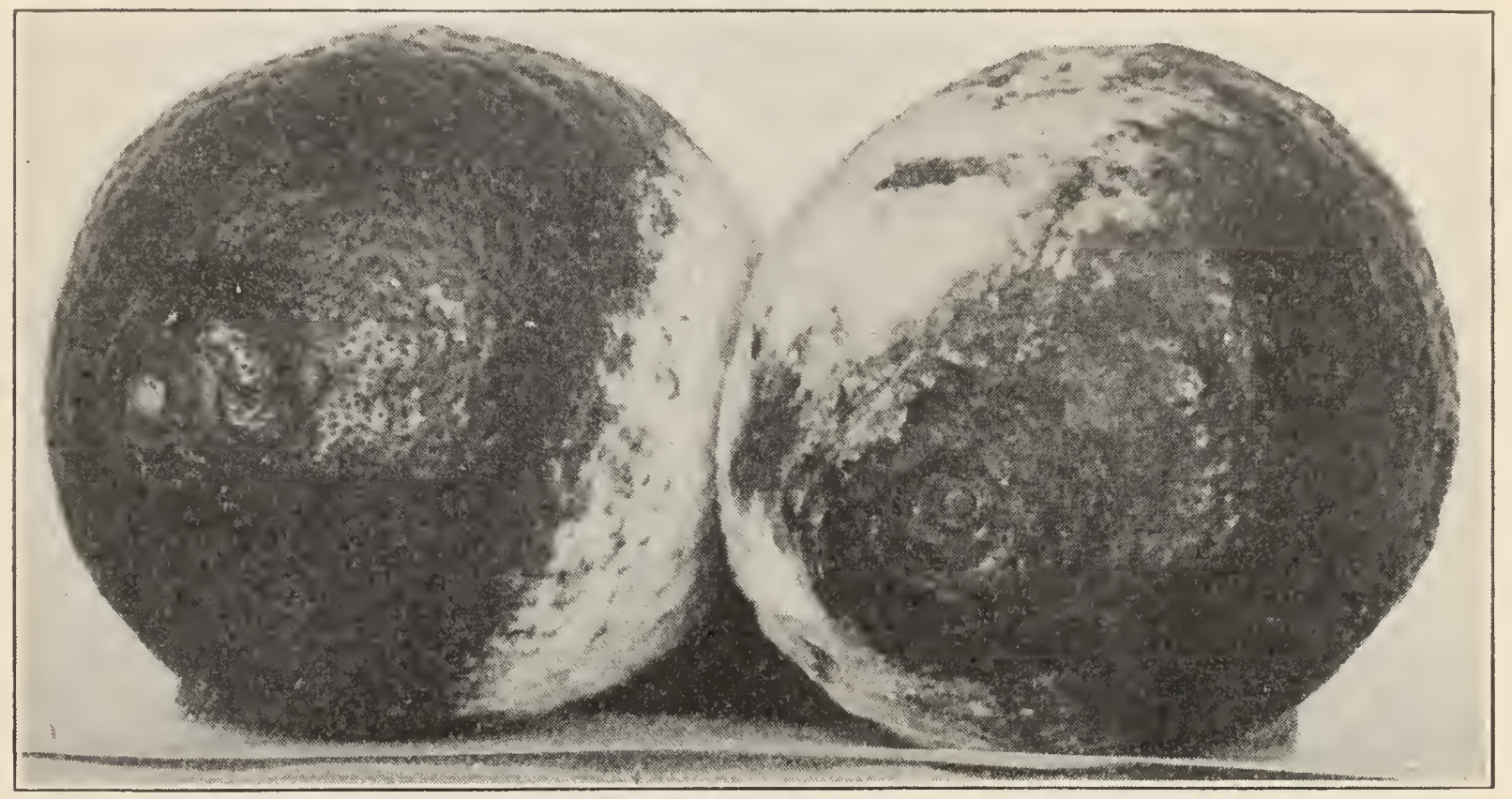

FIG. 50.-Brown rot of lemon (Pythiacystis citrophthora).

of the rind upon which a delicate, scanty white mold develops when considerable moisture is present. Fruit out in the open shows no mold on the surface. Affected fruit has a peculiar odor which is very characteristic. Mostly seen in lemons held in storage for curing. In wet weather this decay often appears on the fruit while still on the tree, but it is mostly confined to that within two feet of the ground. The disease affects all kinds of citrus fruit in this manner.

The fungus which causes this trouble is primarily a soil inhabitant, living naturally in the ground beneath the trees where its spores are produced.

Orchard infection is prevented by keeping the trees pruned up somewhat from the ground, cultivating the soil under the trees in summer and covering it in winter with straw or a green cover crop. Spraying the ground under the trees in winter with thick Bordeaux mixture is also helpful. The worst infection, that of lemons in storage, is con- 
tracted in the tank of the washing machine where the water becomes extremely infectious from the presence of spores brought in with the orchard soil and dust. This is easily controlled by disinfection of the wash water with copper sulphate.

See Bulletin 190, California Experiment Station.

Cottony Mold-White Rot (Sclerotinia libertiana). Figure 51.

Causes decay of the fruit in the curing house with the production of an abundant white mold spreading over the lemons. In this mold

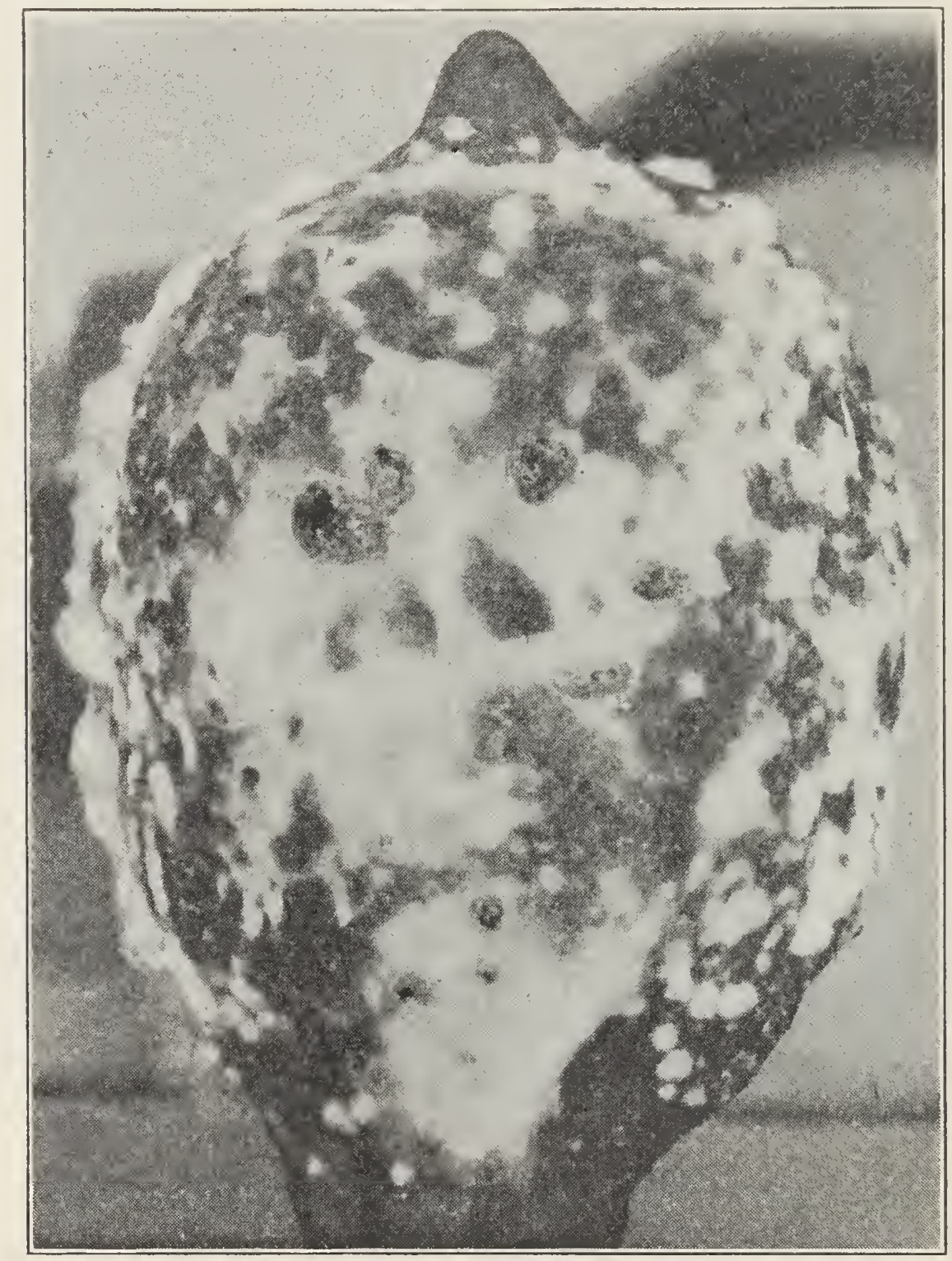

FIG. 51.-Cottony mold of lemon (Sclerotinia libertiana).

are found irregularly-shaped, black, seed-like bodies called sclerotia from which another stage of the fungus develops. The same fungus also develops in the orchard soil during the rainy season and often becomes very abundant upon green-manure crops or other vegetation growing about the lemon trees, particularly upon the vetch. The sclerotia develop upon green-manure crops or directly upon the soil, the latter during the rainy season, and out of them grow little funnelshaped toadstool-like bodies which give off the spores of the fungus. 
The fungus is not actively parasitic and it has been found difficult to infect lemons with its spores save when they are injured or bruised in some way. They also require considerable moisture for infection. Experiments have shown that almost all the infection takes place at the stem end of the lemon where it is cut from the tree, and practically all, it is probable, in the washing water, except in the case of fruit allowed to stand out in the rain for some time, when infection may take place.

Cottony mold sometimes develops to a considerable extent in packing houses where the fruit is being washed in bluestone solution to prevent brown rot, from which fact it appears that a strength of this substance

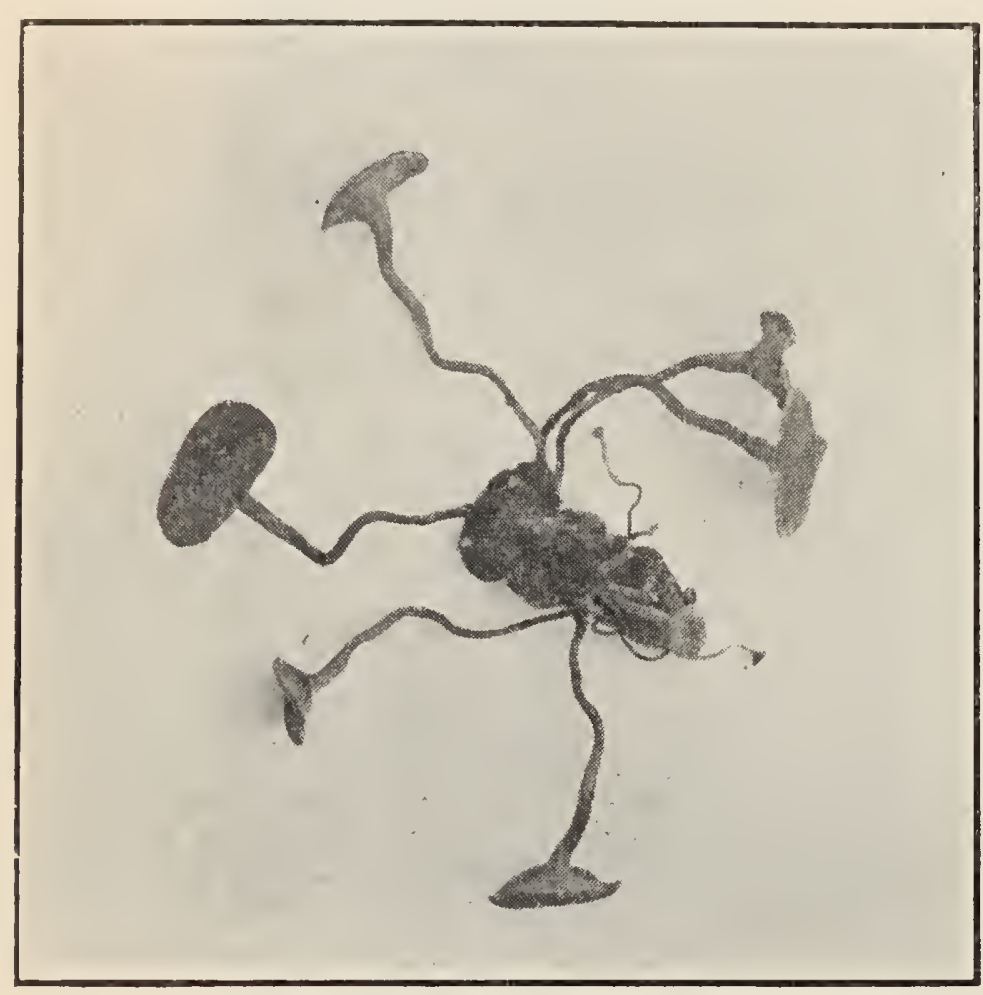

FIG. 52.-Peziza developing from sclerotium of cottony mold fungus (Sclerotinia libertiana). which kills brown rot spores does not kill those of the cottony fungus. Laboratory tests have shown this to be a fact. The control of cottony rot, therefore, depends upon either using the germicide stronger than that used for brown rot or finding means for preventing the development of the fungus in the orchard. Along the former line we may say that it is not safe to use bluestone in the wash water much stronger than it is now being used in many houses for brown rot control; a strength of $1 / 50$ of one per cent, or about $1 \frac{1}{2}$ pounds of bluestone to 1,000 gallons of water. This would mean putting in about the quantity of bluestone stated into a 1,000gallon tank in the morning and fortifying this with about one pound more in the afternoon, after considerable wash water has entered the tank. The question of the strength of bluestone in lemon wash water depends to a large extent upon the quality of the water used as to its alkali content, since the alkali salts neutralize the copper sulphate. This whole question of disinfecting lemon wash water is now being investigated at the Whittier Laboratory.

In regard to orchard control of this trouble, we may say that the cottony mold has had a very marked prevalence since the use of vetch as an orchard cover crop became so general. There is much ground for believing that these facts are related to one another, cottony mold 
having become more abundant on account of the opportunity given for its development in the orchard by the presence of the vetch plant, upon which it develops particularly well. We are by no means ready to advocate the discontinuance of cover crop practice in lemon groves for this one reason, although it may be said that other factors are developing in actual practice which make the growth of such a crop in a lemon

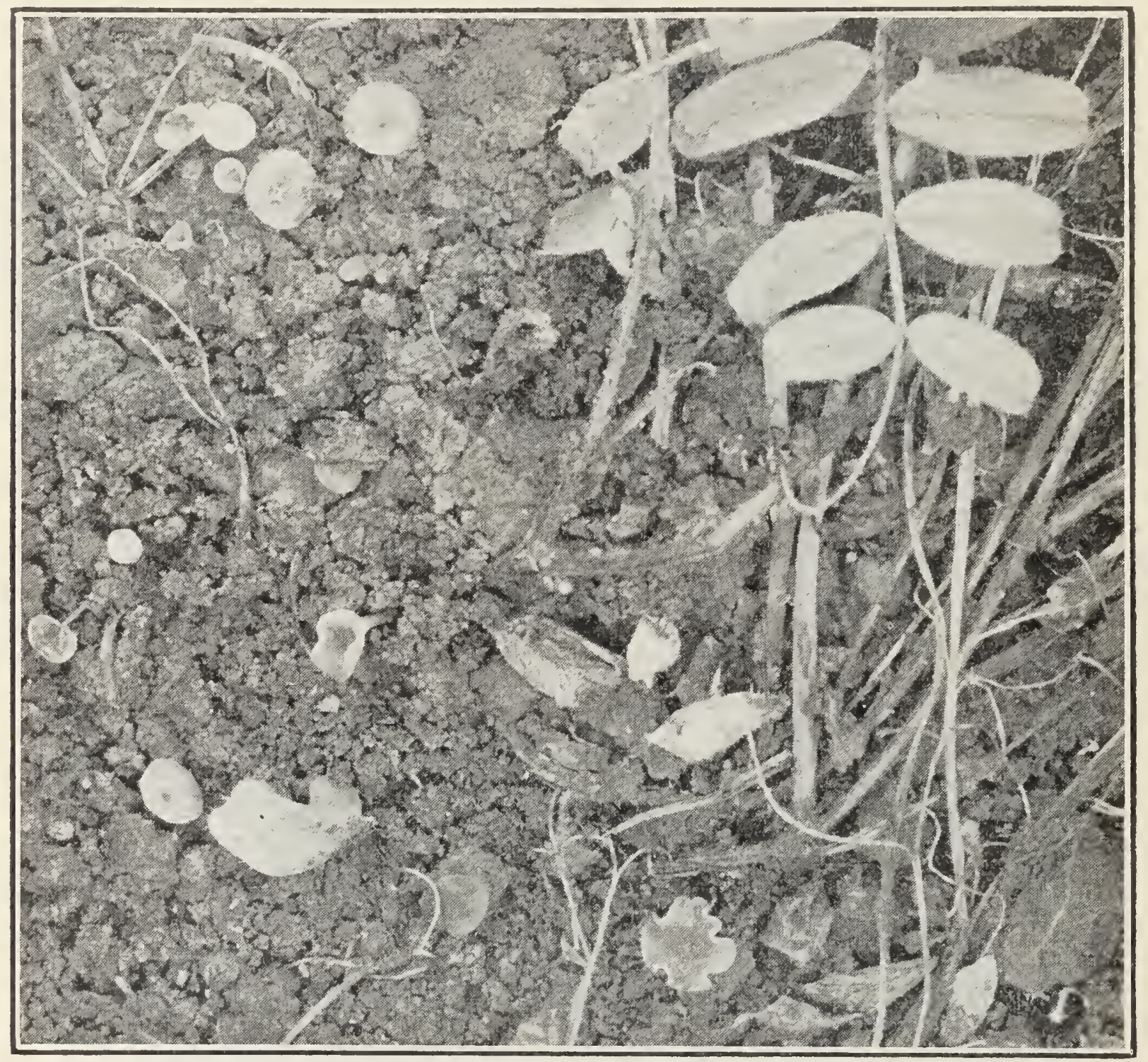

Fig. 53.-Peziza of cottony mold fungus growing in orchard soil.

grove undesirable from some other point of view. This whole subject is now under investigation and will be reported on in a future bulletin.

See Bulletin 190, California Experiment Station.

\section{Gray Mold (Botrytis vulgaris).}

This produces a dark colored decay of the rind on which a dirty gray mold develops. The fungus is able to develop at low temperatures close to the freezing point and sometimes causes considerable loss in fruit held in cold storage. Not ordinarily very serious. 
Blue Axd Greex Mold (P'chicillium italicum and I'. digitatum). See Orange. 'Twig Brigrit (sclerotinia libertiana).

The twigs die back from the tip in moist weather, showing to some extent a white moldy fungus upon the surface in which may be imbedded small, hard, seed-like bodies or sclerotia, at first white but finally becom-

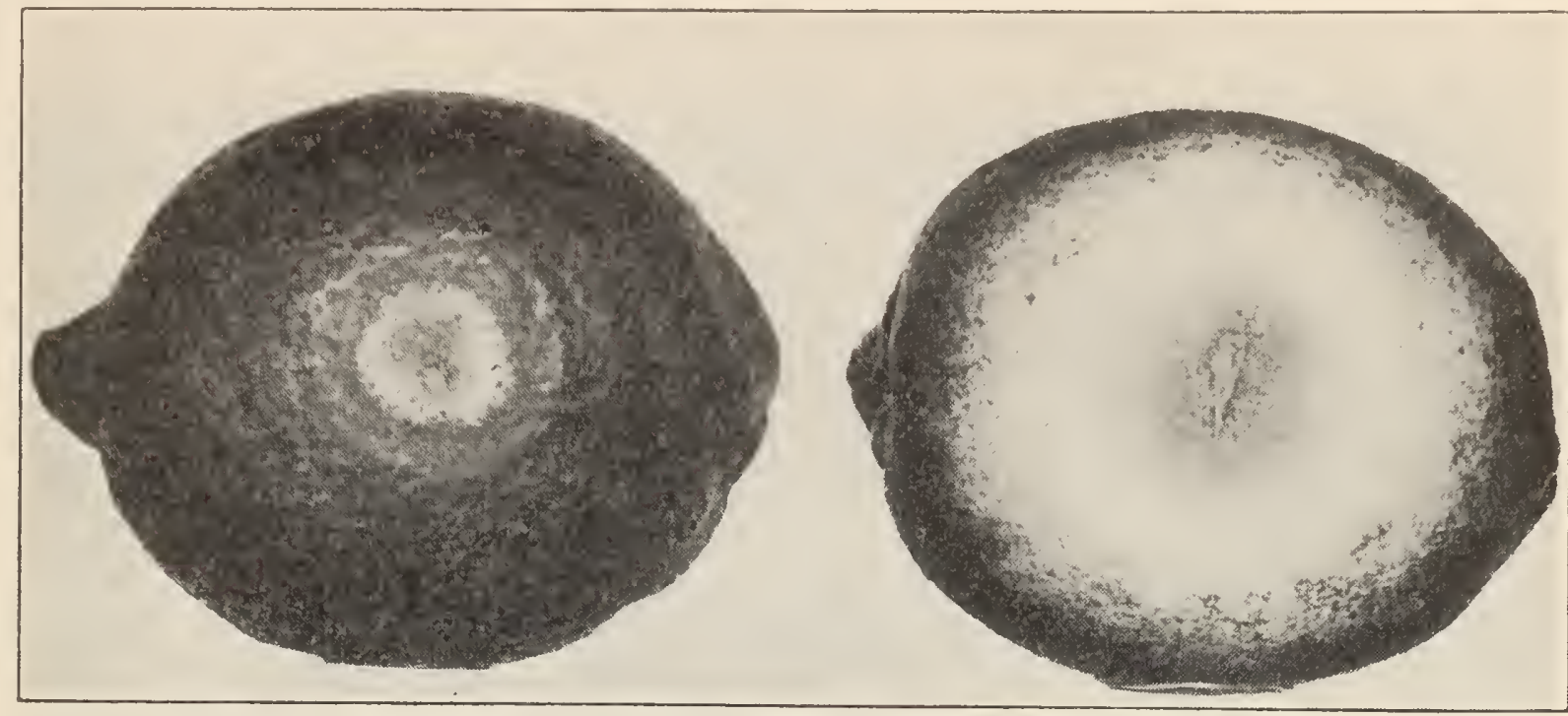

FIG. 54.-Green and blue mold rot of lemon (Penicillium digitatum and italicum).

ing black. A mass of gum exudes at this point. This fungus, which is the same as that causing the cottony mold, occasionally infects the tree itself, both with lemons and other citrus trees, with the effect just

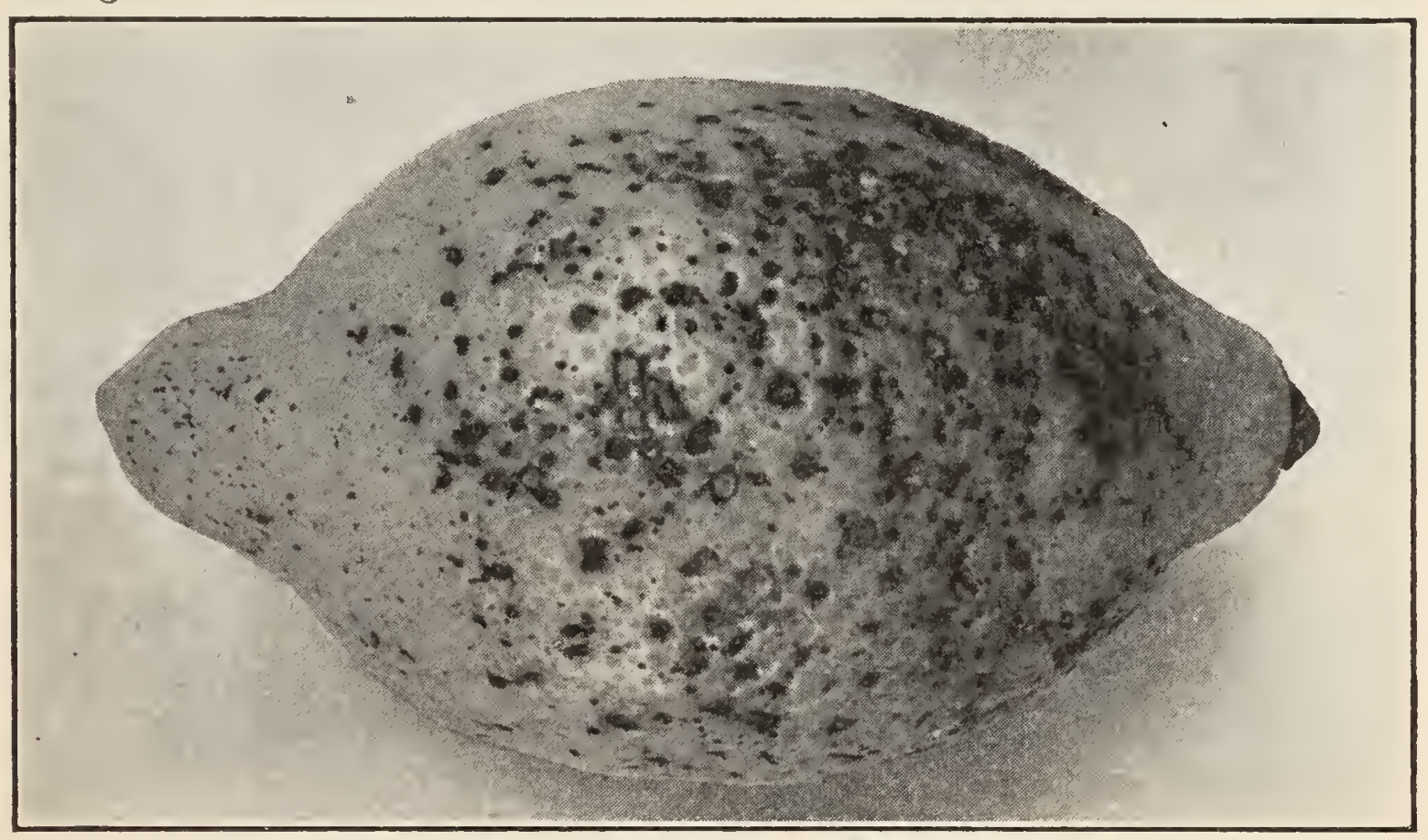

FIG. 55.-Supposed effect of wither-tip fungus on lemon fruit (Colletotrichum gloeosporioides).

described. The infection comes from spores produced by the growth of the fungus upon the green manure crop. Not serious. This effect is sometimes confused with that of the next described disease. 
Wither-Tip, "Tear Stain" (Colletotrichum glocosporioides). Figures 55 and 56 .

The effects of this disease consist in a general way in a spotting of the fruit and leaves and killing back of the twigs, and an attack upon the young, newly-formed fruit, causing it to drop. 'To what extent, however, such effects occur in California solely from the attacks of this fungus, without the aid of other harmful conditions, is somewhat doubtful and difficult to determine. Wither-tip is a trouble of quite common occurrence in Florida and probably most other citrus growing regions. It has been known to exist in California for some time but there has always been a question as to how much this fungus is really parasitic and how much it develops simply in a secondary manner upon tissues injured in other ways. Little attention was given to the subject in California until the winter of 1908-09, when there appeared to be a considerable epidemic of wither-tip in southern California, particularly on lemons and grape fruit. Since that time the subject has received considerable investigation.

The most pronounced effect upon lemons attributed to the wither-tip fungus has been a slight spotting of the fruit, the spots being quite numerous upon the exposed side of the lemons while still on the tree, each spot of small size and reddish color. Such spotting has been quite generally attributed to this fungus and yet it may be said that in numerous efforts made to produce such an effect by direct infection with the spores of the wither-tip fungus, entire failure has always been the result. The same is true in regard to the dropping of young fruit. It has frequently been assumed that this is an effect of the wither-tip fungus, yet efforts made to produce the same effect by spraying young lemons profusely with wither-tip spores have always failed to produce infection or cause such fruit to drop any more than that which was not sprayed.

The fungus commonly shows itself to the eye in the form of numerous minute black dots upon the surface of dead twig tips or on dead spots on the leaf. In the latter case, starting on spots killed by fumigation, fire or other injuries, or possibly without preliminary injury on old, nearly dead leaves, the spots slowly spread in an oval form, with a yellow band between the dead and green tissue and the characteristic black dots (pycnidia) upon the surface of the dead portion.

Another fungus, a species of Pleospora, having a similar appearance and effect, has also been found quite abundantly on citrus trees in the northern part of the State.

The wither-tip fungus is one of the commonest inhabitants of our citrus trees. Every dead twig, every fallen leaf, every leaf or twig injured by fire or any other cause, immediately becomes covered with a flourishing growth of this fungus. Young lemons which fall to the ground from any cause show the same fungus upon them after a short 
time. It has even been found that the most healthy, green leaves, if picked from the tree and placed in a moist chamber, soon become covered with this wither-tip fungus. Trees suffering from gum disease, gophers, drouth or any other influence which causes them to lose their vitality and begin to weaken and die back in the branches soon develop an abundance of this organism. It is also likely that citrus insects, like the red spider and any other which punctures or injures the fruit, may promote the development of this fungus.

All in all, our conclusion has been that it is extremely doubtful whether the wither-tip fungus ever in California attacks sound, unin-

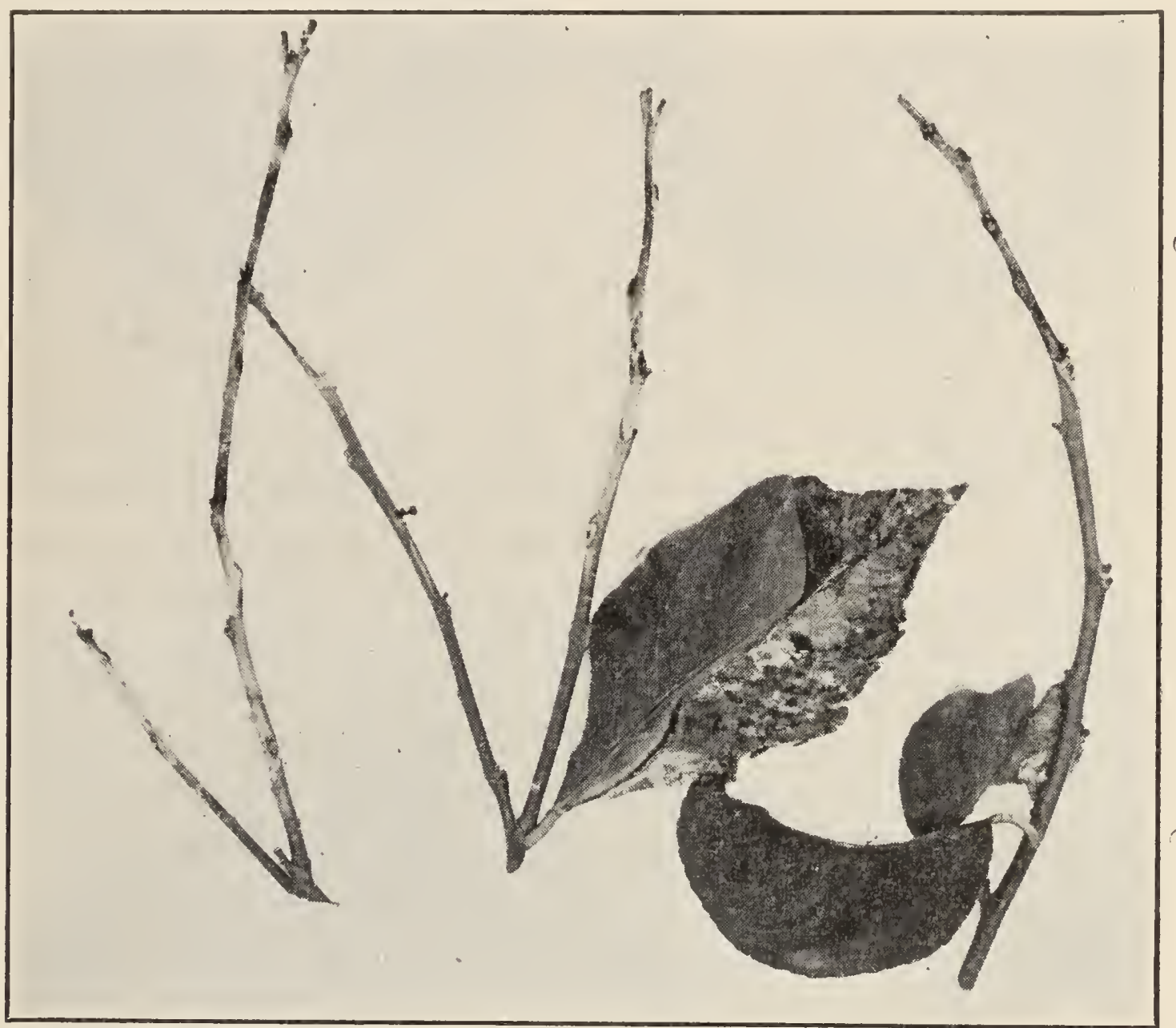

FIG. 56.-Effect of wither-tip fungus on sickly lemon leaf and twig (Colletotrichum gloeosporioides).

jured, vigorous foliage, twigs or fruit, or develops at all, save in a secondary manner or following some other injury. The subject is still receiving careful investigation and will be made the subject of a future bulletin.

Within the last two or three years considerable spraying has been done in lemon groves in southern California with the idea of combating the supposed effects of this fungus. Such work has been done with Bordeaux mixture and also with various sulphur sprays made by combining sulphur with lime, soda or potash. Some growers have believed that they saw good results following such spraying, while others were unable to see such benefits. We are following the results of such work. 
RED Rot. Higure 57.

A curing-house trouble in which the rind develops a rusty bronze color and gradually dries down into a sunken condition with a dark red or black color.

Cause unknown; apparently not a parasite.

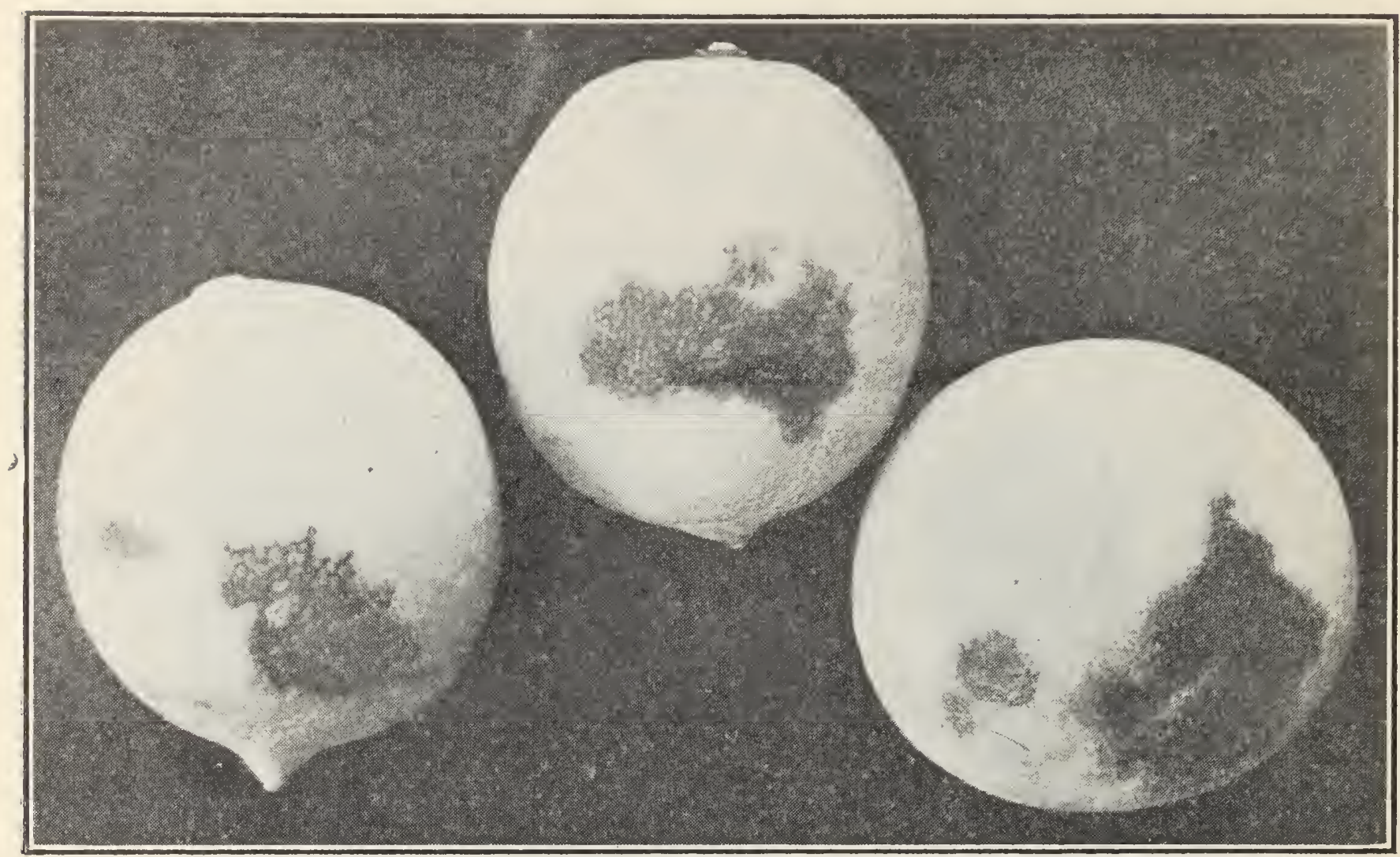

FIG. 57.-Red rot of lemon.

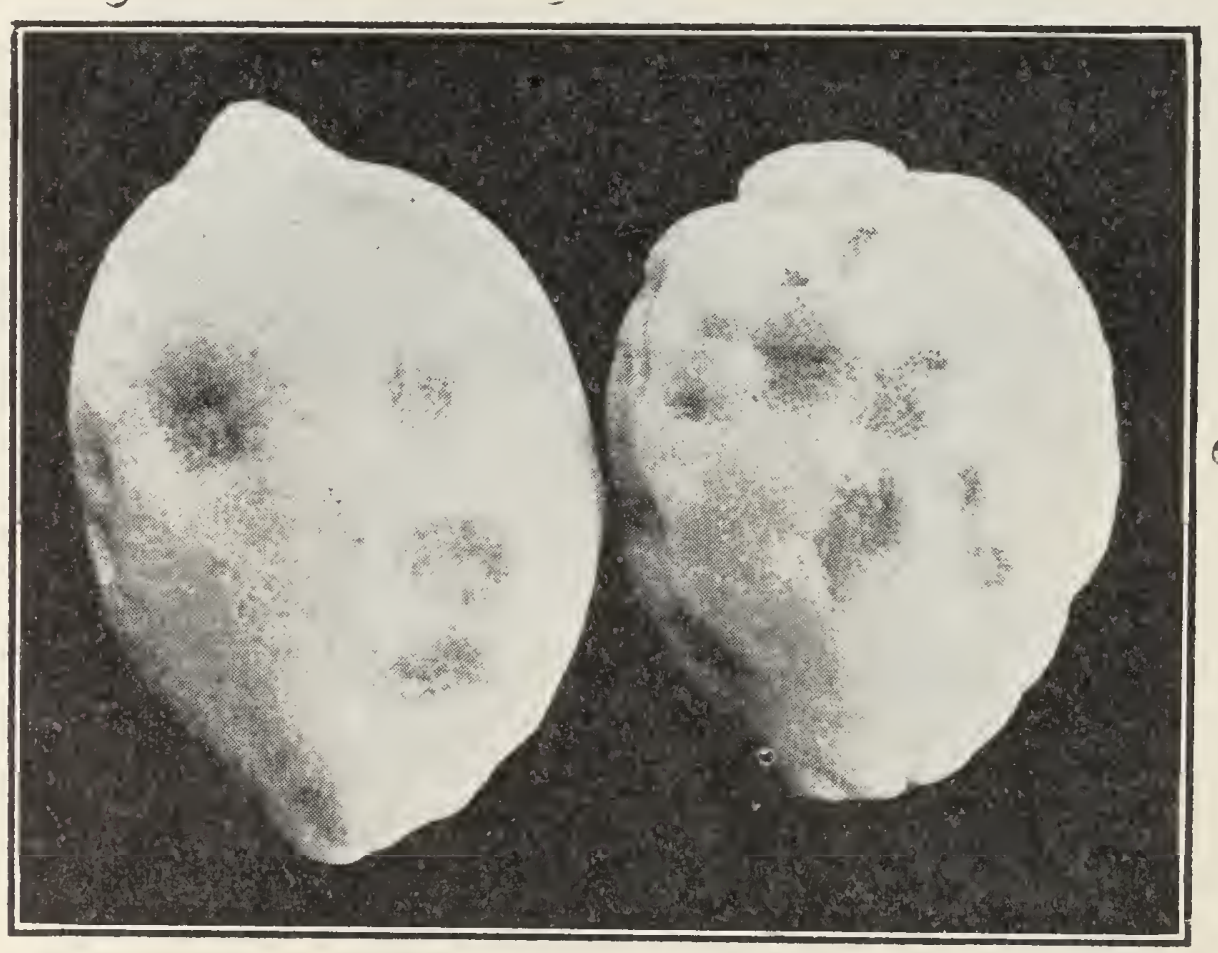

FIG. 58.-Peteca of lemon.

Peteca. Figure 58.

This trouble shows itself in the form of deep sunken pits in the rind of the lemon after it has been in the curing house for some time. The tissue at these spots is found to be dried and shrunken prematurely. 
The trouble is not serious, save in its effect upon the appearance of the fruit. Cause unknown.

\section{LE'TUCE.}

\section{DAMPING OFF (Botrytis vulgaris).}

Drop (Sclerotinia libertiana).

The plants wilt and die, collapsing upon the ground. The stem rots off just at the surface of the ground and one or the other of the above named fungi is usually found at this point. Other damping off fungi may cause the trouble in some instances.

See Tomato.

LOGANBERRY. See Blackberry.

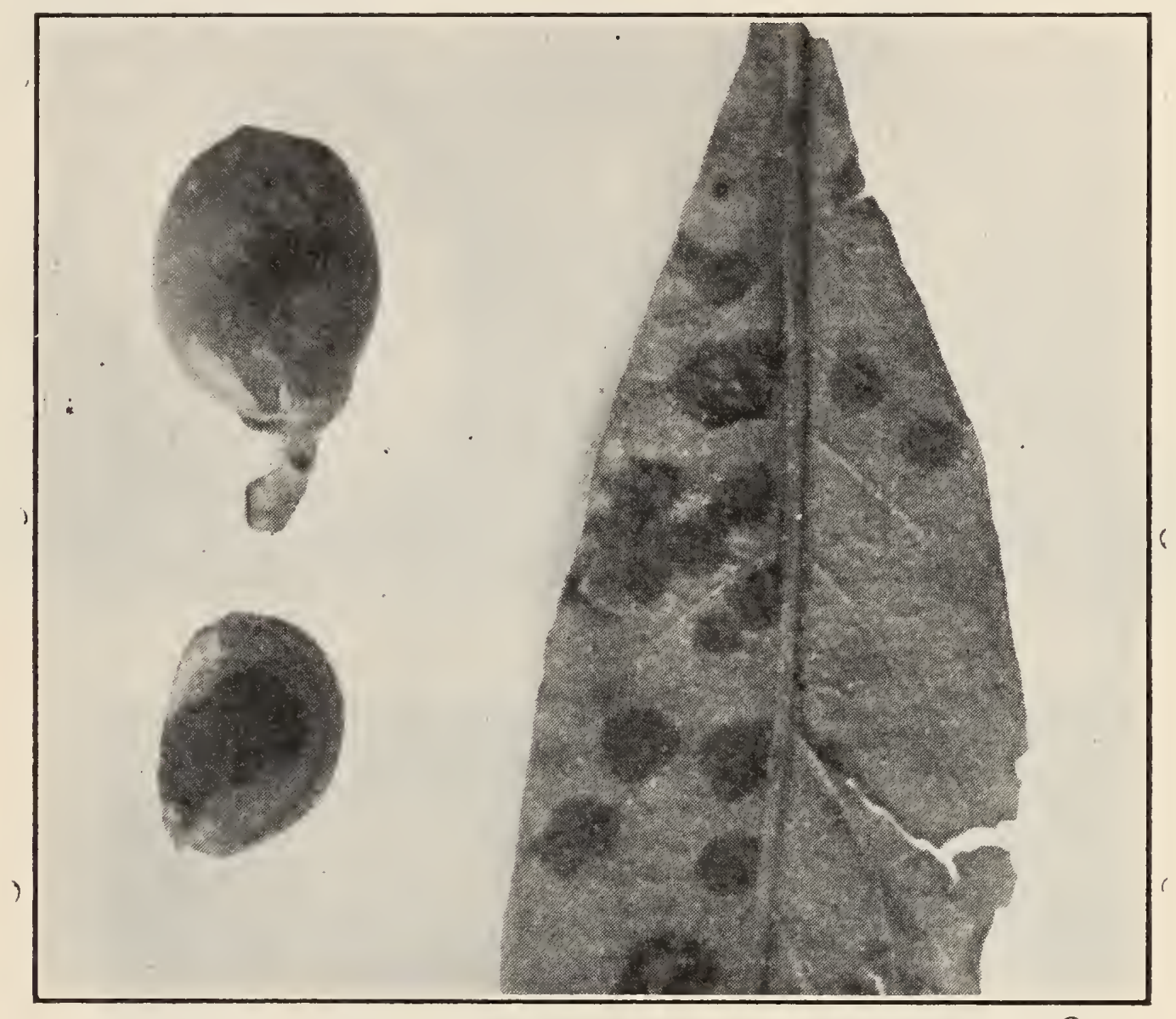

Frg. 59.-Scab of loquat (Fusicladium eriobotryae).

\section{LOQUAT.}

Scab (Fusicladium eriobotryx). Figure 59.

Similar to apple and pear scab, to which trees this is related. Affects both fruit and leaves.

BLight (Bacillus amylovorus).

The blossoms and twigs wither and die. This trouble is caused by the pear blight organism, to which the loquat is quite susceptible.

Same treatment as for pear blight.

\section{MADRONE.}

LEAF SPOT (Sphaerclla arbuticola).

Produces disfiguring dead spots on the leaves. 
NURSERY STOCK.

Crown Gall. Figure 11.

Very common on the roots of nursery trees, particularly those of the stone fruits. See Almond.

Discard affected trees and never use such for planting. Do not grow nursery stock on affected land.

Root Knot (Nematode). Figure 41.

These microscopic worms sometimes invade the nursery, producing galls and swellings all over the roots of the young trees.

Destroy affected plants.

Allow infested soil to dry for a season before using it again.

See page 1076.

\section{OAT.}

Rust (Puccinia graminis).

Produces numerous pustules of the black or red rust condition on the surface of the plants, sometimes covering the leaves with the reddish, powdery spores. Sometimes abundant in wet seasons, badly injuring the crop.

No treatment is feasible save the use of resistant varieties.

Syut (Ustilago avence).

Causes the heads of grain to turn into black, dusty, smutty masses. May be entirely prevented by the seed treatment recommended for barley smut.

OIEANDER.

TWIG GaLL.

(Tuberculosis). Figure 60 .

This plant is sometimes affected with galls or swellings on the stems and twigs, very similar to the olive disease of the same nature. Appears to be caused by the same or a very similar organism. Not serious.

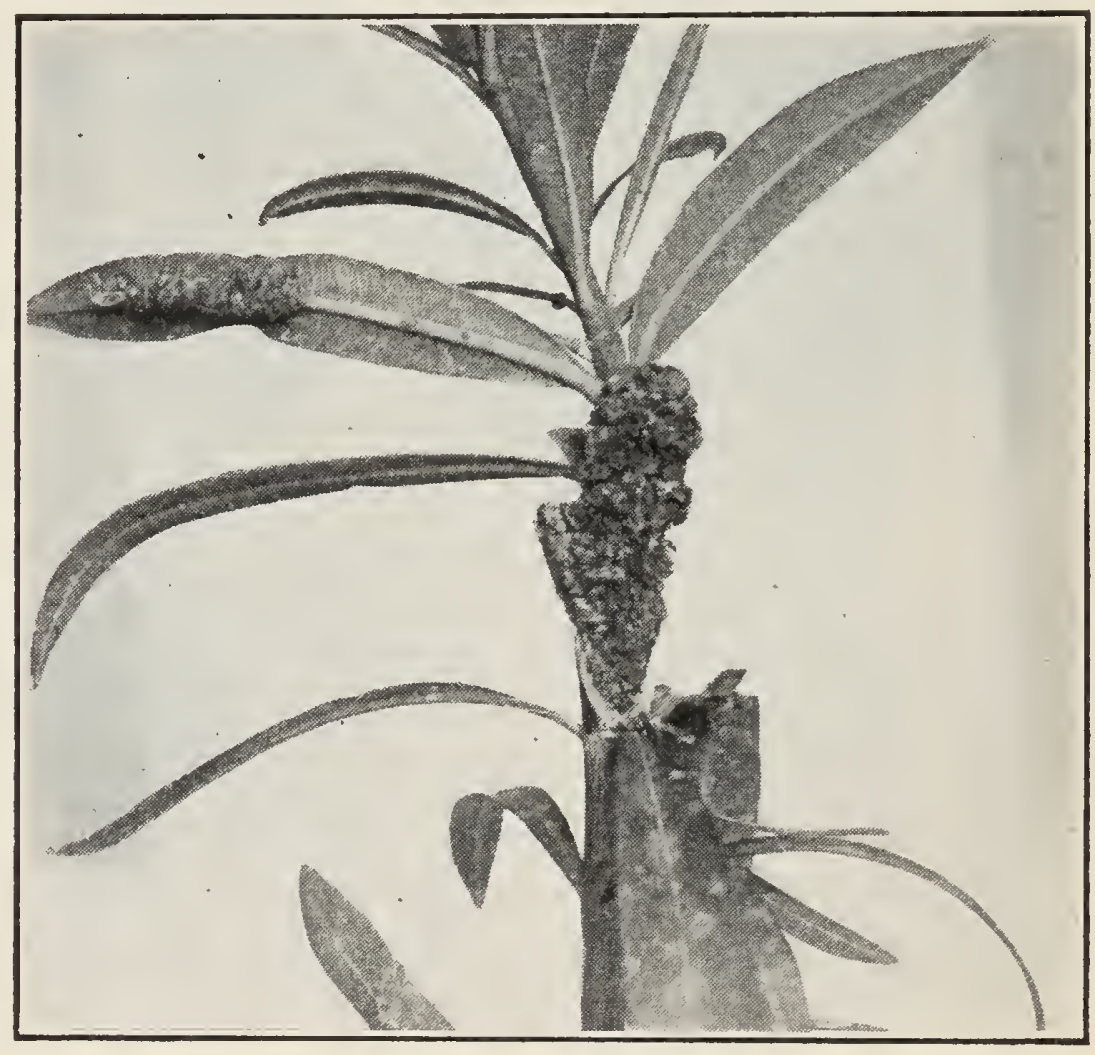

FIG. 60.-Stem gall of oleander.

Leaf Spot (Macrosporium nerium).

Produces dead spots on the leaves. Not important. 
OLIVE.

'Tuberculosis (Bacterium Savastanoi). Figure 61.

This is a bacterial disease, the parasitic organism causing a production of galls of considerable size on the trunk, branches and small twigs. Some varieties are more susceptible than others. If taken in time the

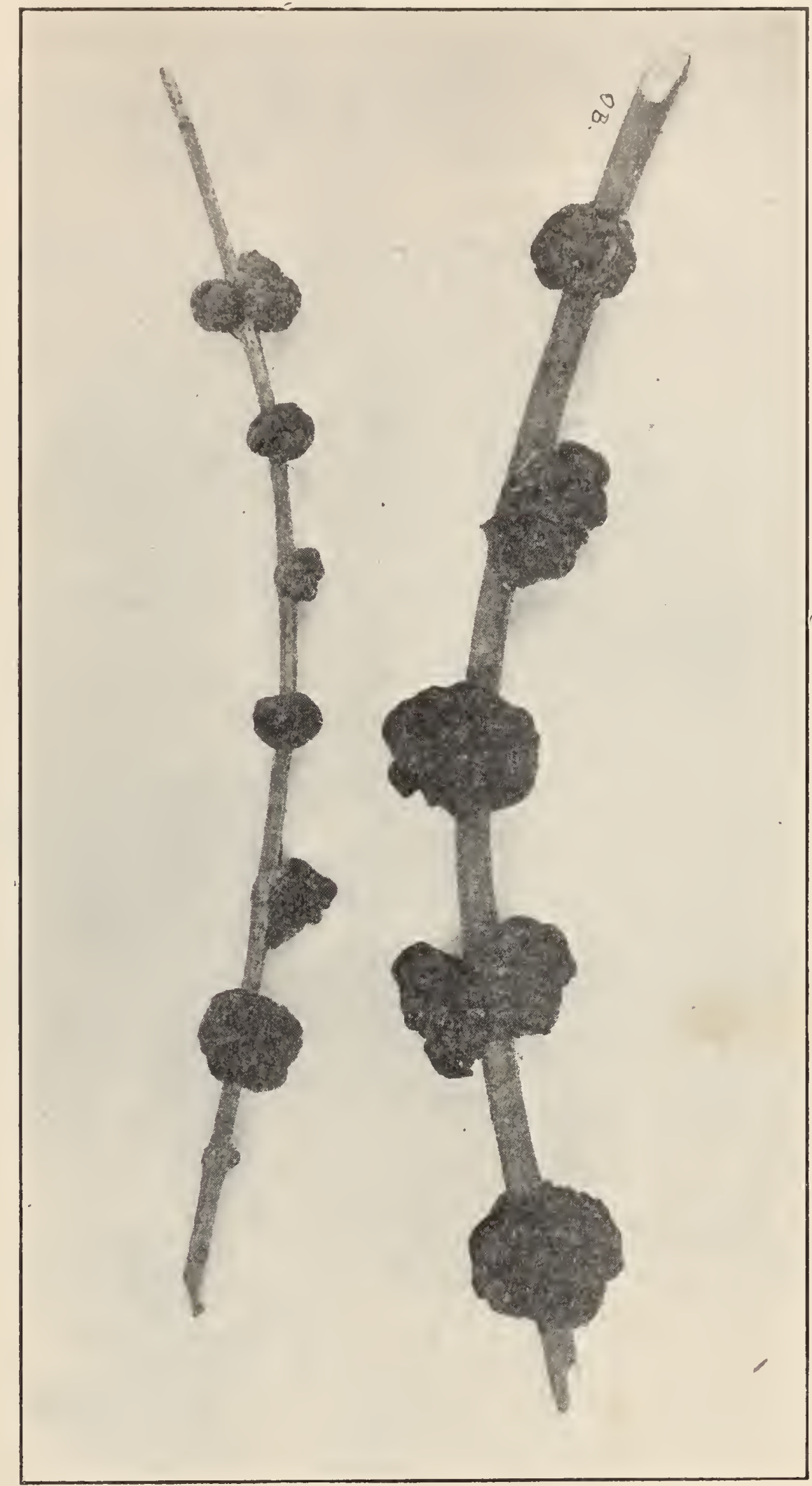

FIG. 61.-Tuberculosis of olive (Bacterium Savastanoi).

disease can be successfully controlled by cutting out all affected parts and saturating the wounds with a strong disinfectant.

See Bulletin 120, California Experiment Station. 


\section{LEAF SPOT (Cycloconium oleaginum).}

Causes spots of considerable size on the leaves. No treatment is usually necessary.

DRY RoT. Figure 62.

Characterized by the appearance of numerous large spots on the fruit which dry and sink in. During some seasons the olive is considerably affected with this trouble. Cause not known.

Root Rot (Toadstool disease). See Almond. ONION.

Jowny Mildew (P'eronospora schleideniana).

Causes serious losses some years in onions grown for seed during the winter. The fungus affects the seed stalks and leaves with the production of large dead areas upon which may be seen the dark, purplish-colored mildew. The seed stalks topple over and fail to develop seed.

'This disease has not been successfully controlled in California, but in Eastern. states has yielded fairly well to spraying with Bordeaux mixture, to which a resin "sticker" has been added. This spraying must be done at frequent intervals, commencing before the mildew appears.

The development of resistant strains by seed selection is promising.

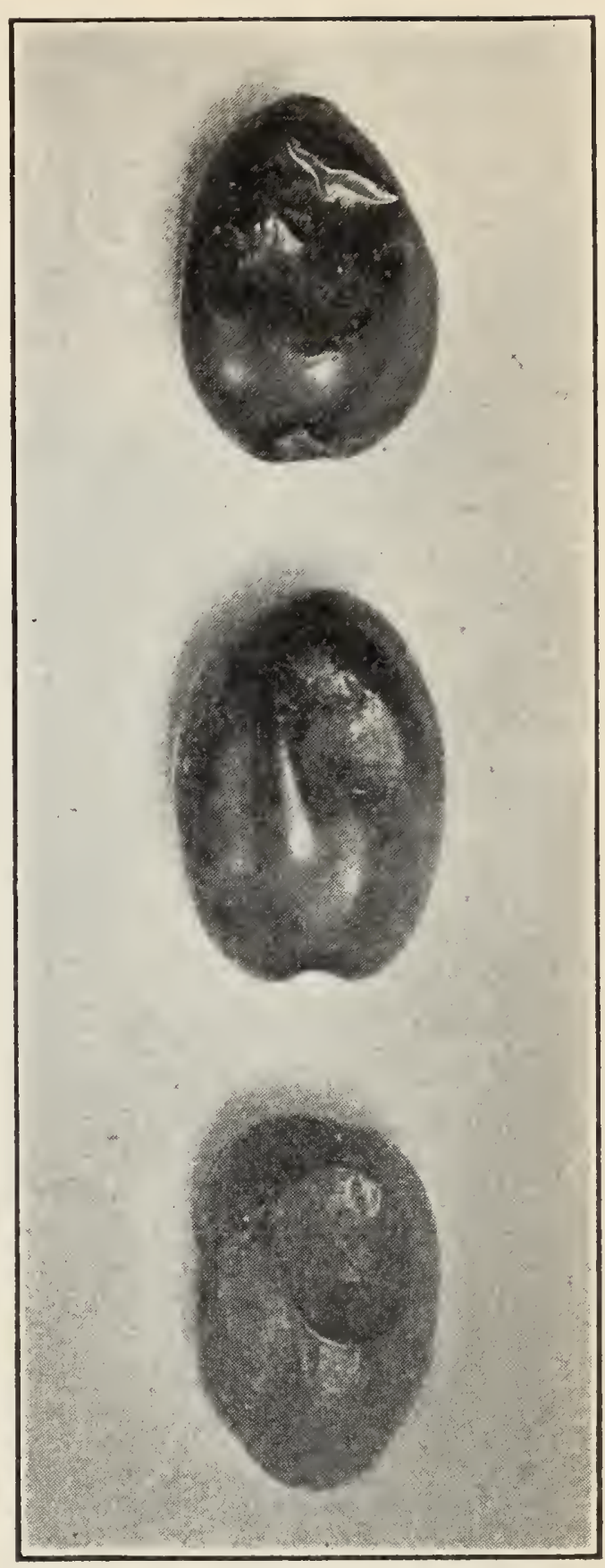

FIG. 62.-Dry rot of olive fruit.

ORANGE.

In the consideration of diseases of the orange and other citrus trees, it is desirable to mention at the outset certain peculiar characteristics of such trees which distinguish them to a considerable extent from any other cultivated plant. These features make the citrus tree specially liable to peculiar, obscure effects of climate, soil or other non-parasitic conditions, and in making an investigation of citrus diseases one should not fail to keep these peculiarities of the citrus tree prominently in mind. First, is the very free circulation of water from the roots up into the tops, which occurs when plenty of moisture is available in the soil. This water carries with it all the food materials from the soil which the tree takes up and thus we see that the citrus tree must take up large 7-BuL. 218 
amounts of such food material very freely when large amounts of soil moisture are available. This feature is of no special importance when the trees receive a uniformly sufficient supply of water, but must have very decided effects when the moisture supply is irregular and the soil becomes alternately, very wet and very dry. In such cases the soil food materials are supplied to the tree in a correspondingly irregular manner.

Connected with this feature is the second peculiarity which we would mention, namely, the quickness with which citrus trees respond when needed water is supplied. Trees which are suffering from dryness, and from no other cause, show a most marvelous sending forth of new shoots and rapidity of growth when water is applied to the roots. Inversely, the trees are as quick to suffer from a lack of moisture as to respond to an addition of it. Their tendency is to form a large amount of new, suceulent tender growth, both in the top and root, when water is supplied and the distress of the tree is proportionately greater if a shortage of water follows, on account of the presence of this growth.

Again, the tree is peculiar in being ready to grow at any time of year, particularly if its growth has been checked somewhat by lack of moisture. It has almost no reaction to seasonal conditions. Normally, however, the tree has three or four fairly well-defined periods of growth during the year, being intermediate in habit between deciduous trees, which have one growing and one resting period, and most evergreen tropical trees which grow more or less continuously all the time.

Still further, a feature of great importance is the tendency of the citrus tree when injured in any way, either mechanically or physiologically, to produce a quantity of gummy substance which may run out at the wounds or break out through the bark. The formation and presence of such gum, when once started, may become a chronic source of irritation to the tissues after the cause of the original injury has entirely disappeared, and furthermore, the gum is often a source of trouble through the secondary fermentation or decay which it may undergo in the tissues of the plant.

It is the tendency in most citrus species, and particularly in the varieties most commonly cultivated, to produce fruit asexually, apparently by purely vegetative growth without the process of pollination. In the Washington navel orange, for instance, and probably to a greater or less extent in other citrus fruits which are seedless or nearly so, the fruit appears to be simply a vegetative growth like the leaves, rather than a product of sexual fertilization. If this be true, it is evident that herein exists a most important difference, from a practical as well as investigational standpoint, between the citrus and most other cultivated fruits.

All these peculiarities are of great significance in any investigation 
concerning the citrus tree, and make, in California at least, the consideration of plant physiology, soil and climatic conditions, and other similar factors of more importance than the study of parasitic attacks.

Gummosis. See Lemon. Figure 49.

SCALY BaRK. Figure 63.

Characterized by the appearance of scaly areas of bark on the trunk or branches, the outer bark rising in scales from the inner. Small drops

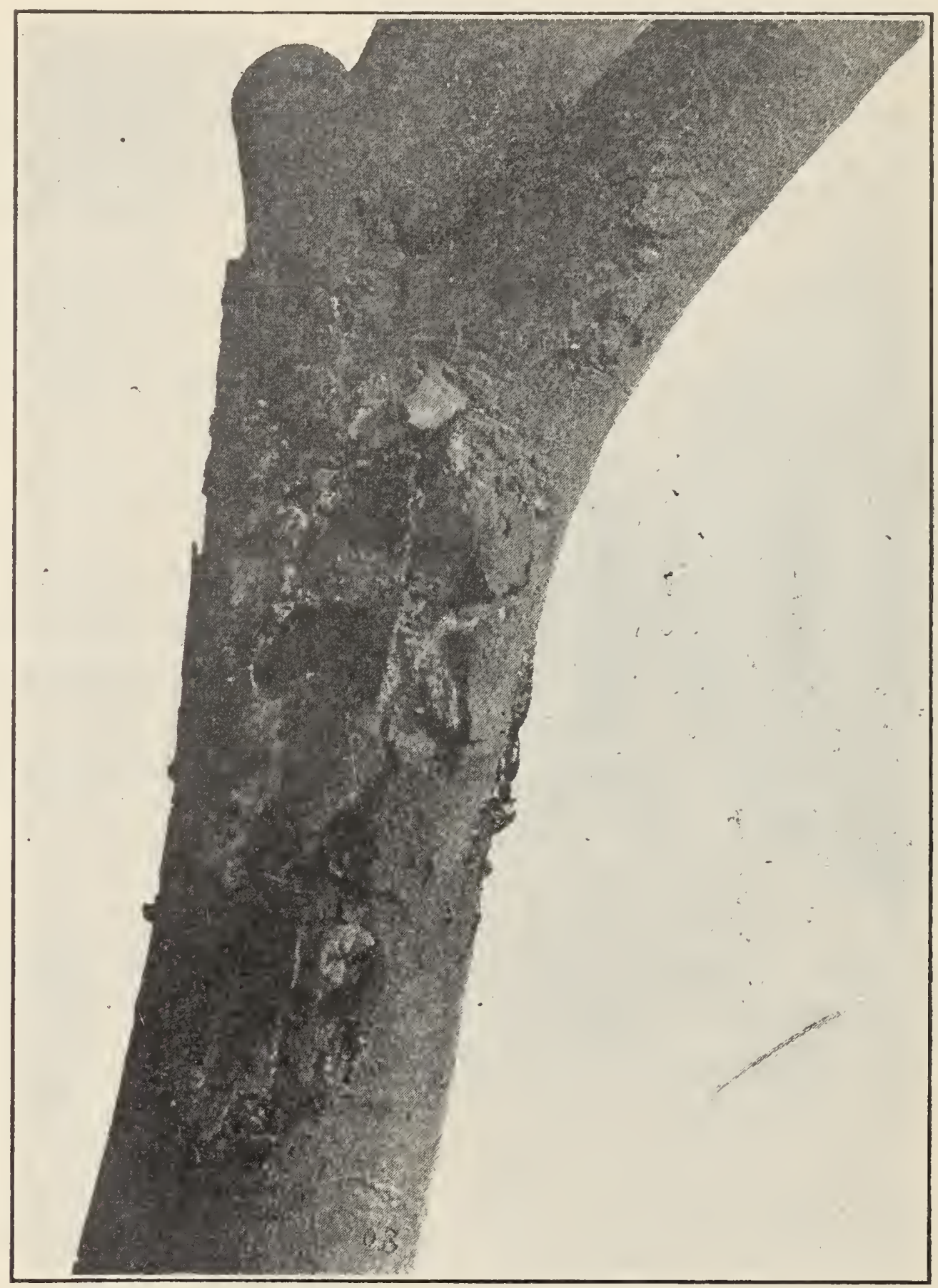

FIG. 63.-Scaly bark of orange.

of gum exude in spots on the affected portion, which gradually spreads. Affected limbs die back slowly but new growth keeps taking their place and the tree lives for many years in an unhealthy condition.

This trouble apparently originates in an irregular moisture condition of the soil. Practically all the affected trees in the State have been in 
their present condition for many years and seem to have become affected at a time when irrigation by flooding was generally practiced and cultivation received little attention.

The worst affected trees can not be saved, but should be dug out and replaced. Trees where the disease exists only on the branches will recover if affected parts are cut off. In case the scaly bark is on the trunk and the patch is not too large the diseased portion should be cut cut to healthy bark and the wound painted over. Such cases will almost invariably heal completely.

If the trunk is badly affected, but the tree in fairly good condition, the scaly surface bark should be scraped off and several slits cut through the affected area. The sealy part may then be painted over with pure neatsfoot oil, linseed oil, 10 per cent caustic soda or potash solution, or kerosene oil.*

The soil about the tree should be thoroughly dug up and the application of oil or whatever is used repeated about once a month for several months. This disease, as well as the last, is not contagious and no infection need be feared to neighboring trees.

See Bulletin 200, California Experiment Station.

MAL DI GOMMA.

A virulent decay of the bark of the roots from the surface of the ground downward. This is occasionally found on trees in extremely heavy, wet soil or where too much water is used close about the trunk of the tree.

Affected trees can rarely be saved but may be replaced successfully if soil conditions can be improved.

See Bulletin 200, California Experiment Station.

Exanthema-Florida Die-Back.

The branches die back from the ends and numerous axillary buds develop, forming bushy tufts of small twigs all through the top of the tree. Corky outgrowths develop on the bark of the twigs and gum exudes from these places. In the first stages of the disease there develop near the center of the tree abnormally large, dark green leaves, giving the tree a false appearance of unusual thrift. The fruit takes on a pale yellow color while still small and immature and has an insipid sweetness with no development of acid quality. Dark brown spots or patches appear on the rind and from these as centers the oranges crack and split.

This disease occurs in California mostly upon coarse or gravelly soils or subsoils, following the application of stable manure or other nitrogenous material in an organic form. It is most apt to occur when such fertilization is practiced on trees which have not previously been receiv-

* Injury is sometimes caused by a too abundant use of these substances, especially on badly affected trees. 
ing it, especially if they have been suffering somewhat from lack of plant food and water. The disease may be likened to a form of indigestion.

On these soils citrus trees should receive very careful irrigation to the end that the ground may be kept continuously moist and not be allowed to become alternately wet and dry, as is the tendency on such porous soils. Fertilization should be uniform without the sudden application of large amounts of manure or organic fertilizers.

See Bulletin 200, California Experiment Station.

CHLOROSIS.

This term applies to cases where the leaves become yellow and pale, lacking the normal green color. No definite disease is indicated by these symptoms, more than that the trees are in distress of some sort. The cause of the trouble is usually to be found in some unfavorable soil condition.

Mottied LeAF. Figure (j.

What has been said in the last case applies to this also. Affected trees show a yellowing of the leaves between the veins, with the green color only along the mid rib and the lateral veins, giving the leaf a mottled appearance. Examination shows that leaves once green never become typically mottled there-

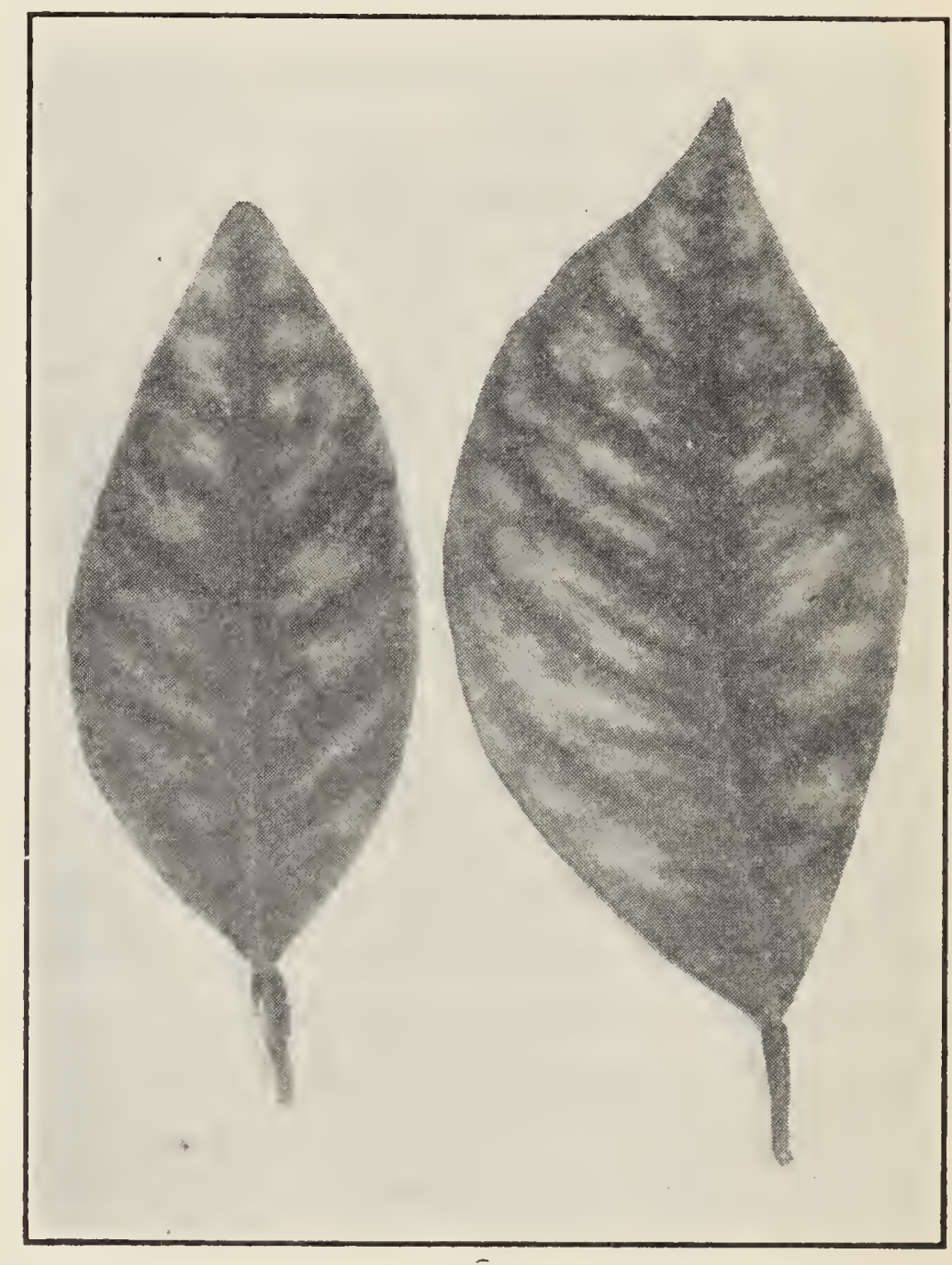

FIG. 64.-Mottled leaf of orange.

after, although they may become lighter in color or even bright yellow. Typical mottled leaves are found only toward the ends of the shoots and represent leaves in which the green color has never completely developed, rather than those in which the chlorophyll has once existed but then disappeared. Mottled leaf is a case of non-development or slow development of chlorophyll. Along with the mottling of the leaves there also occurs, if the trees are badly affected, a decided shortage in the amount of fruit and in typically bad cases the fruit present 
is of very small size, becoming fully colored when only an inch or two in diameter. Considerable die-back also occurs and the foliage is thin and weak, giving the tree a brushy look, with many small, dead twigs at the extremities.

Mottled leaf is by no means to be always regarded as a symptom of disease or a cause for alarm. Frequently in the winter young, rapidlygrowing trees show such a condition in their youngest leaves, especially during periods of long continued cold rain. This is to be regarded as simply a temporary set-back in the development of the leaves and with warm weather the normal green color appears and the leaves soon put on their natural appearance.

A more serious condition of mottled leaf may result from any one of a variety of causes. It does not necessarily indicate any specific disease. There has been, however, in southern California, particularly during the past year, quite a widespread condition of this sort, which appears to be of the same general nature. This condition has been attributed to a variety of causes, most of which probably had nothing whatever to do with the disease. One theory that has been given prominence is that mottled leaf is due to the presence in the soil of an excess of magnesium over lime. Not long previously the opposite theory was held in a similar case in the San Joaquin Valley, namely, that mottled leaf is due to an excess of lime in the soil.*

Examination of typical cases of mottled leaf all over the affected districts shows the following facts to be true: The trouble is less generally abundant near the coast and more abundant inland. Oranges are more affected than lemons, and Valencia oranges more than Washington Navels. Oranges top-worked on other citrus trees are worse affected than those which were budded in the nursery. Oranges top-worked on lemon trees are rather worse than those top-worked on orange trees. (The worst combination in this respect is, therefore, Valencia topworked on lemon.) Trees are worse affected on the south than on the north side. The most heavily fertilized groves are as badly and probably more affected than those which have received less fertilization. (This is particularly the case in connection with the application of stable manure.) Orchards underlaid with gravel, sand or sandy loam are more affected than those having a subsoil of fairly heavy loam containing no sand. Orchards underlaid with plow-sole, hardpan, or extremely heavy, poorly drained soil are likely to be affected. In orchards where a certain area or streak of mottled leaf runs through the orchard this corresponds to an area where the subsoil is different and usually where it is coarser. Young buds top-worked on large trees often show mottled leaf for several years, but gradually come out of it and attain a normal

* Circular No. 27, California Experiment Station. 
condition as the new tops become larger. Trees standing close to corrals or manure piles where they receive a constant supply of liquid manure are likely to be badly affected with mottled leaf.

All these observations taken together point to one conclusion; namely, that the most prevalent and typical form of mottled leaf is due to an irregular supply of moisture and plant food. There should be remembered in connection with the unusual prevalence of this trouble in 1910 and 1911 the following facts: The winter of 1909-10 was unusually cold, and citrus groves suffered much more than usual from freezing. In the winter of 1910 the rains stopped very early and the spring was a very dry one. In the fall of 1910 the rains were late in commencing, so that a period of nearly a year elapsed with very little rainfall. Irrigation was practiced more or less thoroughly during this unusually dry spring and fall, as well as during the summer, but all observation goes to show that in most of the citrus groves the subsoil became much drier than usual during that season. Orchards underlaid with either a porous or a hard, impenetrable subsoil were most subject to this condition, as discussed on page 1069 . The result was that in irrigating only the surface layers of soil were saturated, while between irrigations the soil dried out much more than commonly. This would have the effect of giving the tree an irregular nutrition, soil food-materials being taken up at the time of irrigation, but being unavailable during periods of dryness.

We are led to the conclusion that this is the nature of the trouble from the facts cited in regard to the soils upon which mottled leaf is most prevalent, the fact that the best fertilized groves were apparently more affected, other things being equal, and the fact that trees getting an excess of nutriment, like those top-budded and those standing close to manure piles, were the most affected. The fact that interior districts suffered more than those near the coast and that trees showed more effect on the south than on the north side indicates that where the sun was hottest, drawing most upon the moisture, the trouble became more pronounced.

We do not wish to be understood that the whole question of mottled leaf may be settled in this manner, but simply wish to state these suggestive facts. The methods by which conditions tending to produce this condition may be improved are alluded to on page 1074.

DIE-RACK.

This general term denotes cases where the branches die back from the tips. It is not a specific disease, but as in the last two cases, indicates that something is wrong with the tree. The trouble usually lies underground, and most often denotes unfavorable soil conditions or lack of water. 
Trunk Rot (Schizophyllum commune). Figure 65.

The trunk or large limbs decay at points where they have been cut off or injured, with the production of small, white, bracket toad-stools upon the surface. Not parasitic on sound trees. This allso affects apples, walnuts and other trees.

Cover all large cuts or wounds thoroughly with grafting wax.

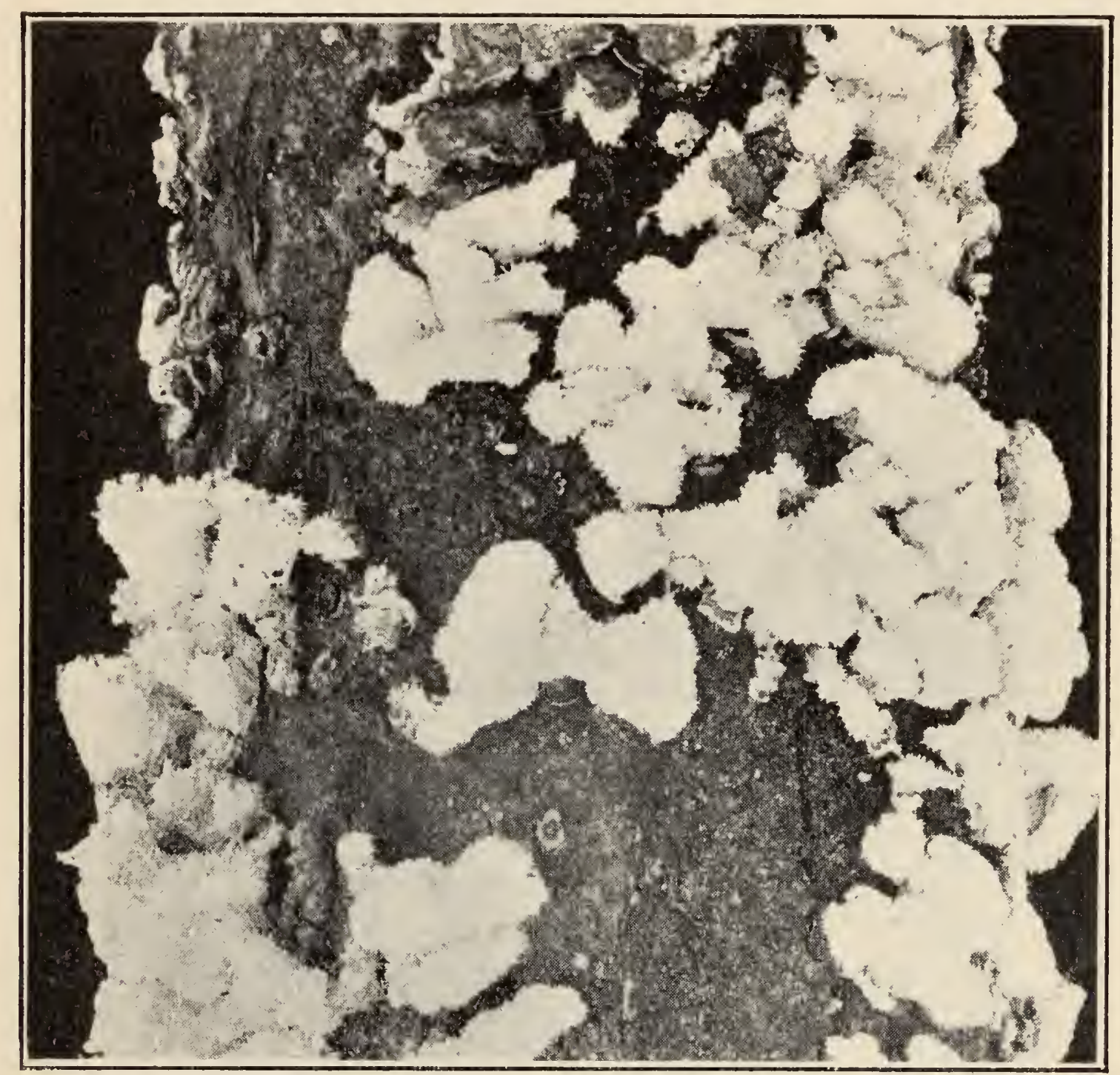

FIG. 65.-Schizophyllum trunk rot of orange.

Root Rot.

Citrus trees are affected by the "toadstool" or oak fungus disease described under "Almond," whenever they happen to be planted upon foot-hill land which has formerly grown oak trees. The trees die with a decay of the roots and the white felty growth of the fungus is found between the wood and bark. (See Almond.)

'Twig Bligirt (Sclcrotinia). See Lemon.

Wither-Tip, Anthracnose, "Tear Stain."

The wither-tip fungus described in connection with the lemon has a somewhat similar relation to the orange. The fungus occurs abundantly upon dead or injured twigs, leaves or trees, but is of doubtful occurrence 
as a true parasite. This fungus occasionally causes a decay of the fruit of the orange, quite different from anything seen in the lemon. The wither-tip rot of the orange consists in a large, rather dry, brown spot, starting sometimes on fruit while on the tree during wet weather, and gradually spreading. These spots usually develop at places where oranges touch each other. The same spotting and decay is quite frequently found to a considerable extent in oranges held in cold storage, particularly if the temperature is a little too low. Under such conditions this fungus may develop abundantly and cause a considerable amount of decay.

Damping OFF (Rhizoctonia, Fusarium). Figure 66.

Causes the loss of great quantities of orange seedlings in the seed bed. The plants begin to die in spots which gradually extend, finally involving large areas if not checked. Two distinct forms of the disease are recognizable, one caused by the first named fungus above, producing a decay of the stem just above ground, while the other shows itself in dead spots on the stem at any point.

These troubles can only be controlled by strict attention to proper methods of planting and watering. The seed bed should be constructed with an inch of clean, fresh sand on top, with heavier soil beneath. For the inexperienced grower, particularly, it is better to make furrows six inches deep and about a foot apart, planting the seed broadcast on the ridges between. The water may then be run in these furrows and allowed to

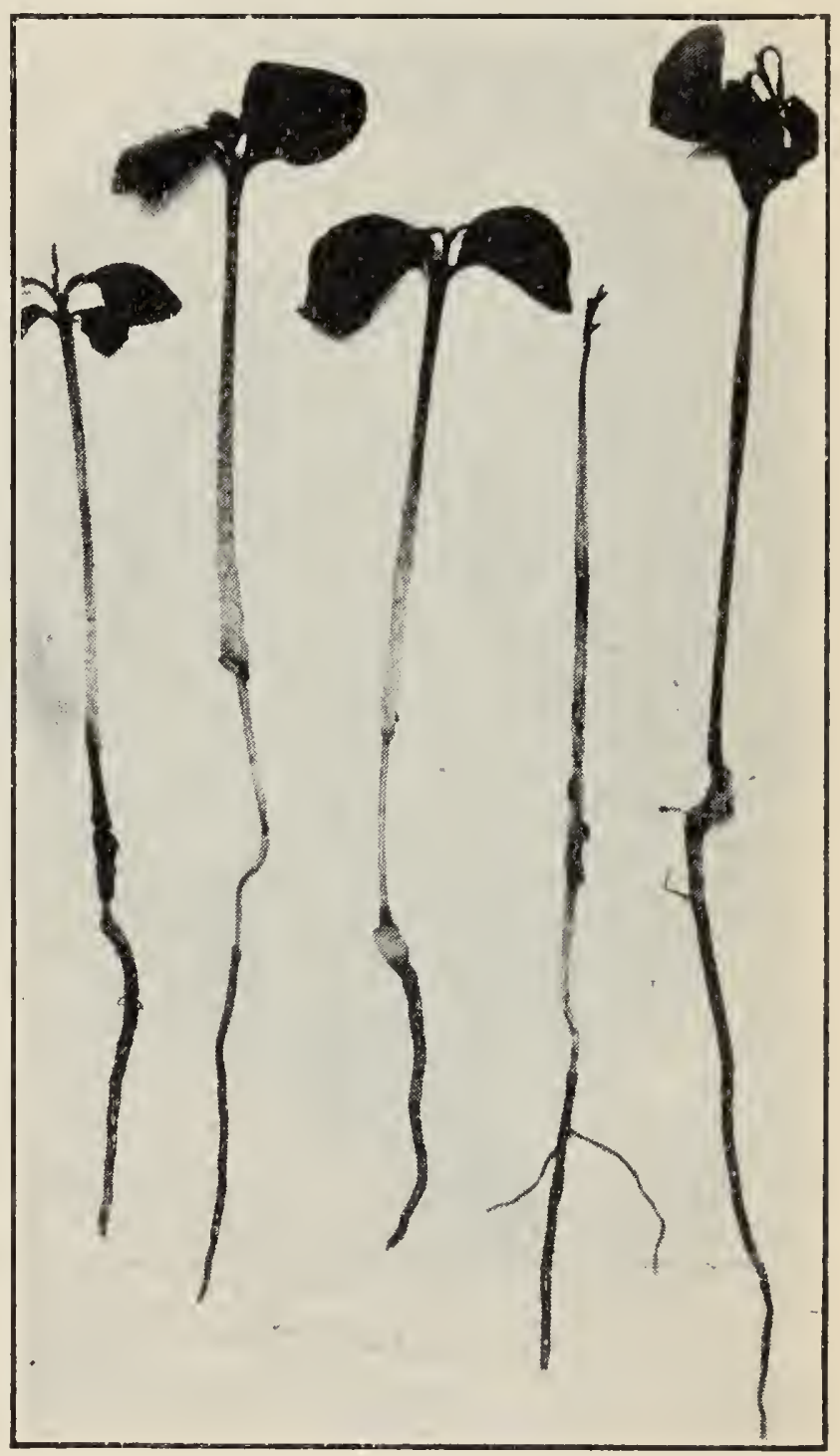

FIG. 66.-Damping off of orange seedlings. soak into the ground laterally, rather than being sprinkled on the surface. Where the seed is sown broadcast all over the surface of the bed and the water applied by sprinkling, watering should always be done in the morning and no oftener than is absolutely necessary. In many cases a good watering once a week is sufficient to keep the soil under the sand wet enough and.twice a week is almost always sufficient until the plants get quite large. It is better to give the bed 
a good soaking at long intervals rather than to keep sprinkling on a little water frequently. One should keep the surface as dry as possible and after the plants get well started determine the need of water by digging down into the soil beneath rather than wetting the bed as soon as the surface sand gets dry.

LenF Spot-Gum Spot. Figure 67.

Dark colored, slightly raised spots or areas appear on the back side of

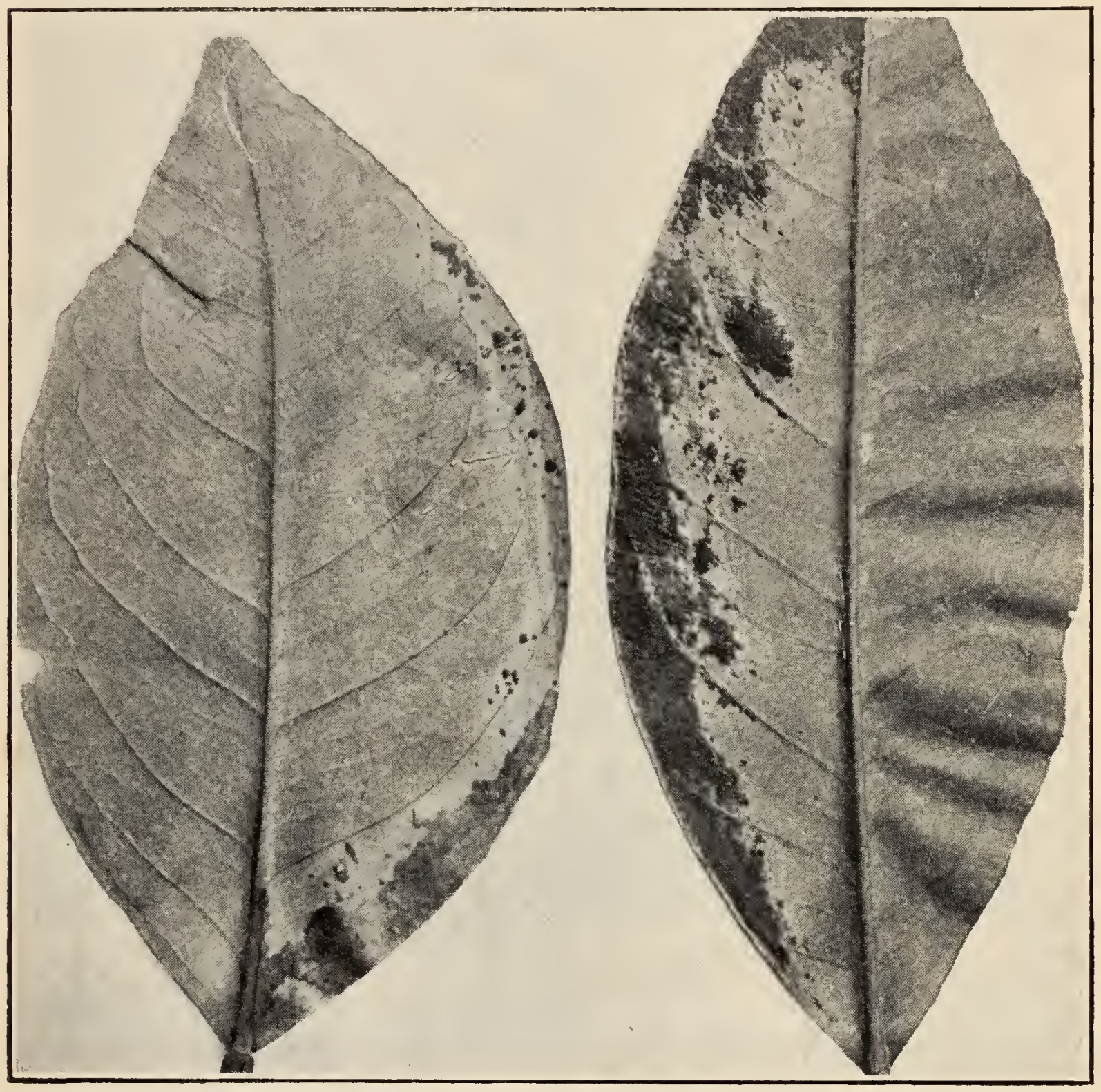

FIG. 67.-Gumming of orange leaves.

the leaf in places where it is turned up and exposed to the sun. These spots are formed by the deposition of a gummy substance in the tissue. The trouble appears to be in a form of gumming resulting from sunburn on the under side of the leaf. Not serious.

Blue Mold (Penicillium italicum and P. digitatum). Figure 54.

The fruit shows a soft, moldy decay, the surface of the affected portion being covered with a dusty mass of spores, of a blue or green color, according as the first or second named fungus is present. The blue 
fungus is somewhat more active than the green and causes occasional infection by contact from one fruit to another.

The two fungi named above are the commonest cause of decay in citrus fruit. Only very slightly parasitic on uninjured fruit; this decay is practically confined, under ordinary conditions, to fruit which has been injured in handling.

The extensive demonstrations of the United States Department of Agriculture have established beyond question that citrus fruit will keep indefinitely so far as blue mold decay is concerned, unless the fruit has been bruised or injured in some manner. Such injury comes about mainly either through cuts in the stem end made in clipping the fruit from the tree, from rough handling during the process of hauling to the packing house, or in grading or packing. As a result of the demonstration mentioned above, the whole practice of citrus fruit handling in California has been revolutionized along the line of more careful handling, and implements and apparatus tending toward less injury in picking and handling fruit have been developed. Each year's experience goes more and more to demonstrate the possibilities of almost absolute prevention of this commonest form of decay through careful handling.

Navel Rot-Black Rot. (Alternaria citri). Figure 68.

Affected oranges color prematurely in the fall and are affected with a dry, black rot in the tissue below

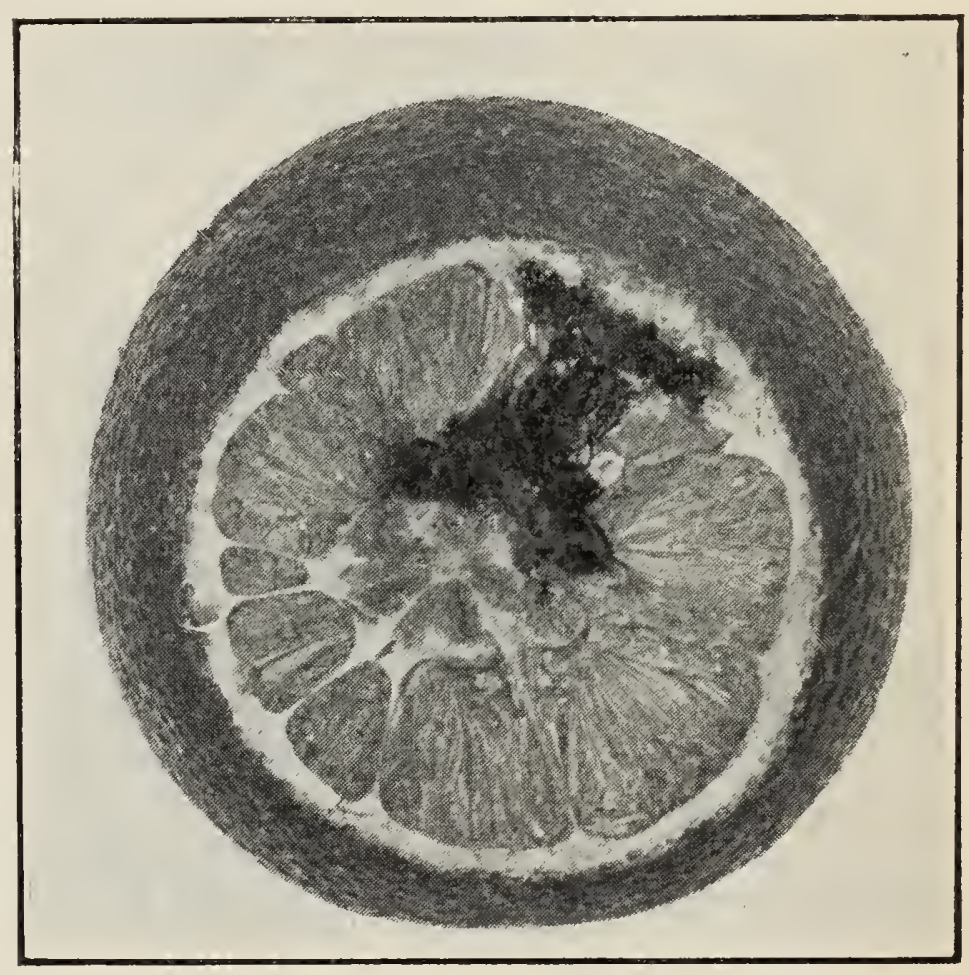

FIG. 68.-Navel rot of orange (Alternaria citri).

the navel end. This rot is not very virulent and often remains confined to one section of the orange. Occasionally in seasons of considerable early rain this trouble becomes quite abundant, but it is not usually a serious matter.

Brown Rot. See Lemon.

Brown Spot. Figure 69.

A serious trouble in some localities, characterized by the development of dark brown, sunken, dead spots of considerable size on the rind, appearing from five to ten days after the fruit is picked. Not visible on the tree. Apparently due to climatic or other local conditions rather than to any parasite. 
The nature of brown spot appears to be that of a premature dying of the rind in certain spots. The fruit shows absolutely no indication of any such trouble while it is on the tree or immediately after picking, but after a few days have elapsed these sunken, dark colored, dead spots begin to appear. Some years they become darker in color than others. So far as known the trouble only affects the Washington navel orange and is worst on the smoothest, highest quality fruit. Coarse, l'ough fruit is not as likely to be affected. The trouble is usually much more prevalent in the inland districts with hotter weather in summer, than it is out toward the coast. The earliest picked fruit is much more affected than that left on the trees until late in the season and, in fact, brown spot usually disappears almost entirely after January. For this reason the growers have a theory that the occurrence of heavy winter rains stops this trouble. Fruit picked very early, while still green,

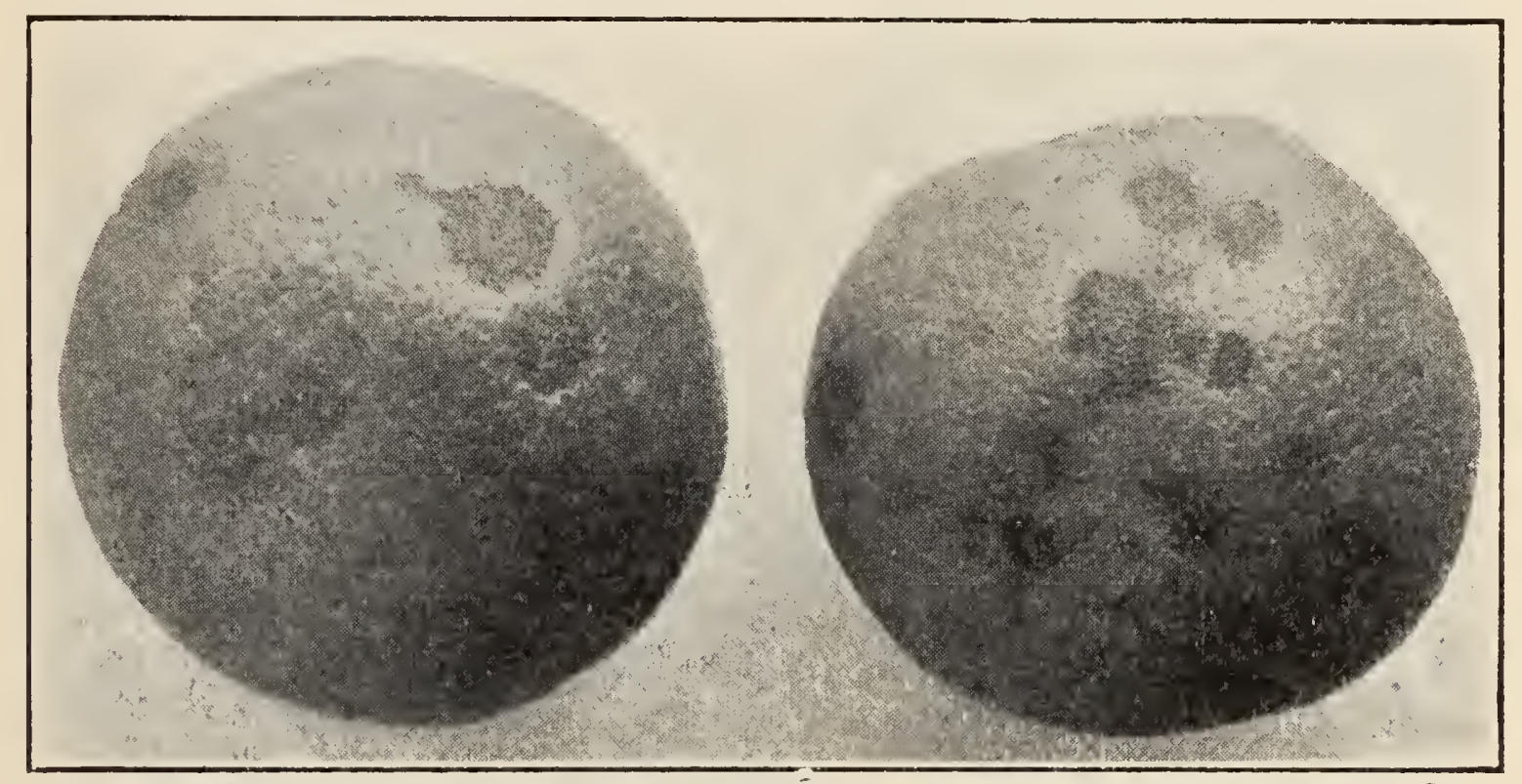

FIr. 69.-Brown spot of orange.

say early in October, shows the spot very decidedly, the spots remaining green when the rest of the rind has turned to its normal yellow color. Fruit from all sides of the tree appears to be equally affected, so far as has been determined. Various forms of spotting may be found on navel oranges while still on the tree, but it is certain that brown spot has no connection with any of these, but that the true brown spots develop in portions of the rind which are absolutely smooth and unblemished when the fruit is picked.

It would appear that in the physiological processes which go on in the rind during its development and ripening, some substance or principle is present in certain areas which inhibits these normal processes. When the orange is picked early in the season it appears that this inhibiting substance is in an active condition and causes the area of tissue where it is present to begin to die as soon as the fruit leaves the tree. If the orange stays on the tree until later in the season the injurious substance 
seems to disappear or be removed in some manner, leaving the rind in a normal condition. When decolorized and treated with iodine, the rind of oranges freshly picked in a brown spot season and locality shows the presence of an accumulation of starch in areas here and there, corresponding to about the size and distribution of the brown spots which would have developed on the same oranges if they had been kept for a week or two. If tested in the same way after the spots have developed, an accumulation of starch is similarly found in the areas forming the spots. It therefore appears that diastatic action in these areas is inhibited in some way.

Investigation has thus far failed to demonstrate the nature of the

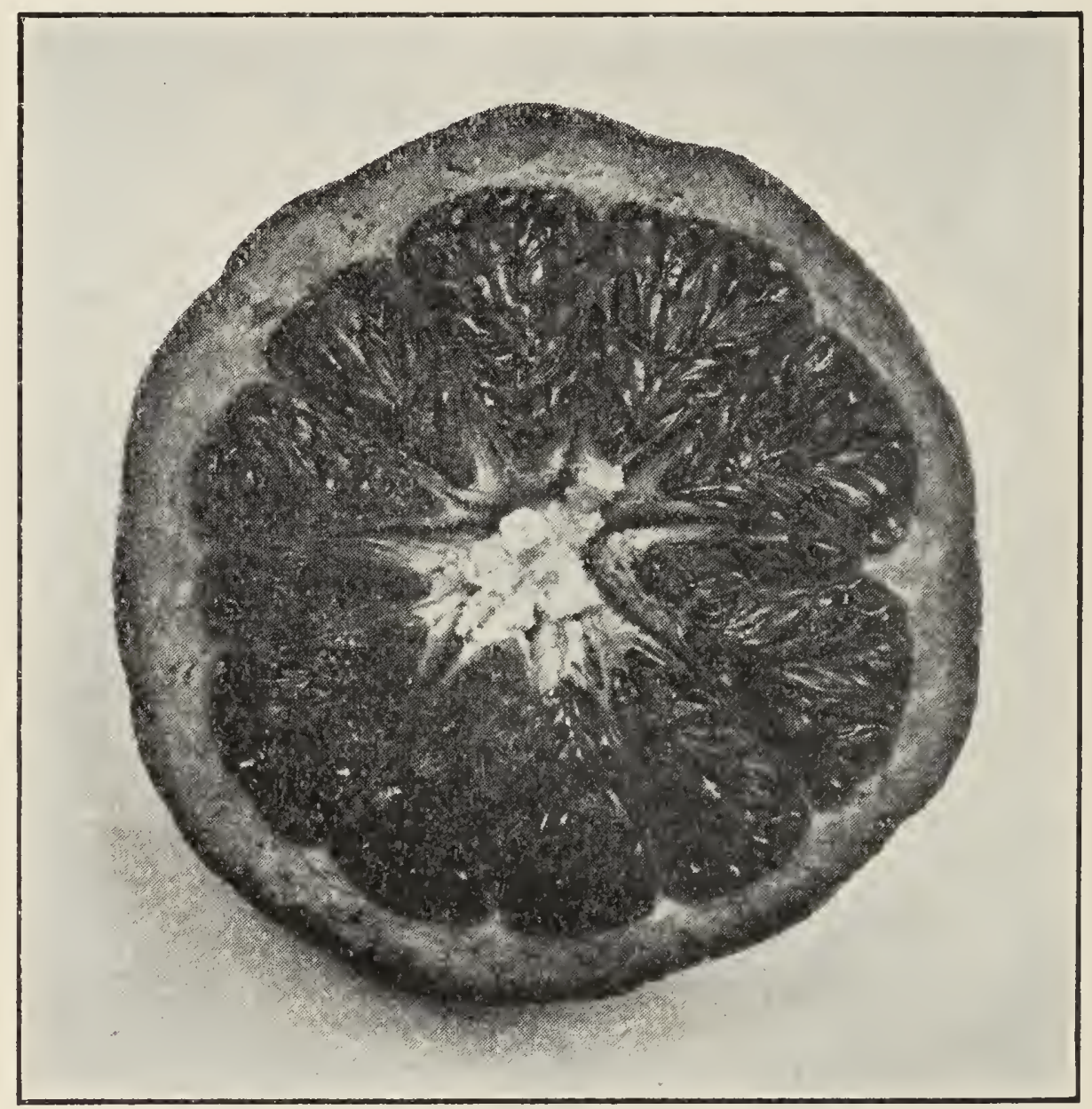

FIG. 70.-Puffing of orange fruit.

initial injury, whether due to some climatic condition, lack of moisture, or possibly an insect puncture. It is certainly not due to frost or cold weather. The fruit from certain groves seems to show the trouble more than that from others, and it is possible that the same is true of individual trees, but this has not yet been determined.

See Bulletin 203, page 47, California Experiment Station.

\section{Splitting.}

The fruit cracks and splits on the tree before maturity. Varies from year to year in abundance. Apparently caused by climatic or seasonal conditions causing irregularity in the growth of the fruit. 
Puffing. Figure 70.

Characterized by a condition of the rind indicated by the above name. The surface of the fruit becomes rough and uneven, due to a spongy condition of the rind. The whole orange becomes soft and structureless with an unnatural sweetness.

This trouble varies with the season and appears to be connected with soil moisture conditions.

StaIN.

A discolored, darkened condition of the rind developing after the fruit has been picked. Occurrence apparently confined to fruit which has been subjected to low temperatures, either in transit or cold storage.

\section{Shoulder Spot-STem ENd Spot. Figure 71.}

A dry, brown, dead spot or area develops upon the orange about the stem end or at one side of the latter" on the "shoulder" of the fruit. These spots are primarily dry and not of the nature of decay, but they often become infected with blue mold or other fungi. Often, too, they are covered with a growth of a Cladosporium fungus, which forms an almost black mold upon the surface. These spots may also become infected with the wither-tip fungus. This form of spot or deterioration at the stem end of the orange occurs only in old fruit, most commonly in the last Washington Navels of the season. It is especially abundant in seasons following years of exceptional drouth, particularly when the fall rains are very late in commencing. The normal deterioration of the orange when its physiological life is ended begins at the stem end and the present trouble appears to be simply a somewhat premature death of the tissue, owing to the age and weakness of the fruit. This is made more pronounced, as has just been suggested, by a long, dry season during the preceding fall which weakens the tree and thus reduces the vitality and length of life of the fruit.

\section{Miscellaneous Spots and Blemishes.}

Oranges and other citrus fruits are subject to a variety of surface spots and blemishes. In a paper prepared by Dr. J. Eliot Coit of this Department, published in the California Cultivator of March 16, 1911, about fifty different forms of such blemishes are classified and described. These are classified as being. caused by insects, fungi, mechanical injuries and physiological troubles. Those which we have described above are by far of the most importance, although occasionally in certain seasons some other form of spotting, blemish or injury occurs which attracts considerable attention for a temporary period. Frequently in such cases certain mold fungi develop upon the surface of the areas affected and are sometimes taken for the cause of the trouble. This is particularly the case with a species of Cladosporium which pro- 


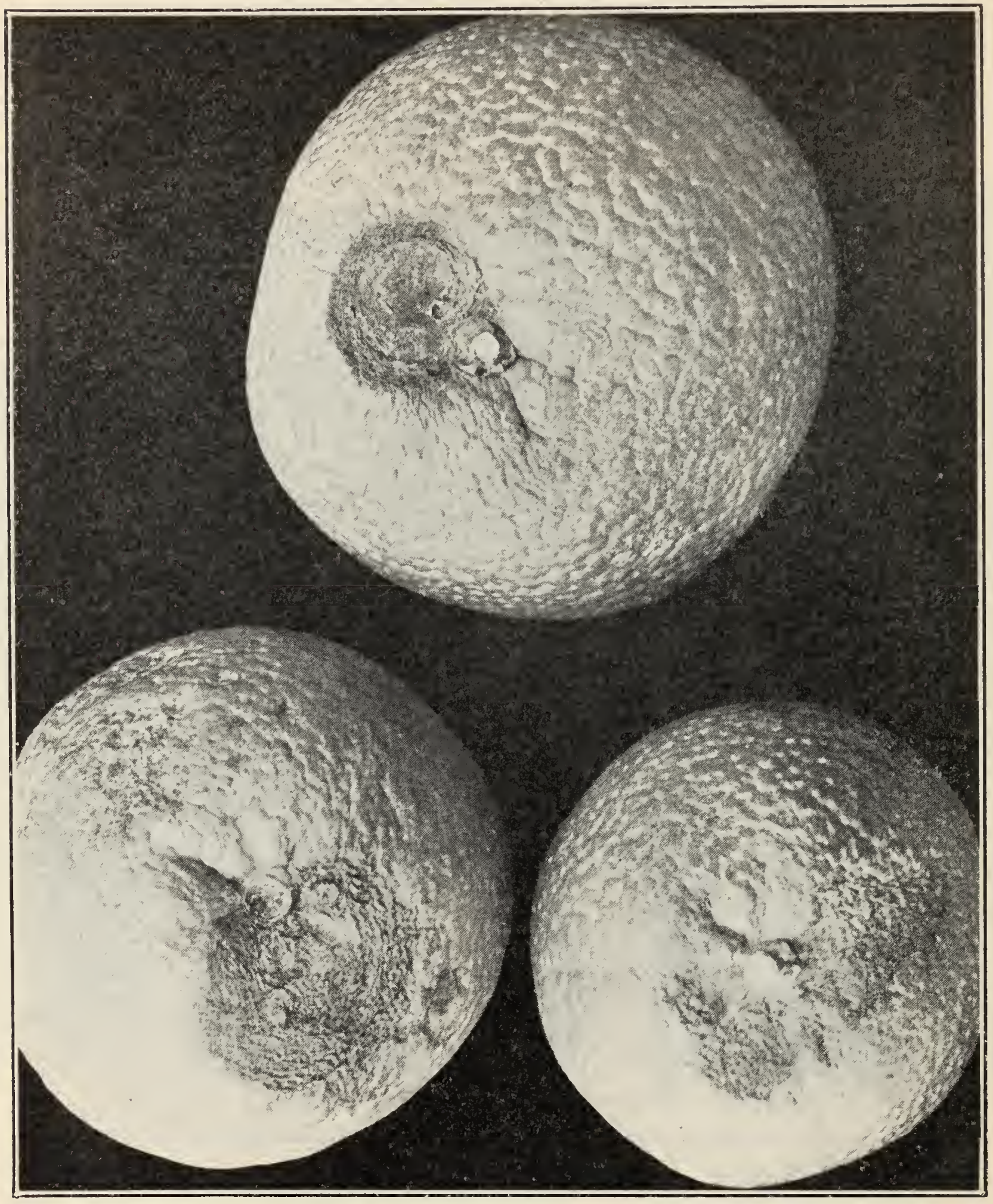

FIG. 71.-Shoulder spot of orange. 
duces a dark brown mold on the surface of the spots. This fungus, however, has nothing to do with originating any form of spot upon citrus fruit.

Palm (Phoenix canariensis, dactylifera, ete.).

LeAF Spot (Graphiola phoenicis). Figure 72.

Injures the lower leaves of the date palms with the production of minute black protuberances of the fungus, mostly on the lower side of the leaves.

Remove all affected leaves, and if this fails to control the trouble the

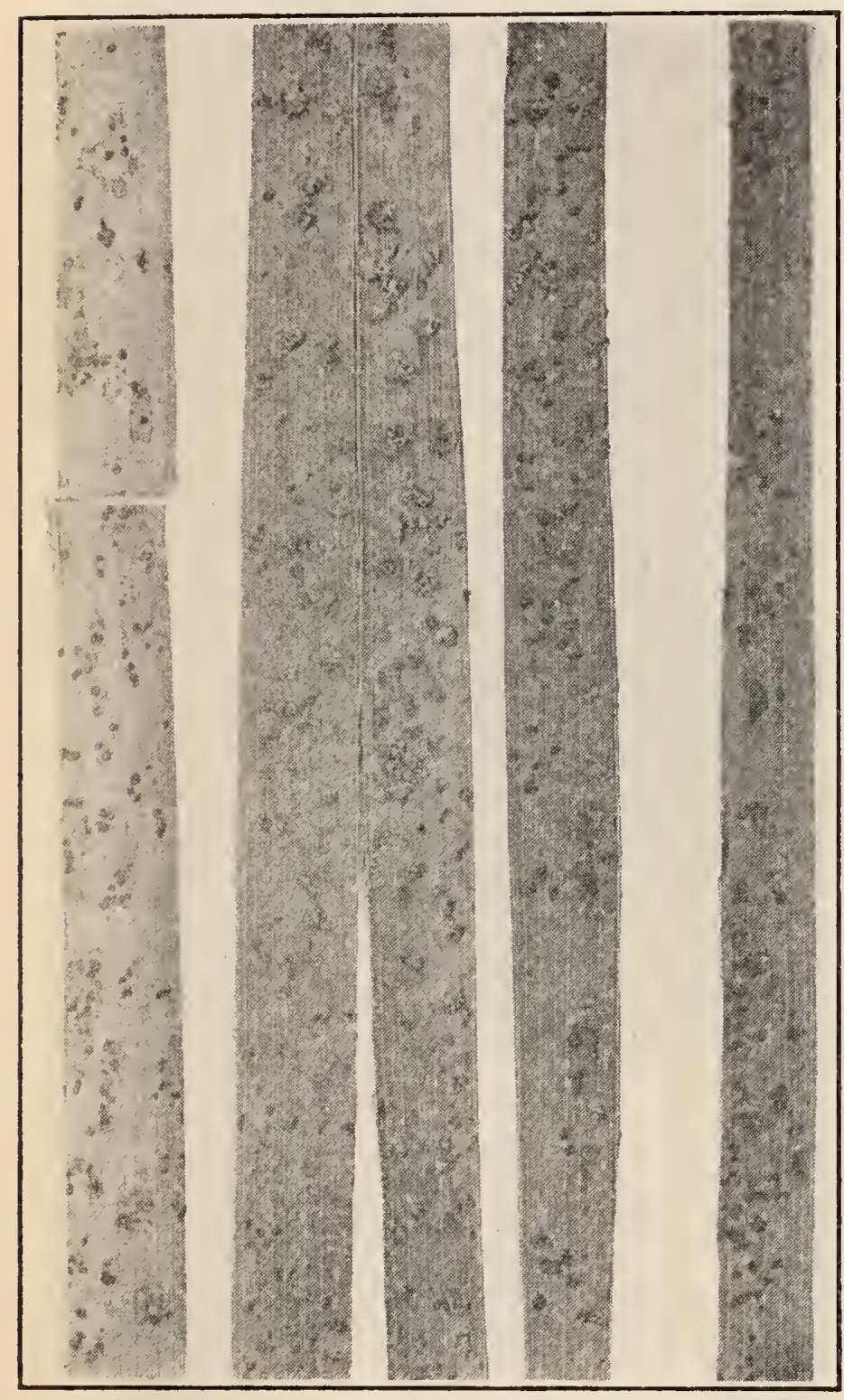

FIG. 72.-Palm leaf spot (Graphiola phoenicis).

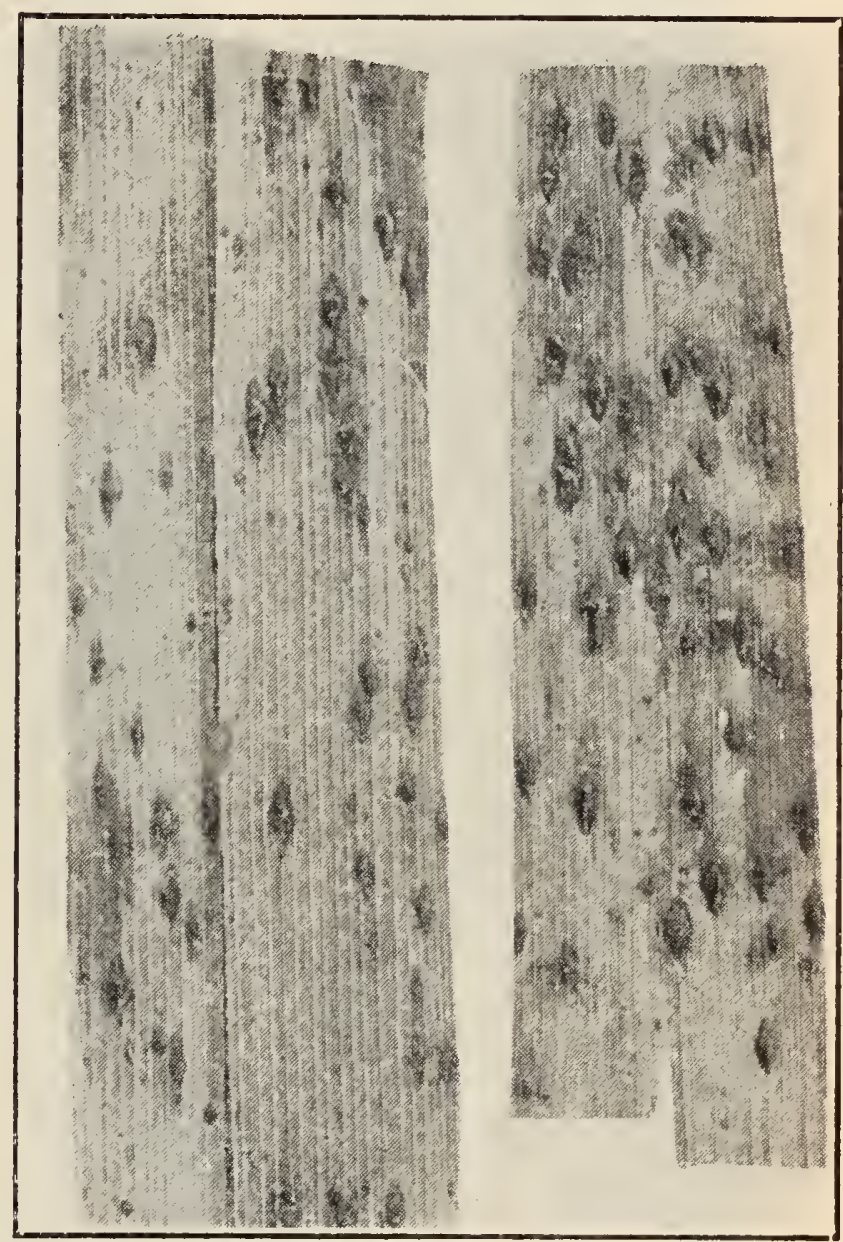

JiG. 73.--Palm leaf spot (Sphaerodothis neowashingtoniae).

trees may be sprayed with the ammoniacal copper carbonate. Bordeaux mixture is effective, but disfigures the tree.

\section{PALM (Washingtonia).}

LEAF SPOT (Sphaerodithis neowashingtoniae). Figure 73.

The leaves become covered with small, elongated, black, slightly elevated spots of the fungus growth, and die:

Affected leaves should be removed. 
PEA.

Mildew (Erysiphe polygoni).

Covers the plants and pods with a white mildew. Most prevalent in wet weather and is usually only serious on the winter crop.

Dust the vines with dry sulphur at the first appearance of the trouble.

In cloudy weather spraying with Bordeaux mixture is most effective.

\section{Buigit (Ascochyta pisi).}

Produces black spots on the leaves and pods and seriously injures the vine. Most troublesome in wet weather.

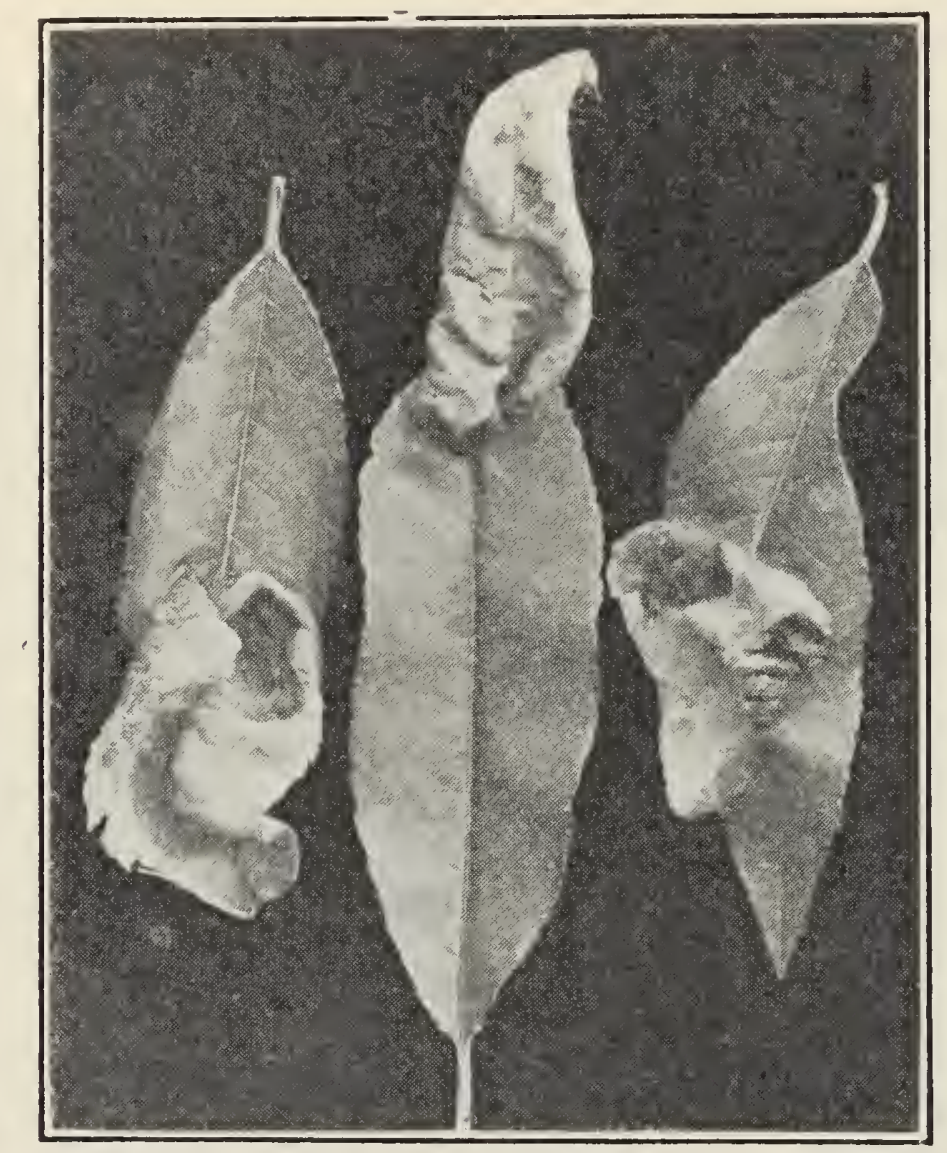

FIG. 74.-Curl leaf of peach (Exoascus deformans).

Spray with Bordeaux mixture if the trouble is serious enough to make it profitable.

\section{PEACH.}

LeAF Curl (Exoascus deformans). Figure 74.

Many of the leaves are curled and deformed in a characteristic manner as they develop in the spring. These afterward wither and fall, together with much of the fruit. A new crop of leaves then develops in a normal manner.

Spray with Bordeaux mixture or lime-sulphur just before the buds open in spring.

\section{Blight (Coryneum beyerinkii). Figure 75.}

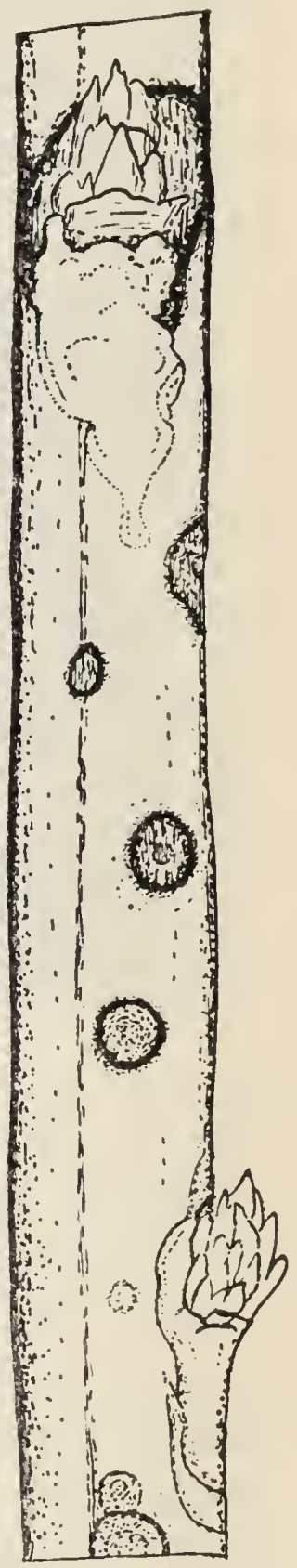

FIG. 75.-Peach blight (Coryneum beyerinkii).

Dead spots appear on the young shoots during the winter, particularly at the buds. The buds are killed, together with much of the young 
growth or fruiting wood. During the spring rains a jelly-like gum exudes in large quantities from these dead spots.

Spray with Bordeaux mixture during November and again with the same material or lime-sulphur just before the buds open. A combined spraying may be made for blight, curl leaf and peach worm by using Bordeaux in the fall and lime-sulphur in the spring.

See Bulletin 191, California Experiment Station.

\section{Mildew (Podosphacra oxyacantho).}

A white powdery mildew appearing on the leaves during the summer. Not serious.

Die-Back. See Almond.

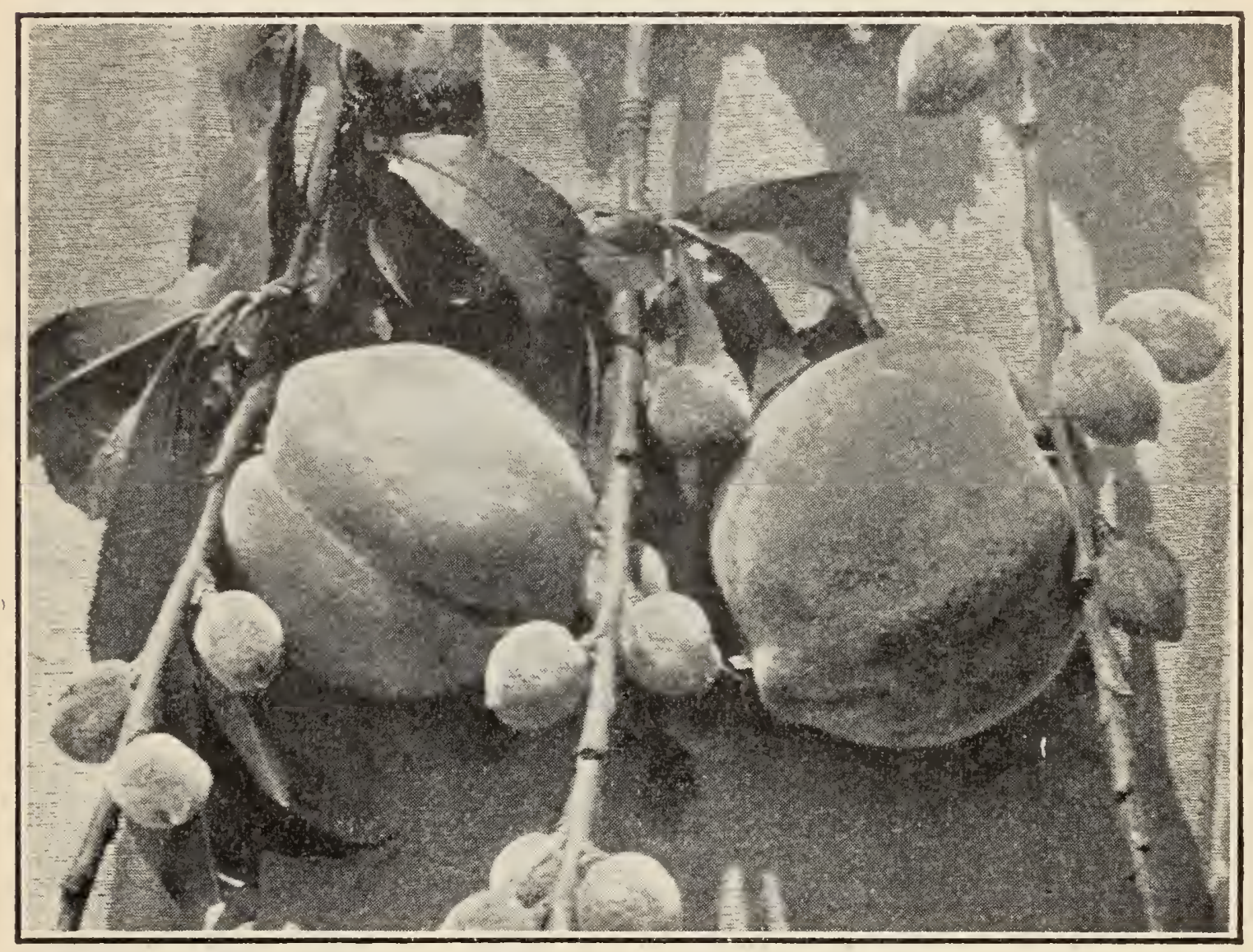

FIG. 76.-Little peach.

Littrle Peach. Figure 76.

Some or all of the peaches remain small and undeveloped, while the normal fruit is reaching full size.

This is not the dreaded little peach disease of eastern states, but appears to be the effect of imperfect pollination. Its occurrence has been found to follow seasons of much rainfall during the blossoming period. Not serious. In some cases Fruit Drop occurs from the same cause. See Almond.

Brown Rot. See Apricot.

Crown Gall, Root Rot, Sour Sap, Rust. See Almond.

Gummosis. See Cherry. 
Split Pit.

The pit cracks and splits into many small fragments while the fruit is still on the tree. Cause not known, but apparently climatic. Possibly due to frost injury in spring.

\section{Fruit Gumming.}

Masses of gum appear on the surface of the fruit, which may be traced through the flesh to their origin in the pit. Apparently somewhat connected with the last trouble.

\section{Little Leaf-California Yellows. Figure 77.}

Characterized by the development of spindling, yellow, sickly looking shoots on the new growth, with small, narrow, yellow leaves. The leaves along the shoots drop off during the summer, leaving tufts at the ends. Fruit fails to develop, shrivels and drops. Worst on trees from three to seven years old.

This trouble also attacks other stone fruits, walnuts, pecans and other trees. Always worst on lighter, drier soils, this feature showing itself by the more pronounced occurrence of the disease on trees standing in sandy streaks or slight elevations in the orchard.

This trouble has no relation to the true Eastern peach yellows, but is decidedly climatic and seasonal in its appearance. Occurs mostly following unusually dry seasons, on trees standing in light soil or one underlaid with a coarse, sandy subsoil. Trees on a fairly heavy subsoil, or those which have received abundant irrigation throughout the preceding season are decidedly free from the trouble even in the worst affected localities. Appears similar in nature to "mottled leaf" of the orange, and, in fact, orange trees growing near peaches affected by "little leaf" show a typical "mottled leaf" condition. Many other kinds of trees are also more or less affected.

The typical peach disease has been seen only in the San Joaquin Valley, in the most sandy regions.

In most cases, regular irrigation during the summer shows a marked effect in controlling this trouble. Such irrigation should be given particularly in the latter part of the season, after the crop is off, especially when the rains are late in commencing.

\section{Climatic Effect.}

The trees fail to leaf out properly in the spring and seem to become confused, so to speak, as to the season. Later in the summer the trees may bloom and leaves begin to appear, but the tops usually die back nearly to the forks of the tree and sometimes the trees die entirely. If not too badly affected, the tree sends out new sucker growth from the trunk and base of the main limbs. Plums, apricots, apples and other trees are sometimes affected. 
This trouble is one which occurs mostly in the southern part of the state as a result of unseasonable climatic conditions. It is usually most pronounced in seasons when a period of warm, stimulating rains in the winter is followed by a long, cold spring. Similar results are also pro-

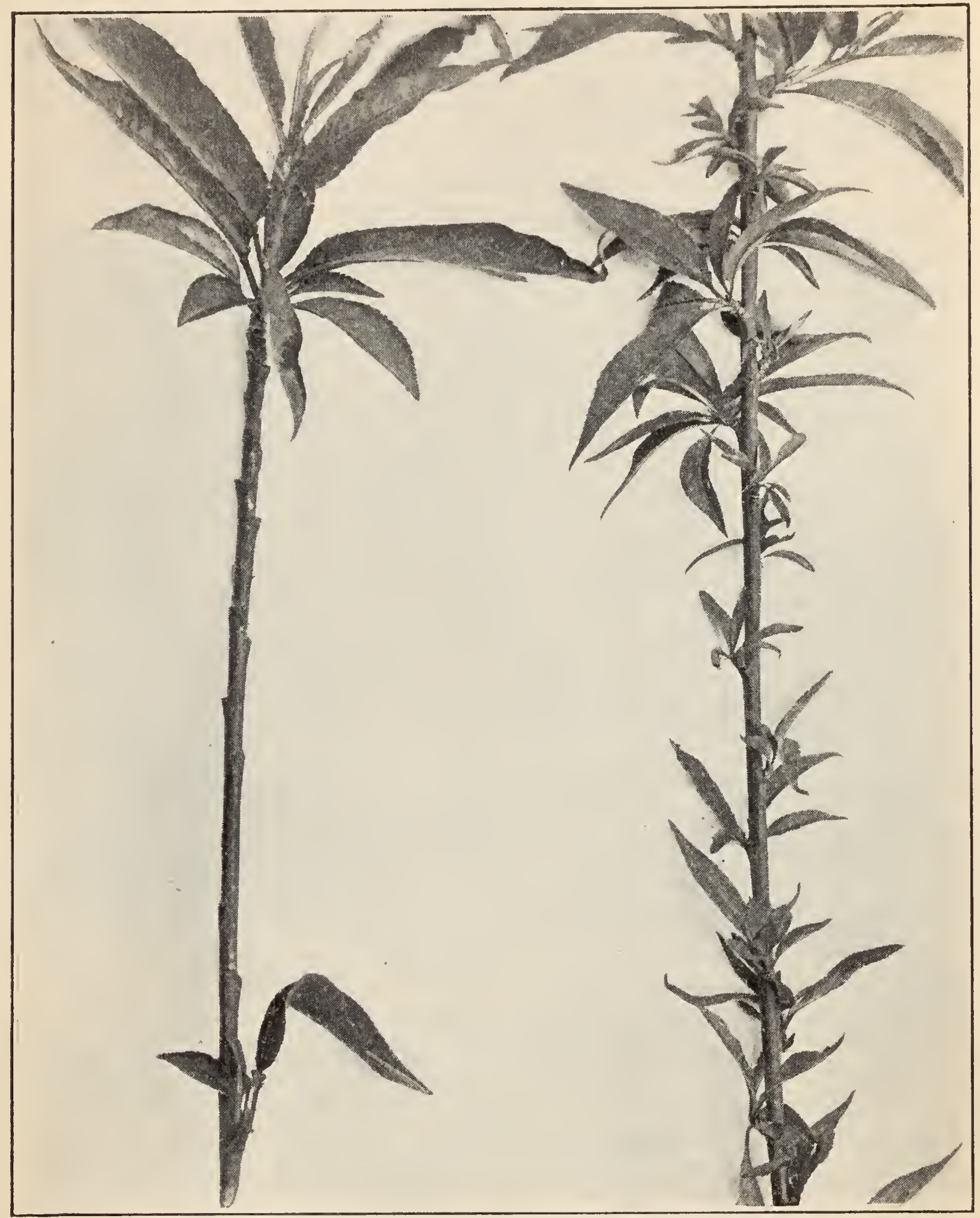

FIG. 77.-Little leaf of peach.

duced by an abnormal, dry fall, throwing the trees into a dormant condition, followed by warm, spring-like weather accompanying the winter rains. These combinations and various others often have unfavorable effects upon trees which are accustomed to a definite resting period during the winter. Many peculiar diseases of deciduous fruits described 
in this bulletin under various names, such as "die-back," "yellows," ete., are no doubt contributed to by such disturbances in the normal period of dormancy. Every few years there is usually a season, especially in the southern part of the State, when deciduous trees are badly affected in such ways as these.

Following such an attack, trees should be pruned back to healthy, vigorous wood, when they will usually form a new top and come back into good condition again. With peaches it is noticeable that varieties of the saucer or Peen To type are not affected in this manner, as are the Persian varieties.

\section{PEAR.}

ScAB (Venturia pirina). Figure 78.

Similar to apple scab, which see. Develops as a dark brown fungus in spots on the young pear or even in the blossoms. Also on the under

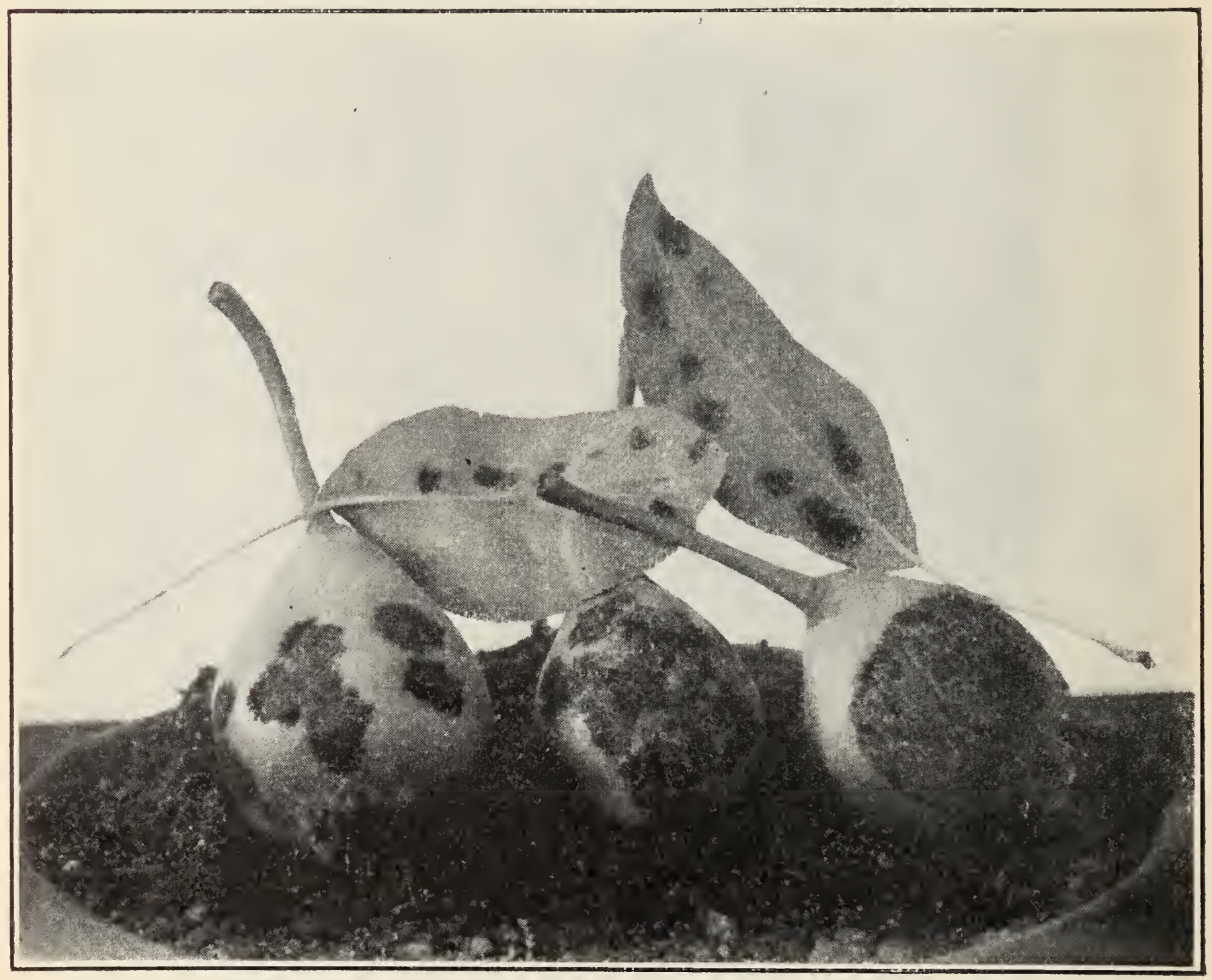

Fig. 78.-Pear scab (Venturia pirina).

side of the leaves. Nuch worse in sections with abundant moisture in spring. Olten causes much of the fruit to fall at the very first of its development, while the affected pears which remain on the tree are scabby and much deformed. 
Spray with Bordeaux mixture. See Apple Scab. Combined spraying may be done for scab and codling worm.

See Bulletin 163, California Experiment Station.

Blight (Bacillus amylovorus). Figure 79.

The leaves, blossoms and young fruit wither and turn black on the affected portions but do not fall, remaining tightly attached to the twigs during the winter after the green leaves have fallen. Caused by a bacterial organism which produces its infection largely through the blossoms, being carried by insects from tree to tree. The infection proceeds downwards through the inner bark of the twigs and branches and when working vigorously the blight kills the twigs or whole branches

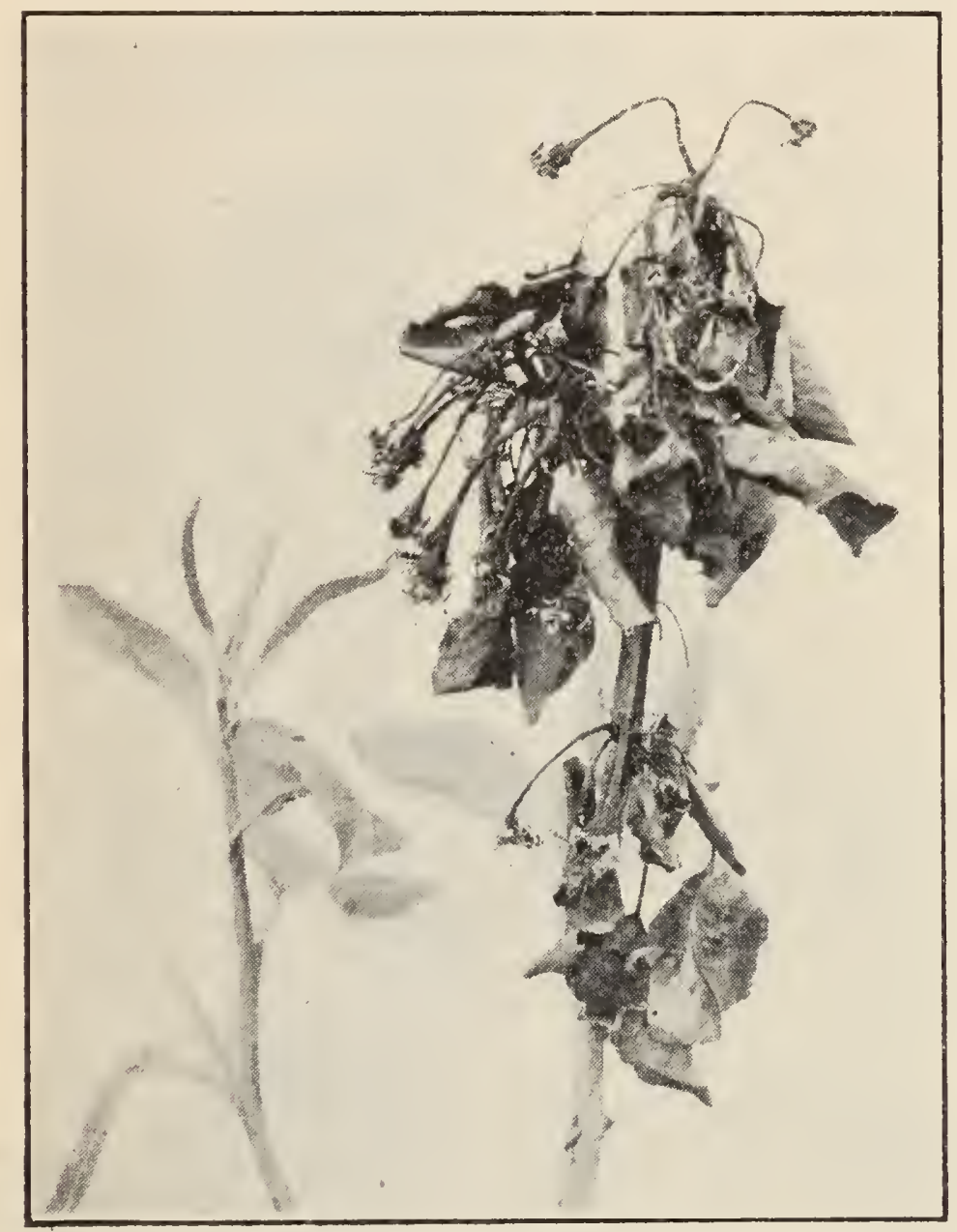

FIG. 79.-Pear blight (Bacillus amylovorus). very rapidly. The disease often runs down into the large limbs, where it remains alive over winter, producing the so-called "hold-over" blight, which is a source of infection during the following season.

The blighted twigs, branches or trunks show a red, sappy, juicy condition of the inner bark when infected with the true pear blight organism. If the disease is fresh and active the bark when cut into is very juicy, exuding the slightly sticky sap quite freely and showing the characteristic bright red color in the inner bark. This symptom is of importance in distinguishing true blight from such troubles as sour sap, crater blight and black leaf.

In the smaller twigs and branches the organism dries out and becomes entirely dead. Infection also takes place through the agency of biting insects in the young shoots and suckers. Through this means the disease frequently gets into the trunk of the tree and also down into the roots. Here it spreads and causes the death of the tree by slow degrees, due to the destruction of the inner bark of the trunk or main roots. In such cases the leaves of affected trees take on a peculiar 
bronzy reddish coloration in the fall, which is quite characteristic to the experienced eye.

From the "hold-over" blight in the trunks and large limbs an infectious sap exudes when growth starts in the spring, which sap contains myriads of the blingl organism. This sap is attractive to insects, which, in feeding upon it, get the blight bacteria upon their bodies and mouth parts, and transfer them to the blossoms or green shoots of other trees, thus spreading the infection.

Cut out and destroy all diseased parts, taking care particularly in the summer time to cut far below any visible sign of the disease, even at the sacrifice of considerable fruit. The pruning instruments should be kept constantly disinfected, using a solution of corrosive sublimate (bichloride of mercury) 1-1000.

Trees badly affected in the trunk or roots should be taken out and destroyed, unless it is possible to cut out all the affected tissue of the inner bark, which can be identified by its reddish color. In some cases the affected tissue can thus be removed, cutting back to sound bark and wood on all sides, and the tree saved. In doing this work the tools should be thoroughly disinfected, and the wounds saturated with the disinfectant and afterwards painted over with white lead paint.

See Bulletin 184, page 221, and Bulletin 203, page 18, California Experiment Station.

\section{BLACK LEAF.}

In this disease one side or one limb of the pear tree dies and the leaves turn black and hang on for some time. The effect is quite similar in a general way to that of pear blight, but there is no sign of the presence of the pear-blight-causing organism as indicated by the red, juicy inner bark of limbs and twigs affected with the real blight. Sometimes there is connected with black leaf a dying of the bark extending in a narrow strip of uniform width down the trunk to the ground. All phases of this disease are distinguished from the true blight by the fact mentioned that there is not present the red, juicy condition of the inner bark, but the bark simply dies down and becomes very hard and dry from the first. This trouble also often occurs in orchards where the blight is not present and does not show the characteristic spreading of blight from tree to tree through the blossoms or by infection of young shoots and suckers.

The disease appears to be more of the nature of sour sap, connected most commonly with an excessive amount of moisture in the ground during the winter and spring. Where individual limbs are affected or narrow strips of bark on the side of the trunk, it appears that certain roots have been badly injured and that the portions affected above ground correspond with such roots. 
Crater Bligit't.

This term is a rather common one among pear growers, but is not applied to any very definite form of disease. It is supposed to signify a dying of certain spots or patches of bark situated on the limbs or trunk. In these patches the bark becomes rough on the outside and dark colored beneath the surface. Some injury of this sort appears to be connected with the disease described above, the bark dying in certain spots rather than in a strip up and down the whole length of the branch or trunk. True pear blight may also cause a similar effect by running in from a small shoot or fruit spur, but many cases of both black leaf and crater blight occur without the presence of the pear blight organism. Frequently, what is called crater blight is rea!! nothing more than the normal roughening of the bark of the pear tree as it grows older. In this tree the bark begins to crack and roughen in patches on the trunk and main limbs, and its normal condition has sometimes the appearance of the outbreak of some disease.

Curly Bark.

This is somewhat similar to the above, the bark cracking in concentric rings in spots upon the surface of the main limbs. It is not of any serious consequence.

Fruit Drop.

The young fruit drops from the tree while still very small and immature. Due to imperfect pollination. Ordinarily, results simply in a desirable thinning of the fruit, but sometimes a large part of the crop drops from this cause. May also be produced by frost affecting the fruit soon after setting. Such fruit may remain on the tree and continue to grow for some time after the frost occurs before falling.

\section{Ringed Fruit.}

Some years many pears are found at maturity with a scabby ring or belt of considerable width extending around the fruit. The pears are constricted in this portion, owing to interference with the growth. It is evident that this effect comes about through some injury to the pear when it is quite young. This is a frost effect, and pears in a very small, young condition may be seen with similar rings about them in a season when much damage has been caused by late frost.

\section{PECAN.}

Rosette or Frizizi es.

While not an important crop in Californ'a, there is considerable interest at present in pecan planting, and it is desirable to call attention to this disease.

Shoots develop of a spindling, yellow, frizzly appearance, continually 
dying back and shooting out anew from axillary buds. The trouble is very similar, if not identical, with that affecting the walnut and also seems to be related to what we have described as the California peach yellows. It is probably the same as the pecan rosette, which occurs in the southeastern states.

PLUM.

Die-Back, Crown Gall, Sour Sap, Rust. See Almond.

Brown Rot. See Apricot.

POMELO. See Orange.

POTATO.

Scab (Oospora scabies). Figure 80.

The growth of this fungus on the surface of the potato produces a rough, scabby condition greatly injuring its appearance and selling

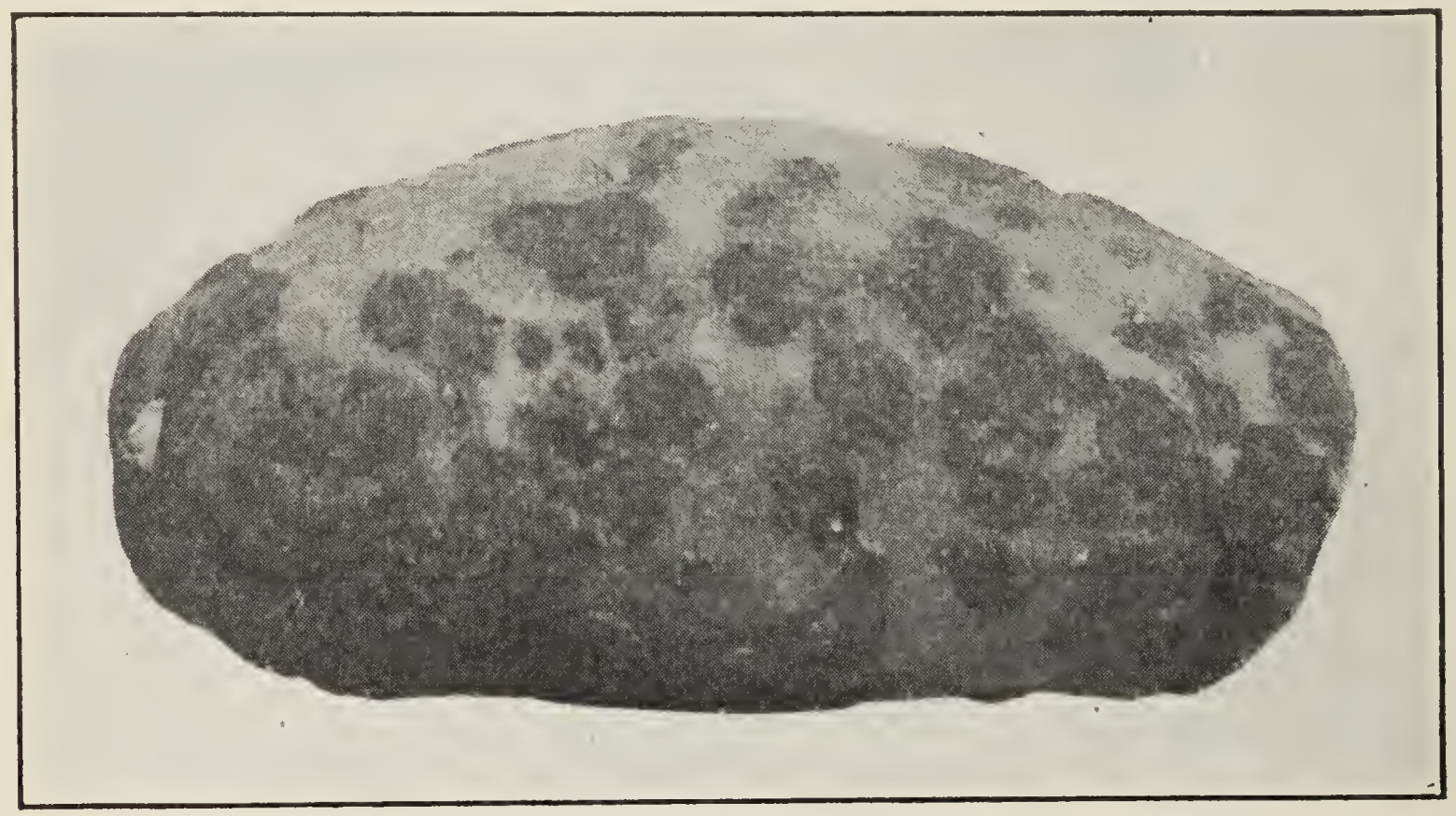

FIG. 80.-Potato scab (Oospora scabies).

value. Possibly this or a similar condition is also caused by other agencies than the fungus above named.

Use clean seed, treating before planting or cutting by soaking one and one half hours in a solution of one pint of formalin to thirty gallons of water. If the soil is badly infested, do not use it for potatoes for several years.

EARLy Blight (Alternaria solani).

Produces dead spots on leaves. Not serious in this State.

Late Blight (Phytophthora infcstans).

Causes death of the leaves and decay of the tubers. This fungus develops only when considerable moisture is present in the air, and its attacks on potatoes in California are therefore confined to those grown in the winter season or in very foggy localities near the coast. Under 
either of these conditions the disease may develop very disastrously and suddenly, killing down and blackening the potato tops, as though they were struck by frost.

Spray with Bordeaux mixture immediately after rains or during foggy weather, if treatment seems necessary.

Dry Rot (Fusarium oxysporum).

This fungus causes a decay of the stems and main roots, resulting in a gradual wilting and dying of the plants. Affected potatoes show a dark ring just inside the surface and from this the fungus may spread all through the tuber, producing a dry rot. Potatoes in storage sometimes develop this quite extensively. The parasite is thus carried in the seed and can be controlled only by planting potatoes which are free from this fungus.

Use seed known to be from a crop not affected by this trouble and do not plant potatoes in badly infested soil.

Brown StreatK.

The tubers show a brown ring or streaks in the flesh just beneath the surface, and sometimes throughout. This is sometimes confused with the disease preceding, but there appears to be a distinct trouble of this sort in which no fungus can be found. Occurs particularly in foothill and mountain districts. Apparently clean seed from outside districts develops the trouble in the first crop in affected regions.

\section{Black Leg (Bacterial).}

The disease appears when the plants are quite young and small. The affected plants are of a pale color, with the leaflets rolled inward and the shoots unnaturally straight. The stem is conspicuously blackened below ground, or in some cases somewhat above ground, especially in moist weather. The seed tuber decays prematurely.

This trouble, which appears to be due to a definite bacillus, has occured quite extensively in southern California.

Do not plant seed potatoes from affected fields. Soak the seed in formalin solution as for scab. Avoid planting in affected soil.

\section{Little Potato.}

Clusters of abnormally small tubers develop near the surface of the ground or even upon the stems above ground.

Apparently due to root or stem diseases which cause decay of the parts below ground. May be caused mainly by Rhizoctonia, which soil fungus is very common in California. In the latter case numerous small, black sclerotia, the resting stage of the fungus, are commonly to be found clinging to the surface of healthy potatoes of normal size, with apparently no ill effect. Figure 81.

Use same treatment as for scab. 


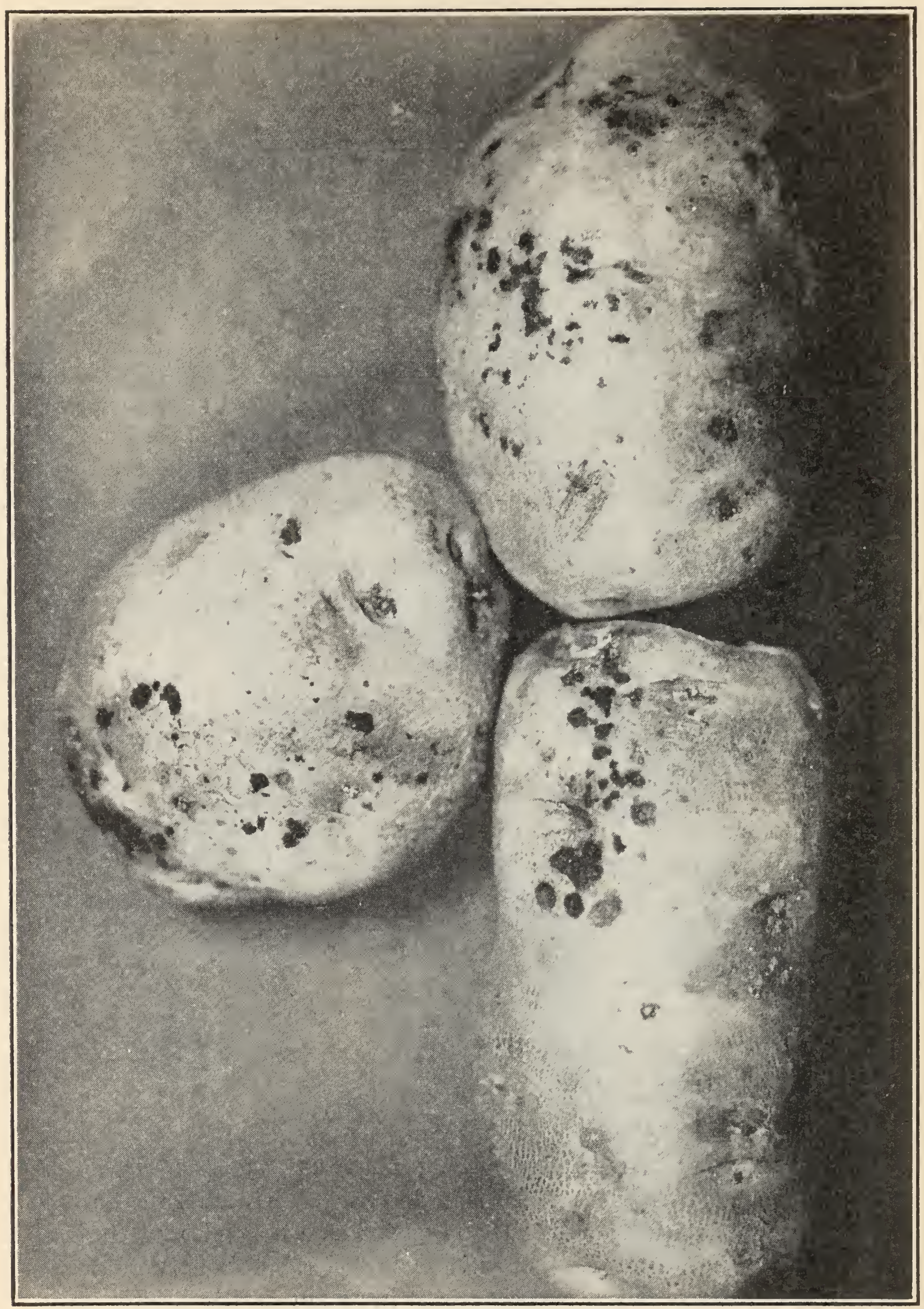

FIG. 81.-Rhizoctonia on potato. 
General Directions for Potato I'lanting.

Use seed from a field unaffected by disease of any sort and plant only potatoes which are free from decay and any internal discoloration.

Avoid planting on land where potatoes were affected the previous year with any disease of the parts below ground.

Before cutting the seed potatoes soak them for one and one half hours in a solution of one pint of formalin to thirty gallons of water.

PRUNE. See Plum.

\section{SilRTVELS.}

The fruit becomes discolored on one side, shrivels and dries before maturity, remaining small and worthless.

Prunes are grown in California very largely without irrigation, and this trouble is undoubtedly due to a lack of water. It occurs particularly in dry seasons when the winter rains cease very early. Under such conditions the water supply fails early in the season and the fruit has not sufficient moisture for its full development. The foliage also suffers from the same cause, many of the leaves fall, red spider becomes prevalent, hastening the fall of the leaves and further weakening the tree, and the fruit is exposed to sunburn, which hastens its premature maturity.

\section{PUMPKIN.}

MILDEW (Erysiphe cichoraccarum).

This white powdery mildew often covers the leaves of pumpkin vines. Not serious.

\section{WiLt (Bacillus tracheiphilus).}

The vines wilt and die from no apparent cause. A decay develops in the stem which appears to be caused by a bacterial organism. So far as investigated, this does not seem to agree entirely with the characteristics of the disease caused by the organism named above, which occurs in other parts of the country.

\section{QUINCE.}

Blight (Bacillus amylovorus). See Pear. Not serious.

Little Leaf. See Peach. Figure 82. BLACK KNOT.

Large black knots or swellings develop abundantly on the trunk and branches. This condition is so common and characteristic on the quince in California that it has come to be regarded as a normal one. It is a fact that there appears to be no particularly bad effect from such knots, as the trees continue to live and bear fruit in an apparently healthy condition. Whether or not these swellings are due to the specific organism. of root knot (Bacterium tumefaciens) has never been determined. 


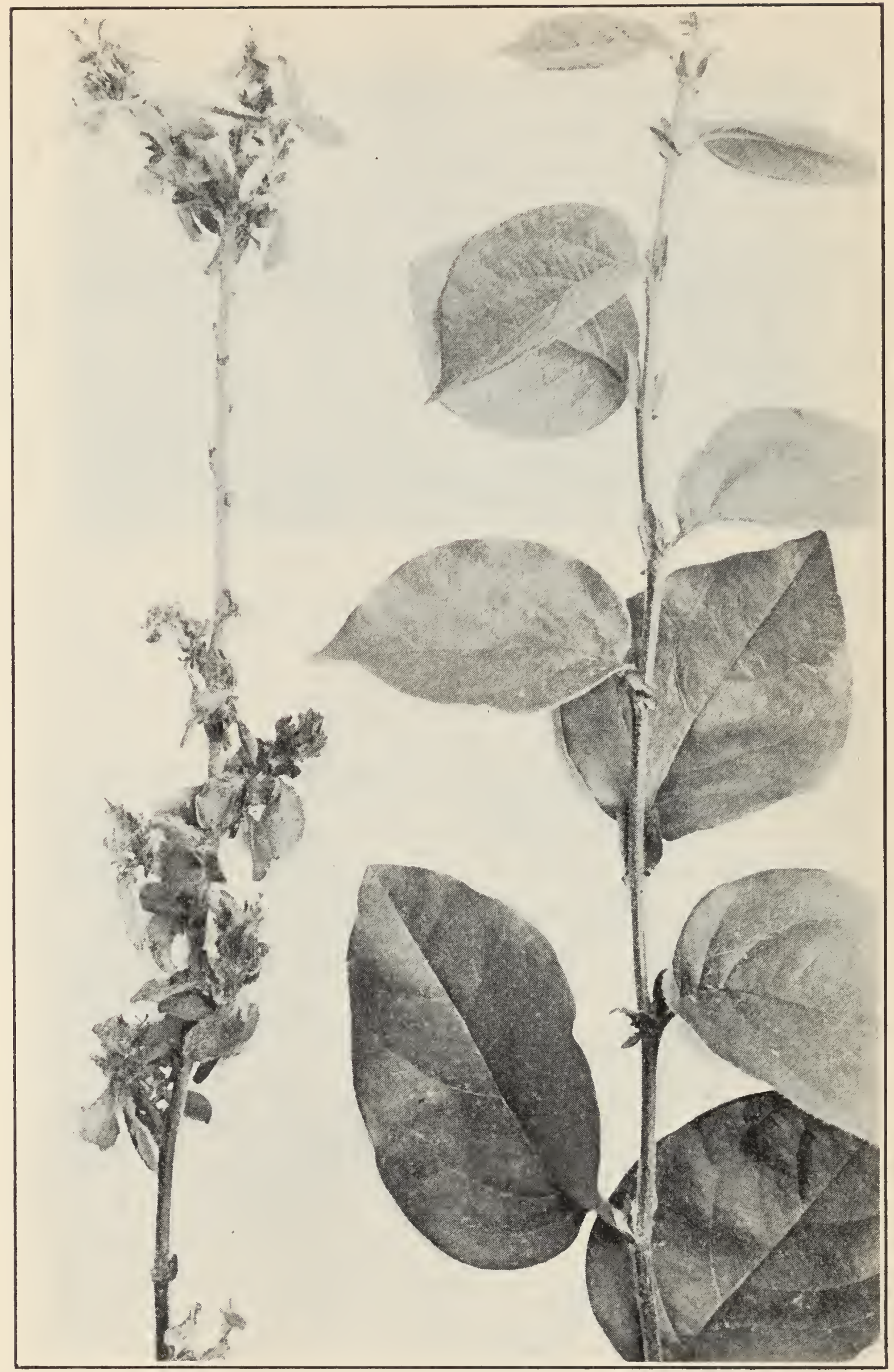

FIG. 82.-Little leaf of quince. 


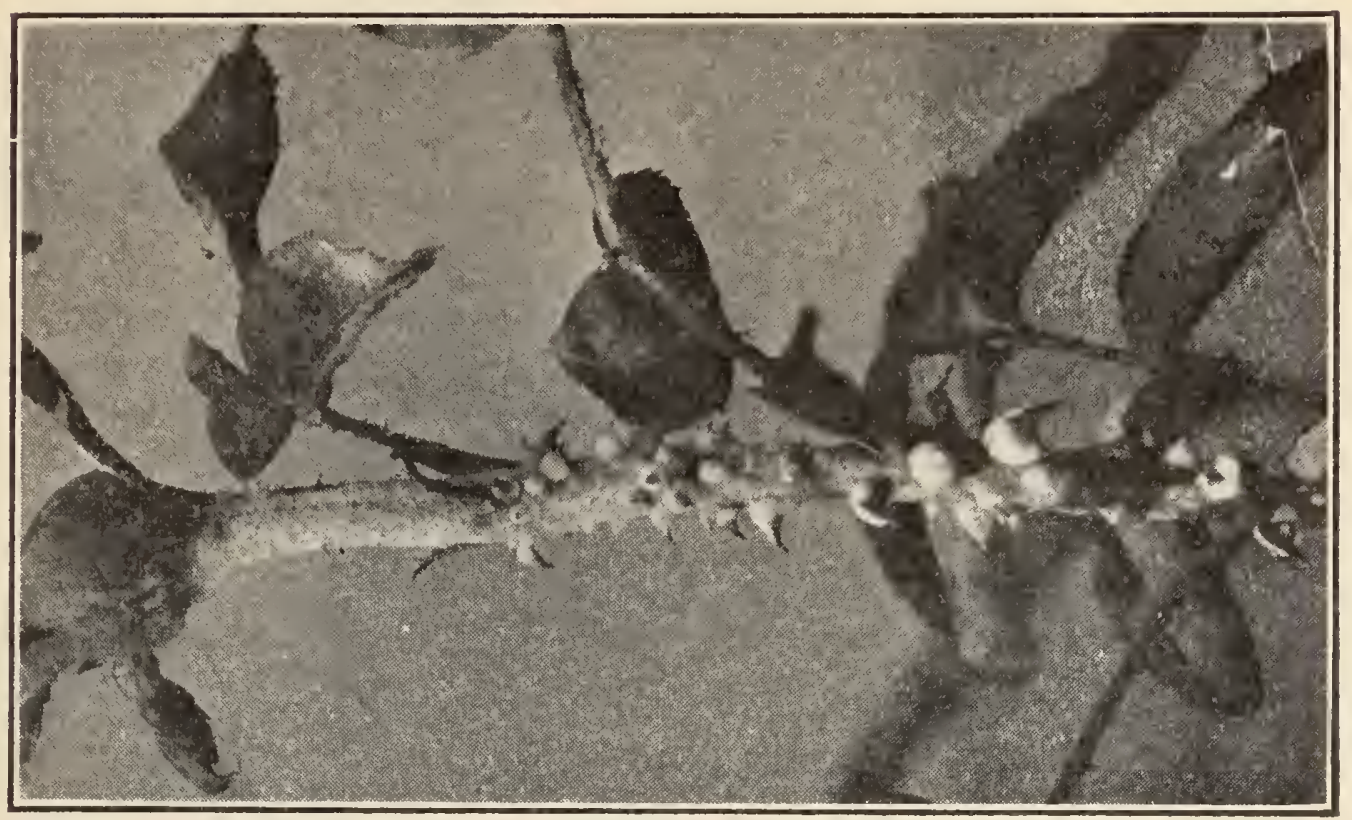

要

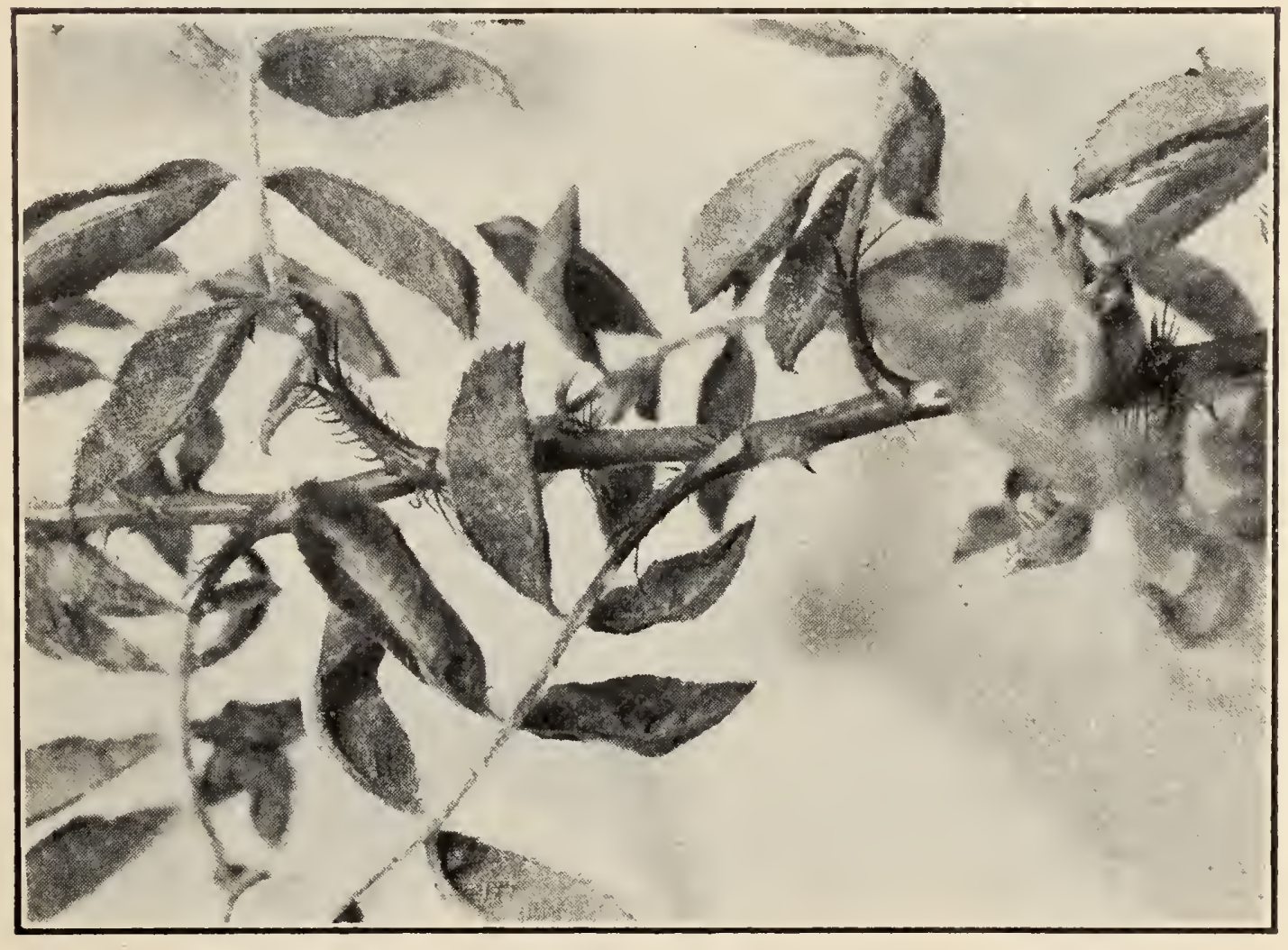

ह 
ROSE.

MILDEW (Sphaerotheca pannosa and S. humuli). Figures 83, 84 and 85.

Roses in California are commonly affected with two different powdery mildews quite different in appearance from one another. The first named is seen most characteristically on the hybrid roses and is particularly severe on the Crimson Rambler. It forms a thick, dense, felty white growth upon the green shoots, buds, and young leaves more than on the surface of the older leaves. This does not affect the tea roses. The latter are particularly susceptible, however, to the second fungus named, which produces a more delicate fungus growth upon the leaves and blossoms rather than the stems, giving them a crinkled appearance.

The most effective treatment for these and the following rose troubles consists in spraying the bushes occasionally with a solution of sulphide of potash (liver of sulphur), one ounce to three gallons of water. Spray the under side of the leaves as well as the top and make up the solution fresh each time the spraying is done. If the bushes are also affected with plant lice an addition of tobacco extract or cheap soap may be made to the spray. In bad cases of mildew further relief may be obtained by dusting the bushes thoroughly with flowers of sulphur while they are still wet with the spray.

Different varieties vary greatly in susceptibility, and the ordinary grower will find the most satisfaction by discarding the most susceptible kinds and growing others which are less liable to disease.

\section{RUsT (Phragmidium subcorticium). Figure 86.}

Affects the hybrid roses, causing the leaves to turn yellow and fall, with black or bright orange pustules of rust spores on the under side.

See Mildew.

Black Spot (Actinonema rosa).

Produces purplish or discolored areas of considerable size on the surface of the leaves, causing them to drop.

See Mildew.

Cane Blight. Figure 87.

Affected wood turns a dark purplish or black color, with a sharply defined line between the sound and diseased bark.

This trouble is common in California and due to a fungus which is apparently undescribed in plant disease literature. It infects stubs left in pruning and often develops down into the main branches, seriously injuring the bushes.

May be largely avoided by proper pruning. 


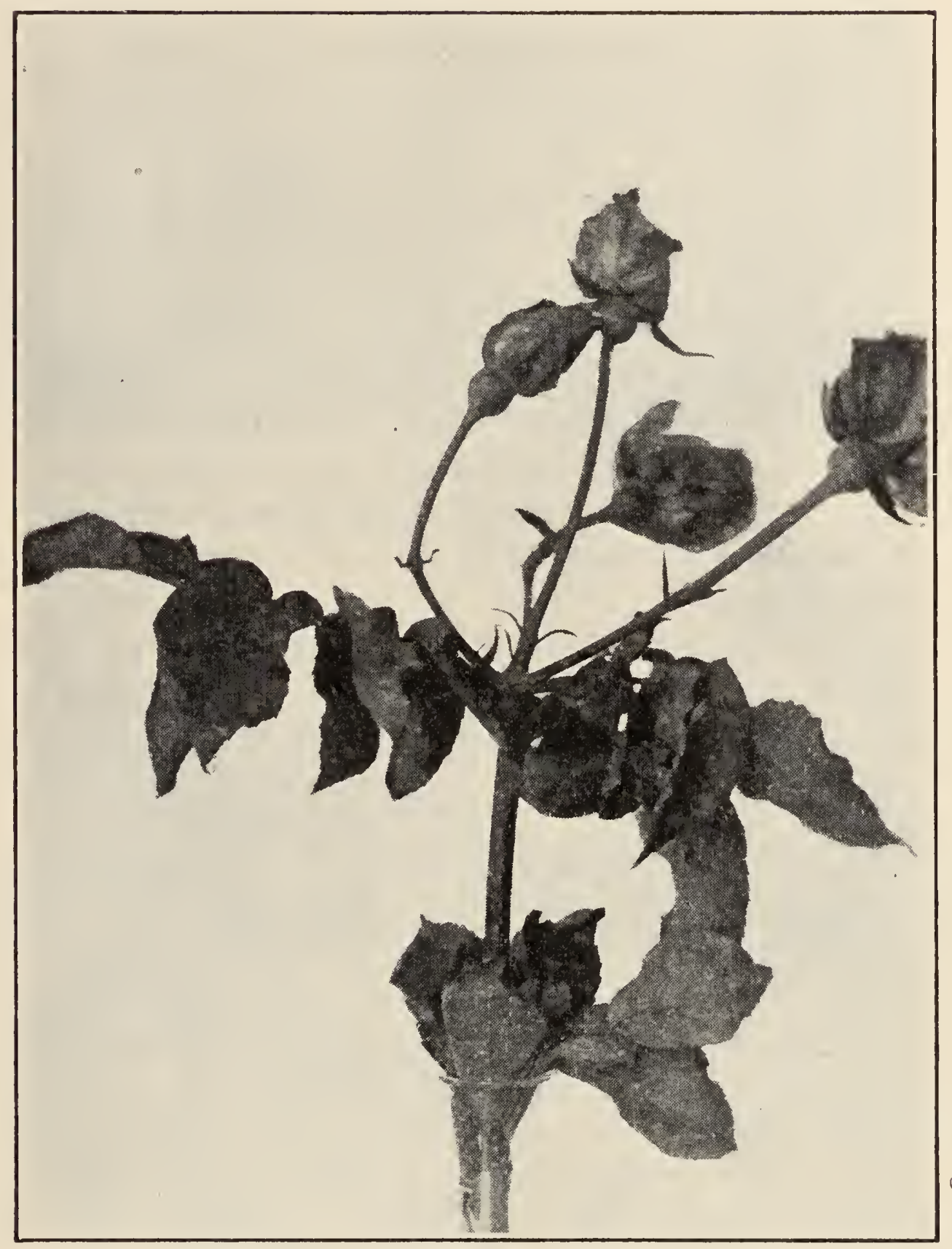

FIG. 85.-Rose mildew (sphatrotheca humuli). 


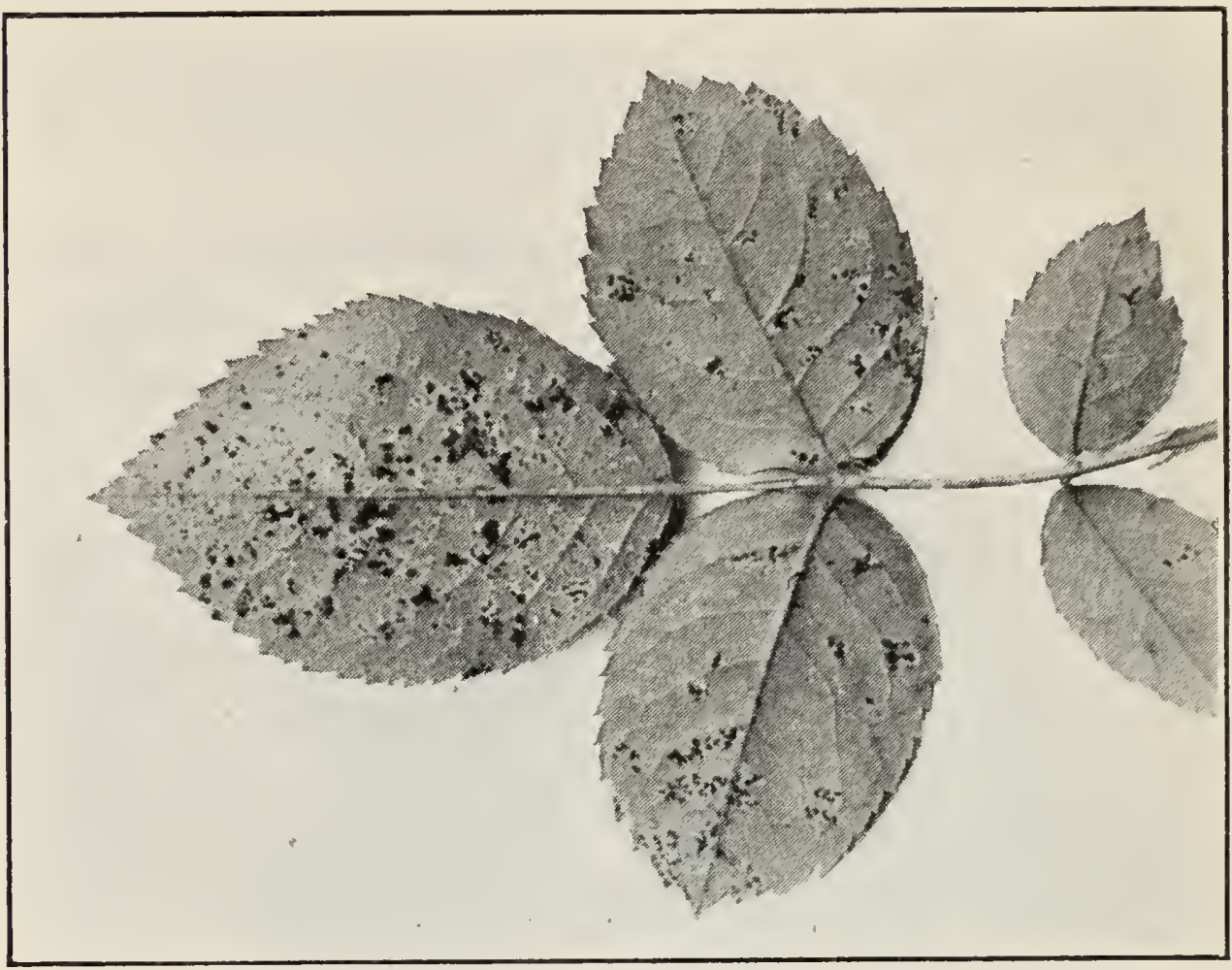

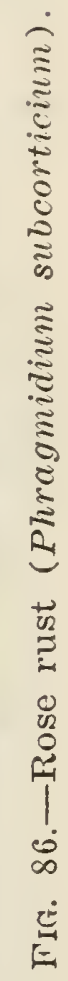

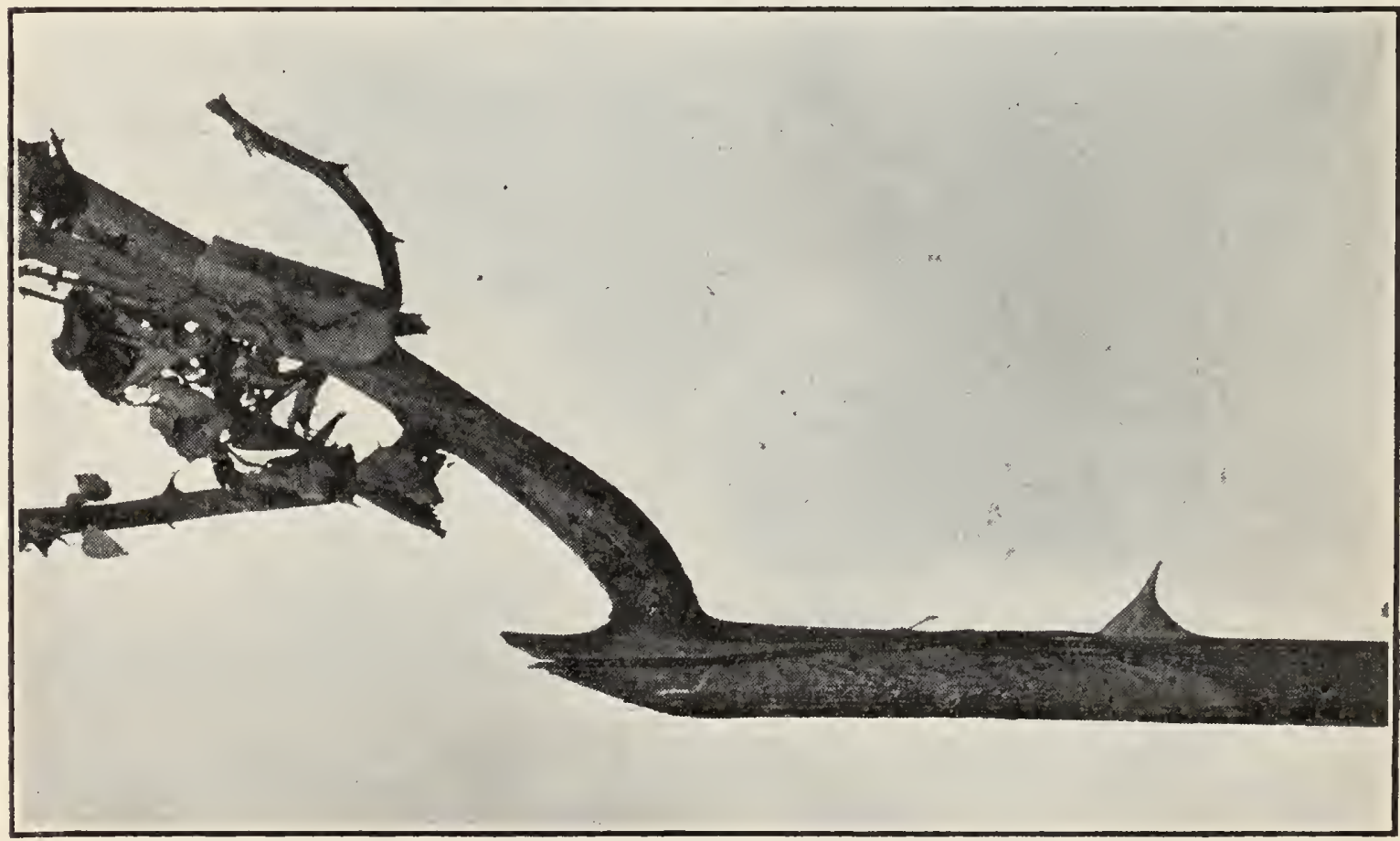

(0)

9-BuL. 218 


\section{SORGHUM.}

SMUT (Sphacelotheca sorghi and S. reiliana).

This crop is affected by two different smut fungi in California, the former developing a black, dusty mass of spores in place of the seeds of the grain, while the latter breaks out in swellings on the plant itself, containing the black, smutty spore masses like corn smut.

Use seed from fields free of smut.

\section{STRAWBERRY.}

... Leaf Spot (Sphaerella fragaria). Figure 88.

This fungus produces on the leaves numerous small dead spots with dark purple margins.

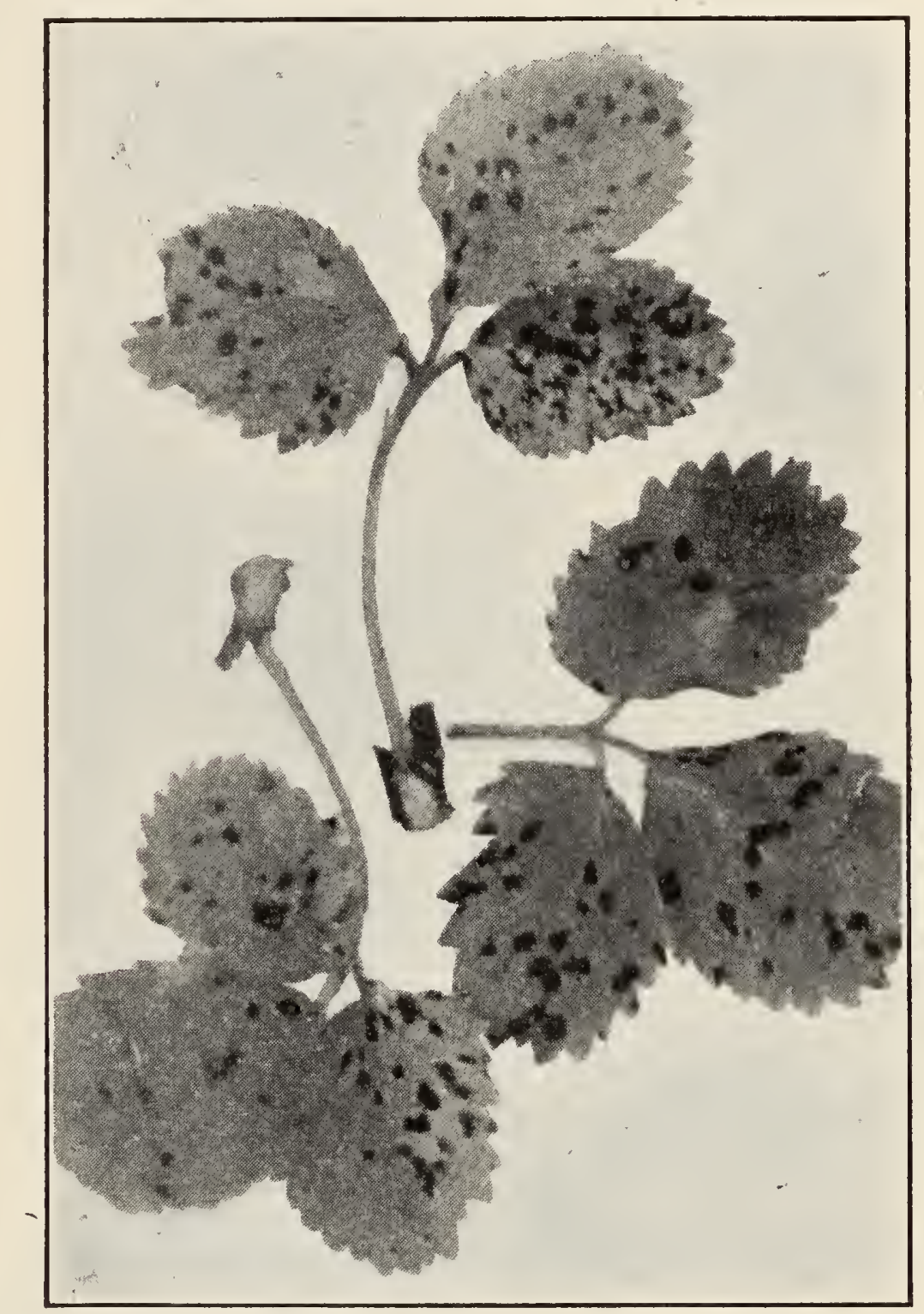

FIG. 88.-Leaf spot of strawberry (Sphaerella fragariae).

In badly affected fields mow the leaves closely and burn them.

Spray with Bordeaux mixture if the trouble is serious enough to warrant this.

$$
\text { MILDEW (Sphaerotheca castagnei). }
$$

A white surface mildew. Not serious. 
SQUASH. See Pumpkin.

SWEET POTATO.

STEM Rot-.Wilt (Fusarium).

The plants gradually die and wither away in the field, the stem and roots being affected by this dry rot fungus.

Use seed from an uninfested locality and plant on fresh land as far as possible.

Gather and burn all affected vines.

BLACK Rot (Ccratocystis fimbriata).

Characterized by black, dry, scabby patches developing on the potatoes while they are in the ground.

Do not use seed from infested fields or plant again on the same ground.

SOFT Rot (Rhizopus nigricans). Figure 89.

A soft decay of the potatoes in storage, caused by a black mold which appears on the surface.

Handle the potatoes carefully while green and let them cure or dry thoroughly before storing. Pack in dry sand for long keeping.

\section{SYCAMORE.}

BLIGHT (Gloeosporium nervisequum).

The young growth is killed back as though by frost. This fungus affects sycamore trees quite universally just after they leaf out in the spring.

No practical means of control, except by spraying specimen or particularly choice trees with Bordeaux mixture just before they leaf out.

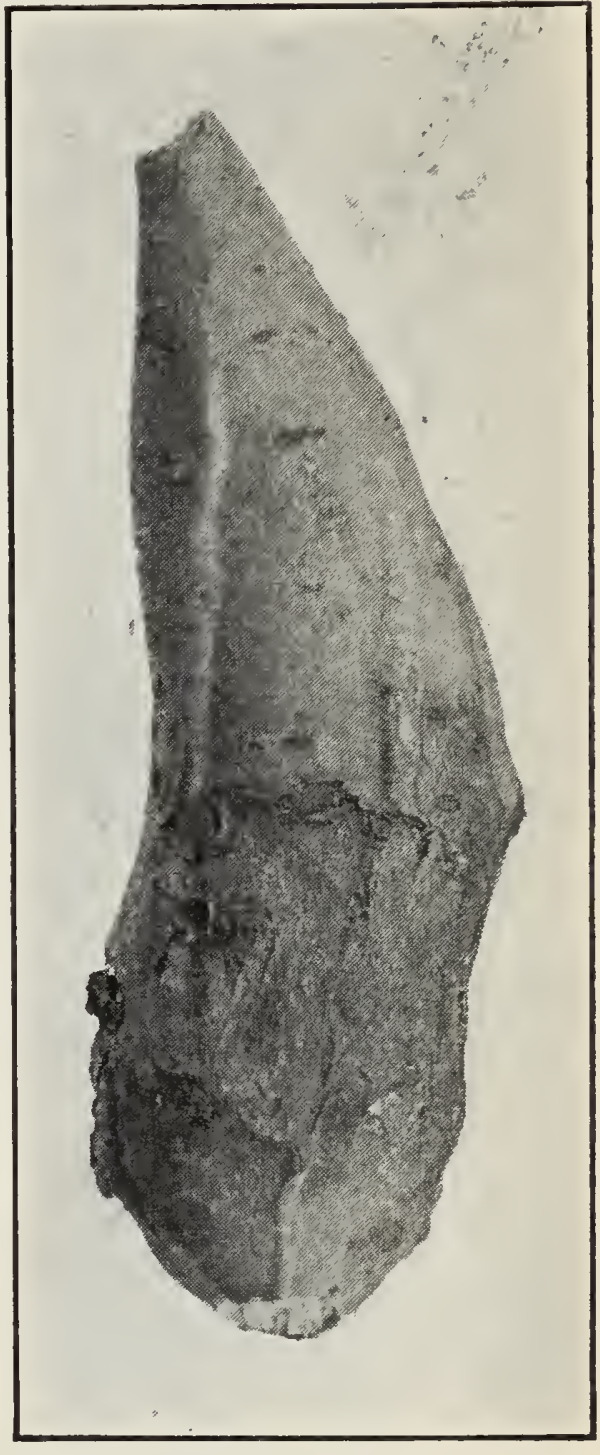

FIG. 89.--Sweet potato rot (Rhizopus nigricans).

\section{MILDEW (Microsphaera sp.).}

A powdery mildew has been found in nurseries on the Sycamore. TOMATO.

Damping Off (Rhizoctonia, Fusarium. Sclerotinia, Botrytis). Figure 90.

Young plants in the seed bed decay at the surface of the ground and die away in large numbers. Much worse in damp, cloudy weather and sometimes difficult to control under such conditions. Caused by various fungi. The trouble is checked by bright sunlight and dry weather.

Make the seed bed soil as sandy as possible. 
Avoid excessive watering when the weather is favorable to this trouble; water only in the morning and on sumy days so far as possible. Give the plants plenty of ventilation and fresh air.

SUMMER BHARIT (F'lsarimm).

Occasional plants here and there in the field gradually turn yellow, sicken and die, after reaching consider-

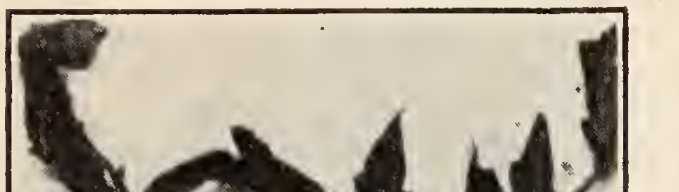
able size. A dry rot is found in the stem and roots, caused by a fungus. This fungus does not infest the soil in the field and the disease may be abundant one year and totally absent the next year in the same field. Affected plants sometimes do not show the fungus until in the last stages, and there is some doubt as to the identity or cause of this trouble. Plants may become infested in the seed bed under conditions favorable to damping off. It is possible that two different diseases are confused in this trouble.

Keep the seedlings as free from damping off as possible and use only the best plants for planting in the field. Select seed from healthy plants.

See Bulletin 175, California Experiment Station.

Winter Buight (Phytophthora infestans). Figures 91 and 92.

The leaves and stems are suddenly blackened and killed and the fruit spots and decays. The whole effect is quite similar to that of frost. Caused by the potato blight fungus. Never occurs during the summer, but occasionally comes on to a disastrous extent on the winter

FIG. 90.-Damping off of tomato seedlings.

on to a disastrous extent on the winter shipping crop following early fall rains, or in early spring plants. Spray with Bordeaux mixture immediately following rain.

See Bulletin 175, California Experiment Station.

Blossom End Rot. Figure 93.

The end of the tomato becomes discolored and affected with a dry rot which spreads to a greater or less extent. Tomatoes of all sizes are affected, particularly those which are half grown. No definite cause has been found for this trouble, which varies in abundance from year to 


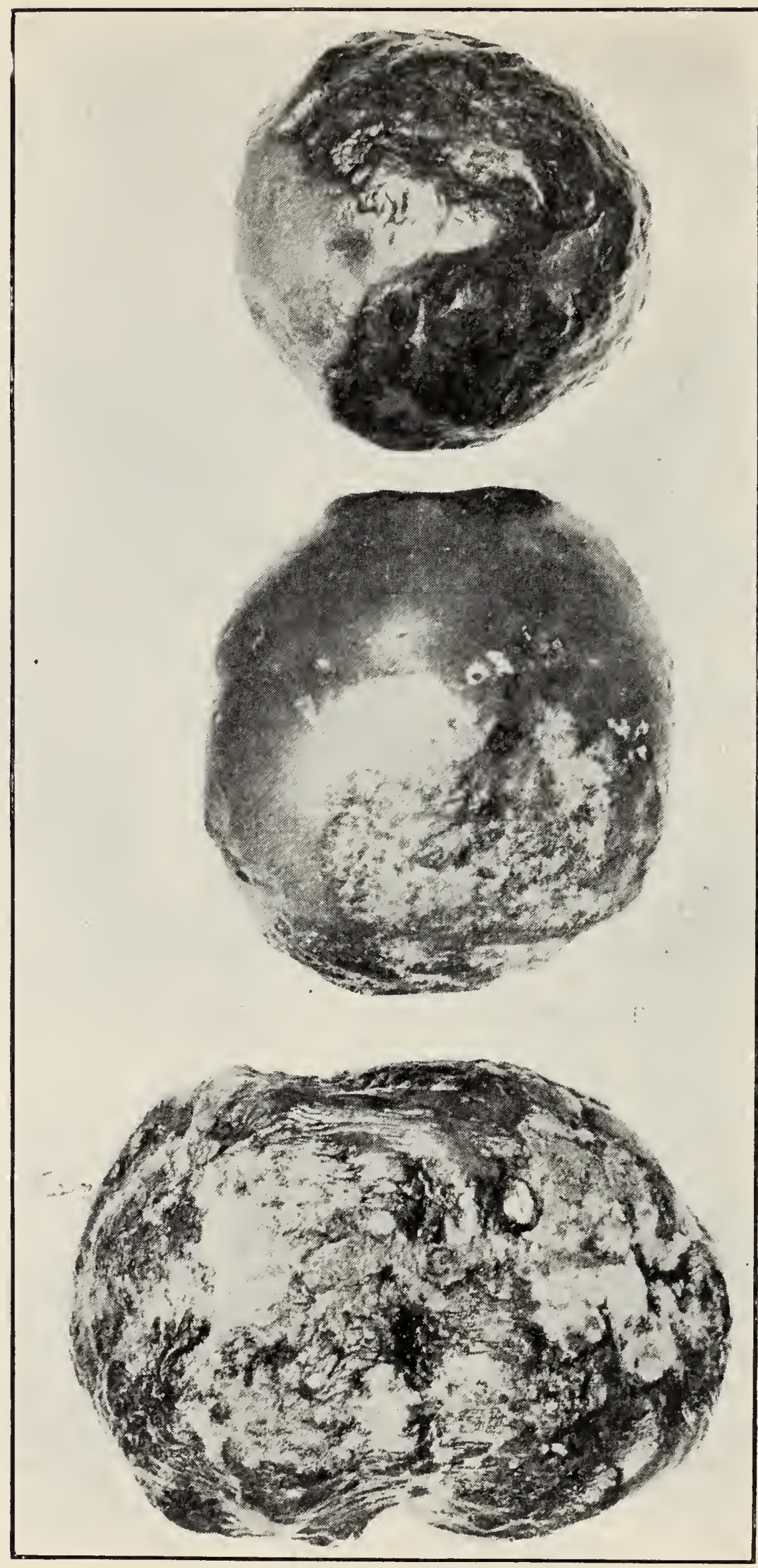

FIG. 91.-Winter blight of tomato fruit (Phytophthora infestans). 
year. Apparently worse on dry ground where the vines do not receive regular irrigation.

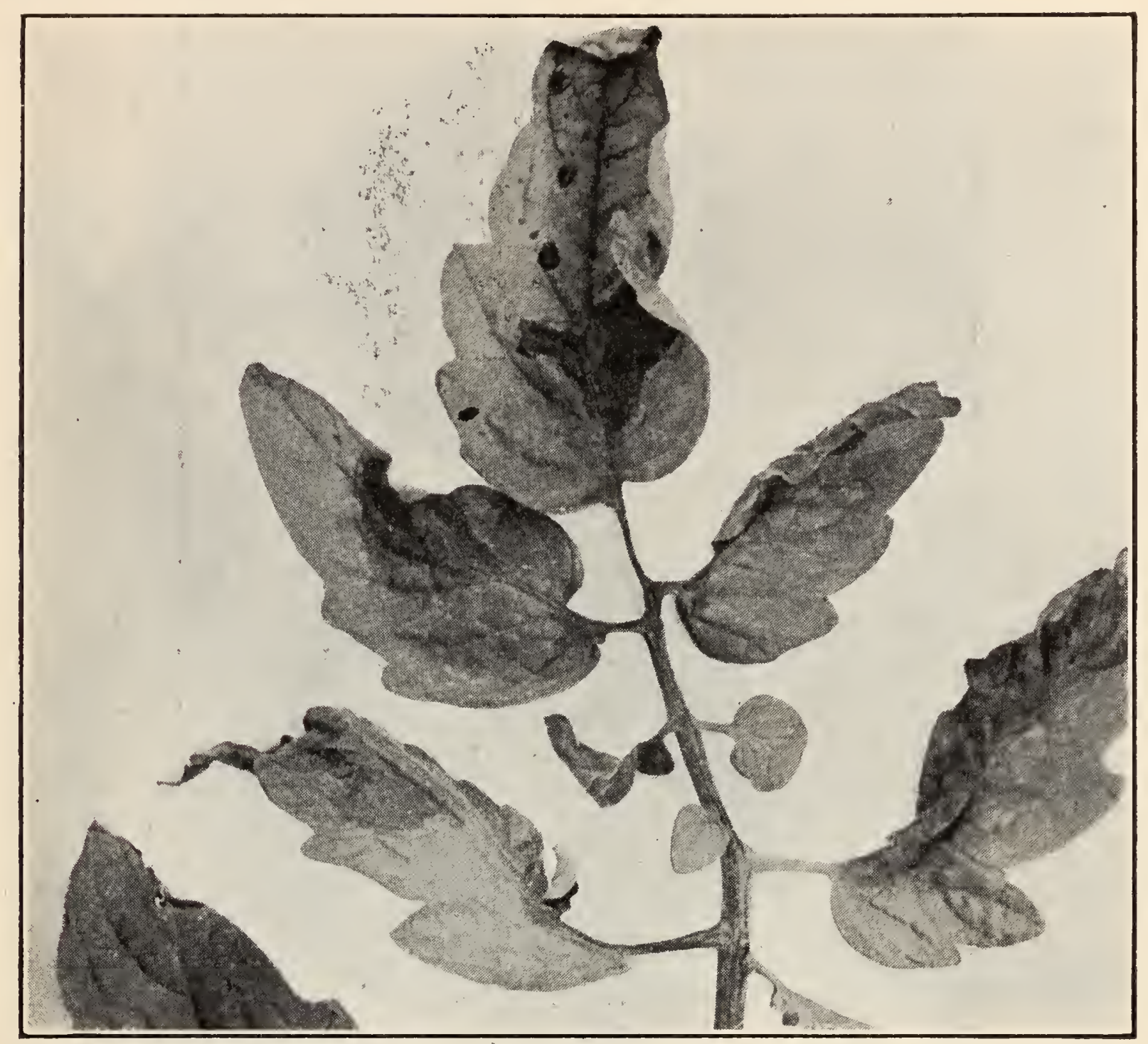

FIG. 92.-Winter blight of tomato leaf (Phytophthora infestans).

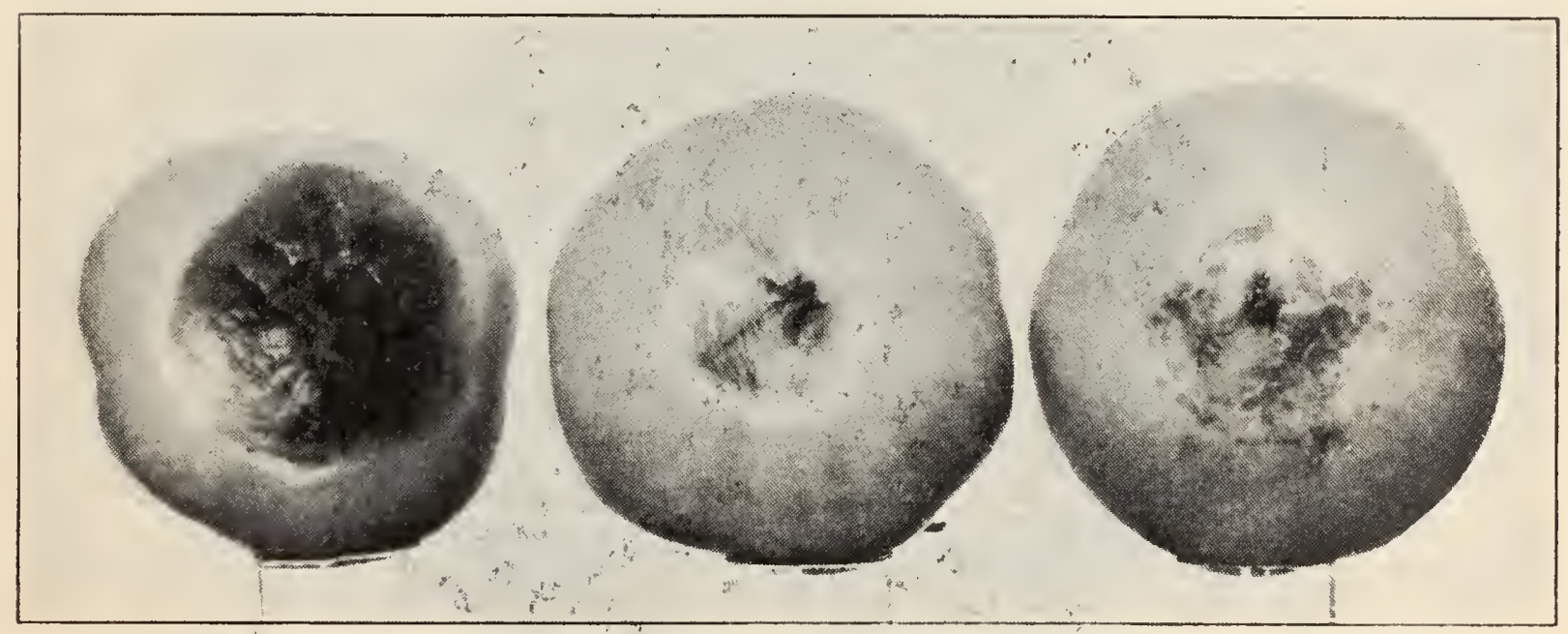

Fig. 93.-Blossom end rot of tomato.

Stem Rot (Sclerotinia libertiana).

A dry rot of the stem and wilting of the vine. Found only in greenhouses. Not serious. 
LEAF SPOT (Septoria lyeopersici).

Small dead spots appear on the leaves. Not common or serious. Found mostly in seed beds.

\section{Roo' KNo' ( Nematode).}

Galls or swellings appear all over the roots and the plants sicken and die. Infection takes place in the seed bed. Carefully discard affected plants in field planting and change the soil in infested beds.

TURNIP. See Cabbage.

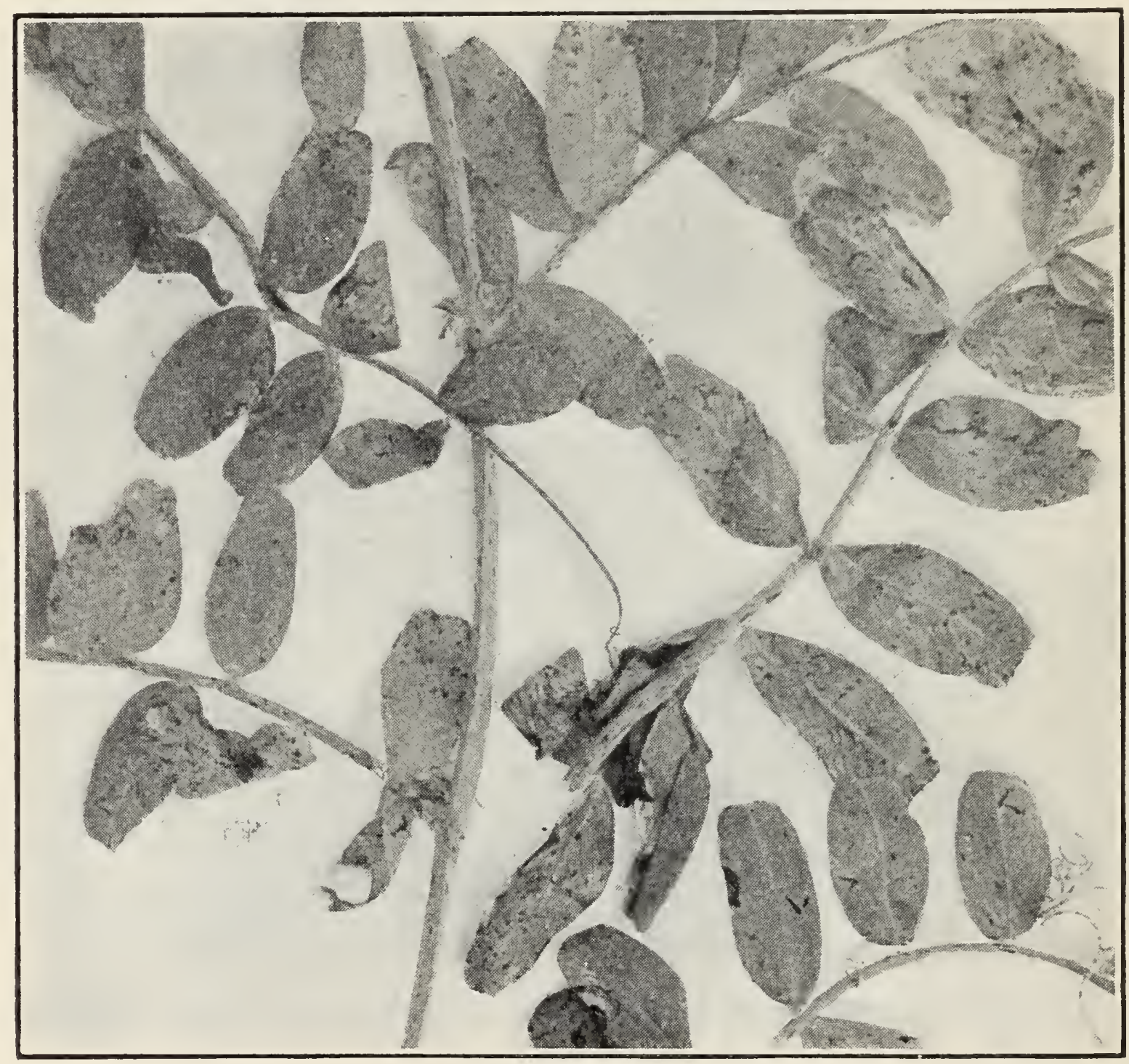

FIG. 94.-Leaf spot of vetch (Colletotrichum sp.).

VETCH.

LeAF Spot. Figure 94.

Small black spots appear on the leaves and the whole plant is more or less killed. Does some damage on vetch planted for a cover crop; usually associated with the cottony mold fungus, Sclerotinia. Caused by a fungus, probably a species of Colletotrichum. 


\section{WALNUT.}

BaCteriosis (I'scudomonas juglandis). Figures 95, 96 and 97.

\section{Buight.}

Causes a black spotting on the surface of the young nuts, many of which drop prematurely. Affected nuts which reach full size have the contents blackened and spoiled. The shoots are also affected with the production of black, canker-like areas, most of which heal out as the wood hardens, leaving wounds and cankers of considerable size. Many of the small fruit spurs and twigs are entirely killed, but the disease

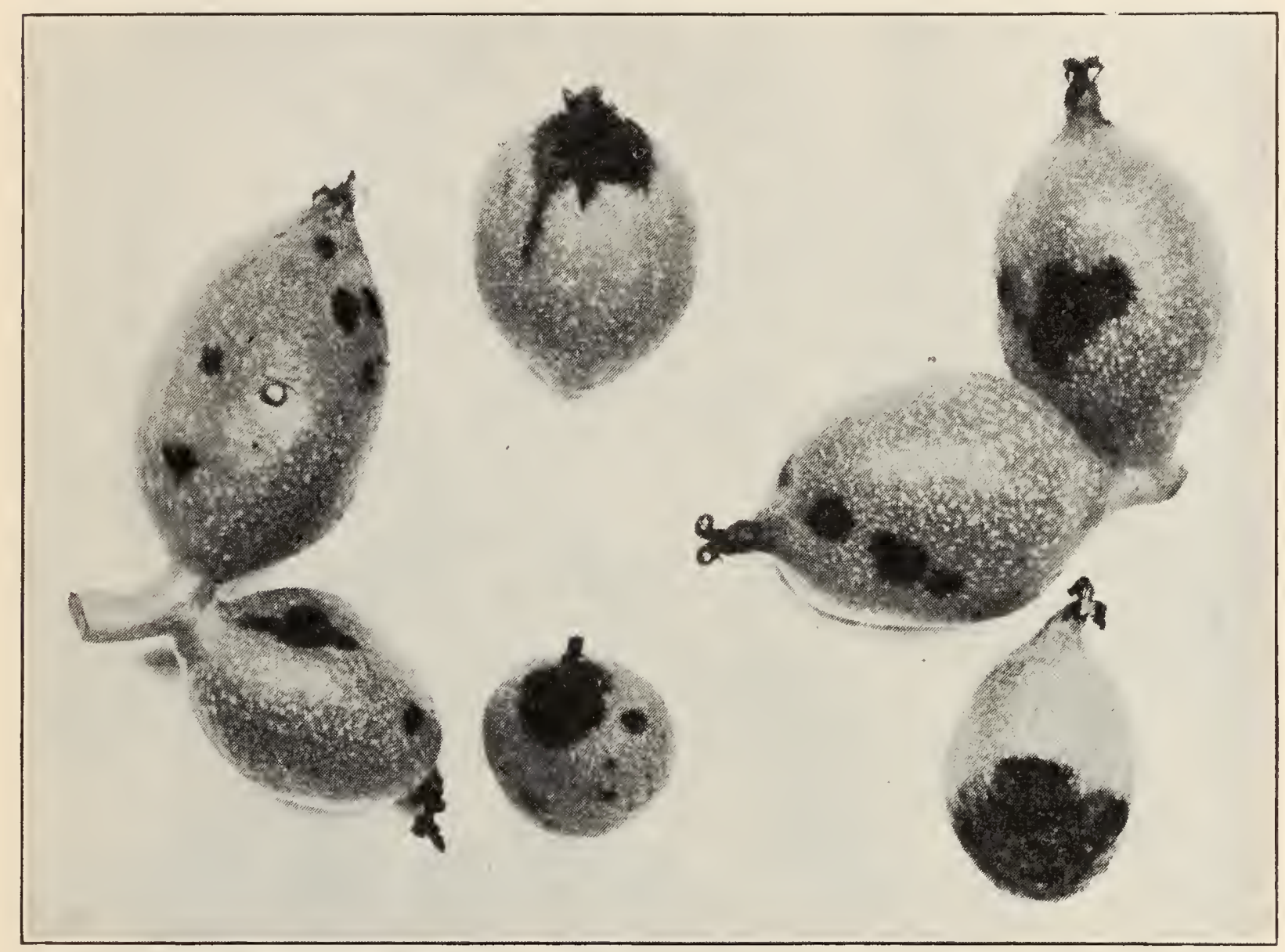

Fig. 95.-Walnut blight on nuts (Pseudomonas juglandis).

does not kill large limbs or whole trees. The leaves are also affected in black spots.

The disease varies in abundance from year to year, being most prevalent in seasons with much fog and moisture late in the spring.

No practical remedy has been found for this disease, but the problem has been largely solved by the development of immune varieties. Such trees are now available to a limited extent and must soon supplant the present plantings of seedlings or susceptible kinds.

Some control may possibly be obtained by spraying with Bordeaux mixture or sulphur sprays just before the buds open. The expense of spraying walnut trees thoroughly is so great, and so much time is required to thoroughly cover trees of this size, that we have no faith in a satisfactory solution of the walnut blight problem along this line. 
On old groves liberal fertilization with nitrogenous fertilizers, together with the use of green manure crops, will go far towards making up for the losses caused by the disease.

Most walnut groves would be benefited by more irrigation than they

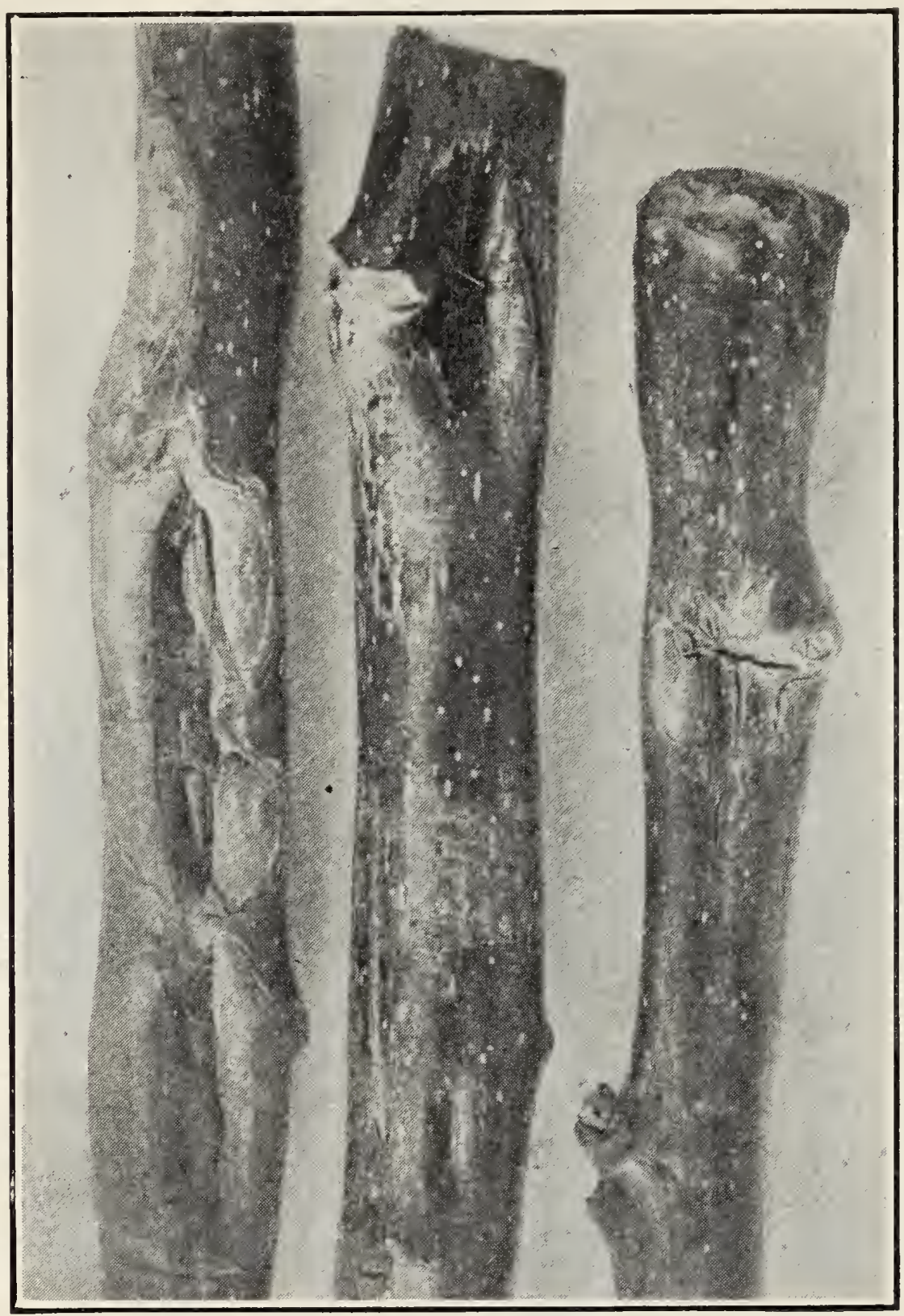

Fig. 96.-Lesions on blighted walnut twigs (Pseudomonas juglandis).

receive at present, particularly during the winter and in the fall after the crop is harvested.

See Bulletin 203, page 24, California Experiment Station.

Trunk Rot (Schizophyllum commune). Figure 65.

The trunk or main branches rot, with a production of small, white bracket toadstools on the surface of the affected wood. This fungus does not affect sound trunks, but follows deep wounds, bruises, heavy cutting, sunburn or other injuries. The wood of the English walnut is particularly susceptible to this form of decay. 


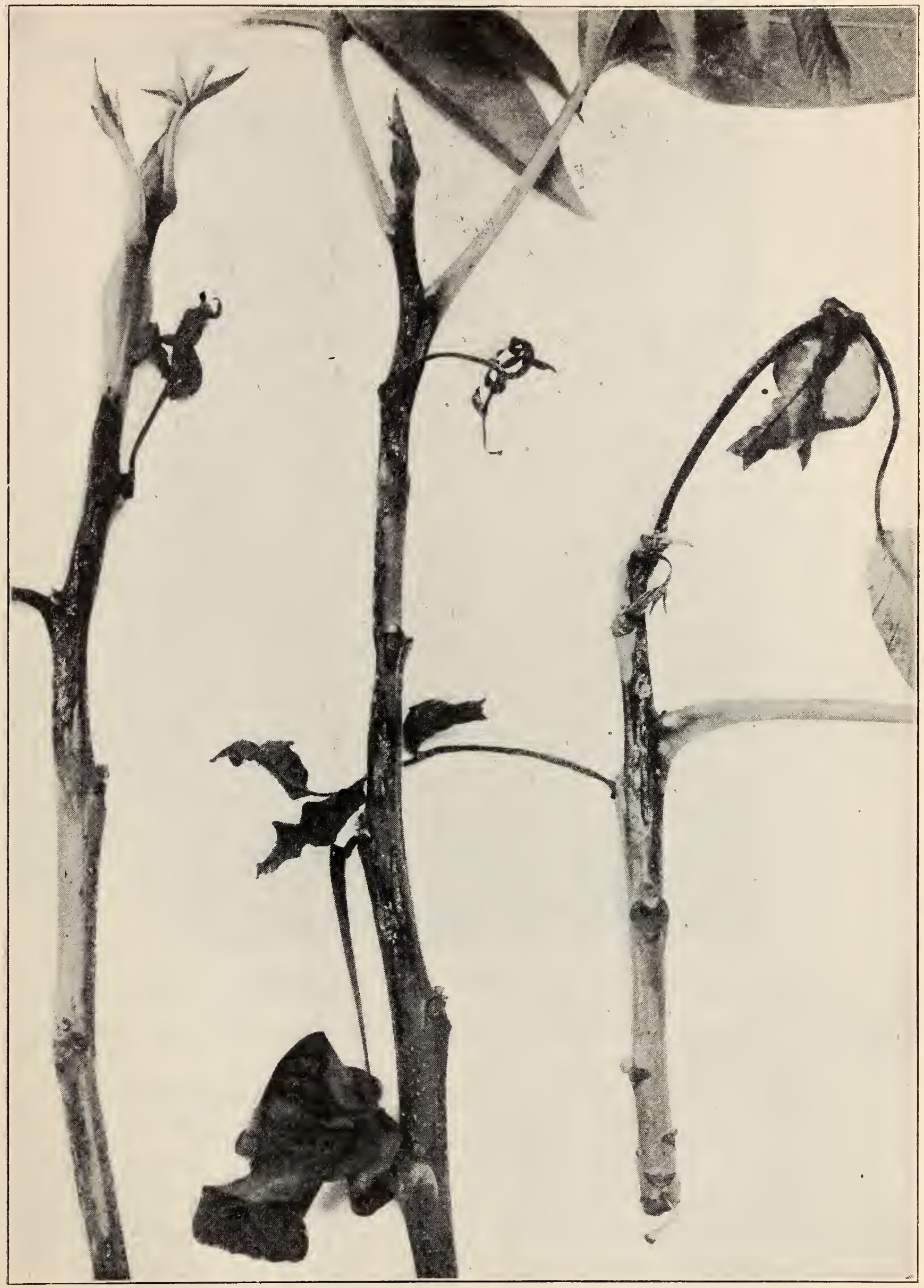

FIG. 97.-Blighted walnut twigs (Pseudomonas juglandis). 
All severe cuts or wounds should be carefully covered with grafting wax to allow healing over without decay. In top-grafting walnut trees this should be given special attention or serious decay may follow.

Sun Burn. Figure 98.

Serious damage is sometimes caused from this source, both on the fruit and the tree. In the latter case the trunk is usually affected, dead areas developing in the bark on the sunny side. This originates mostly in winter when the nights are cold and the days bright and sunny. Not usually serious on thrifty trees growing in good soil. Black walnut

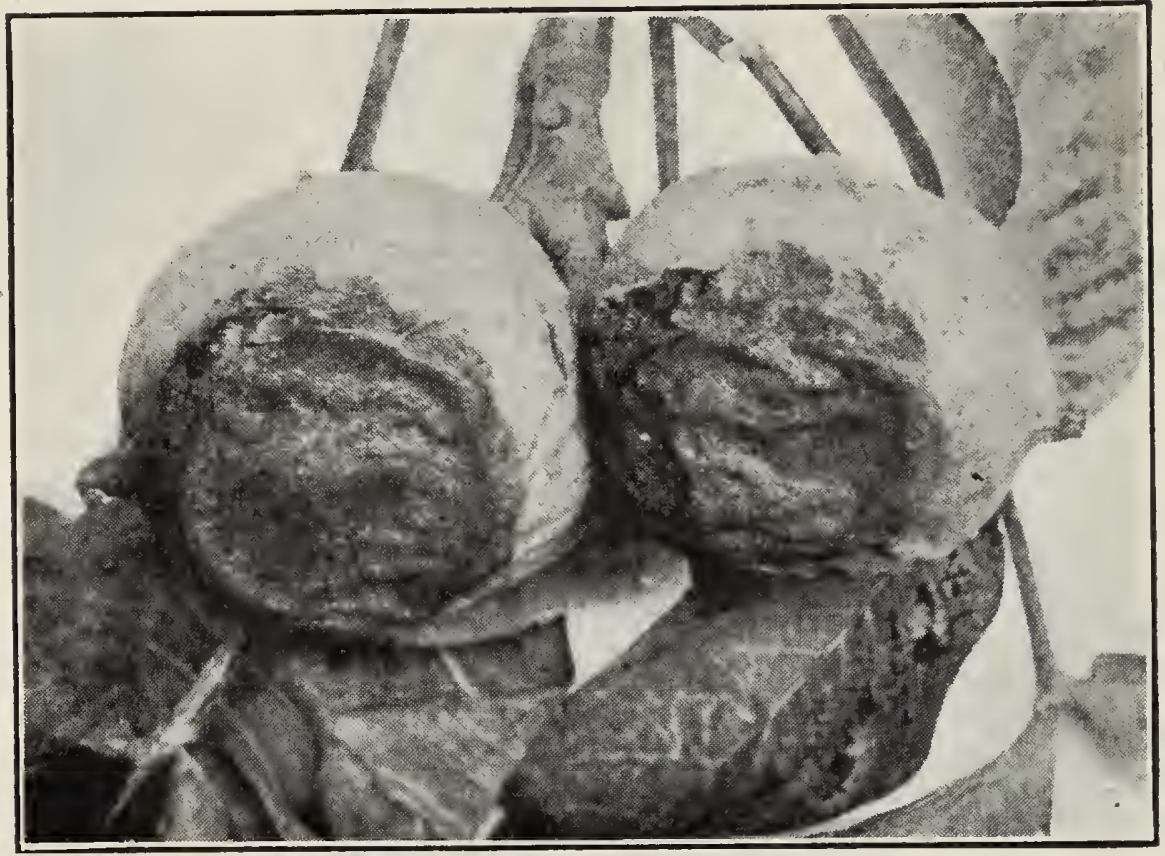

FIG. 98.-Walnuts affected by sun burn.

trunks with rough bark are not affected by sun burn, so that trees grafted high on such trunks are immune.

On the fruit the sun sometimes has a disastrous effect, causing a blackening and burning of the husk on one side during extremely hot weather in summer. The meat is also blackened, and the husk sticks to the shell so that separation is difficult and a black spot is left. Thrifty trees are less affected, particularly when supplied with an abundance of moisture at the root. Individual trees or varieties vary in susceptibility to this trouble, and this quality should be considered in planting in localities where trouble from sunburn is likely to occur.

Perforation. Figure 99.

The shell fails to develop properly, being only partially formed, with numerous openings and thin places. This appears to be simply a lack of development due to climatic conditions and occurs in seasons with a dry spring and a dry, hot summer. Seems worse on trees attacked by aphis. 
Erinose.

Blister-like swellings appear on the leaves, sometimes becoming very abundant. This trouble is eaused by an insect, so minute that it is not visible to the eye.

Not serious or requiring treatment.

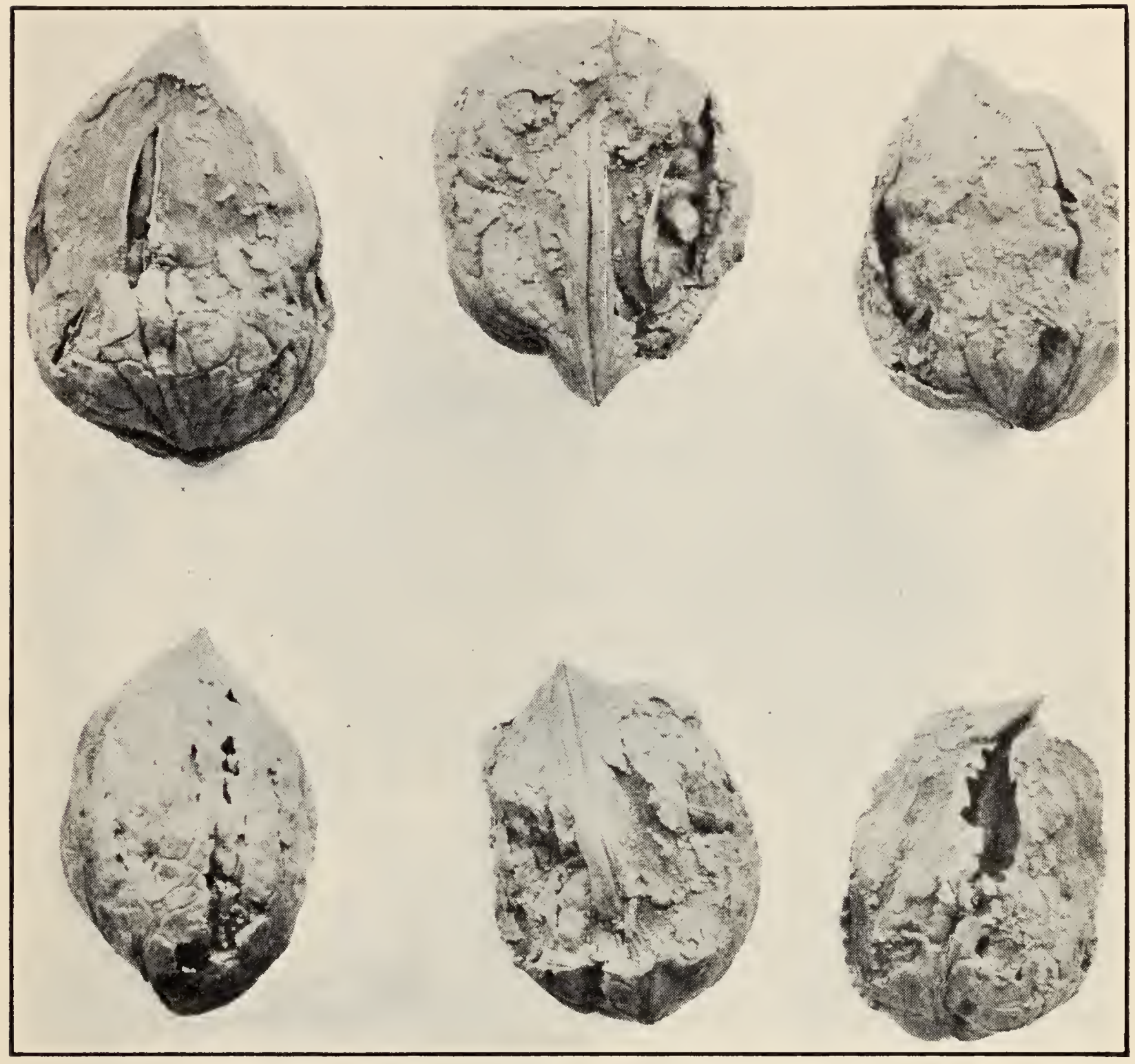

FIG. 99.-Walnut perforation.

Dre-Back. Figure 100.

The limbs die back from the ends, sometimes for only a short distance and sometimes down to the main forks of the tree. All the limbs or only a part of them may be affected. Two general types of die-back may be distinguished, one on the old trees, particularly "hard shells," which die back slowly all over the top, and another in young trees from two to ten years old, which die back suddenly during a single winter in part or all of the limbs, or sometimes the whole tree dies back clear to the ground.

The former type of die-back affecting old trees occurs mostly on light soils where the trees are getting old and the roots find insufficient moist- 
ure. Such dying back is also hastened by lack of cultivation, irrigation and plant food, which lack becomes more pronounced as the trees grow older and the tops and roots more erowded. The only remedy for this trouble is to thin out the trees where they are too closely planted and give the soil better care. Most of these old hard shell orchards, even at best, have now become so unprofitable and undesirable as to make it seem better for the owners to cut down the trees and use the land for some other purpose.

The second form of die-back mentioned, that occurring in young trees which have formerly been thrifty, killing them down to the forks or even to the ground, is a very serious matter at present in some districts. The trouble shows usually to a greater extent in a certain portion of the orchard or in certain orchards worse than in others near by. It developed more extensively in the spring of 1911 than ever before, when a great many trees which had seemed healthy and vigorous the previous fall were found to be almost entirely dead in the spring. Affected trees failed to leaf out at the proper time and more or less of the top proved to be either entirely dead or developed very slowly later in the season. Such trees often threw out new growth or suckers toward the base, which made a very vigorous growth, while the tops were dead or very slow in coming out. The leaves which finally developed

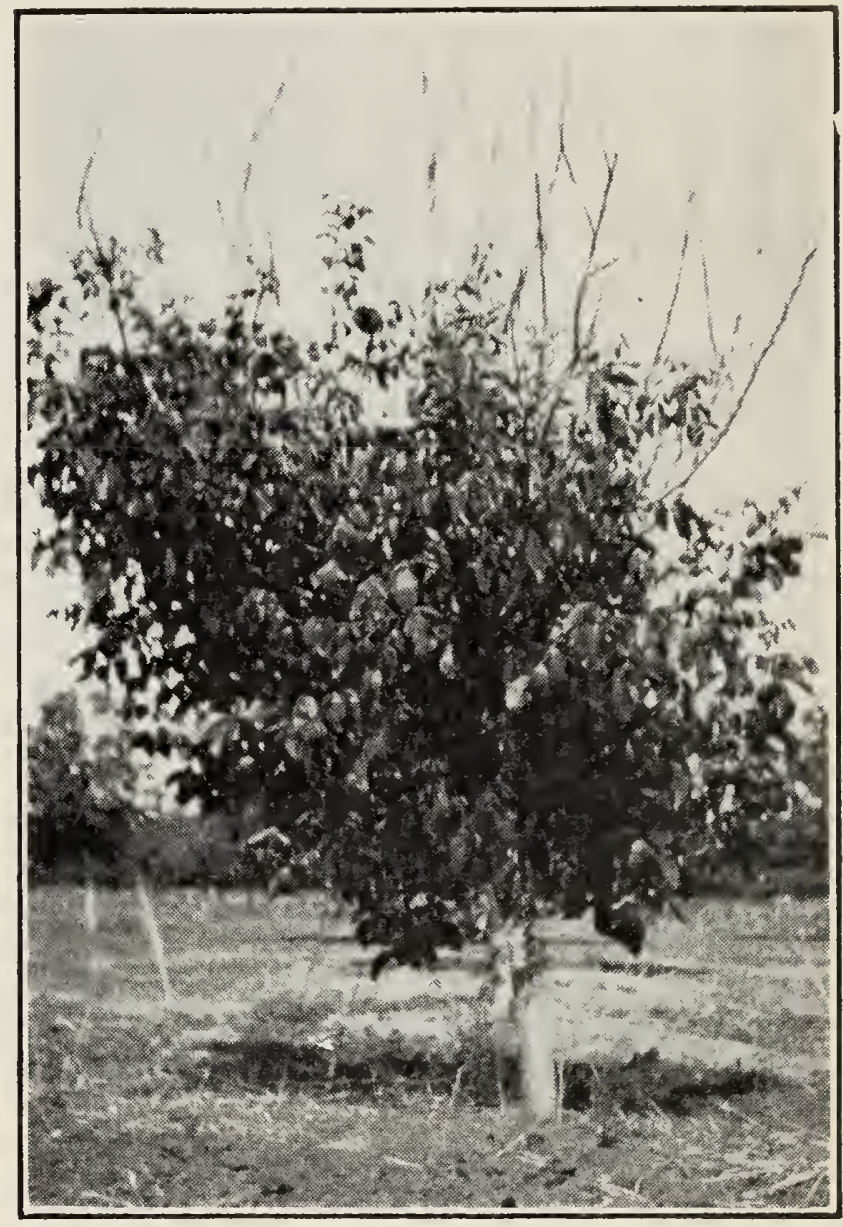

Fig.' 100.-Die-back of walnut. from the affected limbs had a yellow, sickly appearance.

This trouble is more or less the same as that described under walnut "Yellows," and evidently has been caused by the abnormally dry season of 1910. The disease is practically the same in its nature as that described as the "Little Leaf" of the peach and shows similar relations. Trees standing over coarse, dry subsoil or those which had for any reason become drier than usual during the fall of 1910 showed the trouble the worst. Young trees under ten years of age showed the trouble worse than older ones. It is a common practice in some of the worst affected districts to grow alfalfa between the walnut rows and in groves or portions of groves which for this reason became drier than the aver- 
age late in 1910 the trouble has been worse. Even in some fairly heavy soils the packing of the surface on account of several years' irrigation. and handling of alfalfa prevented the moisture reaching the subsoil and. thus the same effect was produced. Frost was also responsible to a. greater or less extent for the dying back of trees in dry ground.

Trees affected in this way should be pruned back to good live wood, if not too far gone, and it is to be expected that a new top will soon be produced. By proper attention to irrigation late in the season, especially in dry years, it is not to be expected that the trouble will occur again save in soils most unsuitable for walnuts on account of coarse subsoil near the surface. We may say here that in choosing crops forinterplanting walnuts, it is not desirable to let the ground remain in alfalfa too long unless an abundant water supply is available, and one can be sure by actual examination that the soil is sufficiently moist at all times, both for the alfalfa and for the trees. In any event, it is ordinarily best to leave a cultivated strip at least eight feet wide on each side of the tree row, and as the trees grow older it is better to plow out the alfalfa and grow some annual crop which will receive regular cultivation, as well as irrigation.

\section{YELLOWS.}

Spindling, yellow shoots develop which usually die back from the tip. All degrees of the trouble may occur from slightly unnatural yellowing and slenderness of the normal shoots to the production of masses of small, yellow shoots, with continual dying back. This affects the English walnut, and is even more pronounced on the Northern California black walnut in certain seasons and places. It has been abundant even on black walnut trees of large size in some parts of northern California during the last two or three years, and very prevalent in nursery trees of the northern California species grown in the southern part of the State. At the same time and in the same nurseries seedlings of the southern California black walnut have never shown the slightest indication of this trouble. This disease appears to be the same which affects the peach (which see), and also to some extent the pecan, apple, and many other trees. It is probably due to a climatic or soil condition rather than to any parasite. Conditions which result in sour sap and similar troubles in the stone fruits seem to be related to this disease, and it is very likely due to a disturbance of the dormant or resting condition through which these trees normally pass during the winter. Also seems to be connected with lack of rain or irrigation late in the season.

Crown Gall-Black KNot. Figure 101.

Walnut trees are affected in some instances with large knots or cankers on the trunk just below ground or a slight distance above 
ground. This trouble is not a common one, but seems to occur in some districts more than others. Whether such knots are due to the real crown gall organism (Bacterium tumefaciens) has never been determined, but their appearance leads one to suspect that they originate from infection of sears or wounds on the trunk by this parasite. Known only upon the English walnut.

As soon as the trouble appears cut out the diseased tissue, disinfect with strong bluestone solution and paint over the wound.

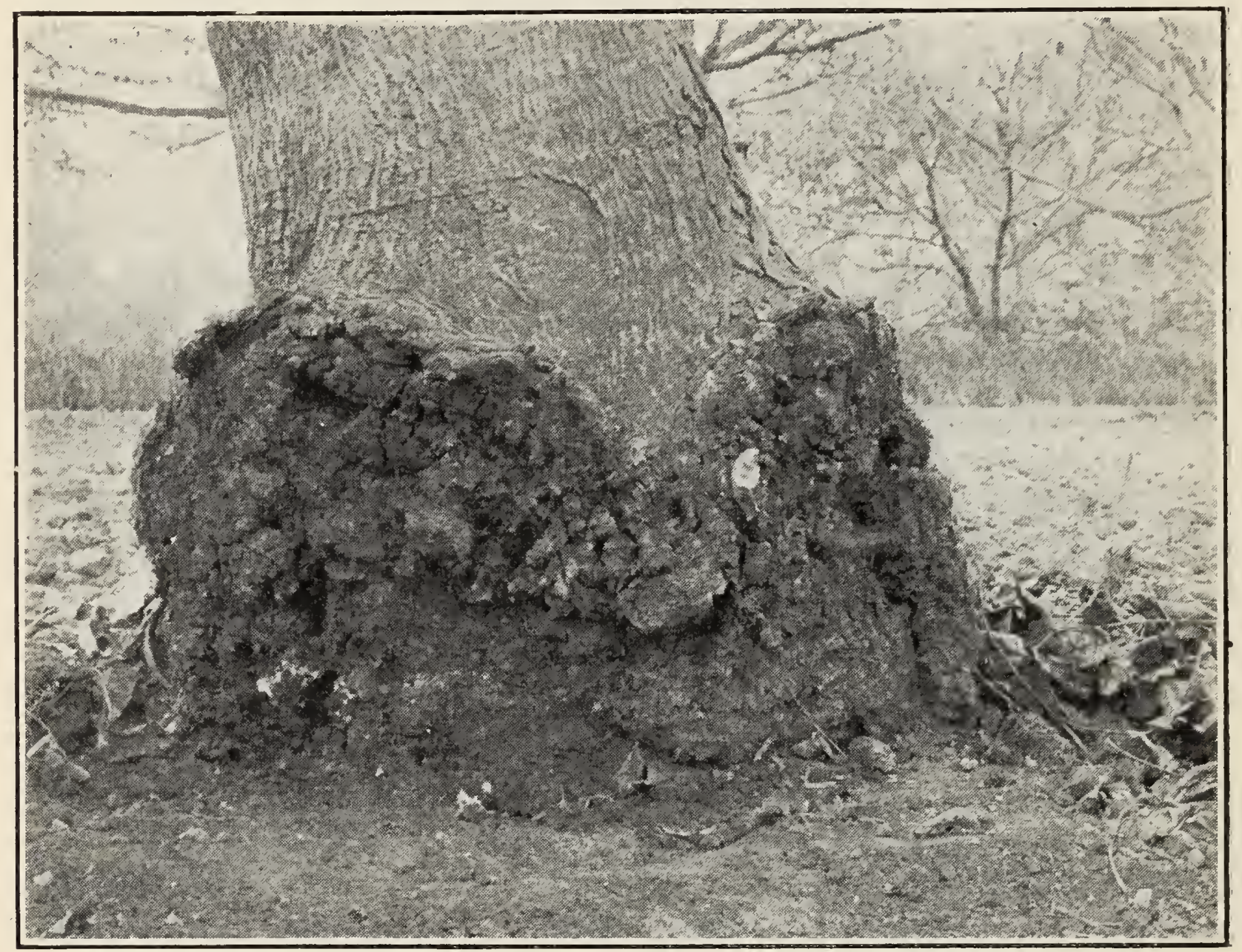

Fig. 101.-Black knot on walnut trunk (Bacillus tumefaciens).

Crop Failure.

It is a very noticeable fact in connection with the California walnut industry that the total product of the groves of the State is not materially increasing, although the acreage has multiplied many times during recent years. This is due to a very general condition of poor production in the large walnut-growing sections of the southern portion of the State. The older groves, although by no means at an age when they should be deteriorating, show very little tendency to increase their yield, and in many cases are gradually going back. The quality and size of the nuts, as well as the quantity, is also a source of complaint. Many of the nuts which mature are empty or poorly filled with shriveled, light weight meat, giving the nut when cracked an unattractive appearance. 
Trouble of this nature is quite commonly attributed to walnut blight, with which disease, however, it has nothing to do. There is probably no one cause or reason for this condition. It is due, generally speaking, to a loss of vitality in the trees, brought about mostly by unavoidable mistakes made in planting when the industry was new and experience in walnut growing very limited. In the first place, all the older groves were planted with the trees too close together. At the common distance of forty feet the branches begin to touch before the trees are ten years old, and by the time they reach full bearing age, the ground is completely shaded and the tops of the trees form a solid mass throughout. This condition is extremely unfavorable to walnut production, and as the groves grow older is the cause of more and more lessening of the crop.

Another factor in walnut deterioration has been the common idea that these trees require very little cultivation, irrigation, or fertilization and the very irregular attention which they have received in this respect. It is true that many walnut trees exist which receive no cultivation whatever and produce very good crops. Such trees, however, usually stand out by themselves with full exposure on all sides, and moreover, while the ground about them is not cultivated, it is at least subject to uniform conditions. The walnut tree seems to particularly resent radical changes in soil treatment. It may do well with no cultivation and will do better, other things being equal, with good cultivation, but it is decidedly injured by irregular treatment in this respect.

Another feature of the situation is the fact that all our older groves are seedling trees, growing thus on their own roots. The English walnut root of the type most commonly grown in southern California is thrifty and vigorous when soil conditions are very favorable, but has little ability to withstand hardship. Many of the present walnut groves have been planted on soil which for one reason or another is not well adapted to this root, and as a result the trees gradually fail as they grow older.

Again, the inherent nature of the trees in regard to quality and quantity of production is responsible to a considerable extent for the present unsatisfactory condition. Almost every walnut tree over ten years of age in Santa Barbara, Ventura, Los Angeles, and Orange counties is of the type known as the Santa Barbara soft shell seedling. These have all descended from a few trees of the original planting of Joseph Sexton and have in most cases been planted with no discrimination or selection of the nuts. As a result of this the type has degenerated to a marked extent and a large proportion of the present trees are decidedly inferior inheritently to their original parents.

In addition to all this, the climatic conditions of the last two or 
three years have been such as to have a decidedly unfavorable effect upon walnuts, as described in other portions of this bulletin. The case is, therefore, not altogether hopeless, since it is to be expected that even under present conditions we may have better walnut seasons and crops than those of the past few years. With better and more regular cultural care of the orchards which is now coming into practice, there is still more hope for the future. Growers are beginning to realize that some of the attention which they give their orange and lemon groves might not be wasted upon walnuts.

The faults outlined above may be counteracted to a considerable extent by thinning out the closely planted trees, either by removing a portion of the tops or taking out some of the trees bodily, and by giving the groves cultivation, irrigation, and fertilization along rational lines. The fact is apparent, however, that the present seedling walnut groves have had their day and that they will gradually disappear just as the seedling apple, the seedling orange and all other fruits of the same nature are gradually supplanted by more desirable, definite varieties. The real hope of the walnut industry lies in the future, and is based upon an entirely new start along the lines just mentioned. Upon this basis there is absolutely no doubt but that the walnut will again come into its own and prove one of our most attractive and profitable crops. A complete bulletin upon walnut culture in all of its phases is now under preparation by the senior writer.

\section{WATERMELON.}

IVILT (Fusarium).

The vines wilt and die with a dry rot of the stem and leaves. Caused by a fungus which infests the soil and lives there from year to year.

Plant on new soil. Resistant varieties are being developed.

\section{WHEAT.}

\section{Closed Smut (Tilletia foetans). Figure 102.}

The grains are converted into a black substance which does not scatter out loosely as in the next. Affected grains have a disagreeable odor.

Use seed treatment as for barley smut.

\section{Loose Sirut (Ustilago tritici). Figure 102.}

The kernels and chaff are converted into a black, powdery mass, which blows away before harvest time, leaving the bare stalks.

Use the hot water treatment as for barley if this form of smut is particularly bad.

\section{Rust (Puccinia graminis).}

The rust appears as an orange-red powder on the leaves, later turning black. Wheat fields are sometimes badly injured when the weather is 10-BUL. 218 
moist and favorable to the rust. Some varieties are considerably resistant.

\section{Yeliows-Wintering.}

Wheat, as well as other grains, sometimes shows in the spring a yellowing and discoloration of the leaves with no apparent specific cause.

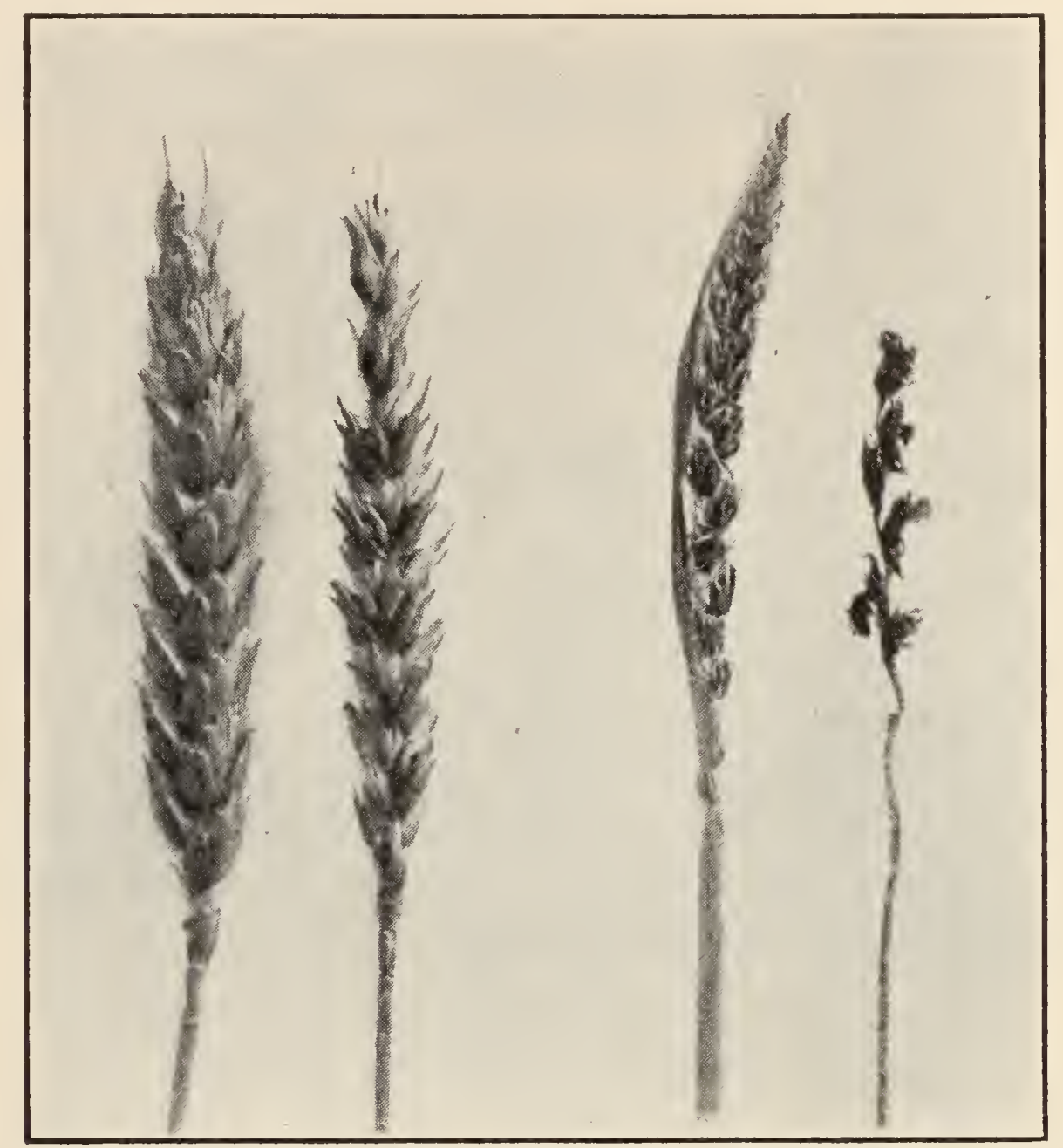

FIG. 102.-Closed and loose smut of wheat (Tilletia foetans and Ustilago tritici).

Sometimes the whole field shows this condition so decidedly as to have the appearance of being badly injured. The trouble appears to be due to climatic conditions, producing a disturbance in the growth of the plant. The yellowing usually disappears in the spring and, if crmditions are favorable, the plants regain their normal appearance. 


\section{FUNGICIDES.}

The following are the chief substances used for the control of plant diseases by spraying, dipping, disinfecting, etc. It should be clearly understood that all control of this nature must be accomplished entirely by prevention rather than cure. In other words, these fungicides where they are to be effective must be applied for the purpose of poisoning and killing the spores or germs of the parasites and thus preventing their further spread and development.

\section{BLUESTONE. (Copper Sulphate.)}

This material comes in the form of large, hard, blue crystals, and is used in large quantities in fungicidal work, as the basis of Bordeaux mixture. The crystals dissolve readily in hot water and more slowly in cold. If thrown into the water and allowed to sink to the bottom they soon form there a concentrated solution and only a small part of the material is dissolved. For this reason it is necessary to either stir the water frequently or suspend the bluestone in a sack or basket so that it just dips under the surface. This substance is extremely caustic to vegetation when used alone, and is, therefore, commonly combined with lime in Bordeaux mixture.

A plain solution of bluestone and water of about 3 pounds to 50 gallons may be used during the winter time on fruit trees to remove moss, etc., from the bark. This solution would be extremely disastrous to green leaves.

\section{LIME.}

This material in the form called "quick-lime" or "stone-lime," is mainly useful in fungicidal work as an ingredient of Bordeaux mixture. For this purpose it must be in a fresh, hard condition and not in the least air-slaked.

Hydrated lime, a form which is coming considerably into use, consists of lime which has been slaked with a small amount of water and then ground to a fine powder. In this condition it can not air slake, but retains its quality indefinitely. This form of lime is being used to some extent for making Bordeaux mixture and quite extensively as a basis of dust sprays.

\section{SULPHUR.}

This in a finely powdered condition is used extensively in the control of plant diseases, particularly for surface mildews and the like. Sulphur acts in these cases through its gaseous fumes, which are produced when the hot sun shines upon it. For such purposes the sulphur should be in as finely divided a condition as possible and this is best obtained in the form known as flowers of sulphur or sublimed sulphur. Ground 
sulphur is to be had in various degrees of fineness, but should never be used for application to plants except in the very finest condition. The sublimed form is somewhat more expensive per pound, but much bulkier, and therefore no more expensive in the end. When used in liquid sprays where cooking takes place and the sulphur becomes dissolved, the cheaper, coarser forms may be used.

\section{COPPER CARBONATE.}

This material is used to a limited extent in the form of a solution in ammonia and water in the case of spraying fruit, flowers, ornamentals, etc., where Bordeaux mixture is objectionable on account of its disfiguring effect. This ammoniacal copper carbonate is prepared in the following manner :

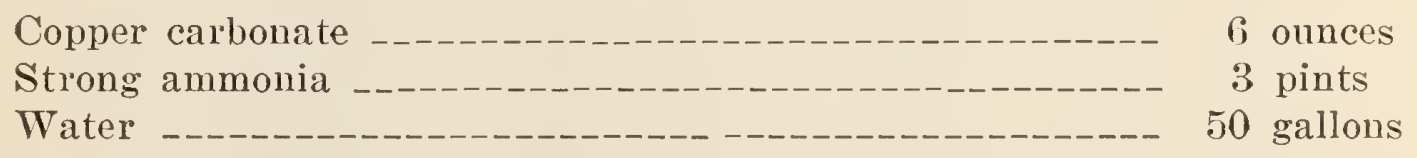

Make a paste of the copper carbonate with a little water and add to this the ammonia diluted with about two gallons of water. Stir vigorously and continue to add the ammonia until all the copper is dissolved. Then dilute to 50 gallons.

\section{POTASSIUM SULPHIDE. (Liver of Sulphur.)}

This material comes in the form of a greenish-yellow solid. Used particularly in a solution of 1 ounce to 3 gallons of water for the control of surface mildews. Both the solid and the solution deteriorate on standing exposed to the air.

\section{FORMALIN.}

This is a clear liquid consisting of a gas dissolved in water. Commercial formalin should have a strength of 40 per cent and the formula given below is based upon this concentration. In buying formalin particular care should be taken to see that the material purchased is a 40 per cent solution. One pint dissolved in thirty gallons of water is used for soaking seed potatoes in the control of scab and for grain in controlling smut.

\section{CORROSIVE SUBLIMATE.}

This is a white, extremely poisonous, solid material which may be bought most conveniently in the form of tablets. It is used particularly for disinfection after cutting out pear blight, dissolved in water in a strength of 1-1000. The tablets may be obtained in a size convenient for making this strength. This material is particularly poisonous to animal life and should not be carelessly used. 
Put the bluestone in a sack and hang so it will be suspended just under the surface of a barrel of water over night, or dissolve in hot water. Use one gallon of water to one pound of bluestone. Slake the lime in a separate barrel, using just enough water to make a smooth, clean, thin whitewash. Stir this vigorously. Use wooden vessels only.

Fill the spray tank half full of water, add one gallon of bluestone solution for each pound required, then strain in the lime and the remainder of the water and stir the mixture thoroughly. Do not mix the solution hot.

For extensive work, large amounts of bluestone and lime may be prepared in advance in separate receptacles, making stock solutions of definite strength. (One pound to the gallon is convenient.) Always dilute well before mixing.

The formula may be varied according to conditions, using from 3 to 8 pounds of bluestone to 50 gallons of water and an equal amount or slight excess of lime. Use the stronger mixture in rainy weather. Keep the mixture constantly agitated while applying.

Recently, the so-called "hydrated" lime has been used to a considerable extent in making Bordeaux. Chemically, the hydrated lime is entirely satisfactory for making Bordeaux mixture, and it is somewhat more convenient for use than stone or quick lime. The same quantities should be employed as with the latter. Objection has been made to hydrated lime in some quarters on the ground that Bordeaux mixture thus prepared settles more readily and has a coarser consistency. We are not prepared to state, however, that this is a general fault of hydrated-lime Bordeaux.

In using large quantities of Bordeaux mixture or any other fungicide it is very convenient to place tanks upon an elevated platform to which water is piped. The various solutions can then be prepared upon this platform and discharged by gravity into a spray tank. In the case of Bordeaux mixture it is advisable to run the diluted bluestone and lime solution into a single trough and let them drop from this into a spray tank, as in this way a more complete mixture is secured.

\section{CAUSTIC SODA AND POTASH.}

Either of these substances may be used for spraying dormant trees in winter, dissolved in water in the proportion of 1 pound to 10 gallons. This is effective in removing moss, lichens, etc., from trees and also has some fungicidal value in certain cases. These materials are also used 
combined with sulphur in liquid sprays in which the sulphur goes into solution.

\section{SULPHUR SPRAYS.}

Quick-lime 20 pounds

Ground sulphur 15 pounds

Water 50 gallons

Slake the lime with hot water in a large kettle, add the sulphur and stir well together. After the violent slaking subsides add more water and boil the mixture over a fire for at least one hour. After boiling sufficiently strain into the spray tank and dilute with water to the proper strength. If a steam boiler is available this mixture may be prepared more easily on a large scale by cooking in barrels into which steam pipes are introduced. This mixture can not be applied safely except during the winter when the trees are dormant.

\section{SELF-BOILED LIME-SULPHUR.}

The heat generated by the lime in slaking is in itself sufficient to dissolve a considerable quantity of sulphur and a mixture may be prepared in this way which is quite satisfactory for fungicidal purposes. This method has been in use for several years in California, as described in Bulletin 163 of the California Experiment Station. The lime is placed in a tight cask instead of a kettle, and over it is poured the sulphur mixed into a thin paste with hot water. Ten or fifteen gallons of boiling water are then added and the cask covered tightly with sacks and a wooden cover. Violent boiling immediately takes place. When this begins to subside the mixture is stirred thoroughly and after the boiling stops it is strained into the spray tank and diluted to the proper strength.

Recently a more dilute form of this mixture has found considerable use for fungicidal purposes for application to trees in foliage during the summer time. This is made in a similar manner to that just described, using 10 pounds of lime and 10 pounds of sulphur to 50 gallons of water.

See Circular 27, Bureau of Plant Industry. U. S. D. A.

CONCENTRATED LIME-SULPHUR.

Another method of preparing the lime-sulphur spray is that described in Bulletin 306, Geneva, New York Experiment Station.

Formula :

Lump lime
Sulphur 60 pounds
Water -125 pounds

This is mixed in a kettle and cooked over a fire, according to the first method given above, boiling for one or more hours. After the cooking 
SOAP.

The addition of 4 or 5 pounds of whale-oil or other cheap soap to each 50 gallons of Bordeaux or other spray is quite effective in increasing its adhesive qualities.

\section{LITERATURE.}

A few references to some of the best books upon the subjects treated in this bulletin may be of use to those who wish to obtain more detailed information along various lines. The following list is given as being well adapted to the general reader :

"Fungous Diseases of Plants." Duggar. Published by Ginn \& Company.

"Diseases of Economic Plants." Stevens \& Hall. Published by The Macmillan Company.

"Diseases of Plants." Tubeuf \& Smith. Published by Longmans \& Company.

"Disease in Plants." Marshall Ward. Published by Macmillan \& Company.

"Text Book of Botany," 2 volumes. Coulter, Barnes \& Cowles. Published by The American Book Company.

"California Fruits." Wickson. Published by Pacific Rural Press Company.

"Soils." Hilgard. Published by The Macmillan Company. 


\section{INDEX.}

Acid soil 1066.

Adhesives 1187.

Air-relation to plant growth 1047.

Alfalfa.

crown gall 1079; dodder 1083; leaf spot 1079; rust 1079; stem rot 1081.

\section{Almond.}

crown gall 1084; die back 1086; fruit drop 1084; oak fungus, root rot 1084; rust 1084; shot-hole 1083; sour sap 1085 .

Anaheim disease. grape 1117.

Apple.

blight 1089; climatic effects 1093; club tip 1093; storage spot 1092; die back, see Almond; fruit spot 1092; hollow 1093; little leaf 1093; mildew 1088; root rot 1089; scab 1089; seasonal effects 1093; stem rot 1089; sunburn 1091; toadstool disease 1089.

\section{Apricot.}

blossom rot 1097; brown rot 1097; bud blight 1096; climatic effects 1098; crown gall, die back, fruit drop, see Almond; fruit spot 1095; gummosis, see Cherry; root rot, see Almond; scab 1097; seasonal effects 1098; shothole 1095; sour sap 1098.

Asparagus. rust 1100 .

Aster. yellows 1101.

Atmospheric effects, injurious 1051.

Bacteria, general acount of, 1078 .

Bacteriosis. walnut 1172.

Barley.

leaf spot 1102; smut, closed and loose 1101.

Bean.

mildew 1102; rust 1102; spot 1102.

Beet.

blight 1104; curly top 1104; downy mildew 1103; eutettix 1104; leaf spot 1102; nematode 1104; root knot 1104; root rot 1104; rust 1102 .

Black knot. grape 1115; quince 1160; walnut 1178.

Black leaf. pear 1155 .

Black leg. potato 1158
Black rot.

cabbage 1108; orange 1143; sweet potato 1167.

Black spot. rose 1163.

Blackberry. crown gall 1107; leaf spot 1107; rust 1107; soft rot 1107 .

Blasting-to loosen soil 1074.

Blight.

apple 1094; apricot bud blight 1089; beet 1104; celery 1108; lemon 1126; loquat 1130; orange, see Lemon; pea 1149; peach 1149; pear 1154; potato, early blight, 1157; late blight 1157; quince, see Pear; rose, cane blight 1163; sycamore 1167; tomato, summer blight 1168; winter blight 1168; walnut. 1172.

Blosom end rot. tomato 1168

Blossom rot. apricot 1097.

Blue mold. lemon 1126; orange 1142.

Bluestone 1183.

Boll rot. cotton 1111.

Bordeaux mixture 1185 .

Brown rot.

apricot 1097; cherry 1109; lemon 1122; orange, see Lemon; peach and plum, see Apricot.

Brown spot. orange 1143.

Brown streak. potato 1158 .

Brunissure. grape 1118 .

Bud blight. apricot 1096 .

Cabbage. black rot 1108; club foot 1108 .

California yellows. peach 1151.

Cane blight. rose 1163

\section{Carnation.} leaf spot 1108; rust 1108; stem rot. 1108; wilt 1108 . 
Chemical elements.

deficiency in the soil 1061.

\section{Celery.}

root rot 1109 ; stem rot 1109 ; summer blight 1108; winter blight 1108 .

Cement dust 1060.

\section{Cherry.}

brown rot 1109; die back 1110; fruit drop 1110; gummosis 1109; root rot 1109.

Chlorosis. orange 1137.

Chrysanthemum. rust 1110 .

Citrus.

diseases, see Lemon and Orange; peculiarities 1133 .

Climatic conditions. irregular 1054; relation to plant 1048 .

Climatic effects. apple 1093; apricot 1098.

club foot. cabbage 1108.

club tip. apple 1093.

Cold 1051.

Cold storage spot. apple 1092.

Copper carbonate 1184.

Copper sulphate 1183.

Corn.

mold 1111; rust 1111; smut 1110 .

Corrosive sublimate 1184.

Cotton.

boll rot 1111.

Cottony mold. lemon 1123.

Coulure. grape 1117 .

crater blight. pear 1156.

Crop production, ideal conditions for, 1041.

Crown gall.

almond 1084; apricot, see Almond; eucalyptus 1114; nursery stock 1131; peach and plum, see Almond; walnut 1178.

Cucumber.

leaf spot 1112; mildew 1111; root knot 1112; stem rot 1111.

Curly bark. pear 1156.

Curly top. beet 1104 .

Currant. mildew 1112.

Dahlia. mildew 1112.
Damping off. eucalyptus 1113; lettuce 1130; tomato 1167.

Dewberry, see Blackbery.

Die back.

almond 1086; apple and apricot, see Almond; cherry 1110; orange, Florida die back 1136, 1139; peach and plum, see Almond; walnut 1176.

Disease.

defined 1039; causes classified 1049.

Dodder. alfalfa 1083.

Downy mildew. beet 1103; onion 1133 .

Drop.

lettuce 1130 .

Dry rot. olive 1133; potato 1156.

\section{Dryness.}

Atmospheric, injurious effects of 1055; soil 1067.

Dust 1060.

Early blight. potato 1157.

Egg plant. rot 1112 ; stem rot, wilt 1113.

Erinose. walnut 1176 .

\section{Eucalyptus.} crown gall 1114; damping off 1113; leaf spot 1113; mildew 1113.

Eutettix. beet 1104 .

Exanthema. orange 1136.

Fertilization, soil 1062.

Florida die-back. orange 1136.

Fluids-movements in plants 1046.

Folletage. grape 1118.

Formalin 1184.

Frizzles. pecan 1156.

Frost 1051. protection 1052.

Fruit drop. almond 1084; apricot, see Almond; cherry 1110; peach, see Almond; pear 1156.

Fruit gumming. peach 1151.

Fruit spot. apple 1092; apricot 1095 .

Fungi, general account of, 1077.

Fungicides 1183.

Gas, illuminating-injury to trees 1075 . 
Gopher 1075.

Grape.

Anaheim disease 1117; black knot 1115; brunissure 1118; coulure 1117; folletage 1118; little leaf 1117 ; mildew 1114; red leaf 1118; rougeot 1118.

Grape fruit, see Orange.

Grey mold. lemon 1125.

Guava. russeting 1119.

Gummosis. apricot, see Cherry; cherry 1109; lemon 1120; orange, see Lemon.

Hail 1057.

Hardpan 1072 . blasting 1074 .

Heat, atmospheric, injurious effects of, 1053.

Hollyhock. rust 1119.

Hollow. apple 1093.

insects 1076.

Introduction 1039.

Iris.

leaf spot 1120 .

Iron sulphide 1187.

Late blight. potato 1157.

Leaf.

functions of 1047; respiration in 1048 .

\section{Leaf curl.}

peach 114y

Leaf gum spot. orange 1142.

Leaf spot.

alfalfa 1079; barley 1102 ; beet 1102 ; blackberry 1107; carnation 1108; cucumber 1112; eucalyptus 1113; iris 1120; madrone 1130; oleander 1131; olive 1133; palm, date 1148; palm, Washingtonia 1148; strawberry 1166; tomato 1171; vetch 1171.

Lemon.

blue and green mold, see Orange; brown rot 1122; cottony mold 1123; gray mold 1125; gummosis 1120; peteca 1129; red rot 1129 ; twig blight 1126; wither-tip, "tear stain" 1127.

Lettuce.

damping off 1130; drop 1130.

Lime 1183.

Lime-sulphur 1186, 1187.

Literature 1188.

Little leaf.

apple 1093; grape 1117; peach 1151; quince, see Peach.

Little peach 1050 .

Little potato 1158.
Loganberry, see Blackberry.

Loquat.

blight 1130 ; scab 1130.

Madrone.

leaf spot 1130.

Mal di gomma.

orange 1136.

Mildew.

apple 1088; bean 1102; beet, downy mildew 1103; cucumber 1111; currant 1112; dahlia 1112; eucalyptus 1113 grape 1114; onion, downy mildew 1133; pea 1149; peach 1150; pumpkin 1160 ; rose 1163 ; strawberry 1166 ; sycamore 1167.

Moisture.

atmospheric, injurious effects of, 1055 excessive, in soil, 1071.

Mold.

corn 1111; lemon, grey mold 1125; blue mold, see Orange; orange, blue mold 1142 .

Moles 1075.

Mottled leaf. orange 1137.

Navel rot. orange 1143.

Nematode. beet 1104; nursery stock 1131; tomato 1171.

Nematode worm 1076.

Nursery stock.

crown gall 1131; nematode 1131; root knot 1131.

Oak fungus.

almond 1084

Oat.

rust 1131; smut 1131.

Oleander.

leaf spot 1131; twig gall 1131

Olive.

dry rot 1133 ; leaf spot 1133 ; root rot and toadstool, see Almond; tuberculosis. 1132

Onion.

downy mildew 1133.

Orange.

anthracnose 1140 ; black rot 1143 ; blue mold 1142; brown rot, see Lemon; brown spot 1143; chlorosis 1137; damping off 1141; die back 1139; exanthema 1136; Florida die back 1136; gummosis, see Lemon; leaf gum spot 1142; mal di gomma 1136; miscellaneous spots 1146; mottled leaf 1137 ; navel rot 1143; puffing 1146; root rot 1140; scaly bark 1135; shoulder spot 1146; stain 1146; stem end spot 1146 ; splitting 1145 ; tear stain 1140; toadstool 1140; trunk rot 1140; twig blight, see Lemon; wither-tip 1140. 
Palm, date.

leaf spot 1148 .

Palm, Washingtonia.

leaf spot 1148 .

Pea.

blight 1149; mildew 1149.

Peach.

blight 1149; brown rot, see Apricot California yellows 1151; crown gall, die back, fruit rot, see Almond; fruit gumming 1151; gummosis, see Cherry; leaf curl 1149; little leaf 1151; little peach 1150; mildew 1150 ; root rot, rust, sour sap, see Almond; split pit 1151; yellows 1151.

Pear.

black leaf 1155; blight 1154; crater blight 1156; curly bark 1156; fruit drop 1156; ringed fruit 1156; scab 1153.

Pecan.

rosette or frizzles 1156.

Perforation.

walnut 1175.

Peteca.

lemon 1129

Photosynthesis 1048.

Physiological diseases 1055 .

Plant.

disease, causes classified 1049; disease defined 1039; disease, directions for examining 1049 ; food, substances taken from soil 1043; growth, factors affecting 1040; movement of fluids in 1046; pathology, scope 1040; physiological diseases 1055; physiology 1041; starch formation in 1048; sugar formation in 1048 .

Plum.

brown rot, see Apricot; crown gall, die back, rust, sour sap, see Almond.

Pomelo, see Orange.

Potash, caustic 1185 .

Potassium sulphide-liver of sulphur 1184.

Potato.

black leg 1158; brown streak 1158; dry rot 1158; early blight 1157; general directions for planting 1159; late blight 1157; little potato 1158; scab i157.

Pumpkin.

mildew 1160 ; wilt 1160 .

Prune.

shrivels 1160; see Plum, also.

Puffing.

orange 1146

Quince.

black knot 1160; blight, see Pear; little leaf, see Peach.

Rabbits 1075 .
Red leaf.

grape 1118.

Red rot.

lemon 1129.

Resin 1188.

Respiration.

in leaves 1047; in root 1044

Ringed fruit. pear 1156.

Root.

functions of 1044; respiration in 1044.

\section{Root knot.}

beet 1104; cucumber 1112; nursery stock 1131; peach, see Almond crown gall; tomato 1171.

Root rot.

almond 1084; apple 1089; apricot, see Almond; celery 1109; cherry 1109; olive 1133; orange 1140 .

Rose.

black spot 1163 ; cane blight 1153 ; mildew 1163; rust 1163.

Rosette.

pecan 1156.

Rot.

egg plant 1112.

Rougeot.

grape $111 \delta$.

Russeting.

guava 1119.

Rust.

alfalfa 1079; almond 1084; asparagus: 1100 ; bean 1102; beet 1102; blackberry 1107; carnation 1108; chrysanthemums 1110; corn 1111; hollyhock 1119; oat 1131; peach and plum, see Almond; rose 1163; wheat 1182.

Saline water, irrigation with, 1065.

Santa Ana 1053.

Scab.

apple 1089; apricot 1097; loquat 1130 ; pear 1153 ; potato 1157.

Scaly bark.

orange 1135.

Seasonal effects.

apple 1093; apricot 1098.

shot hole.

almond 1083; apricot 1095.

Shoulder spot.

orange 1146.

Shrivels.

prune 1160 .

Slime molds 1079.

Slugs 1076 .

Smelter fumes 1058 .

smut.

barley 1101; corn 1110; oat 1131; sorghum 1166; wheat 1182. 
Soap, $118 \delta$.

Soda, caustic 1185.

Soft rot.

blackberry 1107; sweet potato 1167.

Soil.

acid 1066; alkali 1063; artificial substances in 1074; chemical deficiency 1061; chemical nature 1045; chemical, physical and biological relation to plant growth 1043; deficiencies 1061; dryness 1067; excess of water 1071; faulty structure 1072; fertilization 1062; water deficiency 1061, 1067.

Sorghum.

smut 1166.

Sour sap. almond 1085; apricot 1098; peach and plum, see Almond.

Split pit. peach 1151.

splitting. orange 1145 .

spot.

bean 1102; orange, leaf gum spot 1142; miscellaneous spots, shoulder spot, stem end spot 1146.

Squash, see Pumpkin.

Squirrels 1075 .

Stain. orange 1146.

Starch-formation in plant 1048 .

Stem end spot. orange 1146

Stem rot.

alfalfa 1081; apple 1089; carnation 1108; celery 1109; cucumber 1111; egg plant 1113; tomato 1170.

Strawberry.

leaf spot 1166; mildew 1166.

Subsoil, dry 1069.

Subsoil, faulty structure 1072.

Sugar, formation in plant 1048.

Sulphur 1183. sprays 1186.

summer blight. celery 1108; tomato 1168.

Sunburn 1053. apple 1091; prevention of 1054; walnut 1175 .

Sunscald 1053.

Sweet potato.

black rot 1167 ; stem rot 1167 ; soft rot 1167 ; wilt 1167 .
Sycamore.

blight 1167; mildew 1167.

Toadstool disease.

almond, see Root rot 1084; apple 1089; olive, see Almond; orange 1140.

Tomato.

blossom end rot 1168; damping off 1167; leaf spot 1171; nematode 1171; root knot 1171; stem rot 1170 ; summer blight 1168; winter blight 1168 .

Trunk rot. orange 1140 ; walnut 1173.

Tuberculosis. olive 1132.

Turnip, see Cabbage.

Twig blight. lemon 1126; orange, see Lemon.

Twig gall. oleander 1131.

Vetch. leaf spot 1171.

Walnut

bacteriosis 1172; black knot 1178; blight 1172; crop failure 1179; crown gall 1178; die back 1176; erinose 1176; perforation 1175; sunburn 1175; trunk rot 1173; yellows 1178 .

Water.

alkali, irrigation with 1064; alkali, rise of, in soil water 1065; deficiency in soil 1061, 1067; excessive, in soil 1071; fluctuating level in soil 1071; saline, irrigation with 1065 .

Watermelon. wilt 1181.

Wheat.

closed smut 1181; loose smut 1181; rust 1181; yellows 1182 .

White rot. lemon 1123

Wilt.

carnation 1108; egg plant 1113; pumpkin 1160; watermelon 1181.

Wind, injurious effects of, 1056 .

Wind-breaks 1057.

Winter blight. celery 1108 ; tomato 1168 .

Wither-tip. lemon 1127; orange 1140.

Worm, Nematode 1089.

Yellows.

aster 1101; peach, California yellows 1151; walnut 1178; wheat 1182. 



\section{REPORTS.}

1896. Report of the Viticultural Work during the seasons 1887-93, with data regarding the Vintages of 1894-95.

1897. Resistant Vines, their Selection, Adaptation, and Grafting. Appendix to Viticultural Report for 1896.

1902. Report of the Agricultural Experiment Station for 1898-1901.

1903. Report of the Agricultural Experiment Station for 1901-03.

1904. Twenty-second Report of the Agricultural Experiment Station for 1903-04.

\section{BULLETINS.}

Reprint. Endurance of Drought in Soils No. 188. Lining of Ditches and Reservoirs of the Arid Region.

No. 128. Nature, Value, and Utilization of Alkali Lands, and Tolerance of Alkali. (Revised and Reprint, 1905.)

133. Tolerance of Alkali by Various Cultures.

147. Culture Work of the Sub-stations.

149. California Sugar Industry.

151. Arsenical Insecticides.

153. Spraying with Distillates.

159. Contribution to the Study of Fermentation.

162. Commercial Fertilizers. (December 1, 1904.)

165. Asparagus and Asparagus Rust in California.

167. Manufacture of Dry Wines in Hot Countries.

168. Observations on Some Vine Diseases in Sonoma County.

169. Tolerance of the Sugar Beet for Alkali.

170. Studies in Grasshopper Control.

171. Commercial Fertilizers. (June $30,1.905$.

172. Further Experience in Asparagus Rust Control.

174. A New Wine-cooling Machine.

176. Sugar Beets in the San Joaquin Valley.

177. A New Method of Making Dry Red Wine.

178. Mosquito Control.

179. Commercial Fertilizers. (June, 1906.)

180. Resistant Vineyards.

181. The Selection of Seed-Wheat.

182. Analysis of Paris Green and Lead Arsenic. Proposed Insecticide Law.

183. The California Tussock-moth.

184. Report of the Plant Pathologist to July 1, 1906.

185. Report of Progress in Cereal Investigations.

186. The Oidium of the Vine.

187. Commercial Fertilizers. (January, 1907.)

189. Commercial Fertilizers. (June, 1907.)

190. The Brown Rot of the Lemon.

191. California Peach Blight.

192. Insects Injurious to the Vine in California.

193. The Best Wine Grapes for California; Pruning Young Vines; Pruning the Sultanina.

194. Commercial Fertilizers. (December, 1907.)

195. The California Grape Root-worm.

197. Grape Culture in California; Improved Methods of Winemaking; Yeast from California Grapes.

198. The Grape Leaf-Hopper.

199. Bovine Tuberculosis.

200. Gum Diseases of Citrus Tres in California.

201. Commercial Fertilizers. (June, 1908.)

202. Commercial Fertilizers. (December, 1908.)

203. Report of the Plant Pathologist to July 1, 1909.

204. The Dairy Cow's Record and the Stable.

205. Commercial Fertilizers. (December, 1909.)

206. Commercial Fertilizers. (June, 1910.)

207. The Control of the Argentine Ant.

208. The Late Blight of Celery.

209. The Cream Supply.

210. Imperial Valley Settlers' Crop Manual.

211. How to Increase the Yield of Wheat in California.

212. California White Wheats.

213. The Principles of Wine-Making.

214. Citrus Fruit Insects.

215. The Housefly in Its Relation to Public Health.

216. A Progress Report Upon Soil and Climatic Factors in Influencing the Composition of Wheat.

217. Honey Plants of California. 
No. 1. Texas Fever.

5. Contagious Abortion in Cows.

7. Remedies for Insects.

9. Asparagus Rust.

11. Fumigation Practice.

12. Silk Culture.

15. Recent Problems in Agriculture. What a University Farm is $\mathrm{Fol}^{\circ}$

19. Disinfection of Stables.

29. Preliminary Announcement Concerning Instruction in Practical Agriculture upon the University Farm, Davis, Cal.

30. White Fly in California.

32. White Fly Eradication.

33. Packing Prunes in Cans. Cane Sugar vs. Beet Sugar.

36. Analyses of Fertilizers for Consumers.

39. Instruction in Practical Agriculture at the University Farm.

46. Suggestions for Garden Work in California Schools.

47. Agriculture in the High Schools.

48. Butter Scoring Contest, 1909.

49. Insecticides.

50. Fumigation Scheduling.
No. 51. University Farm School.

52. Information for Students Concerning the College of Agriculture.

53. Announcement of Farmers' Short Courses for 1910 .

54. Some Creamery Problems and Tests.

55. Farmers' Institutes and Universit Extension in Agriculture.

57. Announcement of Farmers' Short Courses in Animal Industry and Veterinary Science.

58. Experiments with Plants and Soils in Laboratory, Garden, and Field.

59. Tree Growing in the Public Schools.

60. Butter Scoring Contest, 1910.

61. University Farm School.

62. The School Garden in the Course of Study.

63. How to Make an Observation Hive.

64. Announcement of Farmers' Short Courses for 1911.

65. California Insecticide Law.

66. Insecticides and Insect Control. 